\title{
An Analysis of Potassium Iodide (KI) Prophylaxis for the General Public in the Event of a Nuclear Accident
}

Manuscript Completed: January 1995

Date Published: February 1995

\section{Prepared by}

H. Behling, K. Behling, S. Cohen \& Associates, Inc.

H. Amarasooriya, J. Kotsch, Scientech, Inc.

S. Cohen \& Associates, Inc.

1355 Beverly Road, Suite 250

MeLean, VA 22101

Scientech, Inc.

11821 Parklawn Drive

Rockville, MD 20852

\section{Prepared for}

Division of Systems Technology

Ofitice of Nuclear Regulatory Research

U.S. Nuclear Regulatory Commission

Washington, DC 20555-0001

NRC Joh Code L1844 



\section{DISCLAIMER}

This report was prepared as an account of work sponsored by an agency of the United States Government. Neither the United States Government nor any agency thereof, nor any of their employees, make any warranty, express or implied, or assumes any legal liability or responsibility for thi accuracy, completeness, or usefuiness of any information, apparatus, product, or process disclosed, or represents that its use would not infringe privately owned rights. Reference herein to any spectific commercial product, process, or service by trade name, trademark, manufacturer, or otherwise does not necessarily constitute or imply its endorsement, recommendation, or favoring by the United States Government or any agency thereof. The views and opinions of authors expressed herein do not necessarily state or reflect those of the United States Government or any agency thereof. 


\section{DISCLAIMER}

Portions of this document may be illegible in electronic image products. Images are produced from the best available original document. 


\begin{abstract}
A generic difficulty encountered in cost-benefit analyses is the quantification of major elements that define the costs and the benefits in commensurate units. In this study, the costs of making KI available for public use, and the avoidance of thyroidal health effects predicted to be realized from the availability of that $K I$ (i.e., the benefits), are defined in the commensurate units of dollars.
\end{abstract}


$$
\text { ' }
$$ 


\section{CONTENTS}

Page

Preface $\ldots \ldots \ldots \ldots \ldots \ldots \ldots \ldots \ldots \ldots \ldots \ldots \ldots \ldots \ldots$

Acknowledgements $\ldots \ldots \ldots \ldots \ldots \ldots \ldots \ldots \ldots \ldots \ldots \ldots \ldots \ldots \ldots \ldots$ xvii

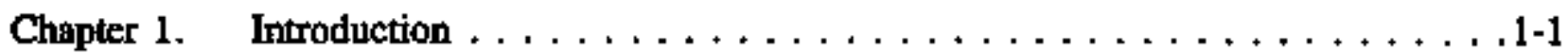

1.1 Past Policy and Recommendations $\ldots \ldots \ldots \ldots \ldots \ldots \ldots \ldots \ldots$

1.2 Events Leading to a Reevaluation of the Federal Policy and the Writing of this Report $\ldots \ldots \ldots \ldots \ldots \ldots \ldots \ldots \ldots \ldots$

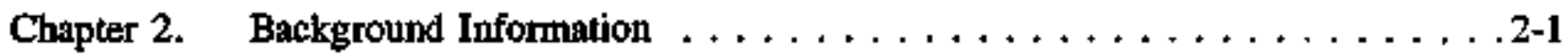

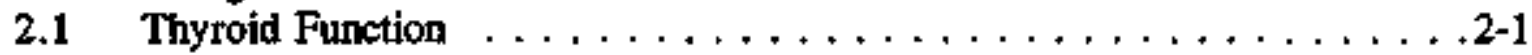

2.2 Thyroid Pathology $\ldots \ldots \ldots \ldots \ldots \ldots \ldots \ldots \ldots \ldots \ldots \ldots \ldots .2-3$

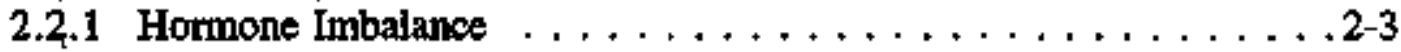

2.2.2 Thyroid Nodules $\ldots \ldots \ldots \ldots \ldots \ldots \ldots \ldots \ldots . . \ldots \ldots$

2.2 .3 Thyroid Adenomas $\ldots \ldots \ldots \ldots \ldots \ldots \ldots \ldots \ldots \ldots$

2.2.4 Thyroid Carcinomas $\ldots \ldots \ldots \ldots \ldots \ldots \ldots \ldots \ldots \ldots$

2.2.5 Life-Expectancy and Thyroid Cancer . . . . . . . . . 2-7

2.3 Health Effects Associated with Radiation Exposure . . . . . . . . . 2-8

2.3.1 Acute Radiation Thyroiditis . . . . . . . . . . . . 2-8

2.3.2 Chronic Lymphocytic Thyroiditis . . . . . . . . . . . 2-9

2.3.3 Hypothyroidism . . . . . . . . . . . . . . . . . . . . 2-9

2.3.4 Thyroid Neoplasms . . . . . . . . . . . . . . . . 2-9

2.3.5 External Radiation and Thyroid Neoplasms . . . . . . . 2-10

2.3.6 Thyroid Neoplasia from Internal Exposures to Radjation . . . . . 2-11

2.3.7 Efficacy of Radioiodides Relatjve to External Radiation . . . . 2-13

2.4 The Basis of Potassium Iodide Prophylaxis . . . . . . . . . 2-14

2.4.1 Dose Requirement for KI Prophylaxis $\ldots \ldots \ldots \ldots \ldots \ldots \ldots$. $\ldots \ldots$

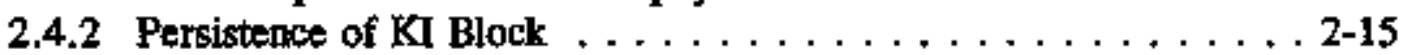

2.5 Radioiodine Exposure In-Utero: A Special Case $\ldots \ldots \ldots \ldots \ldots \ldots 2-17$

2.5.1 Onset of Thyroid Hormone Secretion and Regulation . . , , , 2-17

2.5.2 Transfer of $\mathbf{T}_{4}$ and $\mathbf{T}_{3}$ from Mother to Fetus $\ldots \ldots \ldots \ldots \ldots 2-18$

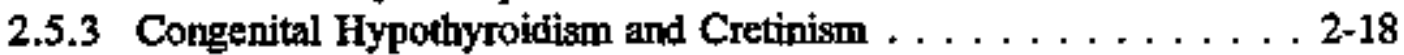

2.5.4 In-Utero Thyroid Dose . . . . . . . . . . . . . . . . . . 2-19

2.5.5 Preguant Females and Stable Iodide Prophylaxis . . . . . . . 2-19

2.6 Potential Adverse Reactions to Stable Iodide . . . . . . . . . . . . 2-20

2.6.1 Intrathyroidal Adverse Reactions $\ldots \ldots \ldots \ldots \ldots \ldots \ldots .2-21$

2.6.2 Extrathyroidal Adverse Reactions . . . . . . . . . 2-23

2.6.3 Adverse Reaction Incidence Rate $\ldots \ldots \ldots \ldots \ldots \ldots .2-23$ 


\section{Contents (Continued)}

Page

Chapter 3. Risks of Radiation Thyroid Effects . . . . . . . . . . . 3-1

3.1 Risk of Thyroid Cancer $\ldots \ldots \ldots \ldots \ldots \ldots \ldots \ldots \ldots \ldots, \ldots \ldots \ldots$

3.2 Risk of Benign Thyroid Nođules $\ldots \ldots \ldots \ldots \ldots \ldots \ldots \ldots \ldots$

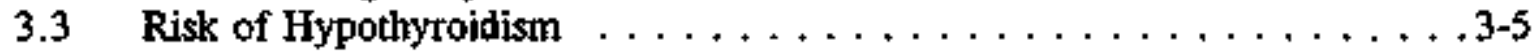

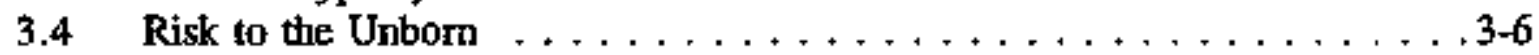

Chapter 4. The Computer Model Used to Estimate Thyroid

Exposures and Risks $\ldots \ldots \ldots \ldots \ldots \ldots \ldots \ldots \ldots \ldots$ 4-1

4.1 Exposure Pathways Considered . . . . . . . . . . . . . . 4-1

4.2 An Overview of the MACCS Model . . . . . . . . . . . . 4-2

4.2.1 Core Inventory and Source Term . . . . . . . . . 4-2

4.2.2 Meteorological Parameters and Plume Dispersion $\ldots \ldots \ldots \ldots, 4.5$

4.2.3 Interna] Thyroid Dose Parameters . . . . . . . . . . . . 4-6

4.3 Reactor Accident Specific Thyroid Doses . . . . . . . . . . . 4-11

4.3.1 Plume Centerline Thyroid Doses by Age and Sex . . . . . . 4-11

4.3.2 Radial Distance and Thyroid Intervention Levels . . . . . . . . 4-15

4.3.3 Estimates of Population Thyroid Effects . . . . . . . . 4-18

4.3.4 Population Distribution Axound Nuclear Power Facilities in the United States . . . . . . . . . . . . . . . . 4-20

4.4 Population Thyroid Health Effects . . . . . . . . . . . 4-23

4.4.1 Potential Reduction in Thyroid Health Effects $\ldots \ldots \ldots \ldots$. . . 26

Chapter 5, The Economic Cosis and Benefits of KI Prophylaxis . . . . . . . 5-1

5.1 The Economic Cost of KI Prophylaxis $\ldots \ldots \ldots \ldots \ldots \ldots \ldots$ 5-1

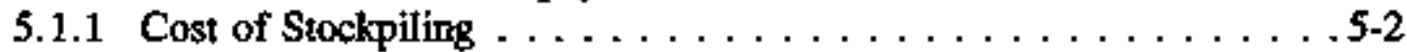

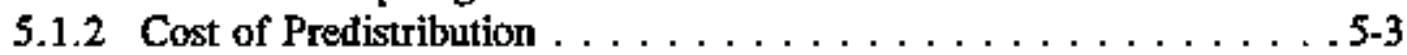

5.2 The Economic Benefits of Kl Prophylaxis:

The Cost-of-Illness Approach $\ldots \ldots \ldots \ldots \ldots \ldots \ldots \ldots$. . 5-4

5.2.1 Derivation of Direct Costs $\ldots \ldots \ldots \ldots \ldots \ldots \ldots \ldots$.5 . . . . . .

5.2.2 Derivation of Indirect Costs . . . . . . . . . . . . 5-7

5.2.3 Detivation of Psychological Costs . . . . . . . . . . . . 5-9

5.3 Summation of Thyroid Health Effects Cost $\ldots \ldots \ldots \ldots \ldots \ldots, 5-11$

5.4 An Evaluation of the Derived Cost Estimates $\ldots \ldots \ldots \ldots \ldots$ 5-13

Chapter 6. The Cost-Benefit Ratio of KI Prophylaxis $\ldots \ldots \ldots \ldots \ldots \ldots \ldots$ 6-1 


\section{Contents (Continued)}

Page

Chapter 7. The Applicability of KJ Cost-Benefit Ratios to a Policy Decision . . . . . 7-I

7.1 Condition \#1: Uncertainties and Their Impact on Cost-Benefit Ratios . . 7-1

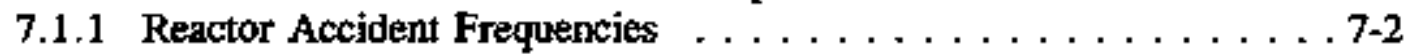

7.1 .2 Core Inventory and Release Fraction . . . . . . . . . .4

7.1.3 Atmospheric Dispersion and Meteorological Factors . . . . . . 7-4

7.1.4 Age- and Sex-Specific Parameters and DCF Values . . . . . . 7-5

7.1.5 Thyroid Risk Coefficients . . . . . . . . . . . . . . 7-5

7.1.6 Uncertainties of Other Assumptions Used in Deriving

Cost-Benefit Ratios . . . . . . . . . . . . . . . 7-5

7.2 Condition \#2: The Reiationship of KI Prophylaxis to

Other Protective Measures . . . . . . . . . . . . . . . . . .7.7

Chapter 8. Conclusion $\ldots \ldots \ldots \ldots \ldots \ldots \ldots \ldots \ldots \ldots \ldots \ldots$

Appendix A Summary Findings of the CRCPD E-6 Committee's Survey $\ldots \ldots \ldots$ A-1

Appendix $\mathrm{B}$ Recommendations by the World Health Organization on the

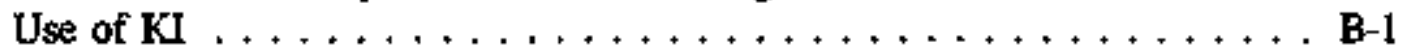

Appendix C Adverse Reactions to Iodide and Estimation of Adverse Incidence Rate $\ldots \ldots \ldots \ldots \ldots \ldots \ldots \ldots \ldots \ldots \ldots \ldots \ldots \ldots$

Appendix D Cost-Benefit Analysis $\ldots \ldots \ldots \ldots \ldots \ldots \ldots \ldots \ldots$ D-1

Appendix E KI Experience in Past Nuclear Emergencies $\ldots \ldots \ldots \ldots \ldots \ldots$ E-1

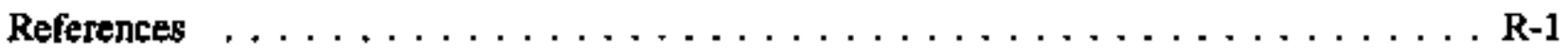




\section{FIGURES}

Page

Chapter 2. Backgrourd Information

2-1 Anatomical Features of the Thyroid Follicle $\ldots \ldots \ldots \ldots \ldots \ldots .2$

2-2 Compounds and Pathways of Thyroid Hormone Production $\ldots \ldots \ldots, 2-2$

2-3 Percent of Thyrojd Blocking Afforded by $100 \mathrm{mg}$ of Stable Iodide as a Function of Time of Administration Before or After

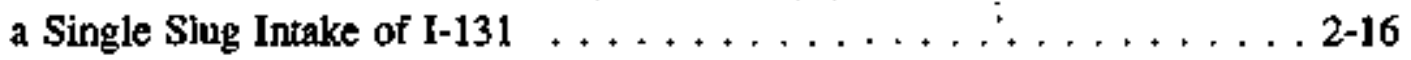

Chapter 4. The Computer Model Used to Estimate Thyroid Expostres and Risks

4-1 Thyroid Dose from RSUR-1 to Different Population Groups . . . . . . . 4-14

4-2 Comparison of Mean Thyroid Doses to Average Person by Distance $\ldots \ldots \ldots \ldots \ldots \ldots \ldots \ldots \ldots \ldots \ldots \ldots \ldots \ldots$ 4-15

4-3 Total Thyroid Dose (RSUR-1, Child Male) . . . . . . . . . . . . 4-16

4-4 Total Thyroid Dose (RSUR-1, Average Person) . . . . . . . . . . 4-17

4-5 Mean Thyroid Dose Contribution from RSUR-1 to Average Person . . . . . . . . . . . . . . . . . 4-19

Chapter 7. The Applicability of KI Cost-Benefit Ratios to a Policy Decision

7-1 The Relationship of Thyroid to Whole Body Doses $\ldots \ldots \ldots \ldots \ldots$. $\ldots$.8 


\section{TABLES}

Pags:

Chapter 2. Background

2-1 Time Distribution of Deaths Due to Papillary and Follicular Carcinoma of the Thyroind . . . . . . . . . . . . . . 2-8

2-2 Adverse Reactions to Iodide . . . . . . . . . . . . . . . . 2-21

Chapter 3. Risks of Radiation Thyroid Effects

3-1 Annual Risk of Total and Lethal Excess Thyroid Cancers . . . . . . . 3-2

3-2 1990 Population Distribution in the United States by

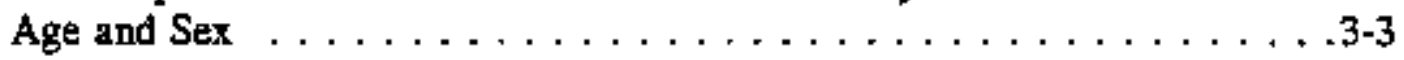

3-3 Years at Risk for Age and Sex Groups of the General Population of the United States for $1990 \ldots \ldots$. . . . . . . . . . . . . . .

3-4 Lifetime Risk of Total and Lethal Excess Thyroid Cancer . . . . . . . . . . 3-4

3.5 Annual Risk of Excess Benign Thyroid Nodules $\ldots \ldots \ldots \ldots$. . . . . 3-5

3-6 Lifetime Risk of Excess Benign Thyroid Nodules . . . . . . . . . . . . 3-5

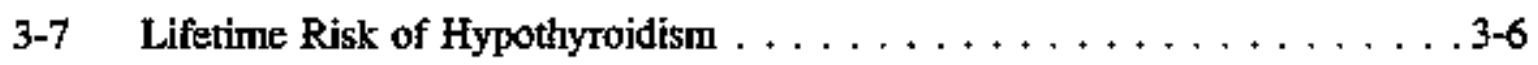

3-8 Lifetime Risks per $10^{6}$ Fetal Thyroid Rads . . . . . . . . . . . . 3-7

Chapter 4. The Computer Model Used to Estimate Thyroid Exposures and Risks

4-1 Core Inventory of Pertinent Isotopes . . . . . . . . . . . . . 4-3

4-2 Radionuclide Release Characteristics into Environment

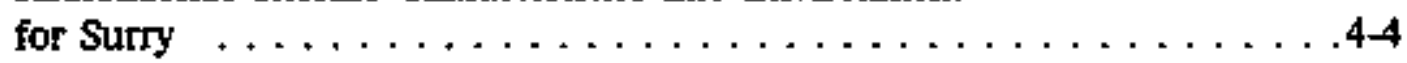

4-3 Accident Characteristics for Sury . . . . . . . . . . . . 4-5

$4-4$ Ventilation Rates by Age, Sex, and Activity $\ldots \ldots \ldots \ldots$ 


\section{Tables (Continued)}

Page

4-5 Variation in Committed Dose for Reference Man with Stable Iodide Intake $\ldots \ldots \ldots \ldots \ldots \ldots \ldots \ldots \ldots \ldots \ldots . \ldots \ldots$

4-6 Thyroid Inhalation Dose Conversion Factors for Radioiodides . . . . . 4-10

4-7 Relative Dose Factors . . . . . . . . . . . . . . . . . 4-11

4-8 Plume Center-Line Thyroid Doses for RSUR-1 Versus Distance . . . . . 4-12

4-9 Plume Center-Line Thyroid Doses for RSUR-2 Versus Distance . . . . . 4-12

4-10 Plume Center-Line Thyroid Doses for RSUR-3 Versus Distance . . . . . 4-13

4-11 Plume Center-Line Thyroid Doses for RSUR-4 Versus Distance . . . . . 4-13

4-12 Percent Contributions to Thyroid Dose for Exposed Population Versus Distance $\ldots \ldots \ldots \ldots \ldots \ldots \ldots \ldots \ldots \ldots \ldots \ldots$ 4-18

4-13 Population Distribution Around U.S. Nuclear Power Plants . . . . . . . 4-21

4-14 Average Population Distribution for U.S. Nuclear Facilities $\ldots \ldots \ldots$ 4-22

4-15 Population Distribution for Reference LWR $\ldots \ldots \ldots \ldots \ldots \ldots$. . .23

4-16 Population Thyroid Effects for Normal Activity with No KI $\ldots \ldots$ 4-25

4-17 Residual Thyroid Effects for Population Exposure under Nornal Activity and Administered KI . . . . . . . . . . . . . 4-27

4-18 Potential Net Reduction in Population Thyroid Effects with KI Prophylaxis $\ldots \ldots \ldots \ldots \ldots \ldots \ldots \ldots \ldots \ldots \ldots \ldots \ldots \ldots \ldots \ldots .28$

4-19 Fetal Thyroid Effects for Normal Activity with No KI . . . . . . . . 4-29

4-20 Residual Thyғoid Effects for Fetal Exposure under Nomnal Activity and Maternal Administration of KI . . . . . . . . 4 4-30

4-21 Potential Net Reduction in Thyroid Effects for Fetuses with KI Prophylaxis $\ldots \ldots \ldots \ldots \ldots \ldots \ldots \ldots \ldots \ldots \ldots \ldots \ldots$ 4-31 


\section{Tables (Continued),}

Page

Chapter 5. The Economic Costs and Benefits of KI Prophylaxis

5-1 Anmual Programmatic Costs of KI Prophylaxis . . . . . . . . . . 5-4

5-2 Summary of Direct Medical Costs $\ldots \ldots \ldots \ldots \ldots \ldots \ldots$ 5-6

5-3 Time Last from Economic Activities Due to Radiation Induced Thyroid Illness $\ldots \ldots \ldots \ldots \ldots \ldots \ldots \ldots \ldots \ldots \ldots$

5-4 Average Lifetime Indirect Costs Associated with Thyroid Disorders . . . . . . . . . . . . . . . . . .5-9

5-5 Average Total Cost per Radiation-Induced Thyroid Effect . . . . . . . 5-12

5-6 Cost Estimates of Thyroid Effects for In-Utero Exposure $\ldots \ldots \ldots \ldots$. . . . .

5-7 Range in Publicly Implied Valuations of Federal Programs . . . . . . 5-13

Chapter 6. The Cost-Benefit Ratio of KI Prophylaxis

6-1 Annual Programmatic Costs of KI Prophylaxis $\ldots \ldots \ldots \ldots \ldots \ldots$. . . . .

6-2 Reactor Accident Frequencies $\ldots \ldots \ldots \ldots \ldots \ldots \ldots \ldots$. . . . . . . . .

6-3 Yearly Reduction in Population Thyroid Effects and Their Equivalent Monetary Values $\ldots \ldots \ldots \ldots \ldots \ldots \ldots \ldots$ 6-3

6-4 Yearly Reduction in Feta] Thyrojd Effects and Their Equjvalent Monetary Values $\ldots \ldots \ldots \ldots \ldots \ldots \ldots \ldots \ldots \ldots$

6-5 The Cost-Benefit Ratio of KI Prophylaxis $\ldots \ldots \ldots \ldots \ldots \ldots \ldots$ 6.7

Chapter 7. The Applicability of KI Cost-Benefit Ratios to a Policy Decision

7-1 The Relationship of Thyroid to Whole Body Exposure for RSUR-1 . . . . . . . . . . . . . . . . . . . . 7-9 


\section{Tables (Continued)}

Page

Appendix A. Summary Findings of the CRCPD E-6 Committee's Survey

A-1 Current $\mathbb{K} \rrbracket$ Stockpiles Maintained by States $\ldots \ldots \ldots \ldots \ldots \ldots$ A-2

Appendix C. Adverse Reactions to Iodide and Estimation of Adverse Incidence Rate

C-1 Adverse Reaction Protile to KI . . . . . . . . . . . . C-1

C-2 Suspected Adverse Reactions to KI Reported Since $1969 \ldots \ldots \ldots$. . . C-3

C-3 Number of Adverse Reactions to KI by Year $\ldots \ldots \ldots \ldots \ldots$ C-5

C-4 Product Profile and Production Quantity for $1986-1990 \ldots \ldots \ldots \ldots$. . . . .

C-5 Adverse Reactions to Iodinated Contrast Media Report to the FDA Between 1969 and August $1991 \ldots \ldots \ldots \ldots \ldots$ C-8

Appendix D. Cost-Benefit Analysis

D-1 Annual Programmatic Costs of KI Prophylaxis $\ldots \ldots \ldots \ldots \ldots$ D-4

D-2 Ranges in Publicly Inplied Valuations of Federal Programs $\ldots \ldots \ldots$ D-5

D-3 Publicly Implied Valuation of Life-Saving Medical Programs . . . . . D-6

D-4 Publicly Inplied Valuation of Traffic Safety Megsures $\ldots \ldots \ldots \ldots$ D-6

D-5 Summary of Direct Health Care Expendinures for Neoplasms

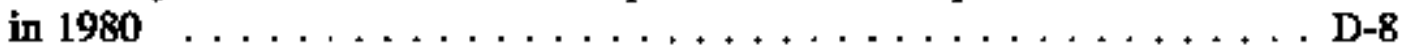

D-6 Summary of Morbidity Costs of Neoplasms $\ldots \ldots \ldots \ldots \ldots \ldots$ D-8

D-7 Summary of Mortality Costs for Neoplasms in $1980 \ldots \ldots \ldots \ldots$. . . .

D-8 Estimated Direct and Indirect Costs for Neoplasms for $1990 \ldots \ldots$ D-10

D-9 Charges Made to Medicare for Treatment During the Initial, Continuing, and Terminal Phases of Cancer of 13 Sites . . . . . . . D D-11 


\section{Tables (Continued)}

Page

D-10 Medical Costs for Benign Thyroid Nodule $\ldots \ldots \ldots \ldots \ldots \ldots \ldots$

D-11 Medical Costs for Thyroid Cancer $\ldots \ldots \ldots \ldots \ldots \ldots$ D-15

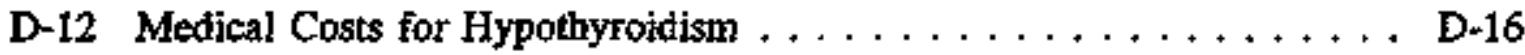

D-13 Summary of Direct Medical Costs $\ldots \ldots \ldots \ldots \ldots \ldots$ D-16

D-14 Time Lost from Econonic Activities Due to Radiation Induced Thyroid Illness . . . . . . . . . . . . . . . . . . . D D 18

D-15 Time Distzibution of Deaths Due to Papillary and Follicular Carcinoma of the Thyroid $\ldots \ldots \ldots \ldots \ldots \ldots$ D-18

D-16 Average Lifetime Indirect Costs Associated with Thyroid

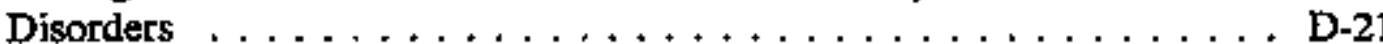

D-17 Social Security Administration's Guidelines for Assessing Inpairments . . . . . . . . . . . . . . . . . . D-23

D-18 Average Total Cost per Radiation-Induced Thyroid Effect . . . . . . . D-32

D-19 Cost Estimates of Thyroid Effects for In-Utero Exposure . . . . . . . D-33

D-20 Cost per Life Saved for EPA's Radon Testing and Mitigation Programs . . . . . . . . . . . . . . . D-34

Appendix E. Experiénce in Past Nuclear Emergencies

E-1 Daily Releases of Radioactivity fnto the Atmosphere . . . . . . . . . E E-5

E-2 Soviet Criteria for Taking Protective Actions $\ldots \ldots \ldots \ldots$. . . .

E-3 Thyroid Burdens to Near-Field Residents of the Chemoby] Nuclear Facility . . . . . . . . . . . . . . . . . E-8

E-4 Thyroid Doses for Protected and Unprotected Populations in Poland Following the Chernobyl Accident . . . . . . . . . . . . E E-10 



\section{PREFACE}

Commercial auclear power is a relatively new technology that was introduced in the 1960 's. Today, more than 100 licensed power reactors in the United States provide nearly 20 percent of the country's electricity. Most of these facilities are sufficiently close to major poptlation centers that in the event of a major accident, human exposure to airborne radiation would be inevitable. Exposure to radioactive isotopes of iodine, in particular todine-131, possibly presents the most serious radiological risk from the accidental release of fission products into the atmosphere.

The early and dominant hazard would arise from population exposure to a passing plume containing radiojodines and other radioactive fission products. There is unanimous scientific consensus that the administration of stable iodine can prevent thyroidal uptake of radioiodine with nearly 100 percent efficiency. In spite of the effective remedial action of stable iodine, there are, however, some limitations on its use in protecting the public.

This report provides a comprehensive overviev. of all topics relevant to arriving at a national policy regarding lpotassium iodide for general public use in the event of a nuclear accident. For a policy decision, relevant topics include not only the scientific basis for iodide prophylaxis, but also an assessment of the economic costs and the economic benefits to society. Intangible factors such as public perception and potential logistical problems, which cannot be defined in scientific or economic terms, must also be considered.

\section{Content and Organization of the Report}

Because of the complexity of relevant subject topics and the potentially diverse background of individuals involved in a policy decision, sufficient background information is provided to assist those who may have expertise in some but not all pertinent subject areas.

Chapters are sequenced in a manner that allows for a logical expansion and transformation of data needed for a final evaluation of the cost-effectiveness of $\mathrm{KI}$ prophylaxis.

The assignment of monetary values to human health effects in deterniging a cost-benefit ratio is far from an established science. For this report, experts in various disciplines were consulted to provide guidance in assigning monetary equivalent values for radiation-induced thyroid effects. Because a cost-benefit evaluation of KI prophylaxis is a central objective of this report and unprecedented methodologies were used to assign monetary values to thyroid health effects, the reader is encouraged not to skip to the final cost-benefit section of the report. A fair evaluation of KI prophylaxis cannot be limited to an assessment of cost-benefit ratio values, but must include a thorough understanding of how these ratio values were derived. Lastly, the text identifies many important subjective factor's that could not be incorporated in the cost-benefit ratio. For these reasons, the inclusion of an executive summary containing "bottom-line" cost-benefit values was considered inappropriate for this report. 
Following an introduction, which defines existing policy and recent recommendations by Federal and non-governmental agencies, the main body of the report begins with background information relating to thyroid function and disease (Chapter 2). This chapter provides a basic understanding of iodide metabolism in health and disease, the mechanism of thyroid blockade by stable iodine, our present knowledge about radiation-induced thyroid effects and their medical treatments, and the potential adverse reactions to iodide when administered in pharmacological doses equal to those recommended for prophylaxis. Chapter 3 derives the lifetime age- and sex-dependent risk coefficient for several population subgroups in terms of thyroid nodules, thyroid cancers, and hypothyroidism. Chapter 4 provides an overview of the exposure pathways and the thyroid dose model used in this report for estimating population thyroid exposure. Potential population thytoid doses are defined for specific severe accident scenarios using 1990 census data and empirical popelation data obtained from existing nuclear facilities. By means of previously derived risk coefficients and thyroid doses, population thyroid health effects are defined for the major reactor accident scenarios with and withoul $\mathrm{KI}$. The economic cost of providing $\mathrm{KJ}$ and the economic equivalence of each thyroid health effect are quantitatively derived in Chapter 5 . In Chapter 6 , the programmatic cost of providing KI is weighed against the total number of expected thyroid health effects multiplied by their respective monetary value for a cost-benefit ratio. The significance of the derived cost-benefit ratios to a policy decision is discussed in Chapter 7 . The final chapter summarizes the findings and attempts to define the limitations of quantitative values assumed and derived in this report.

Additional data and information used to support Chapters 1 through 8 are provided in several appendices. The sequence of appendices follows the order in which they are referenced in the text. Principal appendices include (1) a detailed description of the methodology used for the valuation of thyroid effects (Appendix D), (2) the experience gained from the Three Mile Island accident, the Soviet accident at Chernobyl, and a pilot project at a nuclear facility in Tennessee (Appendix E), and (3) the derivation of an adverse reaction incidence rate to stable iodide from empirical data obtained from pharmaceutical firms and an FDA computer database (Appendix C). 


\section{ACKNOWLEDGMENTS}

The authors acknowledge with gratinde the support provided by many individuals whose scientific input and professional opinions were solicited in the writing of this report.

Prominent indivithals include the following:

Janos Bacsanyii, PhD, Staff Scientist, Food and Drug Administration, Division of Drug Experience

David Becker, M.D., Professor of Radiology and Nuclear Medicine, and Chairman of the American Thyroid Association (Department of Radiology and Nuclear Medicine Center, New York Hospital-Comell Medical Center)

Martin L. Brown, PhD, Health Care Economist, National Institures of Heaith

Don Jose, Esquire, trial lawyer and litigation expert in radiation injury claims (formerly with the U.S. Department of Justice; currently in private law practice)

Eugene Fowinkle, M.D., former Commissioner of Public Health of Tennesset (currently Vice Chancellor for Medical Affairs, Vanđerbilt Uiniversity)

William Hendee, $\mathrm{PhD}$, subject matter expert in medical disability and impairment (American Medical Association, Vice President, Group on Science Technology)

Thomas H. Hodgson, PhD, Chief Economist for the Health Care Financing Administration of the U.S. Department of Health and Human Services

Darrel Mclndoe, M.D., Clinical Endocrinologist specializing in the diagnosis and treatment of thyroid disorders (Saint Joseph Hospital, Division of Nuclear Medicine, Towson, MD)

Alan Morris, President of ANBEX, Inc. (one of two firms licensed by the FDA to provide KJ tgblets)

Elizabeth Neuman, $\mathrm{PhD}$, Pharmacologist and Staff Scientist with Carter-Wallace (one of the two firms licensed by the FDA to provide KI tablets)

Sarah Sell, M.D., former Medical Consultant to the Commissioner (Tennessee), Professor of Pediatrics, Vanderbilt University

Roy Shore, PhD, Dr.P.H., Radiation Epidemiologist (Professor at the Institute of Environmental Medicine, New York University Medical Center) 


\section{CHAPTER 1}

\section{INTRODUCTION}

\subsection{Past Policy and Recommendations}

The option to use potassium iodide for thyroidal blocking to protect the general public resides with State and, in some cases, local health authorities. Guidance in these matters, however, is provided by the Federal Ernergency Management Agency (FEMA) and the U.S. Nuclear Regulatory Commission (NRC). The NRC and FEMA have issued guidance to State and local authorities as well as licensees of operating commercial muclear power plants in 50 FR 30258, July 24, 1985. The guidance suggests that any decision by State and local authorities to use potassium iodide should be based on the site environment and conditions at the time of an emergency for the specific operating commercial nuclear power plant and should inchude detailed plans for distribution, administration, and medical assistance.

The recommendation for stockpiling and distribution of KI during emergencies for thyroida] blocking is currently limited to emergency workers and institutionalized individuals. The Federal position regarding the predistribution or stockpiling of potassium iodide for use by the general public is that it should not be required.

Thyroid blocking for emergency workers and institutionalized individuals was recommended because:

(1) These individuals would be more likely to be exposed to the radioiodine in an airborne radioactive release in the event of a nuclear emergency.

(2) The mumber of individuais involved at any site is relatively small and requires a limited supply of KI that can be readily distributed.

(3) The storage, distribution, and administration of $\mathrm{KJ}$ can be readily controlled.

(4) The known sensitivity to iodide of this limited number of individuals can be reviewed.

(5) These individuals can be readily monitored for adverse side effects by medical personnel.

In the past, the recommendation to exclude the stockpiling and predistribution of $\mathrm{KI}$ for the general public was based on the ability to evacuate the general population, logistical and practical problems, and the low cost-effectiveness of a nationwide program (NUREG/CR-1433).

The Food and Drug Administration (FDA) issued its own recommendation on the use of potassium iodide as a thyroid-blocking agent (47 FR 28158, June 29, 1982). The FDA's recommendations were based on the benefits of using $\mathrm{KI}$ and the radiation risks to the thyroid 
from I-131. Neither costs nor practical and logistical problems associated with stockpiling and distribution were considered. Based on the ability of $\mathrm{KI}$ under optinal conditions to eliminate nearly all intermal thyroid exposure and the assumed minimal number of expected adverse reactions to KI, the FDA concluded that the risk/benefit ratio favors the use of the drug when the projected internal dose to the thyroid is equal to or greater than 25 rads. The FDA recommends potassium jodide in doses of $130 \mathrm{mg}$ per day for adults and children over one year of age and $65 \mathrm{mg}$ per day for infants under one year of age. The FDA's projected thyroid dose for phannacologic intervention equals the upper intervention level of the Environmental Protection Agency (EPA).

Protective Action Guides (PAGs) promulgated by the EPA for projected thyroid dose range from 5 to 25 rem (EPA 1980). Protective action is recommended at the lower level for sensitive populations (pregnant women and children), or if there are no local constraints to providing protection at that level. Protective actions are recommended regardless of local constraints if the projected dose exceeds 25 rem. However, the EPA does not identify the use of $\mathrm{KI}$ as a protective measure for public use. Only evacuation and controlled area access are cited as protective measures.

In 1977, the National Council of Radiation Protection and Measurements (NCRP) issued a report (NCRP 1977) that comprebensively reviewed pertinent scientific information regarding iodine metabolism, physiology, and pathology of the thyroid gland. The report, however, did not attempt to evaluate the cost-effectiveness of a program of $\mathrm{KI}$ prophylaxis. Practical and logistical problems regarding the distribution of $\mathrm{KI}$ to the general population were identified and discussed along with alternative options for public protection. In the report's "Summary and Recommendations," the NCRP recommended daily doses of $130 \mathrm{mg}$ for the duration of potential exposure for projected inhalation thyroid doses of 10 rads or more, but issued a stark warring that:

"The short- and long-term consequences of inhalation of radioactive iodine are far less than the possible injury that might result from individual and mass panic arising from efforts to obtain the blocking agent . . ."

Based on an earlier study conducted by the EPA (EPA 1974), the NCRP paradoxically also concluded that mass evacuation of urban and rural populations can be achieved promptly and safely without loss of life.

\subsection{Events Leading to a Reevaluation of the Federal Policy and the Writing of this Report}

The American Thyroid Association's Environmentat Hazards Committee issued a report in 1984 that assessed the use of iodine as a thyroidal blocking agent in the event of a reactor accident (Becker 1984). This committe of clinical and scientific experts on matters relating to the thyroid gland stated that: 
"The development of an appropriate strategy for proper protection against radioiodine contamination requires risk-benefit (risk-ratio of radioiodine hazards to stable iodine hazards) and cost-benefit evaluations, but adequate data are not now available for either the numerator or the denominator."

On the basis of existing but incomplete risk-benefit information, the American Thyroid Association (ATA) concluoted the following:

(1) Potassium iodide in $130 \mathrm{mg}$ scored tablet form should be manufactured in quantities sufficient to fill anticipated needs if its use is required.

(2) The projected threshold intervention dose of 10 rads recommended by the National Commission on Radiation Protection and Measurement for iodine blockade is overiy conservative.

(3) It is unlikely that clinically significant thyroid disease would result from individual thyroid exposures of less than 100 rads. Iodide prophylaxis is, therefore, recommended for projected doses of 100 rads or greater.

(4) To provide an added measure of protection for sensitive population groups which include children and pregnant women, a radiation dose of 50 rads to the thyroid is suggested as a threshold fot iodine blockade.

(5) Due to the complexity of the problems, predistribution of potassium iodide is not recommended. (The committee recommended the development of emergency plans for the prompt and efficient distribution in the event of a nuclear emergency.)

The ATA's recommendations urged more vigorous attempts to obtain additional data through clinical sudies and a central registry. Clinical studies involving the use of radioiodine as well as potassium iodide would improve our estimates of radiation thyroid risks and adverse reactions to stable iodide. Additionally, the establishment of a central registry for iodide side-effects would provide a more credible means for estimating population risks related to stable iodine.

Following the 1986 Chernobyl accident and the release of information regarding the use of $\mathrm{KI}$ by Soviet and Polish officials, the American Thyroid Association in September 1989 submitted a letter to the chaiman of the Federal Radiological Preparedness Coordinating Committee (FRPCC). The letter stated ATA's support of KJ and requested that the committee reconsider its position on stockpiling KI for general public use. On the basis of the ATA's letter, the FRPCC petitioned the Department of Health and Human Services (HHS) through the Centers for Disease Control (CDC) to review the medical and clinical status of the general use of KI. A workshop chaired by the CDC convened in July 1990 to assess the testimony of various experts. The workshop committee concluded that although no new scientific data were presented that contradicted the scientific basis for the 1985 FRPCC guidance, there was sufficient reason 
to establish an ad hoc Subcommittee on Potassium Iodide. The Subconmittee's principal charter was to monitor the activities of the following groups:

- The Conference of Radiation Control Program Directors (CRCPD)

- International Agencies; The World Health Organization (WHO) and the Commission of the European Communities (CEC)

- Nuclear Regulatory Commission (NRC)

The CRCPD. The Conference of Radiation Control Program Directors' study (as requested by the FRPCC and conducted by the CRCPD's E- 6 Committee) recently assessed the emergency programs of individual States. By means of a survey, the E-6 Committee obtained data from States with commercial nuciear power plants. Survey data pertain to the distribution of KI within the 10-mile emergency planning zone (EPZ). The information received from responoing States is summarized in Appendix A of this report.

The WHO and the CEC. Following the Chernobyl accident, the World Health Organization (WHO) and the Commission of the European Communities (CEC) organized a joint workshop in July 1988 to assess current knowiledge and to make recommendations for national contingency plans involving nuclear emergencies. Eminent experts in public health, endoctinology, and radiation protection attended the workshop. The conclusion and recommendations of the workshop provided the basis for guidelines on iodide prophylaxis that were subsequently issued by the WHO Regional Office for Europe (WHO 1989).

The major scientific isstes addressed by the workshop committee included the efficacy and limitations of stable jodide prophylaxis and all pertinent factors, which modify the benefit as well as the potential adverse reactions to $\mathrm{KI}$. The major variables considered included dietary intake levels of iodide, age, gender, and underlying thyroid pathologies. The WHO/CEC's formal conclusions regarding the impact of these modifying factors reflect the scientific consensus of the workshop participants, who are referenced throughout this report.

The workshop committee submitted recommendations for iodine prophylaxis, which were subsequently adopted as WHO guidelines, in behalf of the following population groups:

- pregnant women

- lactating mothers

- infants

- children and adolescents

- aüults

Appendix B defines the WHO/CEC recommendations for $\mathrm{KI}$ use among the five sub-populations identified and provides supportive rationale. 
The NRC. Concurrently, but independently of the activities of other agencies, the NRC concluded that because of new information regarding $\mathrm{KI}$, there is a need to reevaluate the existing Federal policy (55 FR 39768. September 28, 1990). New information related to (1) revision in estimates of the release fraction in iodine during reactor accidents, (2) revision in thyroid risk coefficients that are age and sex specific, (3) reduction in the efficacy of I-131 to impart thyroid damage, (4) increased shelf-life of $\mathrm{Kl}$, (5) experiences gained from the Chernobyl accident and the pilot projects conducted by the State of Tennessee, (6) improved understancing of potential adverse reactions to stable iodide, and (7) a recommendation by the American Thyroid Association to increase the threshold of the projected thyroid dose for pharmacologic intervention (i.e., KI prophylaxis).

As part of the reevaluation, the Commission contracted this report in order to update the original 1980 analysis (NUREG/CR-1433, "Examination of the Use of Potassium Iodide (KI) as an Emergency Protective Measure for Nuclear Reactor Accidents") with the most current technical information and to expand the cost-benefit analysis to include a more comprehensive evaluation of the monetary value assigned to thyroid health effects.

A comprehensive evaluation of KI prophylaxis and a defensible cost-benefit analysis are complicated tasks made difficult by the need to draw upon multiple disciplines for a complete unierstanding of the benefits, risks, and economic costs of iodide prophylaxis. Essential to an objective assessment is a basic understanding of (1) thyroid histology, physiology, and iodjde metabolism, (2) radiation thyroid pathologies and their treatments, (3) intemal dosimetry relating to radioiodime, (4) epidemiological risk assessment methods, and (5) economic methods used to assign monetary values to human illness and associated health care. 


\section{CHAPTER 2}

\section{BACKGROUND INFORMATION}

\subsection{Thyroid Function}

A basic knowledge of thyroid physiology and metabolism of iodide will help the reader understand the basis for iodide prophylaxis, the potential for adverse reactions to stable iodide, and the evaluation of specific modifying factors relating to internal thyroid dose. Also included in this chapter is a brief overview of the major thyrcid pathologies and their treatments; the intent is to promote a better understanding of radiation-induced thyroid injury and specific cost factors. Principal cost factors are represented by direct medical costs, indirect costs assoclated with loss of economic opportunity, and psychological cost estimates, which reflect a reduction in the quality of life.

The Thyroid Gland. The normal thyroid gland is butterfly shaped and consists of two elongated lobes positioned on either side of the trachen. In the adult, the average weight of the thyroid is between 15 and 20 grams. The dominant microscopic structural feature of the thyroid is its composition of mumerous follicles. Each spherically shaped follicle of about 200 microns is lined by columnar epithelial cells (15 $\mu$ high) that surround a colloid-filled luminar space (Figure 2-1). The colloid is a mixture of proteins of which thyroglobulins comprise about 80 percent. The flow of blood throtigh the thyroid, per unit weight of tissue, is high and exceeds that of the kidney. The nommil thyroid is able to remove iodide from the blood at a rate of 5-12 ml per minute. It is important to note that iodide is concurrently removed from the plasma and excreted by the kidneys at a rate of about $20-30 \mathrm{ml}$ per minute. For a given dietary intake of stable iodide, the kinetics of these two competing removal mechanisms of jodide from the blood form the basis of the iodide uptake fraction from the blood by the thyroid. In instances of radioactive iodine, the uptake fraction (i.e., $f_{2}{ }^{\prime}$ value) proportionately determines the dose to the thyroid.

The iodide concentrating mechanism by thyroid cells is frequently referred to as the iodide pump and involves an active energy-dependent membrane tramsport mechanism. Cell-sequestered iodide becomes a critical constituent of thyroid hormones. In its endocrine role, the thyroid gland exhibits three characteristic functions: (1) trapping of iodide, (2) synthesis of organically bound iodide, and (3) storage and secretion of iodothyronine hommes (Figure 2-2). The thyroid cells actively transport iodide across the cell membrane and maintain a concentration gradient of 25:1 over the level in the blood plasma. Iodination of the amino acid tyrosine is accomplished first at the third position and then at the fifth position to form monoiodotyrosine (MIT). The subsequent synthesis of ditodotyrosine (DIT) and formation of the thyroid homones tritodothyronine $\left(\mathrm{T}_{3}\right)$ and tetraiodothyronine $\left(\mathrm{S}_{4}\right)$ occur within the cells of the follicle before being secreted into the follicular lumen to become part of the colloid (Figure 2-2). 


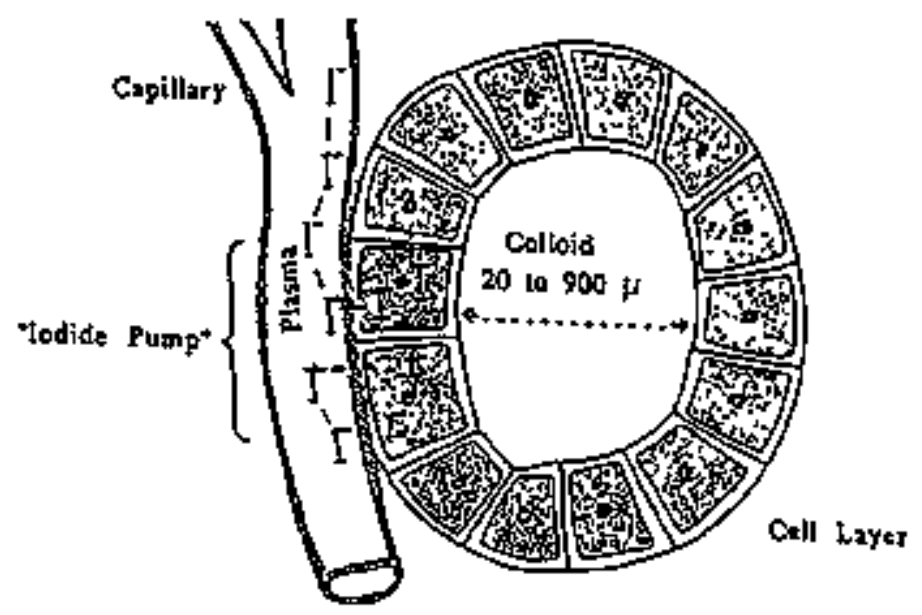

Figure 2-1. Anatomical Features of the Thyrotd Follicle<smiles>N[C@@H](Cc1ccc(O)cc1)C(=O)O</smiles><smiles>NC(=O)C(Cc1ccc(O)cc1)C(=O)O</smiles>
MOMFOODOTYROSINE (MIT)<smiles>NC(=O)C(C(=O)O)c1ccccc1</smiles>
onoootracsike<smiles>COC(=O)[C@H](N)C1=CC=C(Oc2ccccc2)CC=C1</smiles>

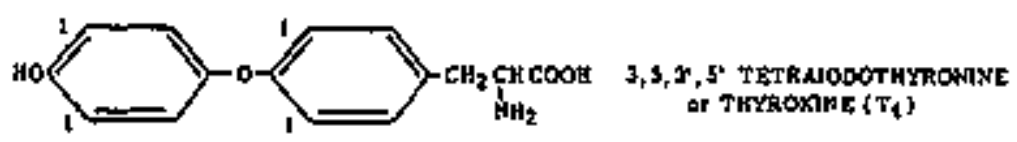

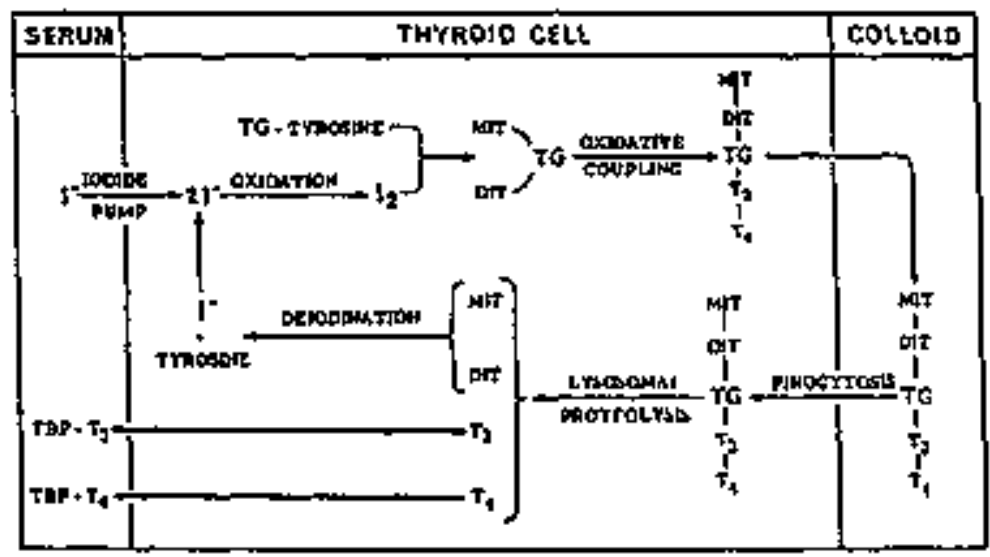

Figure 2-2. Componnds and Pathways of Thyroid Hormone Production 
Each day the thyroid releases approximately 60 to $100 \mu \mathrm{g}$ of hormonal iodide, of which $90 \%$ is thyroxine $\left(T_{4}\right)$ and $10 \%$ is tritodothyronine $\left(T_{3}\right)$. Although the usual ratio of $T_{4}$ to $T_{3}$ secreted by the thyroid is 10 to 1 , the ratio of $T_{4}$ to $T_{3}$ in plasma is normally about 40 to 1 due to metabolism differences and the enhanced affinity of $T_{4}$ to bind plasma proteins.

Both the synthesis and release of iodothyronines into the blood stream are regulated processes that are primarily under the control of the pituitary gland. Pituitary-secreted thyroid stimulating hormone (TSH) is the main regulator of thyroid function. TSH increases the rate of iodide uptake, organification, and release. The TSH homeostatic feedback control system is designed to maintain a constant level of serum $T_{4}$ and $T_{3}$. To achieve this, the gland must gccumulate a constant amount of iodide each day. Variations in dietary iodide intake nust be countered by reciprocal changes in thyroid uptake and organification of serum iodide. Thus, a lowering of dietary intake of iodide produces correspondingly low serum levels of free iodide that is "sensed" by the pituitary gland. The increased release of pituitary TSH stimulates thyroid cell proliferation, which is aimed to increase the efficiency of the thyroid to capture a limited supply of available serum iodide. A marked and prolonged dietary deficiency of iodide results in thyroid eniargemem (simple goiter). On the basis of this homeostatic regulatory mechanism, it is obvious that the fraction of ingested iodide that is accurnulated by the thyroid is heavily dependent on the dietary content of iocide. For nomal (euthyroid) individuals in the United States with an average daily dietary intake of about $225 \mathrm{\mu g}$ of iodide, the daily thyroidal uptake of 50 to $60 \mu \mathrm{g}$ of iodide represents a $25 \%$ fractional uptake (i.e., $f_{2}^{\prime}$ value). For lower dietary intakes of iodide, the fraction of iodide retained by the thyroid can be considerably higher and may reach levels in excess of $90 \%$ (WHO 1989).

The primary significance of dietary iodide levels is that for a common exposure to radioiodide (i.e., inhalation or ingestion), individuals with a lower dietary intake of stable iodide will have a higher thyroid uptake of radioiodide resulting in a proportionately higher thyroid exposure. Daily intake leveis of stable iodide may also influence adverse reactions to stable iodide when administered in doses that greatly exceed dietary levels.

\subsection{Thyroid Pathology}

\subsubsection{Hormone Imbalance}

The thyroid gland is aot indispensable to life, but its presence is necessary for normal growth and development, heat production, and the well-being of the individual. The most prominent effect of the thyroid homones is their regulatory control of respiratory exchange and basal metabolic rate (BMR). The thyroid gland serves as the body's metabolic thermostat by controlling the rate of oxidative metabolism of individual cells, which collectively provide heat and maintain body temperature.

Under conditions of hyperthyroidism (i.e., increased production or auministration of the thyroid hormone), there is increased oxygen consumption, heat production, food metabolism, cardiac output and plasma volume. This clinical state is also referred to as thrrotoxicosis. 
Hyperthyroidism is most conmonly associated with Graves' Disease. Graves' Disease is an autoimmune disease in which the body's own immune system is directed against cellular and secretory products of the thyroid gland. Hyperthyroidism can also be caused by excessive production of hormones by a single "toxic" nadule, by thyroid carcinomas, and by medications inclusive of potassium iodide. Clinical manifestations of hyperthyroidism range from very mild to severe and may include weakness, increased fatigue, weight loss, changes in skin and hair texture, intolerance to heat, perspiration, blured vision, heart arthythmias, and feelings of enotional anxiety.

Hypothyroidism (thyroiditis) is marked by a depression of thyroid hormone production that leads to a progressive slowing down of all bodily activities. Three types of thyroiditis are recognized: chronic, acute, and subacute. Chronic thyroiditis (or Hashimoto's Disease) is not an infection or, in the ustral sense, an inflammation, but like Graves Disease is thought to involve an autoimmune reaction. Acute and subacute thyroiditis are normally associated with bacterial and viral infections of the thyroid and are, therefore, self-limiting. Prominent clinical manifestations of hypothyroidism include cold intolerance, dry skin and sometimes thickening of the skin, hoarse voice, constipation, slow speech, weight gain, fatigue, and emotional changes often confused with depression. In adults, thyroid hormones also participate in the organization of cells. When thyroid function is reduced or eliminated, certain cellular functions become disorganized. Two typical examples of this are the epiphyseal dysgenesis and the myxedema. The epiphyseal dysgenesis is manifested by the spotty and irregular calcification of skeletal tissues. The myxedema of hypothyroidism is characterized by the accumulation of an abnormal protein in the interstitial spaces.

During childhood and puberty, thyroid homones have a profound effect on the rate of body growth and development. A reduced hormone level during this time causes marked reduction in skeletal maturation and prevents full-body growth to adult dimensions. Thyroid deficiency during human fetal life and the post-natal period produces a profound diminution in development and growth, inctuding the central nervous system with a decided loss of intellect. Because radioiodide and stable iodide may uniquely affect fetal thyroid development and function, these effects are discussed separately in Section 2.5.

\subsubsection{Thyroid Nodules}

Single or multiple nodules of sufficient size may cause obvious enlargement of the thyroid. Ustally a nodular thyroid is asymptomatic, but with progressive growth, there may be a visible enlargement in the reck, tracheal compression producing a sensation of choking or coughing, and hoarseness. A nodule(s) refers to a replacement of the normal homogeneous cytostructure of the thyroid with a histologic pattern ranging from colloid-filled cysts and colloid adenomas to follicular adenomas. Nodules are frequently associated with fibrosis and, in some cases, there is evidence of hemorthage and lymphocytic infiltration. In some patients, enlargement and notularity of the thyroid are found during routine physical examinations. Since the incidence is 10 to 20 times as great in women as in men, and since it develops and progressively increases 
in size during life, it is most frequently found in females 50 to 70 years of age. It is not uncommon for nodules to remain undetected until a post-mortem examination.

Small nodules in euthyroid subjects require no therapy. If the gland is grossly enlarged and causes a cosmetic problem or tracheal compression, resection may be suggested along with thyroid hormone replacement therapy. The potential problems of thyrotoxicosis and malignancy ate discussed below.

A small percentage of thyroid nodules tend to produce thyroid hormones uncontrollably and in excess (i.e., the nodule is not under the regulatory control of the pituitary gland and is clinically referred to as toxic nodular goiter). The presence of these autonomously functioning thyroid nodules leads to hyperthyroidism (thyrotoxicosis). Although the pathophysiological problems do not differ from that of other forms of thyrotoxicosis, congestive heart failure, atrial fibrillation, and muscle weakness tend to be more prevalent.

Toxic nodular goiter, like Graves Disease, may be treated surgically (thyroidectomy) or by therapeutic dose(s) with radioactive iodine. A frequent side effect of radioiodine therapy is the induction of hypothyroidism years later.

Although some patients with thyroid nodules are never referred for evaluation or for therapy, the sudden growth of one area of a multinodular gland, the palpation of an untsual firm area, or the development of hoarseness may raise the question of malignancy. Thus, patients for whom surgery (or radioiodine therapy) has been reconmended are obviously highly selected because they have developed symptoms that brought them to a physician and that were considered significant enough for referral. Among those patients who are operated upon, the incidence of verified carcinoma (usually papillary adeno-carcinoma) varies from 2 to 20 percent. Becanse of this frequency, some physicians view the presence of multinodular goiter as sufficient indication for thyroidectorny.

\subsubsection{Thyroid Adenomas}

Adenomas are new growths of thyroid tissue having a hoinogeneous histologic pattern surrounded by a capsule of fibrous tissue or compressed normal cells. Pathologically, adenomas are principally of papillary and follicular forms. They may be present as a single structure in otherwise normal glands, as two or three discrete adenomas, or they may be a feature of the multinadular goiter. The most common variety is the follicular adenoma composed of large colloid-filled follicles. There is uncertainty whether these "colloid" nodules are true adenomas.

On clinical and laboratory examination, most patients with thyroid adenomas are euthyroid, and radioactive iodine uptake and seanning snidies show that the nodule is "cold" with an ability to concentrate iodide that is equal to or less than normal thyroid tissue. Less frequently, thyroid adenomas produce excessive hormones leading to thyrotoxicosis. Thus, the clinical problem most often presented by the thyroid adenomas is not the management of the thyroid nodule, but the ability to differentiate such lesions from thyroid cancer. Although the probability of 
makignancy is reduced for warm or hot (as compared to cold) nodules, nevertheless, 3 to 10 percent of carcinomas are warm to hot. Thus, clinical examination and isotope scanning are not conclusive in establishing whether a nodule is a benign adenorna or a malignant carcinoma.

Treatment: Nodules with strong support for a benign diagnosis can be followed with thyroid hormone suppressive therapy, and hyperfunctioning nodules can be ablated by appropriately large doses of I-131. Nodules with suggestive findings on history (e.g., previous radiation exposure), those with biopsy or cytologic sudy suggestive of malignancy, those that are cosmetically a problem, or noduks causing a real degree of anxiety are best surgically resected.

The operative procedure is usually subtotal lobectomy if the lesion appears benign and with to observable lymph node involvement. If the diagnosis of adenoma is confirmed upon histological tissue examination, no further procedure is required. If the lesion is malignant, a more extensive procedure is carried out. Patients who have a subtotal resection for a benign adenoma commonly require pennanent thyroid hormone replacement therapy.

\subsubsection{Thyroid Carcinomas}

Thyroid carcinomas are generally classified on the basis of cell origin and histological profiles and include (1) papillary, (2) follicular, (3) medullary, and (4) anaplastic carcinomas. Radjation is generally considered a causative agent only for the induction of papillary and follicular carcinornas.

Papillary carcinoma. Nearly 80 percent of all thyroid carcinomas (and about $90 \%$ of radiationinduced thyroid carcinomas) are papiliary tumors. Papillary lesions are frequently very small and often found as incidentally observed microscopic tumors in glands removed from some other lesion. Papillary tumors tend to metastasize early to lymph nodes in the neck at a time when the primary tumor cannot be detected by physical examination or by scanning. The tumor remains confined to cervical lymph nodes for a long time, but may invade locally into strap muscles and the larynx, and metastasize to the Inngs. Tumor growth tends to be partially dependent on TSH and is less aggressive in individuals under the age of 40 . The ten-year survival rate with various forms of therapy is up to about $90 \%$.

Eollicular carcinoma. Follicular thyroid carcinomas vary in histological appearance and tend to metastasize early via the bloodstream to lung and bones. The tumors are TSH responsive and tend to pick up and metabolize iodide and to form the thyroid hormone. In the absence of treatment, the unchecked biosynthesis may lead to clinical thyrotoxicosis. The ten-year survival rate with this type of thyroid carcinoma is about $\mathbf{5 0 \%}$.

Treatment of Thvroid Cancer: The selection of patients for surgery was discussed above. Patients with a neck mass thought to be cancerous, or those with a thyroid mass plus cervical nodes, should have thyroidectomy. During surgery, a diagmosis is made based on examination of the primary lesion, resection of lympi nodes, and subsequent histological tissue examination. If the lesion is differentiated papillary cancer under $1 \mathrm{~cm}$ in size and is confined to the thyroid, 
a total lobectomy is done for the involved side, a subtotal resection is performed on the other side, and resection of the tracheo-esophageal groove is carried out. If there is evidence of multicentricity, if the tumor is over $1 \mathrm{~cm}$ in size, if there is a history of radiation exposure to the area, or if it has metastasized to the neck, a near total thyroidectomy is done (with preservation of the parathyroids) along with a limited neck dissection. If there is definitive evidence of lymph node involvement or metastases, patients are given one or more therapeutic doses of iodine-131 to ablate residual tissues and metastatic foci.

\subsubsection{Life-Expectancy and Thyroid Cancer}

Important parameters in a cost-benefit analysis include not only estimates of potential thyroid effects but also their time of occurrence and their course of outcome. An assessment of time intervals at which cancer may first be diagnosed and, subsequently, the time intervals at which death may occur yield the following two important estimates:

(1) the collective number of years of life lived with diagnosed cancers, and

(2) the total years of life lost due to premature death from thyroid cancers.

Both of these parameters are important in quantifying direct costs, indirect costs, and psychological costs, and are discussed further in Chapter 5 and in Appendix D.

Radiation-induced thyroid cancers are essentially confined to the papilary and follicular kind. The proportion of papillary and follicular thyroid carcinomas, when induced by radiation, are assumed to be $90 \%$ and $10 \%$, respectively. Beach (1962) and Raventos (1964) analyzed the time of thyroid cancer occurrence among 660 cancer cases involving external radiation in childhood. Following a minimum latency period of five years, the time intervals between exposure and cancer diagnosis exhibited a log-normal distribution that reached a plateau about 15 to 25 years after exposure. The mean time of appearance of thyroid cancers was 10.5 years.

Clinical studies indicate that about $10 \%$ of thyroid cancers are fatal and, therefore. result in years of life lost. The times at which deaths from papillary and follicular thyroid cancer occur have been documented by MeConahey (1981) and Cody (1976) and involve a combined population of 1,595 thyroid cancer patients treated between 1931 and 1971. The distributions for the time of death for each of the cancer types as well as their weighted means are provided in Table 2-1. 
Table 2-1. Time Distribution of Deaths Due to Papilary and Follicular Carcinoma of the Thyroid

\begin{tabular}{cccc}
\hline $\begin{array}{c}\text { Time after Diagrosis } \\
\text { (Years) }\end{array}$ & $\begin{array}{c}\text { Papillary } \\
(\%)\end{array}$ & $\begin{array}{c}\text { Follicular } \\
(\%)\end{array}$ & $\begin{array}{c}\text { Average Weighted } \\
\text { Value (\%) }\end{array}$ \\
\hline $1+5$ & 44 & 51 & 44.7 \\
$6-10$ & 22 & 17 & 21.5 \\
$11-15$ & 10.5 & 8.5 & 10.3 \\
$16-20$ & 3.5 & 20.5 & 5.2 \\
21 or tmore & 20 & 3 & 18.3 \\
TOTAL & 100 & 100 & 100 \\
\hline
\end{tabular}

Using the midpoint of time-intervals and the corresponding percentage value as a weighting factor, an overall mean survival time of 9.3 years following cancer diagnosis can be estimated.

\subsection{Health Effects Associated with Radiation Exposure}

Radioiodine uptakes from inhalation could result in acute, chronic, and delayed thyroid effects. For very bigh doses, acute effects include thyroiditis induced within two to three weeks after exposure and hypothyroidism within a period of several months. Following a latency period of years to decades, chronic and delayed thyroid effects may involve the gradual insufficiency of thyroid hormone production (i.e., hypothyroidism) or the appearance of thyroid nodules and cancer.

\subsubsection{Acute Radiation Thyroiditis}

Acute radiation thyroiditis generally occurs within two to three weeks after an internal expasure to radioiodine and is characterized by inflammation and necrosis of thyroid tissue (Maxon 1977). The symptoms are generally mild but in some instances may be intensely exacerbated by the rapid release of stored thyroid hormones (thyroid storm) (Shafer 1971). In most instances, this syndrome is abated within several weeks of onset.

Data from tuman subjects who were administered I-131 for the ablation of residual thyroid tissue after thyroidectomy for thyroid cancer suggest that acute radiation thyroiditis has a threshold dose value of about 20,000 rads. Above the apparent 20,000 rads threshold, it is estimated that about five percent of exposed individuals are likely to develop thyroiditis for each incremental dose of 10,000 rads, which yields a $D_{50}$ or median value of 120,000 rads (Maxon 1977).

Based on these observations, the occurrence of radiation-induced thyroiditis is highly improbable even for severe accident conditions and near field populations. Moreover, if sufficiently high 
thyroid doses were to occur, they would most likely be accompanied by lethal external radiation exposure doses. For this reason, acute radiation thyroiditis is not relevant to a cost-benefit analysis for iodide prophylaxis and will not be considered in this report.

\subsubsection{Chronic Lymphocytic Thyroiditis}

Chronic lymphocytic thyroiditis is an inflammation of the thyroid that is characterized by autoimmune reactions and occurs years after radiation exposure. An abundance of lymphocytes within the thyroid tissue and the prevalence of antimicrosomal and antithyroglobulin antibodies are strong evidence of an autoimmune reaction triggered by radiation (DeGroot 1983). While incidence rates and risk estimates have been established for populations exposed to externa] radiation during childhood, there is insufficient data to pernit risk estimates of chronic thyroiditis for I-13I exposure (DeGroot 1977). From a practical point of view, this condition has limited clinical significance unless the inflammation is associated with hypothyroidism or thyroid nodules in which case risk estimates for hypothyroidism and thyroid nodules would encompass potential manifestations of chronic lymphocytic thyroiditis. Chronic lymphocytic thyroiditis will, therefore, not be assessed as a separate radiation-induced thyroid condition.

\subsubsection{Hypothyroidism}

Hypothyroidism represents a metabolic state in which the thyroid produces an insufficient quantity of the thyroid hormone for normal physiologic function. For radiation- induct hypothyroidism, it most be assumed that a substantial number of cells are either killed or rendered non-finctional, because of the large reserve capacity of the normal thyroid. In recognition of this reserve capacity and the classical sigmoid dose-response relationship of somatic cell survival, a linear model with a threshold is generally assumed for hypothyroidism.

Clinical studies of patients treated with I-131 for Graves' Disease (Becker 1971) and cardiac disease (Segal 1958) convincingly show a linear correlation between the radiation dose to the thyroid and the probability of hypothyroidism above a threshold dose. Based on these and other human data, thyroid doses of 60,000 radis would be expected to result in a $100 \%$ probability of hypothyroidism.

The latency period between exposure and symptoms of hypothyroidism ranges from less than one year to several decades and increases with decreasing doses. Another important variable affecting latency is the age at exposure. As a result, hypotbyroidism can be expected to occur over an jll-defined but limited time period. In this report, a mean latency period of five years is assumed for radiation-induced hypothyroidism.

\subsubsection{Thyroid Neoplasins}

Thyroid neoplasms include benign noduies (adenomas) and cancerous modules (carcinomas). Thytoid neoplasms occur spontaneously in the general population and with increased frequency among populations with radiation thyroid exposure. 
Estimates of spontaneous incidence of thyroid nodules and thyroid cancers for the general population are generaily based on clinically evident thyroid conditions, which do not include "occult" thyroid neoplasins (i.e., thyroid neoplasms, which go undetected and are only noted incidentally). Based on the analysis of several independent studies and fitting data points with a linear regression function, Maxon (NUREG-4214) estimated the spontaneous incidence of clinically detectable thyroid nodules at $0.1 \%$ per year of life for the general population with a liferime risk of approximately $7 \%$. In estimating the number of expected cancers from the total incidence of thyroid nodutes, Maxon assumed that $10 \%$ of the nodules were malignant, yielding an annual risk of $0.01 \%$ and a lifetime risk of about $0.7 \%$.

\subsubsection{External Radiation and Thyroid Neoplasms}

The most informative human data providing a quantitative relationship between radjation exposure and the delayed formation of thyroid neoplasms involve retrospective studies on subjects exposed to doses up to 1,500 rads of external radiation in childhood for a variety of benign diseases. For a period of about 30 years (1925-1955), x-rays were commonly used in (1) scalp irradiation for ringworm (Modan 1974, Shore 1976 or later, Ron 1984); (2) neck and chest irradiation for pertussis (Webber 1975), enlarged thymus (Shore 1985), adenoids, tonsils (Crile 1975); and (3) skin irradiation for facial acne and hemangiomas (Goldschmidt 1977).

Higher doses of external irradiation in the range of 2,000 to 5,000 rads were used between 1920 and 1940 for the treatment of goiter (DeLawter 1963), hyperthyroidism in adults (Einhom 1967), and catcer in the neck region during childhood (Kaplan 1983). Collectively, studies of indiviouals with external thyroid exposures in excess of 1,500 rads show that there is a reduced risk of neoplasms per unit dose than for lower doses. It is generally assumed that at external doses above 1,500 rads, cell-killing increasingly reduces the potential for neoplastic cell transformation. The incidence of thyroid neoplasms among these populations was, therefore, not considered appropriate for formulating risk estimates.

Our current estimates of thyroid risks are based on external exposures ranging from about 5 to 1,500 rads. Thyroid exposures for scaip epitation are estimated to range from 5 to 50 rads, for enlarged thymus 60 to $500 \mathrm{rads}$, enlarged tonsils and adenoids 400 to $800 \mathrm{rads}$, and 600 to 1,500 rads for facial acne.

For risk estimates, the most significant studies to date, involving childhood exposures of less than 1,500 rads, are those of Shore (1976), Maxon (1980), Frohman (1977), Hempelrnan (1975), DeGroot (1983), and Ron (1984). Their sudies indicate a linear dose-response with no clear threshold for thyroid nodules and cancers. Additionally, these studies provide strong evidence of a minimum latency period and a variety of modifying factors involving age, gender, and ettrnic origin. 


\subsubsection{Thyroid Neoplasia from Internal Exposures to Radioiodine}

The thyroidal effects from internal deposition of radiogodines have been studied for three categories of exposed individuals: (1) patients receiving large therapeutic doses of I-131 for thyroid disorders, (2) patients receiving much smalter doses of I-131 for diagnostic purposes, and (3) fallout exposures from atomic weapons.

Therapeutic Exposures. In the treatment of hyperthyroidism associated with Graves' Disease, I-13I is administered in sufficient quantities to cause partial to full ablation of the thyroid. Depending upon patient-specific iodine metabolism and size of thyroid gland, radioiodine may be administered in millicurie quantities which yield thyroid doses from a few thousand to more than ten thousand rads.

In two independent studies involving more than 20,000 adult subjects (Dobyns 1974; Holm 1984), there was no evidence of I-131 induced thyroid cancers. In fact, the thyroid cancer incidence rate among I-131 treated patients with Graves' Disease was well below the level of patients not treated with radioiodine. It has been assumed that this apparent absence of carcinomas may be due in large part to the effects of cell-kilting and/or sterilization at such high dose levels. Additionally, in both studies, the follow-up time (less than ten years) was relatively short, and the studies involved adults whose inyroids are less susceptible than those of children.

In two smalier studies with a combined population of 304 patients between 1 and 20 years of age, two thyroid cancers were observed when only 0.3 cases were expected. The difference between the observed and expected number of cancers, however, was not considered significant (Safa 1975).

Diagnostic Exposures. The most intensive follow-up swdies of patients given 1-131 for diagnostic purposes are the Swedish studies of Holm, et.al. (Holm 1980; 1984; 1988). The most recent study (Holm 1988) assessed the cancer incidence of 35,074 individuals who had survived at least five years following exposure to a diagnostic dose of 1-131. Important statistical parameters for this study population included the following mean values: (1) thyroid dose of about 50 rads; (2) age of exposure at 44 years; and (3) a follow-up period of 20 years. A total of 50 thyroid cancers was observed among the I-131 exposed study group. Based on age and sex composition of the study group, about 39 cases were expected. The resultant standardized incidence ratio of 1.27 was not considered significant inasmuch as the observed standardized incidence ratio fell well within $95 \%$ confidence interval range of 0.94 to 1.67 .

Any potential link of the observed thyroid cancers to I-131 exposure is further minimized by these facts: (1) 10 of the 50 observed thyroid cancers were medullary carcinomas that are generally regarded as non-radiogenic cancers and (2) the majority of observed cancers occurred among individuals who had received a diagnostic dose of I-131 because of suspected thyroid cancer. In summary, these studies provide no evidence that thyroid doses below 150 rads from I-131 significantly increase the risk of thyroid cancer. 
In the United States, an interagency study (involving the Department of Health and Human Services' Bureau of Radiological Health, the National Cancer Institute, and the Nuclear Regulatory Commission) has been in progress since 1973. The study includes persons who during childhood were administered diagnostic levels of I-131 yjelding a mean dose of 94 rads. Although no data have officially been published, to date none of the 443 treated subjects has developed thyroid cancer, and white several cases of benign thyroid nodules have been observed, their incidence is not considered significant.

Exposure to Fallorts. Two population groups that have been exposed to radioiodine from weapon fallout have been extensively studied. Inhabitants of Marshall Island were exposed to fallout from the 1954 BRAVO thermonuclear test. This atmospheric nuclear test heavily contaminated the jslands of Rongelap atoll and, to a lesser extent, Utrik atoll. Thyroid exposure resulted primarily from a combination of external gamma radiation and the intemal exposure to a mixture of radioiodines. For the inhabitants of Rongelap and Utrik atolls, exterial thyroid exposures have been estimated at 175 and 14 rads, respectively. However, radioiodines contributed the largest percentage to the total thyroid doses which ranged from a low of 30 rads to greater than 1500 rads (Conard 1984). The thyroid condition of inhabitants of those two atolls included an increased prevalence of hypothyroidism, thyroid nodules, and thyroid carcinomas (Conard 1984).

In orter to refine the risk of thyroid neoplasia from nuclear fallout containing radioactive iodines. studies of the Marshallese have recently been expanded to include 12 atolls previously thought to be unexposed to fallout (Hamilton 1987). As a result, the study population was expanded to 2,273 persons who were alive at the time of BRAVO test and who lived on one of the 14 atolls. On the basis of new data, a linear dose-response relationship was observed which yielded an absolute risk coefficient of 11 excess cases per one million person/rad years (Hamilton 1987). This risk estimate was 33\% higher than previous estimates, which did not include the total geographical extent of the Republic of the Marshall Islands. Due to the complexity and the assumptions used in estimating thyroid doses and the uncertainty of spontaneous incidence of thyroid neoplasia, the National Research Council's Committee on the Biological Effects of Ionizing Radiation (BEIR) urges caution in interpreting data regarding the Marshall Islanders.

The second popalation group sudied for thyroid disorders include children exposed to fallout resulting from atmospheric testing of nuclear devices at the Nevada Test Site (NTS) between 1951 and 1962. During that period, 105 tests were conducted above ground surface and 14 other tests were conducted below ground, but at a depth where containment was incomplete (Church 1990). A cohort of about 2,600 public school students, who as infants lived proximally to the Nevada Test Site in Utah and Nevada, has been studied since 1965. The prevalence of thyroid abnormalities in these children has been compared to that in a control group selected from a county in Arizona that was presumed to have received little or no fallout from the NTS. Thyroid doses were primarily the result of ingestion of radioiodine-contaminated milk, and cumulative thyroid doses among suidy subjects have been estimated to range from $30-700$ rads (Mays 1966). The significance of milk as the primary pathway for thyroid exposure is that shorter-lived radionuclides of iodine are proportionately excluded from contributing to the 
thyroid dose. Incidences of thyroid neoplasms were first reported in 1974 and 1975 (Rallison 1974 and 1975). At that time, among the 4,819 children, which included 2,140 nonexposed controls, a total of 76 nodules was detected of which 22 were diagnosed as neoplasms. (In addition to neoplastic nodules, observed palpable nodules also included colloid nodules, thyroid cysts, and solitary discrete nodules without tissue diagnosis.)

Although the rate of thyroid neoplasms among the Utah/Nevada subjects of 5.6/1,000 was higher than that of the Arizona control subjects $(3.3 / 1,000)$, the difference was statistically insignificant. In a follow-up study conducted in 1985-1986, in which 3,122 of the original 4,819 subjects were reevaluated, thyroid nodules were found in 125 individuals (Rallison 1990). Of the 125 thyroid nodules detected in this later study period, 65 were considered to be neoplasms. The rate of thyroid neoplasms in Utah/Nevada subjects of $24,6 / 1,000$ was again slightly but insignificantiy higher than that of the Arizona stbjects $(20.2 / 1,000)$. The authors concluded that living near the NTS in the $1950 \mathrm{~s}$ did not result in a statistically significant increase in thyroid neoplasms among exposed subjects when compared to control subjects of the same age and gender.

\subsubsection{Efficacy of Radioiodides Relative to External Radiation}

The studies cited above as well as others provide compelling evidence that internal exposure to I-131 is considerably less efficient in producing thyroid effects per unit absorbed dose than external X- or gamma-ray exposure. In fact, no human study in which thyroid exposure was solely due to internal exposure to radioiodine has provided causal evidence of thyroid carcinogenicity.

Among the Marshallese and Japanese A-bonb survivors where excess nodules and cancers were observed, thyroid exposure to radioiodine was accompanied by external gamma radiation. Their data are further obscured by thyroid doses that resulted in hypothyroidism. Untreated hypothyroidism resulting from partial thyroid ablation induces the excessive production and release of thyroid stimulating hormone (TSH) which is suspected to stimulate nodule formation in residual thyroid tissue. The reduced efficacy of I-131 relative to external gamma radiation is further supported by clinical data. When compared to external doses, considerably higher internal doses are needed to achieve comparable levels of thyroid ablation.

The reduced efficacy of I-131 to produce thyroidal effect per unit dose is primarily thought to be the result of differences in dose rate and dose distribution. When the efficacy of I-13I has been compared to that of external gamma radjation, the external gamma radiation dose was received in a very short period of time. Based on the effective half-life of about seven days, the internal exposure from I-131 is spread out over time, which allows for potential cellular repair. Studies assessing the differences between acute and chronic exposures have concluded that for a common dose, and depending upon the biological endpoint under investigation, a chronic exposure may be two to ten times less effective (NCRP 1980).

Potentially of greater significance are micro-dosimetric factors that result in a non-homogeneous dose distribution within the thyroid. The thyroid gland consists of spherical shaped follicles that 
vary in diameter from 20 to 900 microns, with an average of 200 microns (Gillespie 1970). These structures make tip about $50 \%$ to $75 \%$ of the glandular volume, the remainder being connective tissue. Each follicle consists of a single cell layer, which surrounds the colloid filled lumen (see previous Figure 2-1).

The iodide-containing thyroglobulin is synthesized within the cells and subsequently stored as a liquid colloid within the iumens of the follicles. Organically bound iodine is slowly released by the follicles into the circulating plasma as thyroid hormone. About $90 \%$ of thyroidal iodide is sequestered in the cell-free colloid. Between $90 \%$ and $95 \%$ of the energy absotbed by the thyroid from the radioactive decay of I-131 results from the absorption of beta-particles. Based on the disproportionate concentration of radioiodine within the cell-free volume of the follicle and the limited range of beta particles, it is apparent that a "calculated" thyroid dose (which assumes uniform dose distribution) overestimates the true dose received by the surrounding cellular components.

Both the National Academy of Science, BEIR V Committee (NAS 1990) and the National Council on Radiation Protection and Measurements (NCRP 1987) reviewed the wide range of values reported in the literature and concluded that for $\mathbf{I} 131$, the relative effectiveness for the induction of thyroid cancer per unit dose is one-third that of external gamma radiation. For the induction of benign thyroid nodules and hypothyroidism, I-131 is considered only one-fifth as effective as external radiation (NUREG-4214).

For other fission-produced radioiodides, a relative effectiveness of 1.0 is assumed. This is based on their much shorter half-lives, higher beta energies, and a lack of human evidence suggesting otherwise.

\subsection{The Basis of Potassium Iodide Prophylaxis}

In the event of a nuclear accident involving the release of large amounts of radioiodines, thyroid uptakes from inhalation and ingestion could result in thyroid neoplasms and thyroid dysfinction. Under proper conditions of dosage and time, stable iodide can effectively block the thyroidal uptake of radioiodine. Thyroid blockade is primarily achieved by sanurating the iodide transport mechanisn at the cellular level and diluting the relatively small quantity of radioiodine with stable iodide (Wolff 1964, 1980).

A secondary mechanism for thyroid blockade involves the Wolff-Chaikoff effect. Under normal iodide intake conditions, iodide transport is the rate-limiting step in iodide accumulation in the chyroid. Over a limited range of concentrations, the ratio of iodide in the thyroid to that of the senum (i.e., T/S ratio) is constant. Thus, when sentm levels of iodide increase so does the rate of uptake and organification. But when sertm ievels exceed $25 \mathrm{ag} / \mathrm{dl}$, the thyroida] transport mechanism is saburated and the $T / S$ ratio decreases which in turn triggers a reduction in the organification of iodide. This fall in iodide organification at high plasma iodide concentrations is the Wolff-Chaikoff phenomenon (Wolff 1964). 
For normal individuals, the Wolff-Chaikoff effect is of limited duration. Within hours (and in spite of elevated senum levels of iodide that continue to block the iodide transport mechanism), normal organification of iodide resumes. Thus, for normal individuals, the Wolff-Chaikoff effect has limited significance in terms of its contribution to thyroid blockade.

For some individuals, however, "escape" from the Wolff-Chaikoff effect is impaired by underlying thyroidal pathologies. Unrelieved Wolff-Chaikoff suppression that reads to hypothyroidism is seen among individuals with (1) Hashimoto's thyroiditis, (2) perinatal thyroids, (3) Graves' Disease, and (4) reduced thyroid function due to parial thyroidectomy and/or I-131 treatments. The significance of the Wolff-Chaikoff effect is that a prolonged state of hypothyroidism may be induced by stable iodide among select members of a population inclusive of the fetus. This potential adverse effect of iodide is discussed in Section 2.6 of this chapter.

\subsubsection{Dose Requirement for KI Prophylaxis}

Both the efficacy and persistence of the thyroid blocking effect by stable iodide are dose dependent. After an oral administration, iodide is rapidly absorbed into the bloodstream from the stomach where it is progressively removed either by the thyroid or by the kidneys. This exponential clearance of iodide from the biood stream in normal subjects has been shown to have a half-period value of about five to six hours (Myant 1949). (For abnomatly high and low dietary iodide intakes, there is a corresponding reduction and elevation in thyroid uptake rates that result in longer and shorter half-period values, respectively.) Given the rapid uptake of iodide (radioactive or stable), there is a limited benefit of $\mathrm{KI}$ administration following exposure to radioiodine. For $\mathrm{KI}$ to serve as an efficient blocking agent, it must be administered in sufficient quantities before or concurrently with radioiodine exposure.

The highly effective thyroid block by $100 \mathrm{mg}$ of iodide or more has been demonstrated in a number of studies (Pochin 1962; Cronquist 1971). Blocking by smaller amounts of iodine was also demonstrated by Sternthal (1986). In this study, thyroid blocking was about 60 percent efficient for an iodide dose of $10 \mathrm{mg}$ and asymptotically reached efficiency levels of about $95 \%$ to nearly $100 \%$ for doses of $30 \mathrm{mg}$ and greater. Simitar values were obtained by others as reported by the U.S. National Council on Radiation Protection and Measurements (NCRP 1977).

\subsubsection{Persistence of KI Block}

Although doses of about $30 \mathrm{mg}$ are nearly as effective as higher doses when taken just prior or concurrently with radioiodine, the persistence of the blocking effect to subsequent exposure to radioiodine is reduced. The ability of stable jodide to maintain a thyroid block and prevent the uptake of a subsequent exposure to radioiodine is dependent on a contimued elevated sentm level of stable iodide. Using the value of five hours for the biological balf-period serum clearance rate of iodide, one can readily determine the serum concentration level at any time following an oral goministration of $\mathrm{KI}$ by means of the fotlowing equation: 


$$
C_{s}=Q_{\mathrm{s}} e^{-\left(\frac{069)}{T_{1 / t}} x_{0}\right)}
$$

where:

$$
\begin{aligned}
& \mathrm{C}_{\mathrm{s}}=\text { serum level (mg) at time } \mathrm{h} \\
& \mathrm{Q}_{\mathrm{u}}=\text { uptake quantity (mg) } \\
& \mathrm{t}_{1}=\text { lapse time } \\
& \mathrm{i}_{\mathrm{y}}=\text { half-period }
\end{aligned}
$$

Since a $30 \mathrm{mg}$ dose confers about $95 \%$ blocking when administered just before radioiodine exposure, it would be expected that a $100 \mathrm{mg}$ slug of iodide would still provide a $95 \%$ thytroid block almost nine hours after administration. This relationship is illustrated by the classical study of Il'in, et al (Il'in 1972), in which the blocking effect was assessed with time among individuais given a single $100 \mathrm{mg}$ slug of stable iodide (Fig 2-3).

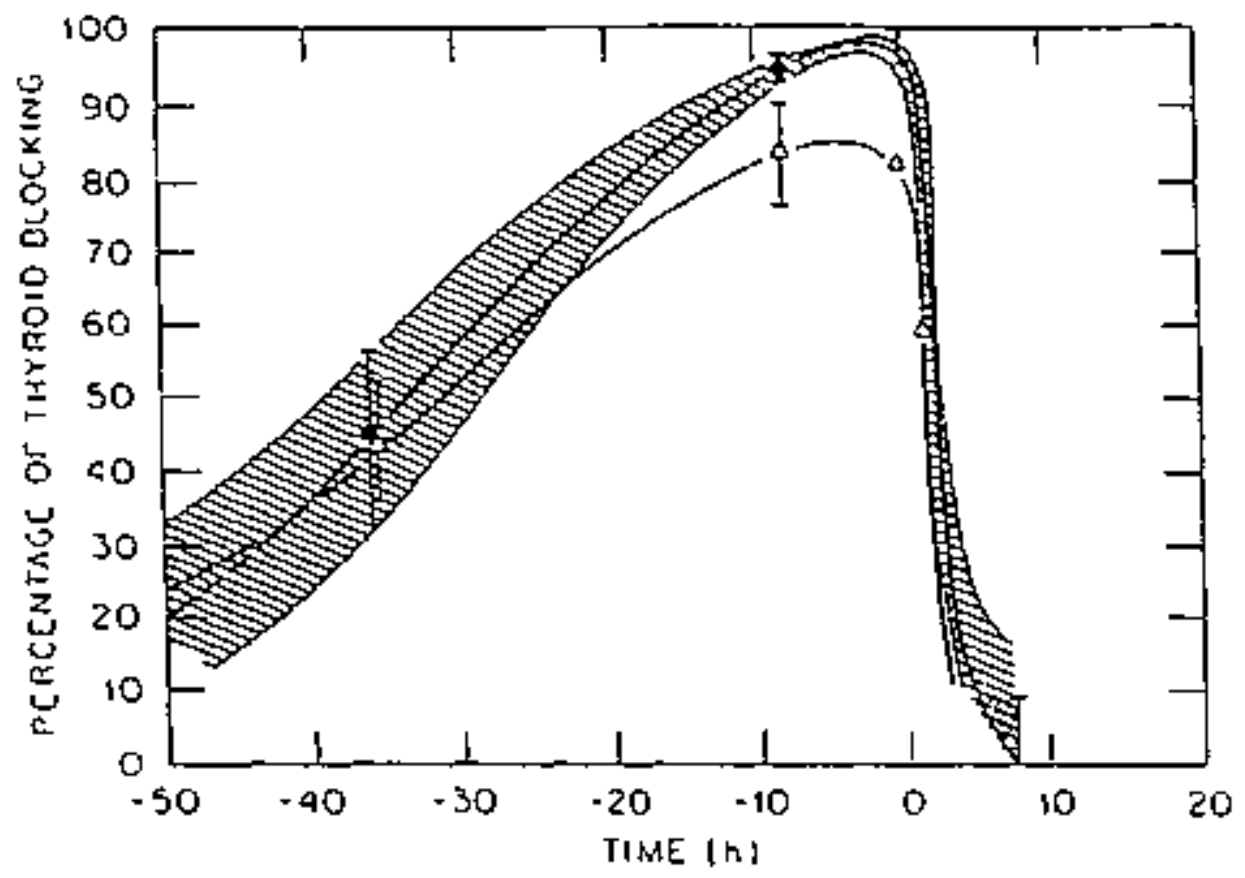

Figure 2-3. Percent of Thyroid Blocking Afforded by $130 \mathrm{mg}$ of Stable KI as a Function of Time of Administration Before (-) or After ( + ) a Single Slug Intake of 1-131. 
From Figure 2-3, it is apparent that for accident conditions in which publis exposure to radioiodine may last several days, there is a diminishing benefit associated with a single slug of stable iodide. For prolonged exposure conditions, Stemthal (1986) determined that a daily iodide dose of $15 \mathrm{mg}, 30 \mathrm{mg}, 50 \mathrm{mg}$, and $100 \mathrm{mg}$ yielded blocking efficiencies of $90 \%, 92 \%$, $94 \%$, and $98.5 \%$, respectively.

The duration of time during which KI must be taken in order to confer thyroid protection corresponds to the period of exposure or potential exposure. For a reactor emergency, this time is assumed to last from a few days to about 10 days.

\subsection{Radioiodine Exposure In-Utero: A Special Case}

The placenta freely passes iodide from the maternal to the fetal circulation (Roti 1983). Exposure of a pregnant female to radioiodide, therefore, has the potential for exposing the fetal thyroid. However, the capacity to concentrate iodide, as measured by the uptake of radioiodide in the fetal gland, does not start until the end of the first trimester (12 weeks). At this time, the fetal thyroid has attained a nominal wejght of $5 \mathrm{mg}$ but begins to increase rapidly in size to about $50 \mathrm{mg}$ by 13 weeks, $100-200 \mathrm{mg}$ by 20 weeks, $200-600 \mathrm{mg}$ by 24 weeks (end of second trimester), and 1-3 g at term. The total iodine content of the fetal thyroid gland increases with thyroid weight and with gestational age. The fetal data indicate that the uptake per gram of thyroid tissue may be considerably greater than that of adults (Evans 1967). Sudies on fetal thyroid glands do not reveal organically bound iodide until about the 19th week despite the appearance of radioiodide uptake at earlier ages (Yamanaki 1959). Labeled $T_{4}$ and $T_{3}$ have been detected in low concentrations in thyroid tissues from 20-24 week old fetuses (Sinadovic 1986; Costa 1986). The capacity to synthesize iodothyronines (e.g., $T_{4}, T_{3}$ ) is not necessarily coincident with the onset of secreting these hormones to the fetal blood stream. Release of iodothyronines to the blood seems to require thyroid stimulation by TSH, which is not secreted by the anterior pituitary until the 28 th week. Coincident with the eievation of fetal plasma TSH, there is a marked sudden increase in plasma $T_{4}$ and $T_{3}$ levels. At birth, fetal serum $T_{4}$ is as high as in the maternal serum.

\subsubsection{Onset of Thyroid Hormone Secretion and Regulation}

Information is limited regarding how early in fetal development the pituitary is capable of responding to changes in thyroid hormone levels. As already indicated, TA and TSH levels in fetal serum concurrently fluctuate sometime after mid-gestation. These findings suggest an increasing sensitivity of the fetal thyroid to TSH and of the fetal pituitary to feedback suppression by thyroid hormones (Fisher 1985; Delange 1984). The responses of the human fetal pituitary near term to thyroid hormone deficiency or excess show that the pituitary-thyroid system functions with at least a degree of autonomy from the maternal thyroid function.

The fully mature thyroid gland has the capacity to modify todine uptake in accordance with circulating lodide levets and independently of TSH. This auto-regulatory system in the fetus is absent and develops only during the final weeks of gestation (36-40 weeks) (Dejange 1984; 
Delange 1985; Carswell 1970). This auto-regulatory mechanism in the mature thyroid permits the gland to overcome the suppressive effects on thyrojd hormone secretion caused by excessive iodide levels (Wolff-Chaikoff blockade). A persistent matemal exposure to $\mathrm{KI}$ priot to the fetal development of this auto-regulatory mechanism may, therefore, impair nomal fetal growth and brain development.

\subsubsection{Transfer of $T_{4}$ and $T_{3}$ from Mother to Fetus}

There is still considerable debate whether maternal thyroid hormones cross the placenta in arnounts significant for fetal development prior to the fetus's independent ability to synthesize and secrete its own (Fisher 1981, Fisher 1985, Thilly 1978, Burrow 1975, Selenkow 1973). The reason for concern is that during the first and passibly during part of the second trimester, the human fetus would be entirely dependent on matemal thyroid function. Therefore, maternal hypothyroidism could result in a decreased availability of thyroid hormone during the initial pheses of gross brain development and during the spurt in forebrain neuroblast proliferation. The outcome of pregnancies in hypothyroid women is very poor, showing a disproportionate incidence of spontaneous abortions, stillbirths, perinatal death, developmental abnormalities, and mental retardation (Greenman 1962; Man 1976). Because there is no information regarding when in the period of gestation the fetus is most vulnerable to maternal hypothyroxinemia, it is not possible to determine if maternal hypothyroxinemia of short duration would have adverse effects on the fetus.

In view of existing information and in spite of unresolved questions, a prudent policy would avoid maternal hypothyroidism or any siguation in which materna! thyroid function might be impaired during the first and second trimesters. During the third trimester, the fetal pinuitarythyroid system appears to be functioning with a high degree of autonomy from the maternal thyroid. During pregnancy, jodide prophylaxis must balance the complex and time-dependent matemal and fetal risks of radioiodine with the potential adverse effects of stable iodide overioad.

\subsubsection{Congenital Hypothyroidism and Cretinism}

Congenital hypothyroidism leading to cretinism is normally observed onty in (1) endemic areas where severe iodine deficiency leads to hypothyroidism in both mother and child during fetal development and (2) individuats with congenital metabolic defects in thyroid hornone formation.

Endemic cretinism induced by iodide deficiency in-utero refers to individuals having a typical constellation of signs and symptoms which at birth include increased hair, low forebead, puffy features, umbilical hernia, enlarged tongue, and stuggish benavior. Other abnormalities may include deaf-mutism, mental retardation, and evidence of spastic paraplegia. If, after birth, a state of hypothyroidism is allowed to continue, stunted body and skeletal growth and mental retardation result. Due to the relatively high dietary iodine intakes in the United States, cretinism due to in-utero iodide deficiency is rarely encountered. 
In the United States, about 1 out of 5,000 newbons suffers from bypothyroidism due to a metabolic defect in thyroid hormone formation, transport, and action. Among these individuals, the basis for congenital bypothyroidism is a genetic deficiency that impairs or prevents normal iodjde trapping, iodide organification, "coupling," recycling of iodide, or resistance to the action of the thyroid hormone. These metabolic defects ustally represent the expression of the homozygous recessive genetic abnormality and may, therefore, be observed in family groupings or inbred populations.

\subsubsection{In-Utero Thyroid Dose}

Congenital hypothyroidisin may also resalt from the destruction of the fetal thyroid from maternal exposure to radioiadine. After the first trimester when fetal thyroid uptake starts, the fetal thyroid may be adversely affected by maternal exposure to radioiodine. Inadvertent administration of high doses of I-131 to women for treatment of thyrotoxicosis or thyroid cancer has occurred in limited numbers when their pregnancy was unknown. In most such instances, exposure occurred early in the first trimester with limited consequences. Several cases, however, have been reported where the radioiodide was administered at the end of the first or beginning of the second trimester (Lightner 1977, VanHerle 1975, Hamill 1961, Fisher 1963, Green 1971, Stoffer 1976). Considerable destruction of fetal thyroid resulting in infant hypothyroidism and other developmental abnotmalities was observed in several cases. The relatively low frequency of permanent damage to the fetas is likely related to the fact that fetal uptake is very low until mid-gestation, and inadvertent administration of I-131 at such an advanced stage of gestation is infrequent.

Johnson developed a model of iodine metabolism in the human fetus from which he calculated the dose to the fetal thyroid as a function of fetal age from intake of radioiodine by the mother. Owing to the small mass of the fetal thyroid, Johnson calculated that the fetal thyroid dose per unit of maternal intake varies with time but on the average is about a factor of two above those to the mother's thyroid (Johnson 1982).

\subsubsection{Pregnant Females and Stable Iodide Prophylaxis}

From the previous discussion, it is apparent that the pregnant female and her fetus are at special risk in case of environmental contamination with radioiodine. Paradoxically, $\mathrm{KI}$ administration also poses some potentially unique adverse effects during pregnancy, whjch may result from iodide overloads to the maternal and/or fetal thyroids. Unfortunately, insufficient data exist regarding the incidence rates of these effects after single or short-term administration of iodide. When exposure to radioiodine yielding high doses is either probable or inevitable, the benefits of KI prophylaxis far outweigh potential adverse effects regardless of the stage of pregnancy. Specific recommendations by the World Health Organization regarding $\mathrm{KI}$ prophylaxis during pregnancy are discussed in Appendix B. 
To guard against the potential consequences of $\mathrm{KI}$-induced congenital hypothyroid, pewborns of pregnant females taking KI should be monitored for an adequate perioxl to detect signs of reduced $\mathrm{T}_{4}$ and/or elevation of TSH levels.

Considering the current lack of information regaroing the transient conseguences of maternal KI overload on early fetal development, matemal thyroid function should also be monitored/controlled following KI administration to pregnant females.

\subsection{Potential Adverse Reactions to Stable Iodide}

Iodine is a ubiquitous but variable constinuent in the environment. Due to its solubility, iodide is readily leached out of soil by rain which ultimately carries it to the world's oceans. From ocean waters, iodide evaporates to the atmosphere where it is concentrated in rain which replenishes the soil (Koutras 1980). Iodide is essential to good health, and the main source for humans is through food. The highest natural iodine content is found in seafood, which may reach concentrations as high as $800 \mu \mathrm{g}$ jodine per $\mathrm{kg}$. Other dietary sources of jodide are eggs, meat, milk, and cereals. Additionally, many foods are artificially enhanced in the United States by additives such' as iodized salt. It is estimated that the daily intake of iodide for adults in the United States ranges between $125 \mu \mathrm{g}$ to $700 \mu \mathrm{g}$ (Oddie 1970; Rubery 1988).

Dietary iodide levels play a key role in potential adverse reaction incidence rates. When dietary levels are high, adverse reactions are assurned to be at their lowest rate. Epidemiological and metabolic saudies support a minimum daily adult requirement of $100 \mu \mathrm{g}$; endemic goiter is usually not found when the dietary intake of iodine is above $100 \mu g$ per day (Stanbury 1980). However, the ATA has stated that:

". . . [while] many anecdotal reports of isolated reactions to iodides have been published, reliable incidence data do not exist. It is reasonable to assume that obvious iodide reactions are rare in the United States where the diet is high in iodine content. . . When reactions do accur, they may be intrathyroidal or extrathyroidal" (Becker 1984).

$i$

In instances of dietary deficiency, the synthesis of thyroid hotmones is festricted and the senum concentration of $T_{4}$ is low. This stimulates the thyroid pituitary feedback mechanism with increased synthesis and secretion of TSH. Elevated serum levels of TSH increase thyroid metabolism of iodide as well as the growth of the thyroid which under prolonged conditions of iodide deficiency becomes goitrous.

Stable iodide prophylaxis is based on the prompt administration of relatively large amounts of stable potassium iodide (i.e., $130 \mathrm{mg}$ per day) over-a period of a few days to a potentially exposed population. This transient increased intake of iodide may produce detrimental changes in iodide metabolism, thyroid function, and inmune reactions among subjects with low dietary iodide intakes. Also at risk for adverse reactions are infividuals with existing thyroid disorders and pathologies. Lastly, the fetal thyroid is potentially at risk from pharmacological levels of 
iodide. Table 2-2 identifies the most common adverse reactions known to be associated with iodide. Adverse reactions to iodide may be categorized as intrathyroidal and extrathyroidal.

\section{Table 2-2. Adverse Reactions to Iodide}

intrathyroidal Effects - Excess or insufficieal production of thyrotid bormones.

- Iodide-induced thyrotoxicosis (hyperthyroidism)

- Iodige-induced hypothyroidism

Extrathyroidal Effects - non-thyroid related reactions and hypersensitivity reactions.

- Erythena nodosium; ioderma; urticaria; bullous enuptions; acne; dermitis herpetiformis; etc.

- Swelling of salivary glands, rhinitis, iodism

- Vasculitis; serum sickness; anaphylactoidd reactions

\subsubsection{Intrathyroidal Adverse Reactions}

Individuals with nornal thyroid function are mot at risk for intrathyroidal effects leading to conditions of hyperthyroidism (thyrotoxicosis) and hypothyroidisn. Hyperthyroidism, when induced by exogenous administration of iodide, is termed "Jod-Basedow" phenomenon and involves an overproduction of the thyroid hormone. This phenomenon is common to indivifuals whose thyroid is no longer under the regulatory control of the pituitary gland's secretion of TSH. The underlying pathologies for autonomously functioning thyroids were previously discussed and include thyroid nodules/cancer, and Graves Disease (Alexander 1965; Vagenakis 1972; Tumbridge 1977).

Iodine supplementation has also been recognized to increase the incidence of hyperthyroidism among individuals in previously iodine-deficient areas following the introduction of iodized salt. This Jod-Basedow phenomenon in previcusly jodide-deficient areas is also thought to involve individuals with autonomously functioning thyroids. Apparenty, the thyroid in these individuals was functioning autonomously at a hyperactive level before supplemental administration of iodide, but was unable to manifest hyperthyroidism owing to the limitation of hormone synthesis imposed by the low dietary intake (Connolly 1970; Fradkin 1983).

For select individuals, the administration of iodide may have the reverse effect of induced hypothyroidism. The antithyroid action of acute iodide overload resulting in a state of hypothyroidism is well documented (Wolff 1969; Nagataki 1974). In normal subjects, an iodide overload causes a transient block of iotide organification (i.e., thyroid homone synthesis) 
known as the "Wolff-Chaikoff effect" (Wolff 1980; 1969). Even with continued administration and elevated serum levels of iodide, healthy subjects escape from this transient and subclinical hypothyroid state within hours and resume normal thyroid hormone procuction. In some individuals, the induction of the Wolff-Chaikoff effect by exogenous iodide is not followed by a prompt escape of its inhibitory effect of iodide organification, so that a state of prolonged hypothyroidism and possible goiter develops. Continuing and unrelieved Wolff-Chaikoff thyroid suppression is seen among individuals with Hashimoto's thyroiditis, Graves' Disease, and after surgical thyroidectomy or l-131 treatments (Wolff 1969; Braverman 1971).

Sub-Populations Likely to Manifest Intrathyroidal Effects from KI Prophylaxis. It is well established that Hashimoto's thyroiditis, Graves' Distase, and idiopathic myxedema are organspecific autoimmune disorders of the thyroid. These and other autoimmune disorders probably develop because of the consequences of an abnormal function or reaction of the immune system that is genetically predisposed. The concept that excess iodine might indirectly influence thyroid tunction by triggering thyroid autoimmune reactions is based on clinical studies that suggest an assocjation between increased consumption of dietary iodine and autoimmune thyroid disorders. Studies have shown a greatly reduced incidence rate of lymphocytic infistration of thyroid tissue, Hashimoto's thyroiditis, and Graves' Disease in jodine-deficient and goiter-endemic areas when compared to areas of iodine sufficiency (Bouki 1983; Hall 1996; McGregor 1985). Although the precise mechanisms responsible for the initiation of autoimmutue phenomena against the thyroid gland in genetically predisposed individuals are highly speculative, there is evidence that iodine can play a role in the initiation and expression of these autoimmune thyroid disorders.

The quantity of exogenous iodide capable of inducing thyroid suppression is not easily defined since it will depend on external factors, stech as dietary intake of jodide, and the interrelationship of internal factors such as the intra-glandular pool of iodide, the efficiency of the autoregulatory mechanism which protects against thyroid overloading, and the underlying thyroid disorder. The American Thyroid Association estimates that daily doses of between 50 and 500 mg of iodide may induce prolonged hypothyroidism among these predisposed individuals (Becker 1984).

A second susceptible target population which may be regarded as normal/healthy includes fetuses in the second and third trimester. The partially developed fetal thyroid during this time has the ability to concentrate iodide, but does not yet possess the autoregulatory mechanism needed to escape the Wolff-Chaikoff effect (Delange 1985; Sherwin 1982).

Chronic consumption of jodide-containing medications such as cough medicine and antiasthmatic drugs has been shown to induce fetal hypothyroidism and fetal goiter (Walfish 1983; Mehta 1983). Fetal and neonatal iodine overload has also been observed following the use of iodinated $x$-ray contrast media during pregnancy (Rodesh 1976) and the cutaneous application of iodinated skin disinfectants (Povidone-iodine) at the time of delivery (Chanoine 1986). The concentration of maternal iodide required to induce a fetal Wolff-Chaikoff effect ha not been properly quantified but is thought to be relatively high (Delange 1988). 


\subsubsection{Extrathyroidal Adverse Reactions}

Numerous non-thyroidal effects have been linked to the pharmacological use of iodide. Persons potentially at risk for non-thyrojdal adverse reactions are individuals with a known sensitivity to iodide. A particularly sensitive target population comprises individuals with hypocomplementemic vasculitis (Curd 1979). The most common reactions involve swelling of the salivary glands (sialademitis or iodide mumps), a host of skin reactions (erythema nodosum, ioderma with necrotic skin lesions, urticaria, buljous eruptions, acne-form skin eruptions, etc.), iodide fever, hinitis, and iodism (Becker 1987; Rubery 1988; Yalow 1983). These reactions are generally observed with large doses of iodide, are self-limiting, and are readily reversed by cessation of drug use. Rare, but of greater significance, are certain hypersensitive or allergic reactions which produce symptons such as fever, pain in joints, edema of the face and glottis, angiitis, vasculitis, add anaphylactoid/anaphylaxis reactions.

\subsubsection{Adverse Reaction Incidence Rate}

Potential adverse reactions to iodide when taken orally in daily doses of $130 \mathrm{mg}$ can be assumed to be very few for the general United States poptation. This assumption is based on the extrapolation of data reported to the Food and Dug Administration (FDA). The FDA's Division of Epidemiology and Surveillance maintains a computerized data base of adverse drug reactions known as the Adverse Reaction Reporting System (ARRS).

The primary purpose of the ARRS is to serve as an early warning system for adverse reactions to drugs subject to FDA regulations. Approximately $90 \%$ of adverse reaction reports received by the FDA are submitted by drug manufactirers who by law must report all adverse events that become known to them. The remaining $10 \%$ of reports are submitted directly by health care professionals in response to suspected adverse reactions among their patients.

An estimate of the potential adverse reaction incidence rate to iodide is best derived from data involving cough syrups and expectorants. Potassium iodide is a major ingredient in these oral medications and results in average daily doses of several hundred milligrams of KI. Among the few adverse reactions that have been reported, the reactions are not life- threatening. In most instances, the reactions are self-limiting or quickly abate with discontimued medication.

A second major class of pharmaceuticals for which adverse reactions have been reported is iodinated $x$-ray contrast media. The high attenuation of diagnostic $x$-rays by organified iodine is the basis for its use in routine medical procedures. However, extrapolation of an adverse reaction incidence rate from iodinated contrast data is subject to numerous uncertainties.

Appendix C contains summary data of adverse reactions to iodide which have been reported to the FDA. Also included are basic assumptions and quantitative methods used to derive a best estimate of the adverse reaction incidence rate.

The most current data suggest an adverse reaction incidence rate to a daity oral dose of $130 \mathrm{mg}$ of $\mathrm{KI}$ at $\mathrm{I} \times 10^{7}$ or less. 


\section{CHAPTER 3}

\section{RISKS OF RADIATION THYROD EFFECTS}

\subsection{Risk of Thyroid Cancer}

Susceptibility to radiation-induced thyroid cancer is greater early in childhood and coincides with the period of thyroid growth. Between birth and early adulthood (approximately 18 years), the thyroid mass increases from a neonatal weight of $1-3 \mathrm{~g}$ to an adult weight of $17-20 \mathrm{~g}$. Since cell sensitivity is affected by cell differentiation and mitotic activity, it is generally assumed that there is a two-fold increase in sensitivity to radiation carcinogenesis for thyroid glands in children and adolescents (18 years of age or less), compared to adults.

Studies of both children and adults consistently indicate that females show a much higher spontaneous thyroid cancer incidence as well as greater effect of radiation carcinogenesis of the thyroid than males exposed under similar conditions. Based on these empirical observations, risk estimates generally assume that females are subject to at least twice the risk of thyroid neoplasia as males under similar conditions. Both the NCRP and BEIR V Committee have adopted the following generic formula to estimate the age, sex, and radiation source specific risk of thyroid cancer (NCRP 1985, NAS 1990):

Specific Risk Estimate $=\mathbf{R} \cdot \mathbf{F} \cdot \mathbf{S} \cdot \mathbf{A} \cdot \mathrm{Y} \cdot \mathbf{L}$

where:

$R=$ Absolute risk estimate of 2.5 excess cases per $10^{6}$ persons per rad per year for consigned (both sexes), ethnically similar, poptulations of children exposed to external $\mathrm{X}$ irradiation and corrected for a minimum induction period for thyroid cancer of 5 years,

$F=$ Dose effectiveness reduction factor (1 for external radiation, I-132, I133 , and I-135; $1 / 3$ for I-131),

$S=$ Sex factor $(4 / 3$ for women and $2 / 3$ for men, assuming that women are twice as susceptible as men and that the $\mathbf{R}$ was derived from a population comprised of equal numbers of both sexes),

A = Age factor ( 1 for populations age 18 or less at exposure and $1 / 2$ for populations over age 18 at exposure),

$Y=$ Anticipated average number of years at risk for the population in question, 
$\mathrm{L}=$ Lethality (assumes a maximum lifetime lethality of $1 / 10$ ). Use this factor only when calculating the specific risk estimate for lifetime deaths to thyroid cancer.

Table 3-1 provides the age, sex, and source-adjusted annual risk estimates applicable to the population of the United States.

To convert the annual risk coefficients defined in Table 3-1 to lifetime risks for the current U.S. population, the number of years at risk for each of the four population subgroups has to be defined. Table 3-2 provides the most current U.S. census data by age and sex. From these data, the median ages for the four subgroups were determined by linear interpolation (Table 33). Mean life expectancies for the median age in each subgroup are specified by parameter \#4. To determine the mean yeats at risk (parameter $\$ 5$ ) for thyroid cancer and thyroid nodules, the respective minimum latency periods of five and ten years were subtracted from the mean life expectancy for each subgroup.

The lifetime risk of thyroid cancer for each of the four subgroups is shown in Table 3-4 and represents the product of the annual risk and the mean years at risk for thyroid cancer. The last column of Table 3-4 also defines the lifetime cancer risk for the general U.S. population.

This collective population risk value represents a weighted average of the four subgroups based on their percentage of the total population. Thus, for the current U.S. population, exposure to 1 million person-thyroid-rads from I-131 would be expected to yield about 23 excess thyroid catcers.

Table 3-1. Ammual Risk of Total and Lethal Excess Thyroid Cancers per Milion Persons per Rad of Thyroid Dose for Doses from 6 to 1,500 Rads (U.S. population)"

\begin{tabular}{|c|c|c|c|c|c|c|c|c|}
\hline \multirow{3}{*}{ Source of irradjation } & \multicolumn{4}{|c|}{$\begin{array}{c}\text { Persons over age } 18 \text { years at time of } \\
\text { exposure }\end{array}$} & \multicolumn{4}{|c|}{$\begin{array}{l}\text { Persons age } 18 \text { or less al time of } \\
\text { exposure }\end{array}$} \\
\hline & \multicolumn{2}{|c|}{ TOTAL } & \multicolumn{2}{|c|}{ LETHAL } & \multicolumn{2}{|c|}{ TOTAL } & \multicolumn{2}{|c|}{ LETHAL } \\
\hline & Male & Female & Male & Fermale & Male & Fentale & Male & Female \\
\hline $\mathrm{J}-13 \mathrm{I}$ & 0.28 & 0.56 & 0.028 & 0.056 & 0.56 & 1.12 & 0.056 & 0.112 \\
\hline $\begin{array}{l}\text { Exiernal } X \text { or gamma rays } \\
\text { and } I-132,-133,-134,-135\end{array}$ & 0.84 & 1.68 & 0.084 & 0.168 & 1.68 & 3.36 & 0.168 & 0.336 \\
\hline
\end{tabular}

Based on an absolute risk estimate of 2.5 cases per $10^{6}$ persons per rad per year it people exposed ro exierital irradiation is childhood. 
Table 3-2. 1990 Population Distribution in the United States by Age and Sex"

\begin{tabular}{|c|c|c|c|c|c|c|}
\hline \multirow{2}{*}{$\begin{array}{c}\text { Age } \\
\text { (years) }\end{array}$} & \multicolumn{6}{|c|}{1990 Population $(x$ J000) } \\
\hline & Matie & $(\$)^{* *}$ & Female & $(\%)^{n+}$ & Total & $(\%)^{-}$ \\
\hline Under 5 & 9,426 & (3.78) & 8,982 & $(3.60)$ & 18,408 & (7.38) \\
\hline $5-17$ & 23,377 & $(9.38)$ & 22,253 & (8.93) & 45.630 & (18.30) \\
\hline $18-24$ & 33.216 & $(5.30)$ & 12,824 & $(5.14)$ & 26,040 & $(10.45)$ \\
\hline $25-34$ & 22,078 & $(8.85)$ & 21,845 & $(8.76)$ & 43,923 & $(17.62)$ \\
\hline $35-44$ & 18,785 & $(7.54)$ & 18,112 & $(7.26)$ & 36.897 & $(14.80)$ \\
\hline $45-54$ & $\mathrm{t} 2,406$ & $(4.98)$ & $13,06 t$ & $(5.24)$ & 25,467 & $(10.22)$ \\
\hline $55-64$ & 10,103 & $(4.05)$ & 11,260 & $(4.52)$ & 21,363 & $(8.57)$ \\
\hline 65.74 & 8,171 & $(3.28)$ & 10,207 & $(4.09)$ & 18,378 & (7 37) \\
\hline 75 and older & 4,681 & $(1.88)$ & 8,505 & $(3.41)$ & 13,186 & $(5.29)$ \\
\hline TOTAL & 122,243 & $(49.04)$ & 127,049 & $(50.96)$ & 249.292 & $(100)$ \\
\hline
\end{tabular}

- Source: U.S. Bureau of the Census, Curreat Population Report Series

- Percent of total population.

Table 3-3. Years at Risk for Age and Sex Groups of the General Population of the United States for 1990

\begin{tabular}{|c|c|c|c|c|}
\hline \multirow{3}{*}{ Parameter } & \multicolumn{4}{|c|}{ Age Grotp (x 1000) } \\
\hline & \multicolumn{2}{|c|}{ Greater than 18} & \multicolumn{2}{|c|}{ Less than or equal to 18} \\
\hline & Male & Fernate & Male & Femate \\
\hline 1. No. of Jgdividuals & 89,440 & 95,814 & 32,803 & 31,235 \\
\hline $\begin{array}{l}\text { 2. \% of Total U.S. } \\
\text { Population }\end{array}$ & 35.88 & 38.43 & 1316 & 12.53 \\
\hline 3. Median Age (Years) & 38.4 & 41.4 & 9.2 & 9.3 \\
\hline $\begin{array}{l}\text { 4. Mean Life Expectaricy } \\
\text { for Median Age Gtoug } \\
\text { (Years) }\end{array}$ & 34.4 & 38.1 & 61.3 & 68.8 \\
\hline $\begin{array}{l}\text { 5. Mean Years at Risk: } \\
\text { - Thyrold Cincer } \\
\text { - Thyroid Nodules }\end{array}$ & $\begin{array}{l}29.4 \\
24.4\end{array}$ & $\begin{array}{l}33.1 \\
28.1\end{array}$ & $\begin{array}{l}56.3 \\
51.3\end{array}$ & $\begin{array}{l}63.8 \\
58.8\end{array}$ \\
\hline
\end{tabular}

- Assumes a 5 and 10 year latency period for thyrosd cancer and nodnles, respectively. 


\section{Table 3-4. Lifetime Risk of Total and Lethal Excess Thyroid Cancers per $10^{6}$ Persons per Rad}

\begin{tabular}{|c|c|c|c|c|c|c|c|c|c|c|}
\hline \multirow{3}{*}{ Source of irradiation } & \multicolumn{4}{|c|}{$\begin{array}{l}\text { Person over age } 18 \text { at } \\
\text { time of exposure }\end{array}$} & \multicolumn{4}{|c|}{$\begin{array}{l}\text { Persons age } 18 \text { or less at } \\
\text { tione of exposure }\end{array}$} & \multicolumn{2}{|c|}{$\begin{array}{l}\text { U.S. Population } \\
\text { for I } 990\end{array}$} \\
\hline & \multicolumn{2}{|c|}{ Total } & \multicolumn{2}{|c|}{ Lethal } & \multicolumn{2}{|c|}{ Total } & \multicolumn{2}{|c|}{ Lethal } & \multirow[t]{2}{*}{ Tolal } & \multirow[t]{2}{*}{ Lethal } \\
\hline & Male & Female & Male & Female & Male & Female & Male & Femaite & & \\
\hline ]-13] & 8.23 & 18.5 & 0.82 & 1.85 & 31.5 & 71.5 & 3.15 & 7.15 & 23.2 & 2.32 \\
\hline $\begin{array}{l}\text { Extetitol } X \text { ot ganma; } \\
1-132,-133,-134,-135\end{array}$ & 24.7 & 55.6 & 2.47 & 5.56 & 94.6 & $2 i 4$ & 9.46 & 21.4 & 69.5 & 6.95 \\
\hline
\end{tabular}

\subsection{Risk of Benign Thyroid Nodules}

The absolute risk of benign thyroid nodules following external radiation therapy in childhood is considered to be 9.3 per $10^{\circ}$ PY per rad (NUREG-4214). Females are considered twice as susceptible as mates, and persons over the age of 18 are considered one-half as susceptible as those under the age of 18 at the time of exposure. I-131 is considered only 1/5 as effective as external radiation or internal exposure from 1-132, I-133, 1-134, and 1-135. For benign thyroid nodules, a latency period of ten years is assumed. The general formula used to calculate age, sex, and radiation source specific risks is given by the following formula (NUREG-4214):

Specific Risk Estimate $=\mathbf{R} \cdot \mathbf{F} \cdot \mathbf{S} \cdot \mathbf{A} \cdot \mathbf{Y}$

where:

$R=$ Absolute risk estimate of $9.3 \times 10^{-5}$ PY per rad for benign thyroid nodules.

$\mathrm{F}=$ Dose effectiveness reduction factor (1.0 for external radiation, I-132, I133 , I-134, and I-135; a value of $1 / 5$ for I-131).

$S=$ Sex factor ( $4 / 3$ for fernales and $2 / 3$ for males).

$A=$ Age factor ( 1 for populations age 18 and under at time of exposure and $1 / 2$ for population over age 18 ).

$\mathbf{Y}=$, Anticipated average number of years at risk for the population. The minimum induction period for thyroid nodules is assumed to be ten years.

Table 3-5 provides annual risk estimates for the four population subgroups. 
Table 3-5. Annual Risk of Excess Benign Thyroid Nodules per 10 $10^{6}$ Persons per Rad of Thyroid Dose for Doses from 6 to 1,500 Rads

\begin{tabular}{|l|c|c|c|c|}
\hline \multirow{2}{*}{$\begin{array}{l}\text { Source of } \\
\text { Irradiation }\end{array}$} & $\begin{array}{r}\text { Persons Over Age 18 Years at } \\
\text { Exposure }\end{array}$ & \multicolumn{2}{|c|}{$\begin{array}{c}\text { Persons Age 18 or Less at } \\
\text { Exposure }\end{array}$} \\
\cline { 2 - 5 } & Make & Female & Male & Female \\
\hline I-131 & 0.6 & 1.2 & 1.2 & 2.5 \\
\hline $\begin{array}{l}\text { External X or ganma rays; } \\
\text { I-132, -133, -134, -135 }\end{array}$ & 3.1 & 6.2 & 6.2 & 12.4 \\
\hline
\end{tabular}

The lifetime risks for benign thyroid nodules are provided in Table 3-6. These were determined by mears for the appropriate mean-years-at-risk values from Table 3-3 as previously described.

Table 3-6. Lifetime Risk of Excess Benign Thyroid Nodules per 106 Persons per Rad of Thyrold Dose

\begin{tabular}{|l|c|c|c|c|c|}
\hline \multirow{2}{*}{$\begin{array}{l}\text { Source of } \\
\text { Irradiation }\end{array}$} & \multicolumn{2}{|c|}{$\begin{array}{c}\text { Persons over age 18 } \\
\text { at time of exposure }\end{array}$} & \multicolumn{2}{c|}{$\begin{array}{c}\text { Persons age 18 or less } \\
\text { at time of exposire }\end{array}$} & $\begin{array}{c}\text { U.S. Population } \\
\text { for 1990 }\end{array}$ \\
\cline { 2 - 6 } & Male & Femsle & Male & Femolte & \\
\hline 1-131 & 14.6 & 33.7 & 61.6 & 147 & 44.7 \\
\hline $\begin{array}{l}\text { External X or ganmia; } \\
\text { I-132, -133, -134, -135 }\end{array}$ & 75.6 & 174 & 318 & 729 & 227 \\
\hline
\end{tabular}

\subsection{Risk of Hypothyroidism}

Due to the excess capacity of the thyroid gland to produce the thyroid hormone, radiationinduced hypothyroidism exhibits a tareshold. For external radiation, a threshold of 200 rads is assumed. Iodine-131, with an efficiency factor of $1 / 5$, is assumed to have a threshold of 1,000 rads. For extermal doses of 12,000 rads or greater and $1-131$ doses of 60,000 rads, a $100 \%$ probability of hypothyroidism has been assumed. Within this range of exposure, the induction period is highly variable and decreases with increase in dose. Due to the uncertainty and variability of the induction period for hypothyroidism, annual risk coefficients are difficult to define. Instead, the risk of hypothyroidism is defined as a lifetime risk (Fable 3-7). 
Table 3-7. Lifetime Risk of Hypothyroidism"

\begin{tabular}{|l|c|c|c|}
\hline \multirow{2}{*}{$\begin{array}{l}\text { Source of } \\
\text { Irradiation }\end{array}$} & \multicolumn{2}{|c|}{ Applicable Range of Dose (Rants) } & $\begin{array}{c}\text { Lifertme Risk: } \\
\text { Cases per 10' Persons Per } \\
\text { Rad }\end{array}$ \\
\cline { 2 - 4 } & Threshold & Upper Limit & 17 \\
\hline I-131 & 1,000 & 60,000 & 83 \\
\hline $\begin{array}{l}\text { External radiation, } \\
\text { I-132, I-133, I-134, l-135 }\end{array}$ & 200 & 12,000 & 800 \\
\hline
\end{tabular}

- Reference: NUREG-4214

\subsection{Risk to the Unborn}

Within the first trimester, the fetal thyroid is insufficiently developed to concentrate jodine. Matemal exposure to radioiodine during this period, therefore, poses minimal thyroid risk to the fetus. Data indicate that maternal exposure to radioiodine during the second and third trimester results in a fetal thyroid dose that is about twice that of the matemal thyroid dose (Johnson 1982).

Human data involving in-utero thyroidal exposute to radioiodine are sparse at best. The only documented effect of radioiodine in the human fetus is that of hypothyroidism. In isolated instances, the mothers had been treated with $\mathrm{k}-131$ doses ranging from about 12 to $225 \mathrm{mCi}$ (Russell 1957; Fisher 1963; Hamill 1961; Green 1971). The children in these reported instances of fetal exposure manifested the characteristic symptoms and signs of cretinism. Due to limited data, however, a dose-response relationship and risk estimate for fetal hypothyroidism are not possible. Among this small group of individuals, there was one case of thyroid adenomas having a latency of 19 years (Conard 1975).

In the absence of human data providing a scientific basis for estimating fetal thyroid risks, it is reasonable to assume that the fetal thyroid is at least as sensitive to radiation as the thyroids of individuals less than 18 years of age.

For quantifying potential thyroid effects, this report assumes the fetal risk coefficients for benign nodules, cancer, and hypothyroidism are equal to annual risk values for males and females under the age of 18. For fetal exposure, the lifetime risk, however, will be based on a 75 -year life span (i.e., years at risk). The lifetime risks of thyroid cancer and nodules for individuals exposed in-utero are presented in Table 3-8.

The potential rumber of fetal exposures resulting from a nuclear emergency can be estimated from the 4.07 million live births for 1990 for a total U.S. population of about 250 mitlion. This corresponds to a birth rate of 16.3 per 1,000 population per year (National Center for Health Statistics, U.S. Dept. of Health and Human Services). Adjusting for the fact that the feta! 
thyroid is sensitive only during the second and third trimester, the potential number of fetuses subject to radioiodine injury at any moment in time is reduced to about 8 per 1,000 exposed population.

Table 3-8. Lifetime Risks per $10^{6}$ Fetal Thyroid Rads

\begin{tabular}{|c|c|c|c|c|c|c|c|}
\hline \multirow{4}{*}{$\begin{array}{l}\text { Source of } \\
\text { Irradlation }\end{array}$} & \multicolumn{7}{|c|}{ Thyroid Effeets } \\
\hline & \multirow{2}{*}{\multicolumn{2}{|c|}{ Nodules }} & \multicolumn{4}{|c|}{ Cancer } & \multirow{3}{*}{$\begin{array}{c}\begin{array}{c}\text { Congenital } \\
\text { Hypothyroidism }\end{array} \\
\text { Male or Female }\end{array}$} \\
\hline & & & \multicolumn{2}{|c|}{ Total } & \multicolumn{2}{|c|}{ Fatad } & \\
\hline & Male & Female & Male & Female & Male & Female & \\
\hline$I=131$ & 90 & 188 & 42 & 84 & 4.2 & 8.4 & 17 \\
\hline $\begin{array}{l}\text { External } X \text { or gamma; } \\
\mathrm{J}-132,-133,-134,-135\end{array}$ & 465 & 930 & 126 & 252 & 12.6 & 25.2 & 83 \\
\hline
\end{tabular}




\section{CHAPTER 4}

\section{THE COMPUTER MODEL USED TO ESTMMATE THYROID EXPOSURES AND RISKS}

The calculation of popalation exposure doses from an airbome release is complex and requires the use of a computer model. For this report, population thyroid doses were assessed with the MELCOR Accident Consequence Code System (MACCS) computer code (Chanin 1990; Rollstin 1990). MACCS is a state-of-the-art computer code used for consequence analysis. It is significantly improved from the computer code used previously in NUREG/CR-1433. This chapter presents an overview of the critical pathways analyzed, major parameters that affect the computer modeling of integrated air concentrations, and age- and sex-specific variables by which integrated air concentrations are converted to thyroid doses.

\subsection{Exposure Pathways Considered}

In the event of a nuclear accident in which radioiodines are released into the amosphere, thyroid exposure may be the result of extemal and internal exposure. It is useful to distinguish four independent pathways in which extemal and intemal exposures contribute to the total thyroid dose:

- Plume immersion and cloud-shine - an external dose caused by exposure to radiation emitted by radionuclides in the effluent cloud. The cloud dose that an individual at ground leve] receives as a result of the radionuclides in the efftuent cloud is the sum of the contributions of direct radiation from all sources distributed in the air around that individual. For a passing cloud, the dose rate would begin when the cloud approaches, reach a maximum when the cloud is overhead, and talls off as the cloud recedes. The dose is estimated as a time integral of the contributions of the radionuclides in each volume element as the cloud passes through (or above) the position concerned. If the radionuclide release (radioiodine as well as other gamma emitting nuclides) is of short duration compared with the longitudinal dispersion divided by the wind speed, so is the plume immersion dose.

- Ground deposition - an external dose caused by radiomuclides that have deposited by gravitation and contaminated ground and surface areas. The ground dose depends on the persistence of the contaminant, on the quantity and distribution of source material deposited at ground level, and on the subsequent time that the individual remains in the contaminated regfon. Since the ground-level deposit results from the fallout of aerosols, the surface source strength also depends on the radionuclide concentration in the cloud at ground level integrated over time. 
- Inhalation - an internal exposure resulting from the inhalation of airborne radioactivity of a passing plume. The magnitude of the thyroid dose is primarily affected by the air concentration of radioiodines and the duration of exposure to the passing plume.

- Food pathway - an internal exposure resulting from the ingestion of food and trink that have been contaminated by radionislides in the enviromment.

The uncensored ingestion of contaminated food products has the potential for high thyroid doses. However, regional populations in the United States are not critically dependent on local food sources, and the protective measures imposed by local health authorities following a nuclear accident would limit the avajlability and intake of contaminated food soutces. Therefore, it is assumed that thyroid doses from the food pathway can readily be avoided or trivialized. External exposure doses from phume immersion and ground contanination are considered significant and have been incorporated in the computer code for thyroid dose estimates. By far the largest sounce of thyroid expostre, however, is the prompt inhatation of contaminated air from a passing plume. Moreover, the benefit of stable iodide prophylaxis is confined to mitigating untemal exposure that results from the plume inhalation of radioiodines.

\subsection{An Overview of the MACCS Model}

The MACCS computer code models the off-site consequences of a severe reactor accident in which a plume of radioactive materials is released to the atmosphere. For such an accidental release, the radioactive gases and aerosols in the plume are dispersed in the atmosphere and transported by the prevaijing winds. The environment is contarninated by radioactive materials deposited from the plume, and the population is exposed to radiation. The fundamental purposes of computer models for off-site consequence estimates are to track the dispersal of radioactive material away from the accident site, to account for its eventual disposition in the environument, and to estimate potential exposure doses to the surrounding population. Given information on the characteristics of the radioactive release, the local and regional weather, and population distribution, such models calculate the downwind transport, airborne dispersion and ground deposition of the radioactive material, and the radiation doses received by exposed populations from all relevant pathways.

\subsubsection{Core Inventory and Source Term}

Cote Inventory - The radioactive inventory of the core at accident initiation (e.g., reactor scram) is required as an input. The core inventory is a function of the type and the operating power of the reactor and the duration of operation after loading fuel. The MACCS code models 60 radionuclides.

The core inventory of a pressurized water reactor (PWR) of thermal power of $3,050 \mathrm{MW}$ at the enf of a power cycle was used for the calculation. The inventory of seven radionuclides 
important for the present calculation is given in Table 4-1. The isotopes Te-131m and -132 are important as they decay into I-131 and -132 respectiveiy.

Table 4-I. Core Inventory of Pertinent Isotopes

\begin{tabular}{cc}
\hline Isotope & Inventary $(\mathrm{C})$ \\
\hline Te-13lm & $1.13 \mathrm{E})$ \\
Te-132 & $1 . t 2 \mathrm{E} 8$ \\
$1-131$ & $7.74 \mathrm{E} 7$ \\
$1-132$ & $1.14 \mathrm{ES}$ \\
$\mathrm{I}-133$ & $1.64 \mathrm{E} 8$ \\
$1-134$ & $1.80 \mathrm{ES}$ \\
$1-135$ & $1.54 \mathrm{~EB}$ \\
\hline
\end{tabular}

Source Term - The atmospheric source tern produced by the accident is required as an input. This involves the number of plume segments released, sensible heat content, timing, duration, height of each segment of release, and for each important radionuclide, the fraction of that radionuclide's release with each plume of release. Using similar chemical characteristics, 60 radionuclides are grouped into nine release categories. These are the groups of noble gas, iodine, cesium, tellurium, strontium, rubidium, lanthanum, cerium, and barium.

For thyroid exposures and health effects calculations, four radiological source terms were identified (Table 4-2). These four accident categories represent all the accidents postulated for the Surry nuclear power plant, which were described in detail in NUREG-1150. With the exception of source term category RSUR-2, all the other source terms consist of two discrete plume releases. The first plume is characterized by the event that caused the release. The second release results from corium (molten core) and concrete interactions (CCI). 
Table 4-2. Radionuclide Release Characteristics into the Environment for Surry

\begin{tabular}{|c|c|c|c|c|c|c|c|c|c|c|c|c|c|c|}
\hline \multirow{2}{*}{$\begin{array}{l}\text { Source } \\
\text { Term }\end{array}$} & \multirow{2}{*}{$\begin{array}{l}\text { Freq. } \\
\left(y r^{1 b}\right.\end{array}$} & \multirow{2}{*}{$\begin{array}{l}\text { Ele. } \\
\text { (In) }\end{array}$} & \multirow{2}{*}{$\begin{array}{l}\text { Energy } \\
\text { (MW) }\end{array}$} & \multirow{2}{*}{$\begin{array}{c}\text { Rel. } \\
\text { Timbs } \\
\text { (b) }\end{array}$} & \multirow{2}{*}{$\begin{array}{c}\text { Release } \\
\text { Duration }\end{array}$} & \multicolumn{9}{|c|}{ Fraction of Core lnventory Released } \\
\hline & & & & & & NG & I & C8 & $\mathrm{Te}$ & $\mathbf{S r}$ & Ru & La & $\mathrm{Ce}$ & $\mathbf{B a}$ \\
\hline RSUR-1 & $2.9 \mathrm{E}-7$ & $\begin{array}{l}10 \\
10\end{array}$ & $\begin{array}{l}28 \\
28\end{array}$ & $\begin{array}{c}6 \\
6.06\end{array}$ & $\begin{array}{l}200 \mathrm{~s} \\
2 \mathrm{~h}\end{array}$ & $\begin{array}{l}1 \\
0\end{array}$ & $\begin{array}{l}0.25 \\
0.1\end{array}$ & $\begin{array}{l}0.18 \\
0.13\end{array}$ & $\begin{array}{l}0.08 \\
0.1\end{array}$ & $\begin{array}{l}0.02 \\
0.04\end{array}$ & $\begin{array}{l}0.005 \\
0.001\end{array}$ & $\begin{array}{l}0.001 \\
0.005\end{array}$ & $\begin{array}{l}0.005 \\
0.005\end{array}$ & $\begin{array}{l}0.02 \\
0.04\end{array}$ \\
\hline RSUR-2 & 2.4E-6 & 0 & 0 & 12 & $3 \mathrm{~h}$ & 1 & 0.06 & 0.03 & 0.09 & 0.003 & 0.001 & $4 \mathrm{E}-4$ & $4 E-4$ & 3E-3 \\
\hline RSUR-3 & 3.3E-5 & $\begin{array}{l}0 \\
0\end{array}$ & $\begin{array}{l}0 \\
0\end{array}$ & $\begin{array}{c}6 \\
16\end{array}$ & $\begin{array}{l}10 \mathrm{~h} \\
10 \mathrm{~h}\end{array}$ & $\begin{array}{l}2.5 \mathrm{E}-3 \\
2.5 \mathrm{E}-3\end{array}$ & $\begin{array}{l}1.5 \mathrm{E}-5 \\
1.5 \mathrm{E}-5\end{array}$ & $\begin{array}{l}1.2 \mathrm{E}-8 \\
1.2 \mathrm{E}-8\end{array}$ & $\begin{array}{l}7.5 \mathrm{E}-9 \\
7.5 \mathrm{E}-9\end{array}$ & $\begin{array}{l}2.5 \mathrm{E}-9 \\
2.5 \mathrm{E}-9\end{array}$ & $\begin{array}{l}\text { 2E-10 } \\
2 \mathrm{E}-10\end{array}$ & $\begin{array}{l}3 \mathrm{E}-10 \\
3 \mathrm{E}-10\end{array}$ & $\begin{array}{l}4 E-10 \\
4 E-10\end{array}$ & $\begin{array}{l}2.5 \mathrm{E}-9 \\
2.5 \mathrm{E}-9\end{array}$ \\
\hline RSUR-4 & $1.6 \mathrm{E} \cdot 6$ & $\begin{array}{l}10 \\
10\end{array}$ & $\begin{array}{l}28 \\
28\end{array}$ & $\begin{array}{c}1 \\
1.5\end{array}$ & $\begin{array}{l}30 \mathrm{mip} \\
2 \mathrm{~g}\end{array}$ & $\begin{array}{l}1 \\
0\end{array}$ & $\begin{array}{c}0.075 \\
0.04\end{array}$ & $\begin{array}{l}0,06 \\
0.06\end{array}$ & $\begin{array}{l}0.02 \\
0.05\end{array}$ & $\begin{array}{l}0.005 \\
0.02\end{array}$ & $\begin{array}{l}0.001 \\
6 \mathrm{E}-04\end{array}$ & $\begin{array}{l}3 \mathrm{E}-4 \\
0.003\end{array}$ & $\begin{array}{l}0.001 \\
0.003\end{array}$ & $\begin{array}{c}0.005 \\
0.02\end{array}$ \\
\hline
\end{tabular}


The characteristics of the four accident categories, RSUR-1 through -4, are given in Table 4-3. For the first three categories, the initiating event of the accident is the loss of off-site power, while for the other category, RSUR-4, the initiating event is containment bypass resulting from a large break in a system interfacing with the primary reactor cooling systern. The highest release of iodine is associated with the release category RSUR- $I$ in which the containment ruphure coincides with the breach of the reactor pressure vessel induced by steam explosions. For the RSUR-2 category, the contaimment failure involves a leak and follows the occurrence of CCI. For RSUR-3, the containment functions as intended, and a release accurs through a leak that is within the design limits of the contaimment. The RSUR-3 source term is further mitigated by the operation of a containment spray system, which is not available for the other three categories. For RSUR-4, no containnent failure occurs but two plumes release by bypassing the containment. For all four accident categories, $\mathrm{CCI}$ occurs, and the reactor coolant system is at low pressure $(<200$ psia) at the breach of the reactor pressure vessel.

Table 43. Accident Characteristics for Surry

\begin{tabular}{|c|c|c|c|c|c|c|c|c|}
\hline \multirow{2}{*}{$\begin{array}{l}\text { Release } \\
\text { Category }\end{array}$} & \multirow{2}{*}{$\begin{array}{c}\text { Plant } \\
\text { Damage } \\
\text { State }\end{array}$} & \multicolumn{7}{|c|}{ Accident Progression Characteristics } \\
\hline & & $\begin{array}{l}\text { Containment } \\
\text { Fatlure Time }\end{array}$ & $\begin{array}{l}\text { Containmeat } \\
\text { Failute Size }\end{array}$ & $\infty \mathrm{Cl}$ & $\begin{array}{l}\text { Amt. } \\
\mathrm{CCl}\end{array}$ & $\begin{array}{l}\text { RCS Pres. } \\
\text { (psia) }\end{array}$ & $\begin{array}{c}\text { VB } \\
\text { Mode }\end{array}$ & Sprays \\
\hline RSUR-1 & LOSP & $\mathrm{CF}$ at $\mathrm{VB}$ & Rupture & Prm-Dry & Mediun & $<200$ & Alpha & No \\
\hline RSUR-2 & LosP & CF after CCI & Leak & Prin-Dry & Large & $<200$ & Pour & No \\
\hline RSUR-3 & LOSP & No CF & No CF & Prm-Dry & Large & $<200$ & Pousr & $\mathbf{L}+\mathbf{V} \mathbf{L}$ \\
\hline RSUR-4 & Bypass(V) & No $\mathrm{CF}$ & Bypass & Prm-Dry & Large & $<200$ & Pour & No \\
\hline
\end{tabular}

Alpha Steam explosion infuced failure

Pour Pouring or corium (molten core)

CCl Corium and concrete interactions

CF Contaimment failure

L Late period

LOSP Loss of off-site power

Prm-Dry CCI takes place promptly following VB. There is no overtying water pool to sentb the release.

$\checkmark \quad$ Large break in a system interfacing the bigh pressure coolant system

VB Vessel breach

VL. Very late period

\subsubsection{Meteorological Parameters and Phme Dispersion}

To assess the effect of meteorological variables, a single source term is dispersed at various times throughout a year and, for each set of conditions, consequence calculations are made. Each release is simulated for ensuing hours, often days, until the radioactive material travels out of the defimed population area. The result is a distribution of consequences whose frequencies are dependent on the frequencies of various types of weather conditions throughout a year. 
Using an entire year of weather data, about $\mathbf{1 5 0}$ individual consequence calculations are made for a typical risk calculation.

To reduce computational time for these extensive calculations, a processor groups weather data into similar bins. The binning, or grouping process, is called stratified importance sampling, and it is used to ensure that important weather conditions are fairly represented. For example, peak consequences arise from low wind speeds, narrow plumes, rainfall, and sudden calms, whereas the average consequence calculations can be associated with average weather conditions.

In the MACCS code, all releases (sonrce terms) travel radially downwind, away from the site. as essentially a plane wave. The MACCS rainfall model predicts the washout of radionuclides from the atmosphere. For deposition of material out of the accident plume onto the ground during dry weather, MACCS includes provisions for particles of different sizes.

For accidents in which the radioactive releases occur over many hours, the release is treated most effectively as a series of "puffs." This time-varjant capability is especiafly important for severe accident scenarios involving releases of such muclides as strontium, barium, and lanthanum. These radiomuclides may evolve during core-concrete interactions and are, therefore, released much later (hours) than more volatile chemical species (e.g., noble gases, iodine, cesium). In summary, MACCS accounts for radioactive decay ant daughter product buildup within the plant before the various radionuclides are sequentially released to the environment.

The MACCS code simulates the dispetsion of radjoactive material over long distances using a Gaussian-distributed plume model. The code includes a plume liftoff criterion, which limits the rise off the ground from a heated release (source term). As the distance from the source increases, the concentration of the cloud monotonically decreases at its center. The plume may be depleted by contacting surfaces or by intercepting rainfall. Rainfall can be intercepted at various distances from the source, such that ground contamination can either increase or

decrease at various distances from the source. Radiological expostres can result from plume immersion, plume shine, ground contamination, and plume inhalation.

\subsubsection{Internal Thyroid Dose Parameters}

The MACCS model for internal thyroid dosimetry is defined by all relevant radionuclides of iodine that enter the body and the factors governing their uptake, distribution, and retention within the thyroid. The internal dose of the thyroid from inhalation of airborne radioiodine can be derived from time-integrated air concentrations $\left(\mu \mathrm{Ci}-\mathrm{h} \mathrm{m}{ }^{-3}\right)$ at fixed distances from a source term by the following equation:

$$
D_{\text {intal }}=\left[\left(C_{o} \times f_{o p} \times \vee \times f_{o}\right)+\left(C i \times f_{i p} \times \vee \times f_{i j}\right)\right] \times D C F_{\text {intal }}
$$


where:

$$
\begin{aligned}
& \mathrm{D}_{\text {nhd }}=\text { thyroid inhalation dose (rad) } \\
& \text { Co }=\text { time-integrated outdoor air radioiodine concentration } \\
& \left(\mu \mathrm{Ci}-\mathrm{h} \mathrm{m} \mathrm{m}^{-3}\right) \\
& \text { C. }=\text { time integrated indoor air radioiodine concentration } \\
& \left(\mu \mathrm{Ci}-\mathrm{h} \mathrm{m} \mathrm{m}^{-3}\right) \\
& \mathrm{f}_{\mathrm{op}} \quad=\text { fraction of outdoor air racioiodine on respirable particles } \\
& f_{i} \quad=\text { fraction of incioor air radioiodine on respirable particles } \\
& \mathrm{V}=\text { ventilation rate }\left(\mathrm{m}^{3} \mathrm{~h}^{-1}\right) \\
& f_{\text {ol }} \quad \Rightarrow \text { fraction of plume passage time spent outdoors } \\
& \mathrm{f}_{\mathrm{i}}, \quad=\text { fraction of plume passage time spent indoors } \\
& \mathrm{DCF}_{\mathrm{idha}} \quad=\text { inhalation dose conversion factor }\left(\mathrm{rad} \mu \mathrm{Ci}^{-1}\right. \text {, }
\end{aligned}
$$

When it is conservatively assumed that an individual may be outdoors $100 \%$ of the time during plume passage, equation $4-1$ is reduced to:

$$
\mathrm{D}_{\text {inhel }}=\mathrm{C}_{\mathrm{0}} \times \mathrm{V} \times \mathrm{DCF}_{\mathrm{iahed}}
$$

Estimates of dose for risk assessment have traditionally been based on models developed for the radiation protection of adult workers. For this reason, the basic biokinetic model represented by "Reference Man" (i.e., a subject with the anatomical and physiological characteristics of a healthy young adult male weighing $70 \mathrm{~kg}$ ) was deemed appropriate. While the concept of Reference Man provides a degree of consistency for occupational dosinetry and risk assessment, Reference Man is clearly not intended to represent the general population and cammot be used for modeling population thyroid doses.

Basic principles of intermal dosimetry dictate that the thyroid dose from an inhaled quantity of radioiodine is strongly influenced by several physiological parameters, some of which are ageand sex-dependent. Population thyroid doses in this report are based on the most currently available data defining the United States population in terms of gender and age distribution.

Ventilation Rates. Equation 4-1 shows that for a given air concentration, the thyroid dose is directly proportional to the indjvidual's ventilation rate. Ventilation rates for male and female subjects of different age groups have been estimated by the NCRP (NCRP 1984). In general, ventilation rates increase with age from infant to adult and are significantly higher for active as opposed to resting conditions. They are also slightly greater for males than for females.

A reasonable selection of ventilation rates assumes that the average individual is active (i.e., engaged in physical activities, occupational and non-occupational) $50 \%$ of the time and is engaged in sleep or passive activities the remaining time. A weighted average, therefore, is the mean value of active and resting ventilation rates. Table 4-4 defines the age- and sex-dependent ventilation rates used in this report to generate population thyroid doses. 
Table 4-4. Ventilation Rates by Age, Sex, and Activity"

\begin{tabular}{|c|c|c|c|c|}
\hline \multirow{2}{*}{ Age Group } & & \multicolumn{3}{|c|}{ Ventilation Rate $\left(\mathrm{m}^{3} / \mathrm{hr}\right.$ ) } \\
\cline { 3 - 5 } & Sex & Resting & Active & Weighted Average \\
\hline $0-12$ months & Male & 0.090 & 0.26 & 0.175 \\
& Female & 0.090 & 0.26 & 0.175 \\
$1-11$ yetrs & Mate & 0.39 & 1.1 & 0.75 \\
$12-18$ years & Female & 0.31 & 0.90 & 0.61 \\
& Male & 0.46 & 1.8 & 1.13 \\
& Female & 0.34 & 1.5 & 0.92 \\
& Male & 0.53 & 1.8 & 1.17 \\
& Femalt & 0.38 & 1.5 & 0.94 \\
\hline
\end{tabular}

- Source: NCRP Repart No. 76 (NCRP 1984).

Parameters Affecting Inhalation DCF Values. For common plume inhalation exposure conditions, variations in dose among individuals or groups of individuals arise from variations in the uptake and metabolism of radioiodide as well as from anatomical differences. For a heterogeneous population, the following factors must be considered in the assignment of dose conversion factors (DCFs) for radioiodine:

- Lung Deposition Fraction. The magnitude of a thyroid dose resulting from the inhalation of radioiodide particulates is affected by physical parameters that influence the initial deposition and distribution of activity writhin various compartments or regions of the respiratory tract. The ICRP Task Group Lung Model (ICRP 1966) defines the respiratory system as consisting of the nasopharyngeal (N-P), tracheo-bronchial (T-B), pulmonary (P), and lymphatic regions. In the model, the regions $N-P, T-B$, and $\mathbf{P}$ are assumed to receive fractions $D_{3}, D_{4}$, and $D_{5}$, respectively, of the inhaled activity. When the sum of these three fractions is less than 1 , it is assumed that the complementary fraction is promptly exhaled. The values of $D_{3}, D_{4}$, and $D_{5}$ primarily depend on the effective particle size defined in terms of the activity medium aerodynamic diameter (AMAD) of the inspired particles. In the absence of empirical information and for risk analysis, it is conventional to use the AMAD value of 1 micron. This value corresponds to deposition fractions of 0.30 (N-P), 0.08 (TB), and $0.25(\mathrm{P})$, or $63 \%$ of the total respired particulates. It is further assumed that radioiodine is rapidly and completely absorbed into the bloodstream either directly from the respiratory tract or by respiratory clearance into and absorption by the gastro-intestinal tract. In summary, thyroid inhalation dose values derived in this report asstme an AMAD value of one micron for radioiodides. 
- Organ uptake fraction - The fraction of iodide taken up from the blood by the thyroid varies widely among individuals because of differences in dietary iodine levels and metabolic factors that are age and sex related. The classic work of J. B. Stanbury has shown an inverse retation between the thyroid uptake of radioiodine and the supply of iodine in the daty diet (Stanbury 1954). Variations in committed dose from I-131 for Reference Man under various conditions of dietary intake of stable iodine were calculated by Johnson (Johnson 1982(a)) as shown in Table 4-5.

Table 4-5. Varjations in Committed Dose for Reference Man with Stable Iodide Intake

\begin{tabular}{|c|c|}
\hline $\begin{array}{l}\text { Daily Iodide } \\
\text { Intake }(\mu \mathrm{g})\end{array}$ & $\underset{\mathrm{I}-131}{\mathrm{Rad} / \mu \mathrm{Cl}}$ \\
\hline 75 & 2.72 \\
\hline 100 & 2.28 \\
\hline 150 & 1.72 \\
\hline 200 & 1.38 \\
\hline 300 & 0.996 \\
\hline 600 & 0.54 \\
\hline 1000 & 0,32 \\
\hline
\end{tabular}

In countries of the world where dietary intakes of iodide are low, glandular uptake may reach levels of up to $90 \%$. In the United States, the daily dietary intake is high, varying between $125 \mu \mathrm{g}$ and $700 \mu \mathrm{g}$ with an average value of about 200 $\mu \mathrm{g}$ (Odioie 1970; Dumont 1988); for the normal adult, this range of dietary intake corresponds to a thyroid uptake fraction of between $15 \%$ and $30 \%$.

Empirical measurements by Dunning and Schwarz found mean thyroid uptake fractions of $47 \%$ for newborns, $39 \%$ for infants, $47 \%$ for adolescents, and $19 \%$ for adults (Dunning 1981).

- Qxgan mass - The variability in thyroid mass is related to age and body weight. The mass increases doring childhood and continues to increase until adulthood at which time the net growth of the organ ceases. Based on data reviewed by Dunning (Dunning 1981), the mass of an adult thyroid ranges from $2 \mathrm{~g}$ to $62 \mathrm{~g}$ with an average value of $18.3 \mathrm{~g}$. This value is essentially identical with that given by the ICRP, which assumes a value of $17 \mathrm{~g}$ for females and $20 \mathrm{~g}$ for mates (ICRP 1975). 
- Effective half-life of radioiodide - The variabiitity of the effective half-life of radioiodide is determined by the physical half-life of the isotope and its biological half-life (i.e., metabolic utilization and retention of organified iodide). Children and adolescents can be expected to exhibit higher turnover and elimination rates than adults (Rosenberg 1958; Heinrichs 1982; ICRP 1988). Dunning and Schwarz (1981) concluded that for adults, the observed range in biological halflives was from 21 to 372 days and for young children 4 to 39 days.

- Effective energy per disintegration - The effective energy per disintegration (Mev/dis) of a radionuclide within an organ depends upon the decay energy and the effective radius of the organ (ICRP 1959). Considering differences in thyroid mass with age, there is a small corresponding increase in the effective energy per disintegration (Bryant 1969).

Taking into account these age-dependent parameters, empiricalty derived inhalation dose conversion factors have been cited that are consistently similar (NUREG-0172; Johnson 1981; Heinrich 1982; Dunning 1981, NUREG/CR-3955; ICRP 1988). Table 4-6 identifies the inhalation dose conversion values used in this report to estimate thyroid doses for five discrete age groups. In this report, the dose conversion factors for I-131 are based on values reported by Dunning and Schwarz (Dunning 1981); the DCF values for I-132, I-133, I-134, and I-135 are those of Killough and Eckerman (NUREG/CR-3955). All inhalation dose conversion factors assume that $63 \%$ of the inhaled iodide is absorbed into the blood and that iodide is a Class D aerosol with an AMAD of one micron.

Table 4-6. Thyroid Inhalation Dose Conversion Factors for Radioiodides

\begin{tabular}{|c|c|c|c|c|}
\hline \multirow{2}{*}{ Radionuclide } & \multicolumn{4}{|c|}{ Dose Conversion Factor (rad/ $\mu \mathrm{Ci}$ ) } \\
\cline { 2 - 5 } & $0-12$ mos. & $1-11$ yrs. & $12-18$ yrs. & $>18$ y Ts. \\
\hline I-131 & 12.99 & 7.26 & 2.78 & 0.88 \\
I-132 & 0.076 & 0.027 & 0.01 & 0.006 \\
I-133 & 2.63 & 0.84 & 0.36 & 0.16 \\
I-134 & 0.011 & 0.005 & 0.002 & 0.002 \\
I-135 & 0.42 & 0.14 & 0.05 & 0.03 \\
\hline
\end{tabular}

Fefal Thyroid Dose_Factors. In the fetus, iodine accumulation begins at 10.12 weeks after conception and thereafter increases nearly linearly until birth. But due to the rapid change in fetal thyroid mass ouring the second and third trimesters, the fetal thyroid burden per unit mass is not linear (Dyer 1972; Evans 1967). Johnson (1982) has estimated fetal thyroid dose per unit uptake by the mother. The fetal thyroid dose per maternal unit of uptake increases over the period from 12 to 22 weeks gestation and reaches a peak value of about three rads per 
microcurie in the maternal blood. This value is more than twice the dose received by the maternal thyroid. Following a steady decline in relative dose, about two percent of the iodide in the maternal blood will be accumulated by the fetal thyroid at term, which on the basis of relative mass, yields a fetal dose essentially that of the mother.

Fetal thyroid doses in this report are conservatjvely estimated at twice the value of the maternal thyroid. Maternal thyroid exposures are based on ventilation and dose conversion values corresponding to females greater than 18 years of age.

\subsection{Reactor Accident Specific Thyroid Doses}

This section provides thyroid dose estimates for population cells in the plume pathways corresponding to reactor accident categories RSUR-1, RSUR-2, RSUR-3, and RSUR-4. Thyroid risk coefficients were applied to estimate the corresponding population thyroid health effects. All exposure values were estimated for nomal activity. Normal activity assumes that individuals spend approximately $75 \%$ of their time indoors and $25 \%$ outdoors. Table 4-7 provides relative dose factors for individuals (1) located outdoors, (2) engaged in nomal activity, and (3) sheltered.

Table 4-7. Relative Dose Factors

\begin{tabular}{lccc}
\hline Exposture Soures & Outdoors & $\begin{array}{c}\text { Normal } \\
\text { Activity }\end{array}$ & Sheltering \\
\hline $\begin{array}{l}\text { Plume immersionf } \\
\text { cloud-shine }\end{array}$ & 1.0 & 0.75 & 0.6 \\
Ground deposition & 1.0 & 0.33 & 0.2 \\
Inhalation & 1.0 & 0.41 & 0.33 \\
\hline
\end{tabular}

\subsubsection{Plume Centerline Thyroid Doses by Age and Sex}

Tables 4-8 to 4-11 present the plume centerline thyroid doses from all exposure pathways for each of the seven population subgroups located at discrete distances from the reactor facility. Independent of reactor accident release category, a comparison of thyroid doses among the subpopulations reveals that the male child (age 1-12) receives the highest thyroid dose while the adult female receives the lowest (Figure 4-1). Subgroup differences reflect the impact of ageand sex-specific variations (i.e., ventilation rate, iodide metabolism, and thyroid mass) on the thyroid dose. The last column in each of the four tables defines the plume centerline dose to the "average person." This set of values was derived by weighting each subgroup value by its respective percentage of the total population. For near-field residents residing within a five-mile radius, thyroid exposures in the thousants of rads are estimated for RSUR-1, RSUR-2, and RSUR-4. Thyroid doses for RSUR-3 are lower by several orders of magnitude and beyond ten miles may be considered trivial. 
Table 4-8. Plume Centerline Thyroid Doses' (rem) for RSUR-1 Versus Distance

\begin{tabular}{|c|c|c|c|c|c|c|c|c|}
\hline $\begin{array}{c}\text { Distance } \\
\text { Range (mi) }\end{array}$ & Infant & $\begin{array}{l}\text { Female } \\
\text { Child }\end{array}$ & $\begin{array}{l}\text { Male } \\
\text { Child }\end{array}$ & $\begin{array}{l}\text { Female } \\
\text { Teenage }\end{array}$ & $\begin{array}{l}\text { Male } \\
\text { Teenage }\end{array}$ & $\begin{array}{l}\text { Female } \\
\text { Adull }\end{array}$ & $\begin{array}{l}\text { Male } \\
\text { Adull }\end{array}$ & $\begin{array}{l}\text { Average } \\
\text { Person }\end{array}$ \\
\hline$<5$ & $2.0 E+04$ & $3,4 E+04$ & $4.2 E \div 04$ & $2.2 E+04$ & $2.6 E+04$ & $8.1 E+03$ & $1.1 \mathrm{E}+04$ & $2.0 \mathrm{E}+04$ \\
\hline $5-10$ & $7.4 E+03$ & $1.3 E+04$ & $1.6 \mathrm{E}+04$ & $8.1 E \div 03$ & $9.8 \mathrm{E}+03$ & $3.0 \mathrm{E}+03$ & $4.2 \mathrm{E}+03$ & $7.3 \mathrm{E}+03$ \\
\hline$\$ 0.25$ & 1. $8 \mathrm{E}+03$ & $3.1 E+03$ & $3.8 \mathrm{E}+03$ & $3.9 \mathrm{E}+03$ & $2.4 E+03$ & $7.3 E+02$ & $1.0 \mathrm{E}+03$ & $1.8 E+03$ \\
\hline $25-50$ & $3.0 \mathrm{E}+02$ & $5.2 \mathrm{E}+02$ & $6.3 E+02$ & $3.3 E+02$ & $4.0 \mathrm{E}+02$ & โ. $2 E+02$ & $1.7 \mathrm{E}+02$ & $3.0 \mathrm{E}+02$ \\
\hline $50-100$ & $6.9 \mathrm{E}+0 \mathrm{~J}$ & $1.2 \mathrm{E}+02$ & $1.5 \mathrm{E}+02$ & $7.7 \mathrm{E}+01$ & $9.3 \mathrm{E}+0 \mathrm{l}$ & $2.9 E+01$ & $3.9 E+01$ & $7.0 \mathrm{E}+01$ \\
\hline $500-[50$ & 3. $[E+0]$ & $5.5 E+0]$ & $6.8 \mathrm{E}+0 \mathrm{I}$ & $3.5 E+01$ & $4.2 \mathrm{E}+\mathrm{Ol}$ & $1.3 \mathrm{E}+01$ & $1.8 \mathrm{E}+0 \mathrm{]}$ & $3.2 \mathrm{E}+0 \mathrm{~J}$ \\
\hline $150-200$ & $1.9 \mathrm{E}+01$ & $3.4 \mathrm{E}+0 \mathrm{]}$ & $4.2 \mathrm{E}+01$ & $2.1 \mathrm{E}+01$ & $2.6 \mathrm{E}+01$ & $7.9 \mathrm{E}+00$ & I.1E+0! & $1.9 \mathrm{E}+0 \mathrm{t}$ \\
\hline $200-350$ & $8.2 E+00$ & $\mathrm{I} .5 \mathrm{E}+01$ & 1.9E $+0 \mathrm{~F}$ & $9.5 \mathrm{E}+00$ & 1. $2 \mathrm{E}+0 \mathrm{I}$ & $3.5 \mathrm{E}+00$ & 4.7E +00 & $8.5 \mathrm{E}+00$ \\
\hline
\end{tabular}

Table 4-9. Plame Centerline Thyroid Doses' (rem) for RSUR-2 Versus Distance

\begin{tabular}{|c|l|l|l|l|l|l|l|l|}
\hline $\begin{array}{c}\text { Distatice } \\
\text { Range } \\
\text { (mi) }\end{array}$ & lnfant & $\begin{array}{l}\text { Femiale } \\
\text { Child }\end{array}$ & $\begin{array}{l}\text { Male } \\
\text { Child }\end{array}$ & $\begin{array}{l}\text { Female } \\
\text { Teenage }\end{array}$ & $\begin{array}{l}\text { Male } \\
\text { Teenage }\end{array}$ & $\begin{array}{l}\text { Femaje } \\
\text { Adult }\end{array}$ & $\begin{array}{l}\text { Male } \\
\text { Aduli }\end{array}$ & $\begin{array}{l}\text { Average } \\
\text { Person }\end{array}$ \\
\hline$<5$ & $5.6 \mathrm{E}+03$ & $1.0 \mathrm{E}+04$ & $1.2 \mathrm{E}+04$ & $6.7 \mathrm{E}+03$ & $8.1 \mathrm{E}+03$ & $2.8 \mathrm{E}+03$ & $3.9 \mathrm{E}+03$ & $6.1 \mathrm{E}+03$ \\
$5-10$ & $7.0 \mathrm{E}+02$ & $1.2 \mathrm{E}+03$ & $1.5 \mathrm{E}+03$ & $8.2 \mathrm{E}+02$ & $9.9 \mathrm{E}+02$ & $3.5 \mathrm{E}+02$ & $4.8 \mathrm{E}+02$ & $7.5 \mathrm{E}+02$ \\
$10-25$ & $1.3 \mathrm{E}+02$ & $2.4 \mathrm{E}+02$ & $2.9 \mathrm{E}+02$ & $1.6 \mathrm{E}+02$ & $1.9 \mathrm{E}+02$ & $6.8 \mathrm{E}+01$ & $9.2 \mathrm{E}+01$ & $1.5 \mathrm{E}+02$ \\
$25-50$ & $2.2 \mathrm{E}+01$ & $4.0 \mathrm{E}+01$ & $4.9 \mathrm{E}+01$ & $2.7 \mathrm{E}+01$ & $3.2 \mathrm{E}+01$ & $1.1 \mathrm{E}+01$ & $1.6 \mathrm{E}+01$ & $2.5 \mathrm{E}+01$ \\
$50-100$ & $5.1 \mathrm{E}+00$ & $9.2 \mathrm{E}+00$ & $1.1 \mathrm{E}+01$ & $6.1 \mathrm{E}+00$ & $7.4 \mathrm{E}+00$ & $2.6 \mathrm{E}+00$ & $3.6 \mathrm{E}+00$ & $5.6 \mathrm{E}+00$ \\
$100-150$ & $2.3 \mathrm{E}+00$ & $4.2 \mathrm{E}+00$ & $5.1 \mathrm{E}+00$ & $2.8 \mathrm{E}+00$ & $3.4 \mathrm{E}+00$ & $1.2 \mathrm{E}+00$ & $1.6 \mathrm{E}+00$ & $2.5 \mathrm{E}+00$ \\
$150-200$ & $1.4 \mathrm{E}+00$ & $2.5 \mathrm{E}+00$ & $3.3 \mathrm{E}+00$ & $1.7 \mathrm{E}+00$ & $2.0 \mathrm{E}+00$ & $7.0 \mathrm{E}-01$ & $9.6 \mathrm{E}-01$ & $1.5 \mathrm{E}+00$ \\
$200-350$ & $6.1 \mathrm{E}-01$ & $1.1 \mathrm{E}+00$ & $1.4 \mathrm{E}+00$ & $7.5 \mathrm{E}-01$ & $9.1 \mathrm{E}-01$ & $3.1 \mathrm{E}-01$ & $4.3 \mathrm{E}-01$ & $6.9 \mathrm{E}-01$ \\
\hline
\end{tabular}

Thyroid dose includes all radionuclides and pathways (i.e., inhalation, cloud-shine, plume immersion, ground deposition); exposure condition is for "normal activity." 
Table 4-10. Plume Centerline Thyroid Doses" (rem) for RSUR-3 Versus Dlstance

\begin{tabular}{|c|l|l|l|l|l|l|l|l|}
\hline $\begin{array}{c}\text { Distance } \\
\text { Range } \\
\text { (mi) }\end{array}$ & Infant & $\begin{array}{l}\text { Female } \\
\text { Child }\end{array}$ & $\begin{array}{l}\text { Male } \\
\text { Chilt }\end{array}$ & $\begin{array}{l}\text { Female } \\
\text { Teenage }\end{array}$ & $\begin{array}{l}\text { Male } \\
\text { Teenage }\end{array}$ & $\begin{array}{l}\text { Female } \\
\text { Adult }\end{array}$ & $\begin{array}{l}\text { Male } \\
\text { Adult }\end{array}$ & $\begin{array}{l}\text { Average } \\
\text { Person }\end{array}$ \\
\hline$<5$ & $1.8 \mathrm{E}+00$ & $3.0 \mathrm{E}+00$ & $3.7 \mathrm{E}+00$ & $1.9 \mathrm{E}+00$ & $2.3 \mathrm{E}+00$ & $6.8 \mathrm{E}-01$ & $9.3 \mathrm{E}-01$ & $1.7 \mathrm{E}+00$ \\
$5-10$ & $2.2 \mathrm{E}-01$ & $3.8 \mathrm{E}-01$ & $4.7 \mathrm{E}-01$ & $2.4 \mathrm{E}-01$ & $2.9 \mathrm{E}-01$ & $8.8 \mathrm{E}-02$ & $1.2 \mathrm{E}-01$ & $2.2 \mathrm{E}-01$ \\
$10-25$ & $4.5 \mathrm{E}-02$ & $7.7 \mathrm{E}-02$ & $9.5 \mathrm{E}-02$ & $4.9 \mathrm{E}-02$ & $5.9 \mathrm{E}-02$ & $1.8 \mathrm{E}-02$ & $2.4 \mathrm{E}-02$ & $4.4 \mathrm{E}-02$ \\
$25-50$ & $8.5 \mathrm{E}-03$ & $1.5 \mathrm{E}-02$ & $1.8 \mathrm{E}-02$ & $9.3 \mathrm{E}-03$ & $1.1 \mathrm{E}-02$ & $3.3 \mathrm{E}-03$ & $4.5 \mathrm{E}-03$ & $8.3 \mathrm{E}-03$ \\
$50-100$ & $1.9 \mathrm{E}-03$ & $3.4 \mathrm{E}-03$ & $4.1 \mathrm{E}-03$ & $2.1 \mathrm{E}-03$ & $2.5 \mathrm{E}-03$ & $7.4 \mathrm{E}-04$ & $1.0 \mathrm{E}-03$ & $1.9 \mathrm{E}-03$ \\
$100-150$ & $8.1 \mathrm{E}-04$ & $1.4 \mathrm{E}-03$ & $1.8 \mathrm{E}-03$ & $8.9 \mathrm{E}-04$ & $1.1 \mathrm{E}-03$ & $3.1 \mathrm{E}-04$ & $4.2 \mathrm{E}-04$ & $7.9 \mathrm{E}-04$ \\
$150-200$ & $4.7 \mathrm{E}-04$ & $8.5 \mathrm{E}-04$ & $1.0 \mathrm{E}-03$ & $5.2 \mathrm{E}-04$ & $6.3 \mathrm{E}-04$ & $1.8 \mathrm{E}-04$ & $2.5 \mathrm{E}-04$ & $4.7 \mathrm{E}-04$ \\
$200-350$ & $1.9 \mathrm{E}-04$ & $3.5 \mathrm{E}-04$ & $4.3 \mathrm{E}-04$ & $2.2 \mathrm{E}-04$ & $2.6 \mathrm{E}-04$ & $7.6 \mathrm{E}-05$ & $1.0 \mathrm{E}-04$ & $1.9 \mathrm{E}-04$ \\
\hline
\end{tabular}

Table 4-11. Phume Centerline Thyroid Doses" (rem) for RSUR-4 Versus Distance

\begin{tabular}{|c|l|l|l|l|l|l|l|l|}
\hline $\begin{array}{c}\text { Distance } \\
\text { Range } \\
\text { (mi) }\end{array}$ & Infant & $\begin{array}{l}\text { Fenale } \\
\text { Child }\end{array}$ & $\begin{array}{l}\text { Male } \\
\text { Child }\end{array}$ & $\begin{array}{l}\text { Female } \\
\text { Teenage }\end{array}$ & $\begin{array}{l}\text { Male } \\
\text { Teenage }\end{array}$ & $\begin{array}{l}\text { Fetmaje } \\
\text { Adult }\end{array}$ & $\begin{array}{l}\text { Male } \\
\text { Aduli }\end{array}$ & $\begin{array}{l}\text { Average } \\
\text { Person }\end{array}$ \\
\hline$<5$ & $5.8 \mathrm{E}+03$ & $9.8 \mathrm{E}+03$ & $1.2 \mathrm{E}+04$ & $6.3 \mathrm{E}+03$ & $7.6 \mathrm{E}+03$ & $2.5 \mathrm{E}+03$ & $3.4 \mathrm{E}+03$ & $5.8 \mathrm{E}+03$ \\
$5-10$ & $2.2 \mathrm{E}+03$ & $3.6 \mathrm{E}+03$ & $4.5 \mathrm{E}+03$ & $2.3 \mathrm{E}+03$ & $2.8 \mathrm{E}+03$ & $9.0 \mathrm{E}+02$ & $1.2 \mathrm{E}+03$ & $2.1 \mathrm{E}+03$ \\
$10-25$ & $5.1 \mathrm{E}+02$ & $8.6 \mathrm{E}+02$ & $1.1 \mathrm{E}+03$ & $5.5 \mathrm{E}+02$ & $6.6 \mathrm{E}+02$ & $2.1 \mathrm{E}+02$ & $2.9 \mathrm{E}+02$ & $5.0 \mathrm{E}+02$ \\
$25-50$ & $8.6 \mathrm{E}+01$ & $1.5 \mathrm{E}+02$ & $1.8 \mathrm{E}+02$ & $9.4 \mathrm{E}+01$ & $1.1 \mathrm{E}+02$ & $3.6 \mathrm{E}+01$ & $5.0 \mathrm{E}+01$ & $8.5 \mathrm{E}+01$ \\
$50-100$ & $2.0 \mathrm{E}+01$ & $3.4 \mathrm{E}+01$ & $4.2 \mathrm{E}+01$ & $2.2 \mathrm{E}+01$ & $2.6 \mathrm{E}+01$ & $8.4 \mathrm{E}+00$ & $1.1 \mathrm{E}+01$ & $2.0 \mathrm{E}+01$ \\
$100-150$ & $8.9 \mathrm{E}+00$ & $1.6 \mathrm{E}+01$ & $1.9 \mathrm{E}+01$ & $1.0 \mathrm{E}+01$ & $1.2 \mathrm{E}+01$ & $3.8 \mathrm{E}+00$ & $5.2 \mathrm{E}+00$ & $9.0 \mathrm{E}+00$ \\
$150-200$ & $5.3 \mathrm{E}+00$ & $9.4 \mathrm{E}+00$ & $1.2 \mathrm{E}+01$ & $6.0 \mathrm{E}+00$ & $7.3 \mathrm{E}+00$ & $2.3 \mathrm{E}+00$ & $3.1 \mathrm{E}+00$ & $5.4 \mathrm{E}+00$ \\
$200-350$ & $2.3 \mathrm{E}+00$ & $4.2 \mathrm{E}+00$ & $5.2 \mathrm{E}+00$ & $2.7 \mathrm{E}+00$ & $3.2 \mathrm{E}+00$ & $9.9 \mathrm{E}-01$ & $1.4 \mathrm{E}+00$ & $2.4 \mathrm{E}+00$ \\
\hline
\end{tabular}

Thyroid dose includes all radionuxlides and pathways (j.e., inhatation, cloud-shine, plume inmersion. graund deposition); exposure condition is for "gormal activity." 


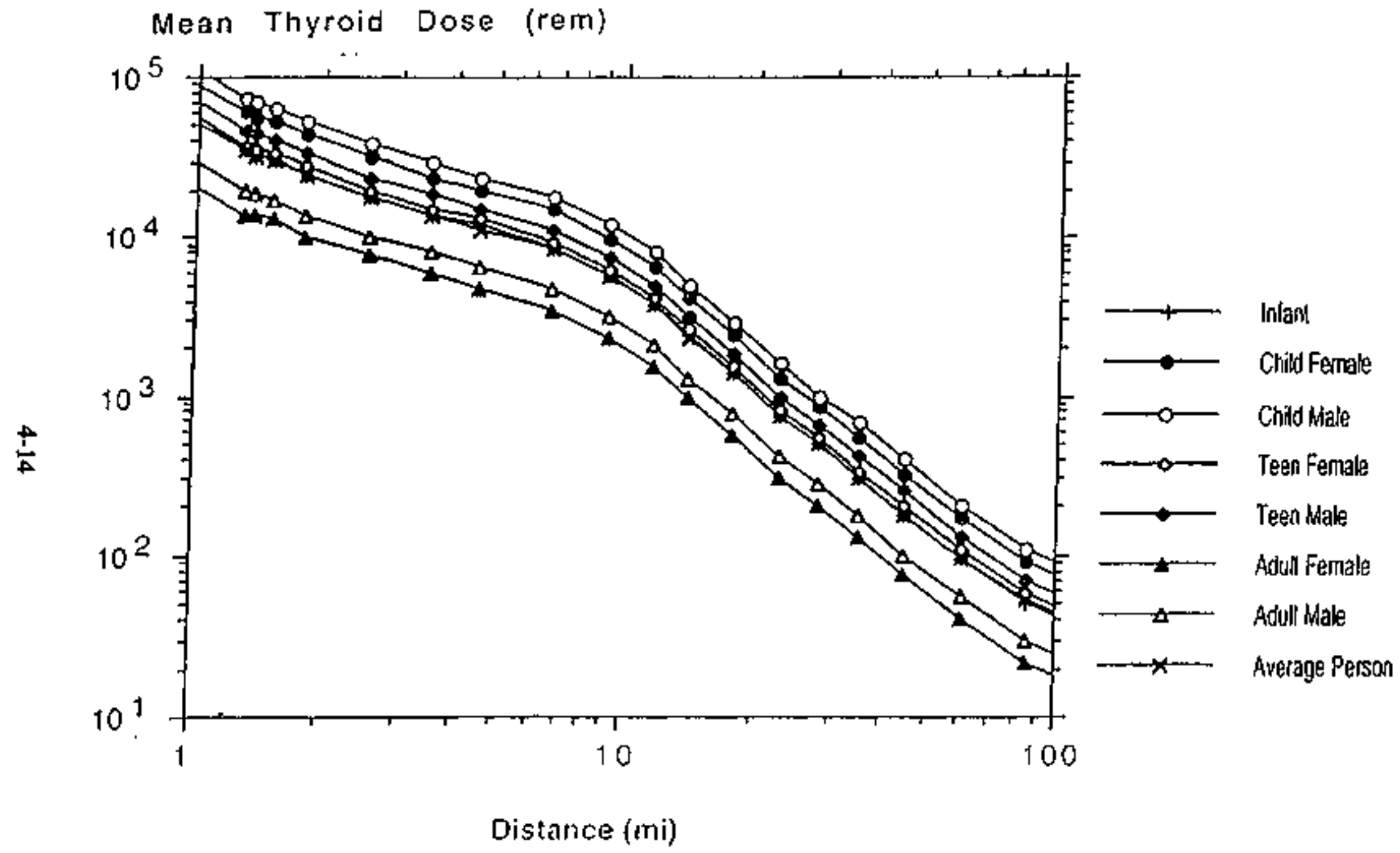

Figure 4-1. Thyroid Dose from RSUR-1 to Different Population Groups 
Figure 4-2 graphically compares the mean thyroid dose to the average person for each of the four accident scenarios and demonstrates the reduction of mean thyroid doses as a function of distance. For incremental distances, the thyroid dose is reduced prinarily due to the combined effects of plume dispersion, plume depletion, and radioactive decay of short-lived radioiodines.

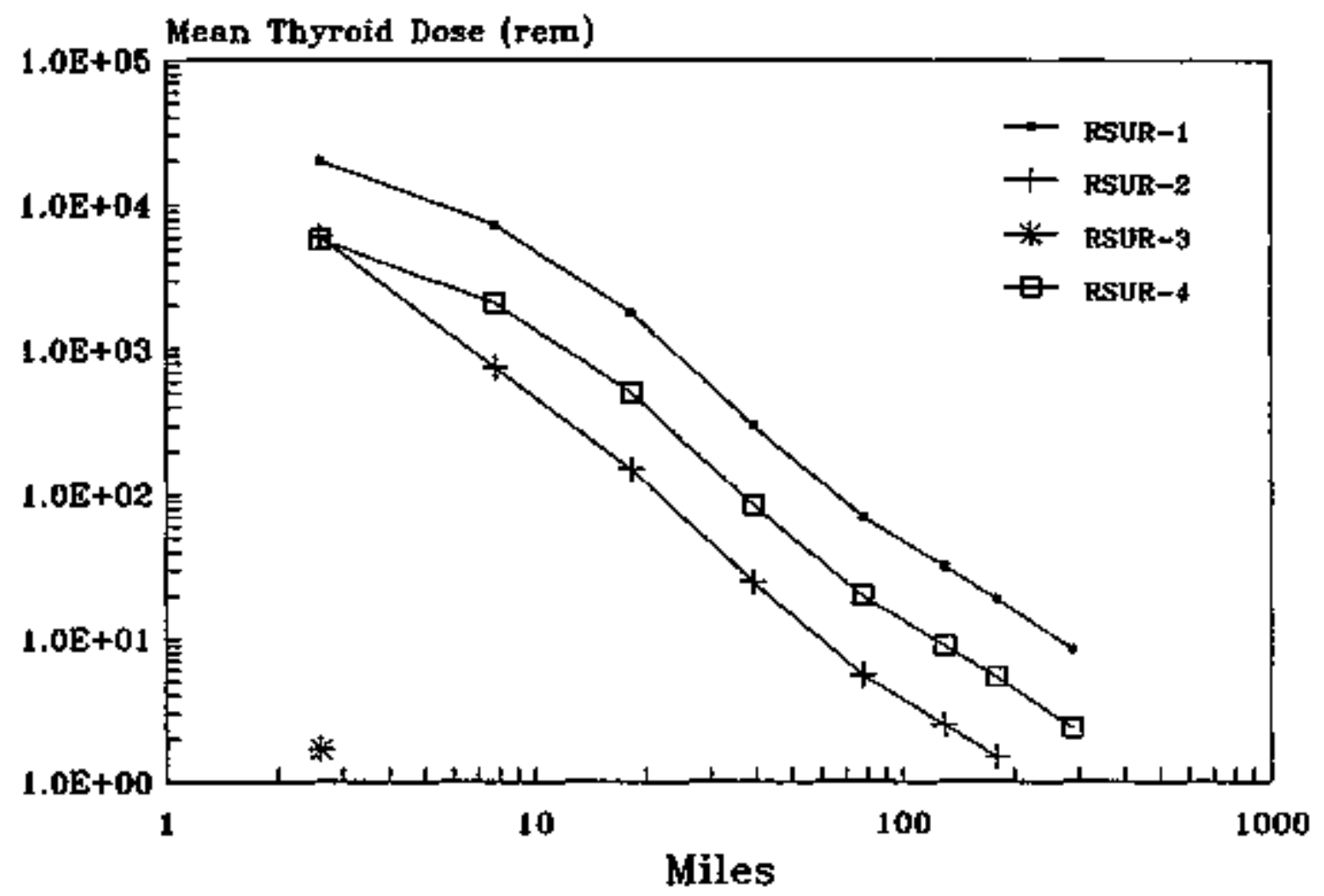

Figure 4-2. Comparison of Mean Thyroid Doses to Average Person by Distance

\subsubsection{Radial Distance and Thyroid Intervention Levels}

Central to the cost-benefit analysis is the need to estimate the potential population size for which $\mathrm{KI}$ may have to be made available. A highly conservative approach is to (1) define that distance at which the most vulnerable sub-population may exceed a pre-selected thyroid dose under the worst accident condition(s) and (2) assume that KI would be distributed to select population stubgroups. A less conservative approach assumes that $\mathrm{KI}$ will be distributed/administered to all sub-populations. For this assumption, the population radius may be more appropriately defined by that distance at which the "average person" thyroid dose may exceed a selected intervention level. Prospective thyroid intervention levels include those of the EPA (5 - 25 rem), NCRP (10 rem), FDA (25 rem), and ATA ( 50 and $100 \mathrm{rem}$ ). Figure 43 is a probability plot that quantifies the radial distances corresponding to male child thyroid doses of $5,10,25$, and 50 rem for RSUR-1 accident conditions. The conditional probability curves depict the variability 
of mean thyroid values. For example, in the downwind sector, the child thyroid dose of at least 50 rem has a probability of nearly $100 \%$ for distances out to about 50 miles. Between 50 and 175 miles, the probability of exceeding 50 rem declines steadily and approaches a zero value. A 0.5 conditional probability corresponds to a radial distance of about 160 miles, which agrees closely with the mean thyroid values shown in Table 4-8. Similar plots for RSUR-1 are shown for the population averege and inciude the ATA's upper intervention level of 100 rem (Figure 4-4). For the thyroid intervention levels of 50 and 100 rem, the 0.5 conditional probability of exceeding these levels occurs within the radial distances of about 75 miles and 50 mites. respectively. For thyroid dose intervention levels lower than those proposed by the ATA, larger radial distances would have to be considered for stockpiling.

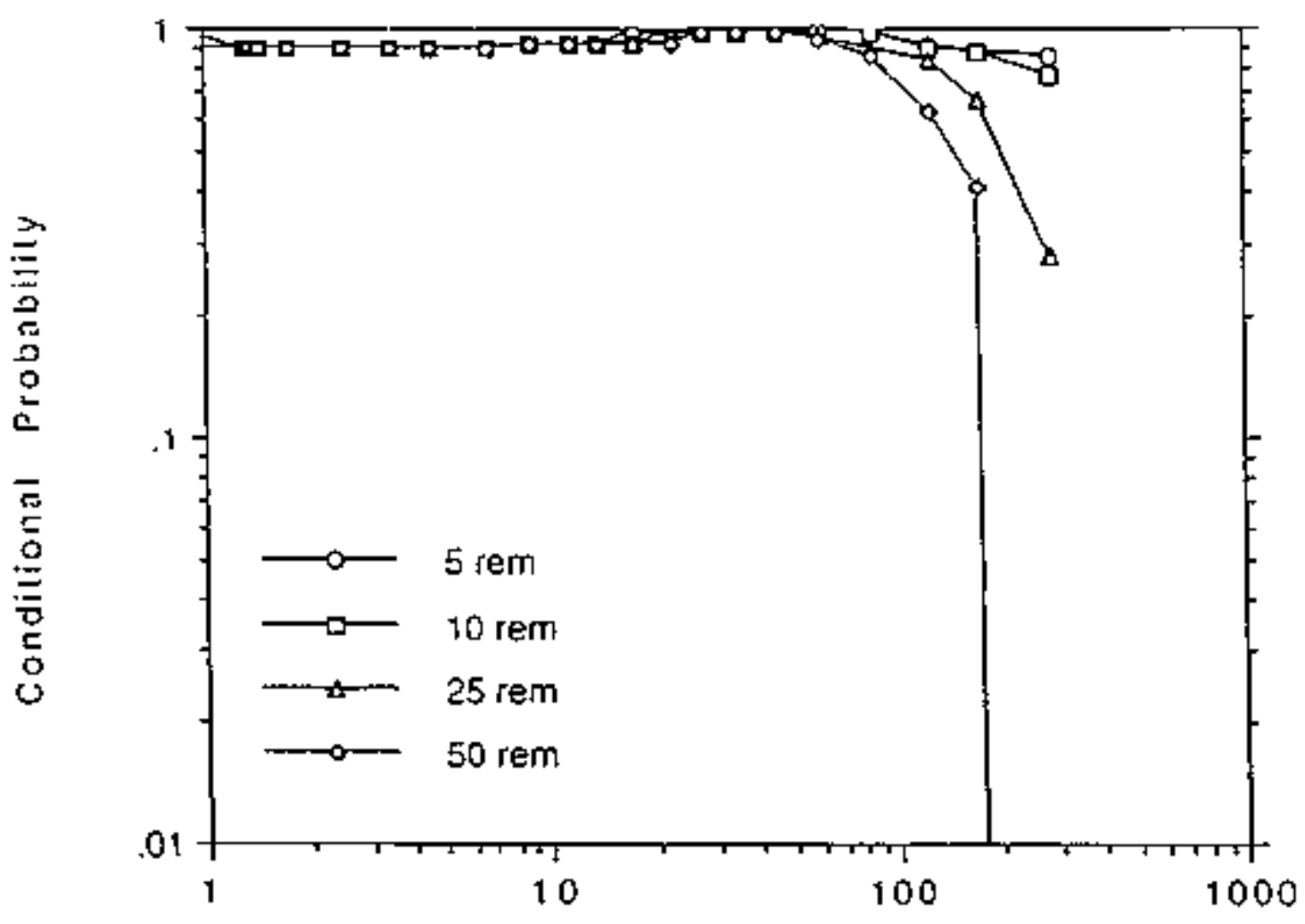

Distance (riti)

Figure 4-3. Total Thyroid Dose (RSUR-1, Child Male) 


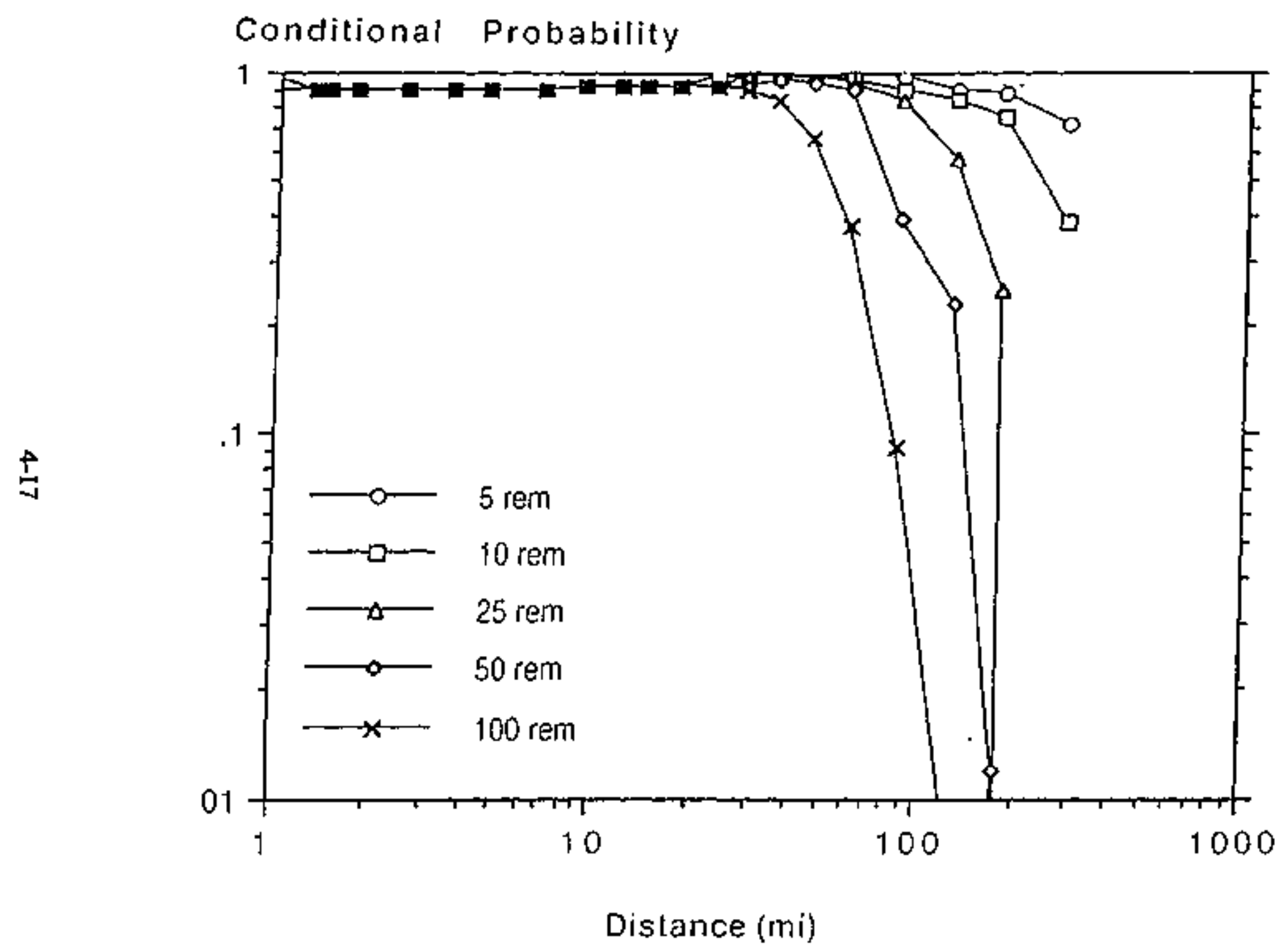

Figure 4-4. Total Thyroid Dose (RSUR-1, Average Person) 


\subsubsection{Estimates of Population Thyroid Effects}

The prophylactic value of $\mathrm{KI}$ is limited to reducing internal exposure to the thyroid from radioiodides. It is, therefore, important to idencify that component of the total thyroid dose which can be mitigated by stable iodide. Table 4-12 shows the percent contribution to total thyroid dose by inhaled radioiodides and all other sources for distance intervals of 0-25 miles, 25-100 miles, and greater than 100 miles. The ratio of thyroid dose from internal radioiodines to all other components of mean thyroid dose varies arnong the four accident categories and for a given accident category varies with distance. In general, differences among accident categories and for increased distances are relatively small and refiect small differences in plume depletion rates among radionuciides by deposition and radiosctive decay. It is evident from Table 4-12 that (1) the inhalation of radioiodides contributes about $90 \%$ or more to the thyroid dose, (2) of the radioiodides, I-131 accounts for $65-86 \%$ of dose, and (3) the thyroid dose from the combined inhalation of non-radioiodides, plume immersion, cloud-shine, and ground exposure is a small contributor to the total thyroid dose. The relative contribution of I-131 and other radioiodides to the total thyroid dose is depicted in Figure 4-5.

\section{Table 4-12. Percent Contributions to Thyroid Dose" for Exposed Population Versus Distance}

\begin{tabular}{|c|c|c|c|c|c|}
\hline \multirow{2}{*}{$\begin{array}{l}\text { Accident } \\
\text { Category }\end{array}$} & \multirow{2}{*}{$\begin{array}{l}\text { Distance } \\
\text { (miles) }\end{array}$} & \multicolumn{2}{|c|}{ Inthaled Rabioiódides } & \multirow{2}{*}{$\begin{array}{l}\text { All Othes } \\
\text { (\%) }\end{array}$} & \multirow{2}{*}{$\begin{array}{l}\text { Tota } \\
(\%)\end{array}$} \\
\hline & & $\begin{array}{l}I-131 \\
(\%)\end{array}$ & $\begin{array}{c}\text { Other Jodides } \\
(\%)\end{array}$ & & \\
\hline RSUR-1 & $\begin{array}{c}0-25 \\
25-100 \\
100-500\end{array}$ & $\begin{array}{l}71 \\
70 \\
80\end{array}$ & $\begin{array}{l}23 \\
20 \\
12\end{array}$ & $\begin{array}{c}6 \\
10 \\
8\end{array}$ & $\begin{array}{l}100 \\
100 \\
100\end{array}$ \\
\hline RSUR-2 & $\begin{array}{c}0-25 \\
25-100 \\
100-500\end{array}$ & $\begin{array}{l}68 \\
65 \\
76\end{array}$ & $\begin{array}{l}28 \\
24 \\
17\end{array}$ & $\begin{array}{c}4 \\
11 \\
7\end{array}$ & $\begin{array}{l}100 \\
100 \\
100\end{array}$ \\
\hline RSUR-3 & $\begin{array}{c}0-25 \\
25=100 \\
100-500\end{array}$ & $\begin{array}{l}76 \\
78 \\
86\end{array}$ & $\begin{array}{r}18 \\
15 \\
8\end{array}$ & $\begin{array}{l}6 \\
7 \\
6\end{array}$ & $\begin{array}{l}100 \\
100 \\
100\end{array}$ \\
\hline RSUR 4 & $\begin{array}{c}0-25 \\
25-100 \\
100-500\end{array}$ & $\begin{array}{l}66 \\
66 \\
77\end{array}$ & $\begin{array}{l}27 \\
23 \\
14\end{array}$ & $\begin{array}{c}7 \\
11 \\
9\end{array}$ & $\begin{array}{l}100 \\
100 \\
100\end{array}$ \\
\hline
\end{tabular}

- Assumes normal activity. 


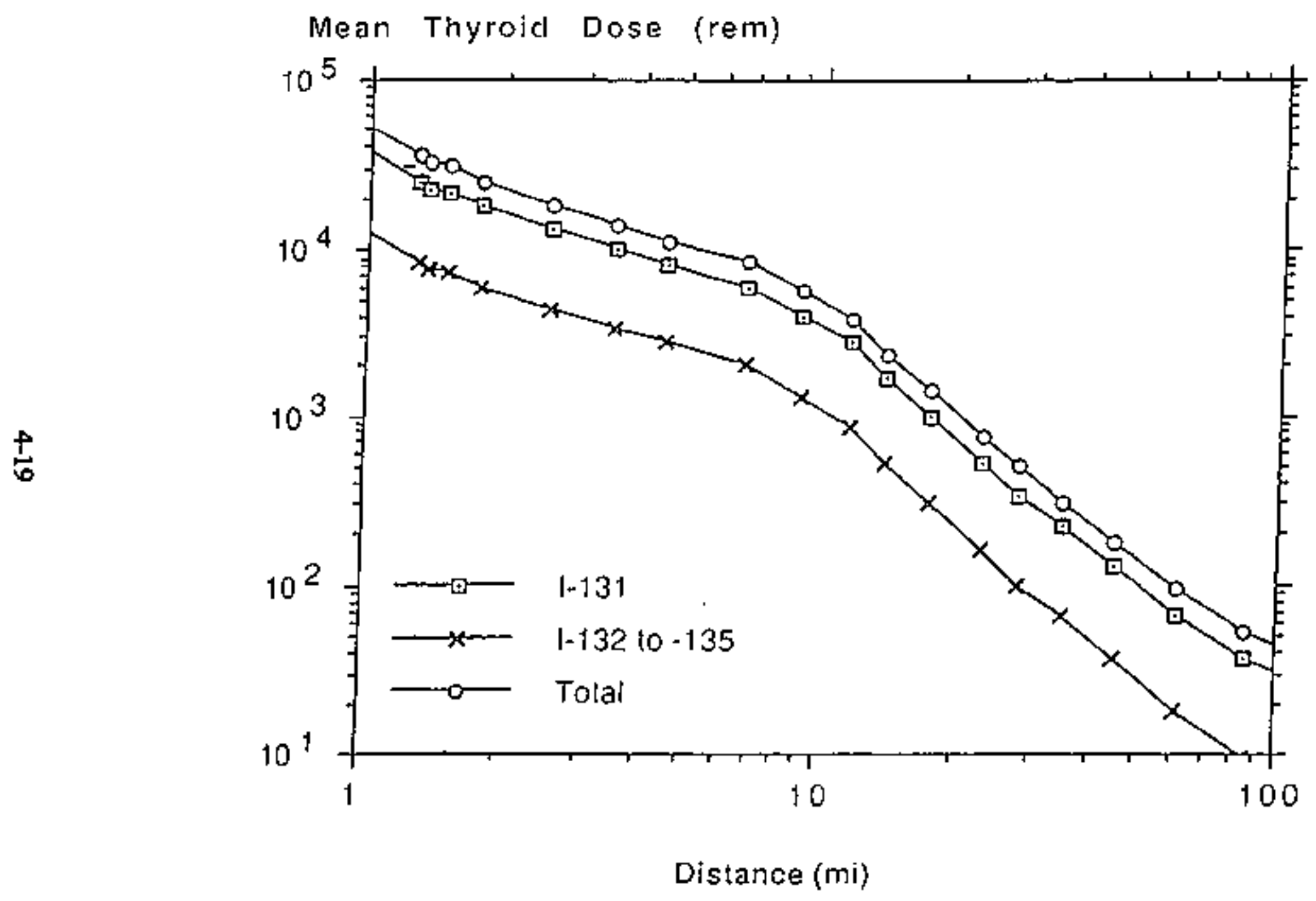

Figure 4-5. Mean Thyroid Dose Contribution from RSUR-1 to Average Person 


\subsubsection{Population Distribution Around Nuclear Power Facilities in the United States}

For risk analyses, it is common practice to use a constant population density estimate that may be expressed as the number of individuals per squate mile. Even if such a single value represents an empirically derived average value, it will lead to erroneous results and conciusions if the population is, in fact, not homogeneously distributed. In assessing the cost-benefit of KI prophylaxis, this potential error becomes obvious when it is recognized that the cost of protecting an individual is constant and independent of potential thyroid exposure; the protective "benefit." however, is not constant but decreases proportionately with reducing thyroid doses. For individuals living close to a reactor facility where potential exposures are greatest, the benefit (i.e., avoidance of thyroid effects) is also greatest per unit expense associated with the stockpiling/predistribution of KI tabiets. For this reason, an attempt was made to determine representative population densities around reactor facilities as a function of distance.

To date, comprehensive information regarding population densities around nuclear facilities does not exist in the open literature. A suitable altemative was to construct a "Reference LWR Population" dersity distribution from Final Safety Analysis Reports (FSARs) filed by utilities as part of the NRC licensing process. At the time of filing, FSARs typically contain the most current population data, as well as projected data, typically at ten-year intervals, taking into account national and regional poputation trends.

FSAR population data were obtained from the NRC's Public Document Room from all currently ticensed facilities. For some licensees, however, population data were either insufficiently detailed or formatted in such a way that the data could not be collated with that of other utilities. In total, usable population data were obtained for 55 facilities representing 26 BWRs and 60 PWRs. Population data for 16 sectors were added to yield total population values for each successive annular area starting at the exclusion zone of a facility and out to a 50-mile radius. These facility-specific data are presented in Table 4-13. 
Table 4-13. Population Distribution Around United States Nuclear Power Plants

\begin{tabular}{|c|c|c|c|c|c|c|c|c|c|c|c|}
\hline She & $<1$ & 1.2 & $2-3$ & $3-4$ & 4.5 & $5-20$ & $10-20$ & $20-30$ & $30-40$ & $40-50$ & Reacior \\
\hline 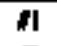 & 0 & 53 & 470 & 465 & 1,095 & 34,020 & 126,640 & 169,505 & 336,930 & 147.780 & Brownst Ferty \\
\hline $\boldsymbol{n}$ & 81 & 610 & 3,270 & 87 & 1.082 & 11,712 & 91.715 & 20,604 & 35,330 & 66.880 & Bnunswilek \\
\hline$m$ & $\mathbf{3}$ & 30 & 369 & 227 & 201 & 1,59: & 1280 & 34.465 & 33,100 & 93,288 & Cooper \\
\hline $\mathbf{A S}$ & 443 & S.1S52 & 3,486 & 5.164 & 4,387 & 8,701 & 349,674 & $2,020, \$ 02$ & 2,855,963 & $1,961,502$ & Fertri \\
\hline AS & 3 & 405 & 808 & $\$, 588$ & 3,548 & 41,662 & 69.73) & 131,168 & 523,320 & 427,900 & Firpartick \\
\hline$\pi 6$ & 51 & 143 & 116 & 946 & 1,709 & $5,4 \div 2$ & 13,859 & $7,9 m 0$ & 104,459 & 95,598 & Orand Duff \\
\hline$n$ & 54 & 69 & 146 & 242 & 377 & 4,405 & 40,295 & 48,177 & 60.870 & IIS.6600 & Hach \\
\hline 48 & 0 & 0 & 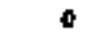 & 299 & 1,026 & 21,550 & 341,000 & 623.300 & 1.992 .600 & $2,367,200$ & Hope Crett \\
\hline 19 & 219 & 105 & 111 & 280 & 647 & 14,837 & 80.972 & 132.041 & 327,699 & 515,504 & LAstut \\
\hline s) & $\$ 27$ & 6.tets & 13,313 & 34.781 & 19,671 & 98,276 & $16 n, 384$ & 2,371,996 & $2,217.772$ & $1.356,901$ & Limertak \\
\hline$w t$ & 1.027 & 9.260 & 7.179 & 2.726 & 5,673 & 99,157 & 296,754 & 575.646 & $1,594,268$ & $2,300,116$ & ac \\
\hline HI2 & g & 1,718 & 9,095 & 2,805 & 5,275 & 102,537 & 260,268 & 574,520 & $1,409,4013$ & $1.207 .7 \mathrm{FB}$ & Petry \\
\hline N13 & 53 & 140 & 235 & 1,206 & 5,397 & 21,671 & 304,832 & 125,065 & 104,601 & 136,070 & gind Cinies \\
\hline SBd & 4 & 172 & 514 & 1,490 & 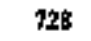 & 19,416 & 71,322 & 389,315 & 18,360 & 211.057 & River Bend \\
\hline HIS & 248 & $1.1 \pi$ & 1,531 & 2,531 & $9, \mathbf{s} 5 \mathbf{t}$ & 46,400 & 261,400 & 351.260 & 419,000 & 551,600 & Stequehims \\
\hline 116 & 60 & 1,500 & 1,300 & 1,100 & 3.800 & 21,179 & 101.893 & $132, \mathbf{3 1 3}$ & 373,620 & 535,442 & $\forall_{6}$. Yanite \\
\hline A17 & a & 0 & 0 & 20 & 464 & 98 & 62,192 & 62,434 & 43,841 & 85.775 & WNP-2 \\
\hline HII & 6 & 12 & 4* & $n$ & 245 & 1,TSS & $\pi, 915$ & $310, \pi \pi$ & 132,436 & 144,419 & Vogtle \\
\hline 시 & I33 & 912 & 1,666 & 2,934 & 5,120 & 28.910 & 61,001 & 96,680 & 116,694 & 196,675 & Artanar Ont \\
\hline mo & 1,025 & 8,300 & 4,098 & $4,0 \times 3$ & 3.403 & 204,000 & $\$ 16,000$ & 1.517 .000 & 1.586 .000 & 1.274 .060 & Beaver Valley \\
\hline 21 & 25 & 西 & 9 & 150 & soto & 8,969 & 29.907 & 123,452 & 132.247 & {$[22,505$} & Callsway \\
\hline Hit & 173 & 844 & 2,817 & 1,860 & 2,050 & 34,372 & 92146 & 190,043 & $4 \$ 4,858$ & $2,913,460$ & Catrenchirts \\
\hline n21 & 112 & 824 & 1,954 & 6.843 & 5,025 & 64,900 & 490,59 & 396,213 & 294,339 & 343,853 & Cerenta \\
\hline$\$ 24$ & 0 & 0 & 10 & 40 & 409 & 14.245 & 9.099 & 17.796 & 96,327 & 128,091 & Cryesed Rher \\
\hline H25 & IAI & 410 & 459 & 367 & 583 & 13,659 & $109,39 n$ & 911,289 & 573.558 & $1.386,284$ & Dovis Besse \\
\hline$m 6$ & $\mathbf{0}$ & 4 & 2 & 18 & $s t$ & 6,206 & 111.460 & 90,500 & 78,000 & 56.600 & Dinbla Canyad \\
\hline$m$ & 107 & 1,360 & 2,996 & $3,47 \%$ & 3,565 & 65,147 & 179.896 & 526,176 & 275,281 & 640,942 & DC Conk \\
\hline$n$ & 450 & 370 & 1,210 & 5.270 & 5,420 & 11,550 & 276,950 & 407,200 & 91,200 & 72,704 & Fit Calhowa \\
\hline 129 & $m$ & I,II1 & 2.310 & 2.955 & 6,126 & 23.275 & 59,940 & 177,180 & 202,410 & 308,507 & Robinan \\
\hline 100 & 23 & 39 & 222 & 636 & 1,959 & 9,500 & 82,505 & 57,430 & 116,652 & 115,316 & Faniey \\
\hline MI & 396 & 2,521 & 3.516 & 3,432 & 2,551 & 59.776 & 511,6047 & $1,394,599$ & 1.779.mt & $1,190,051$ & $H=40$ a \\
\hline $\boldsymbol{B} 2$ & 1,599 & 16,037 & 19,198 & 27,633 & 45.905 & 549,818 & 1,068,626 & $3,130,318$ & $8,295,439$ & $5,011,505$ & Indian Pt. \\
\hline $\mathbf{m 3}$ & 20 & 175 & $4 / 3$ & 605 & 1.104 & 13,626 & 115,262 & 214,394 & 201,162 & 294,107 & Kewartake \\
\hline I34 & 39 & 49 & 1,063 & 1,325 & 2.207 & 75.399 & 707,673 & 409,946 & 375,475 & 318,597 & Mcturire \\
\hline PSS & 98 & $\operatorname{sen}$ & 691 & 1,840 & 1.975 & 23.609 & 63,600 & IS0.600 & 206,400 & 128,000 & Mine Yanlate \\
\hline 56 & $\mathbf{0}$ & 170 & 523 & $\mathbf{s 9 z}$ & 640 & 9,013 & 11,290 & 175,450 & $5+3,190$ & 440,530 & N. Annen \\
\hline 137 & 0 & 486 & $1,12 t$ & 1.488 & 1,554 & 41,576 & 60.752 & 300,200 & 205.258 & 201,306 & Oeabe: \\
\hline Agd & $4 t$ & 494 & 1.391 & 1.390 & 2,468 & 29,643 & 81,632 & 9,130 & 281,590 & 407,146 & Patsondes \\
\hline $\operatorname{mas}$ & 21 & 0 & $|4|$ & 157 & 175 & 3.080 & $11,0 n s$ & 9,645 & I10,555 & $1,047,5,55$ & Palp Verdo \\
\hline 200 & 57 & 252 & 375 & tos & 524 & 28,048 & 89.765 & 171.360 & 256,607 & 260,460 & Pt. Bach \\
\hline 741 & 106 & 330 & 292 & 571 & 1,123 & 13,040 & 118,110 & 357.100 & $1,333,400$ & $1,132,143$ & Proirie 6. \\
\hline 242 & 31 & 85 & 144 & 34 & 529 & 6,607 & 23:.94 & 1.709.641 & 337, at2 & 575,545 & Rencho Sese \\
\hline 743 & 0 & o & 0 & $\operatorname{ser}$ & I,9] & 34,618 & 412,737 & $\$ 67.062$ & $1,967,403$ & $2,40 \%, 169$ & PSERC \\
\hline 144 & 0 & 32 & 362 & $7 \%$ & 1,016 & 19,120 & 258,350 & 455,570 & 351.710 & $\$ 13.760$ & SherrodHerris \\
\hline 175 & 0 & 2,050 & 6.460 & 8,200 & 10,750 & $\$ 5.390$ & 42,500 & 756,790 & $2,021,000$ & $3.231,0003$ & San Doofre \\
\hline id6 & 0 & 4 & 75 & 40 & 665 & 2,900 & 31,201 & 40,635 & 161.802 & 203,879 & S. Terus \\
\hline 147 & I35 & 1,590 & 2,264 & 4,913 & 5,0035 & 51,502 & 433,340 & 260,598 & 194.253 & 150.193 & Seqwoyrih \\
\hline Wh & $\mathbf{0}$ & $\$ 10$ & 1,395 & 5,748 & 16,323 & 100.323 & [D], 342 & $111.6 \mathrm{n}$ & 149,634 & 319,227 & Sr. Luele \\
\hline$M 9$ & 4 & 121 & 200 & 996 & 457 & 5,578 & $76,70 \mathrm{~A}$ & 393,930 & t91. 163 & 280,707 & v C Summe \\
\hline w5 & $\mathbf{0}$ & 7 & 68 & 134 & 467 & 160.77 & 295.789 & 135,906 & 610,096 & 631,219 & Surny \\
\hline 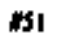 & 736 & 2,436 & 2,109 & 11,004 & I0, 848 & 160.912 & 661,598 & 491,682 & 313,703 & 132,235 & ThI \\
\hline 452 & 284 & 40 & 2,527 & 2,415 & $3,82: 5$ & 80,100 & 55,230 & 148,643 & 815,022 & 543,495 & Trojin \\
\hline 453 & $\mathbf{0}$ & $\mathbf{0}$ & $\boldsymbol{0}$ & $\boldsymbol{0}$ & 0 & 168,258 & 710.158 & 946,133 & 223,650 & 306,115 & Tuckey Ph. \\
\hline US4 & \$1: & $\$ 31$ & 399 & 512 & SAls & 16.034 & B.801 & 160,414 & 345,805 & 750,932 & Yarike Rom \\
\hline 455 & 289 & 15,217 & 12,676 & 4,462 & 6.599 & 191,997 & 321,006 & 544,362 & 460,537 & $4,226,5 \%$ & ZZlap \\
\hline
\end{tabular}


Table 4-14 shows the average values and the standard deviations for each population cell. In all cases, the standard deviations of the mean exceeded their mean values. Population densities were determined by dividing the average number of individuals within each cell by the corresponding area. The first five miles yield population densities of about 140 individuals per square mile. Beyond tive miles, the average population density essentially doubles in value (Table 4-14).

Table 4-14. Average Population Distribution for U.S. Nuclear Facilities

\begin{tabular}{ccc}
\hline $\begin{array}{c}\text { Distance } \\
\text { (miles) }\end{array}$ & $\begin{array}{c}\text { Average No. } \\
\text { Individuals } \pm 1 \text { SD }\end{array}$ & $\begin{array}{c}\text { Population Density } \\
\text { (No. lnd./Mile) }\end{array}$ \\
\hline$<1$ & $185 \pm 314$ & 63 \\
$1-2$ & $1,560 \pm 3,365$ & 166 \\
$2-3$ & $2,172 \pm 3,698$ & 138 \\
$3-4$ & $2,977 \pm 6,019$ & 135 \\
$4-5$ & $3,979 \pm 6,969$ & 141 \\
$5-10$ & $55,122 \pm 84,811$ & 234 \\
$10-20$ & $240,581 \pm 318,939$ & 255 \\
$20-30$ & $507,664 \pm 809,435$ & 323 \\
$30-40$ & $702,317 \pm 1,228,789$ & 320 \\
$40-50$ & $831,796 \pm 1,062,887$ & 294 \\
\hline
\end{tabular}

Population densities beyond the 50-mile radius are not defined in FSARs and had to be derived by alternate means. All States in which at least one licensed commercial nuclear facility exists or whose borders are within 50 miles of a reactor facility were identified. The average population density was defined for each State by dividing the 1990 State poputation by the State's area defined in square miles. States with multiple reactors were weighted proportionately. An overall population'density of about 200 indjviduals per square mile was thus obtained. This value was used to represent population density beyond a 50-mile radius.

Table 4-15 provides the population distribution of the Reference LWR facility used to estimate thyroid dose and, health effects for the four reactor accident categories 
Table 4-15. Population Distribution for Reference LWR

\begin{tabular}{|c|c|c|c|}
\hline \multirow{2}{*}{$\begin{array}{c}\text { Distance } \\
\text { interval } \\
\text { (miles) }\end{array}$} & $\begin{array}{c}|c| \\
\text { Density } \\
\text { (person/mile) }\end{array}$ & \multicolumn{2}{|c|}{ Total (persons) } \\
\cline { 2 - 4 } & 63 & Radiat Segmont & Cumulative \\
\hline$<1$ & 138 & 185 & 185 \\
$1-5$ & 234 & 10,406 & 10,591 \\
$5-10$ & 284 & 55,142 & 65,733 \\
$10 * 25$ & 309 & 468,472 & 534,205 \\
$25-50$ & 200 & $1,820,396$ & $2,354,601$ \\
$50-100$ & 200 & $4,713,000$ & $7,067,601$ \\
$100-150$ & 200 & $7,855,000$ & $14,922,601$ \\
$150-200$ & 200 & $10,994,000$ & $25,919,601$ \\
$200-350$ & 200 & $51,843,000$ & $77,762,601$ \\
$350-500$ & & $80,121,000$ & $157,883,601$ \\
\hline
\end{tabular}

\subsection{Population Thyroid Health Effects}

Population thyroid health effects for the Reference LWR are estimated by deriving the cumulative population thyroid exposure for each population subgroup and applying the appropriate risk coefficient. The percentage of individuals representing each sub-population for the Reference LWR is assumed to be identical to that of the whole U.S. population, as defined by 1990 census 'data. By multiplying the age- and sex-adjusted populations at fixed radiat distances with the corresponding thyroid dose values of the exposed individuals, population thyroid doses were derived for each distance interval. It is important to note that the exposed population is limited to individuals within the plume pathway, which based on dispersion parameters may represent only a small fraction of the total population residing 360 degrees around a reactor facility. Additionally, thyroid doses within the plume pathway for any given radial distance are assumed to exhibit a Gaussian distribution whose maximum value is equal to the plume centerline values cited in Tables 4-8 through 4-11.

Population thyroid doses are converted to thyroid health effects by means of the previously derived risk coefficients for thyroid cancer, thyroid nodules, and hypothyroidism. The mean numbers of thyroid cancers, nodules, and ablated thyroids estimated to occur within selected distance intervals for the four accident categories are given in Table 4-16. These estimates of thyroid effects represent a population exposed under normal conditions with no KI. The number of expected thyroid effects is highest for RSUR-1, tollowed by RSUR-4 and RSUR-2. The 
small release fraction for RSUR -3 results in small population thyroid doses and yields estimates of less than 0.5 excess thyroid cancers and nodules for all population segments. A less than 0.5 probability of observing a single thyroid cancer or nodule for a population cell is reported as a zero (0) value.

The relative frequencies of total cancers to fatal cancers and to nodules are a constant among population cells. This constancy occurs because the relative frequencies of these thyroid affects are solely defined by the relative magnitude of their corresponding risk coefficients (see Chapter 3). For I-131, the risk coefficients of $23.2,2.3$, and 44.7 per $10^{6}$ thyroid rads were previously cited to correspond to cancer, fatal cancer, and nodule, respectively. On the average, these risk coefficients predict that for every fatal thyroid cancer, there will be nine additional non-fatal cancers, and 19.4 thyroid nodules.

A comparison of the absolute mumbers of thyroid effects per population cell for increasing radial distances shows a complex trend reflecting a steady decrease in individual doses and a near exponential increase in the exposed population size. Thus, the total number of thyroid effects for populations at large distances must be viewed in the context of individial risks that fall off precipitously with distance. Individual risks can be readily estimated by dividing the mumber of thyroid effects for a population cell by the total number of individuals residing within that radial segenent.

The number of cases of hypothyroidism for the four accident categories are aiso shown in Table 4-16. Since hypothyroidism is a non-stochastic effect with a dose-threshold, its occurrence is limited to those populations in which individual thyroid doses exceed threshold values (defined in Table 3-7). With the exception of RSUR-1, the likelihood of exceeding the threshold value is minimal beyond a distance of 25 miles. 
Table 4-16. Population Thyrold Effects for Normal Activity Without $\mathrm{Kr}^{*}$

\begin{tabular}{|c|c|c|c|c|c|c|c|c|}
\hline \multirow{2}{*}{$\begin{array}{l}\text { Distance } \\
\text { Intervil } \\
\text { (miles) }\end{array}$} & \multicolumn{4}{|c|}{$\stackrel{\text { A }}{\text { Total Thyroit Cancers }}$} & \multicolumn{4}{|c|}{$\begin{array}{c}\text { B } \\
\text { Fatal Thyroid Cancers }\end{array}$} \\
\hline & RSUR-1 & RSUR-2 & RSUR-3 & RSUR-4 & RSUR-1 & RSUR-2 & RSUR-3 & RSUR 4 \\
\hline$<5$ & 137 & 58 & 0 & 52 & 14 & 6 & 0 & 5 \\
\hline $5-10$ & 278 & 59 & 0 & 105 & 28 & 6 & 0 & 11 \\
\hline $10-25$ & 432 & 72 & 0 & 157 & 43 & 7 & 0 & 16 \\
\hline $25-50$ & 351 & 58 & 0 & 128 & 35 & 6 & 0 & 13 \\
\hline $50 \cdot 100$ & 232 & 36 & 0 & 84 & 23 & 4 & 0 & 8 \\
\hline $100-150$ & 174 & 27 & 0 & 63 & 17 & 3 & 0 & 6 \\
\hline $150-200$ & $1 \quad 138$ & 21 & 0 & 49 & 14 & 2 & 0 & 5 \\
\hline $200-350$ & 264 & 41 & 0 & 93 & 26 & 4 & 0 & 9 \\
\hline $350-500$ & 449 & 72 & 0 & 153 & 45 & 7 & 0 & 16 \\
\hline \multirow{2}{*}{$\begin{array}{l}\text { Distance } \\
\text { lnterval } \\
\text { (miles) }\end{array}$} & \multicolumn{4}{|c|}{$\underset{\text { Thyroid Nodules }}{\mathrm{C}}$} & \multicolumn{4}{|c|}{ D } \\
\hline & RSUR-1 & RSUR-2 & RSUR-3 & RSUR-4 & RSUR-1 & RSUR-2 & RSUR-3 & RSUR-4 \\
\hline$<5$ & 361 & 155 & 0 & 139 & 150 & 31 & 0 & 33 \\
\hline $5-10$ & 726 & 157 & 0 & 283 & 186 & 11 & 0 & 49 \\
\hline $10-25$ & 1123 & 193 & 0 & 420 & 146 & 1 & 0 & 21 \\
\hline $25 \cdot 50$ & 909 & 154 & 0 & 340 & 11 & 0 & 0 & 0 \\
\hline $50-100$ & 594 & 94 & 0 & 220 & 0 & 0 & 0 & 0 \\
\hline $100-150$ & 438 & 70 & 0 & 162 & 0 & 0 & 0 & 0 \\
\hline $150 \cdot 200$ & 343 & ss & 0 & 124 & 0. & 0 & 0 & 0 \\
\hline $200-350$ & 635 & 103 & 0 & 230 & 0 & 0 & 0 & 0 \\
\hline $350+500$ & 962 & 168 & 0 & 340 & 0 & 0 & 0 & 0 \\
\hline
\end{tabular}

The administration of $\mathrm{KI}$ is assumed to reduce the thyroid dose from inhalation of radioiodides with a $99 \%$ efficiency. 


\subsubsection{Potential Reduction in Thyroid Health Effects}

The potential reduction in the mean number of thyroid effects that would result from the use of $\mathrm{KI}$ are governed by the fraction of the thyroid dose from the inhalation exposure of radioiodide. When $\mathrm{KI}$ is properly administered, it reduces internal thyroid expostres from radioiodides with a $99 \%$ efficiency. Thyroid exposure from external radiation and internal exposure from nonradioiodide nuclides is unaffected by the prophylactic administration of $\mathrm{KL}$. Table 4-17 shows the residual number of thyroid cancers, fatal thyroid cancers, thyroid nodules, and ablated chyroids (i.e., abłated thyroids resulting in a clinical state of hypothyroidism). The difference between values shown in Table 4-16 and 4-17 provides an estimate of the net potential reduction in thyroid health effects attributable to $\mathrm{KI}$ administration. The number of thyroid health effects that can be potentially avoided if $\mathrm{KI}$ is administered nnder optimal conditions is shown in Table 4-18.

An estimate of fetal thyroid effects employs a similar methodology and uses parameter values previously defined. Critical parameters include the following:

- Fetal thyroid dose: assumed to be twice the maternal dose and corresponds to twice the values for females above 18 years of age (see Tables 4-8 to 4-11).

- Fetal thyroid risk coefficients for cancer, nodules, and thyroid ablation are assumed to be equal to those of males and fermales under the age of 18, but are adjusted for 75 years at risk.

- The number of fetuses at risk is based on the fact that radioiodide is concentrated in the fetal thyroid only during the second and thitd trimesters. At the current birth rate of 16 live births per 1,000 individuals per year, the number of fenses at risk at any moment in time is eight fetuses per 1,000 persons exposed to the plume.

Although the fetus may be considered the most sensitive member of the general population, the number of fetuses likely to be exposed from a passing plume is relatively small.

Table 4-19 identifies the number of fetal thyroid cancers, nodules, and ablated thyroids for matemal plume exposure when no $\mathrm{KI}$ is administered. Table 4-20 provides estimates of residuai fetal thyroid effects that cannot be avoided even if $\mathrm{KI}$ is administered to pregnant women. The difference in corresponding values of Tables 4-19 and 4-20 yields the net potential reduction of fetal thyroid effects attributable to maternal $\mathrm{KI}$ prophylaxis (Table 4-21). 
Table 4-17. Residual Thyroid Effects for Population Exposed Under Normal Activity and Administered $\mathbf{K I}^{*}$

\begin{tabular}{|c|c|c|c|c|c|c|c|c|}
\hline \multirow{2}{*}{$\begin{array}{l}\text { Distance } \\
\text { Interval } \\
\text { (mitles) }\end{array}$} & \multicolumn{4}{|c|}{$\frac{\text { A }}{\text { Total Thyroid Cancers }}$} & \multicolumn{4}{|c|}{$\begin{array}{c}\text { B } \\
\text { Faral Thyroid Cancers }\end{array}$} \\
\hline & RSUR-I & RSUR-2 & RSUR-3 & RSUR-4 & RSUR-1 & RSUR-2 & RSUR-3 & RSUR-4 \\
\hline$<5$ & 18 & 16 & 0 & 8 & 2 & 2 & 0 & 1 \\
\hline $5-10$ & 37 & 17 & 0 & 16 & 4 & 2 & 0 & 2 \\
\hline $10-25$ & 58 & 21 & 0 & 24 & 6 & 2 & 0 & 2 \\
\hline $25-50$ & 51 & 17 & 0 & 21 & 5 & 2 & 0 & 2 \\
\hline $50-100$ & 35 & 11 & 0 & 14 & 3 & 1 & 0 & ] \\
\hline $100-150$ & 26 & 8 & 0 & 11 & 3 & 1 & 0 & 1 \\
\hline $150 \cdot 200$ & 21 & 7 & 0 & 8 & 2 & 1 & 0 & ] \\
\hline $200-350$ & 41 & 13 & 0 & 17 & 4 & $I^{\prime}$ & 0 & 2 \\
\hline $350-500$ & 61 & 19 & 0 & 25 & 6 & 2 & 0 & 2 \\
\hline \multirow{2}{*}{$\begin{array}{l}\text { Distance } \\
\text { Interval } \\
\text { (miles) }\end{array}$} & \multicolumn{4}{|c|}{$\begin{array}{c}\text { C } \\
\text { Thyroid Nodules }\end{array}$} & \multicolumn{4}{|c|}{$\begin{array}{c}\text { D } \\
\text { Hypathyrajoisen }\end{array}$} \\
\hline & RSUR-1 & RSUR-2 & RSUR-3 & RSUR-4 & RSUR-1 & RSUR-2 & RSUR-3 & RSUR-4 \\
\hline$<5$ & 58 & 52 & 0 & 25 & 5 & 4 & 0 & 1 \\
\hline $5-10$ & 117 & $\$ 4$ & 0 & $\$ 1$ & 6 & 0 & 0 & 1 \\
\hline $10 \cdot 25$ & 186 & 68 & 0 & 77 & 1 & 0 & 0 & 0 \\
\hline $25-50$ & 162 & 56 & 0 & 68 & 0 & 0 & 0 & 0 \\
\hline $50-160$ & 111 & 35 & 0 & 45 & 0 & 0 & 0 & 0 \\
\hline $100-150$ & 83 & 26 & 0 & 34 & 0 & 0 & 0 & 0 \\
\hline $150-200$ & 67 & 21 & 0 & 27 & 0 & 0 & 0 & 0 \\
\hline $200 \cdot 350$ & 131 & 41 & $\mathbf{0}$ & 53 & 0 & 0 & 0 & 0 \\
\hline $350-500$ & 193 & 62 & 0 & 79 & 0 & 0 & 0 & 0 \\
\hline
\end{tabular}

The administration of $\mathrm{KI}$ is assumed to reduce the thyroid dose from inhalation or ratioiodides with $99 \%$ efficiency. 
Table 4-18. Avoidable Population Thyroid Effects with KI Prophylaxis

\begin{tabular}{|c|c|c|c|c|c|c|c|c|}
\hline \multirow{2}{*}{$\begin{array}{l}\text { Distance } \\
\text { Interval } \\
\text { (miles) }\end{array}$} & \multicolumn{4}{|c|}{$\begin{array}{c}\text { A } \\
\text { Total Thyroid Cancers }\end{array}$} & \multicolumn{4}{|c|}{$\begin{array}{c}\text { B } \\
\text { Fatal Thyroid Cancers }\end{array}$} \\
\hline & RSUR-1 & RSUR-2 & RSUR-3 & RSUR-4 & RSSUR-1 & RSUR-2 & RSUR-3 & RSUR-4 \\
\hline$<5$ & 119 & 41 & 0 & 44 & 12 & 4 & 0 & 4 \\
\hline $5-10$ & 241 & 42 & 0 & 89 & 24 & 4 & 0 & 9 \\
\hline $10-25$ & 374 & 51 & 0 & 133 & 37 & 5 & 0 & 13 \\
\hline $25-50$ & 301 & 40 & 0 & 107 & 30 & 4 & 0 & 11 \\
\hline $50-100$ & 197 & 25 & 0 & 70 & 20 & 2 & 0 & 7 \\
\hline $100-150$ & 148 & 18 & 0 & 52 & 15 & 2 & 0 & 5 \\
\hline $150-200$ & 117 & 15 & 0 & 43 & 12 & 」 & 0 & 4 \\
\hline $200-350$ & 223 & 28 & 0 & 77 & 22 & 3 & 0 & B \\
\hline $350-500$ & 388 & 53 & 0 & $\$ 31$ & 39 & 5 & 0 & 13 \\
\hline \multirow{2}{*}{$\begin{array}{l}\text { Distance } \\
\text { Interval } \\
\text { (miles) }\end{array}$} & \multicolumn{4}{|c|}{$\begin{array}{c}\text { C } \\
\text { Thyroid Nodules }\end{array}$} & \multicolumn{4}{|c|}{$\begin{array}{c}\text { D } \\
\text { Hypothyroidism }\end{array}$} \\
\hline & RSUR-1 & RSUR-2 & RSUR-3 & RSUR-4 & RSUR-I & RSUR-2 & RSUR-3 & RSUR-4 \\
\hline$<5$ & 303 & 103 & 0 & 114 & 99 & 28 & 0 & 32 \\
\hline $5 \cdot 10$ & 609 & 103 & 0 & 231 & 180 & 10 & 0 & 48 \\
\hline $10 \cdot 25$ & 937 & 124 & 0 & 342 & 144 & $\mathbf{5}$ & 0 & 21 \\
\hline $25-50$ & 748 & 98 & 0 & 272 & 11 & 0 & 0 & 0 \\
\hline $50-100$ & 482 & 60 & 0 & 174 & 0 & 0 & 0 & 0 \\
\hline $100-150$ & 355 & 43 & 0 & 128 & 0 & 0 & 0 & 0 \\
\hline $150-200$ & 276 & 34 & 0 & 98 & 0 & 0 & 0 & 0 \\
\hline $200-350$ & 504 & 63 & 0 & 177 & 0 & 0 & 0 & 0 \\
\hline $350-500$ & 769 & 105 & 0 & 261 & 0 & 0 & 0 & 0 \\
\hline
\end{tabular}


Table 4-19. Fetal Thyroid Effects for Normal Activity Without Kr

\begin{tabular}{|c|c|c|c|c|c|c|c|c|}
\hline \multirow{2}{*}{$\begin{array}{c}\text { Distance } \\
\text { Interval } \\
\text { (miles) }\end{array}$} & \multicolumn{4}{|c|}{$\stackrel{\text { A }}{\text { Total Thyroid Cancers }}$} & \multicolumn{4}{|c|}{ Fatal Thiyroid Cancers } \\
\hline & RSUR-1 & RSUR-2 & RSUR-3 & RSUR 4 & RSUR-1 & RSUR-2 & RSUR-3 & RSUR-4 \\
\hline$<5$ & 3 & I & 0 & 1 & 0 & 0 & 0 & 0 \\
\hline $5 \cdot 10$ & 6 & $\mathbf{1}$ & 0 & 2 & 1 & 0 & 0 & 0 \\
\hline $10-25$ & 9 & 2 & 0 & 3 & 1 & 0 & 0 & 0 \\
\hline $25 \cdot 50$ & 7 & 1 & 0 & 3 & 1 & 0 & 0 & 0 \\
\hline $50-100$ & 5 & $t$ & 0 & 2 & 0 & 0 & 0 & 0 \\
\hline $100-150$ & 4 & $t$ & 0 & ] & 0 & 0 & 0 & 0 \\
\hline $150 \cdot \mathbf{2 0 0}$ & 3 & 1 & 0 & $t$ & 0 & 0 & 0 & 0 \\
\hline $200-350$ & 5 & 1 & 0 & 2 & 1 & 0 & 0 & 0 \\
\hline $350-500$ & 9 & 2 & 0 & 3 & 1 & 0 & 0 & 0 \\
\hline \multirow{2}{*}{$\begin{array}{l}\text { Distance } \\
\text { lnterval } \\
\text { (miles) }\end{array}$} & \multicolumn{4}{|c|}{$\stackrel{c}{\text { Thyroid Nodules }}$} & \multicolumn{4}{|c|}{$\begin{array}{c}\text { D } \\
\text { Hypothymoidism }\end{array}$} \\
\hline & RSUR-1 & RSUR-2 & RSUR-3 & RSUR-4 & RSUR-1 & RSUR-2 & RSUR-3 & RSUR-4 \\
\hline$<5$ & 9 & 4 & 0 & 4 & 1 & 0 & 0 & 0 \\
\hline $5 \cdot 10$ & 18 & 5 & 0 & 7 & 1 & 0 & 0 & $\mathbf{0}$ \\
\hline $10-25$ & 27 & 6 & 0 & 11 & 1 & 0 & 0 & 0 \\
\hline $25 \cdot 50$ & 23 & 5 & o & 9 & 0 & 0 & 0 & 0 \\
\hline $50-100$ & 15 & 3 & 0 & 6 & 0 & 0 & 0 & 0 \\
\hline $100 \cdot 150$ & 11 & 2 & 0 & 4 & 0 & 0 & 0 & 0 \\
\hline $150-200$ & 9 & 2 & 0 & 3 & 0 & 0 & 0 & 0 \\
\hline $200-350$ & 16 & 3 & 0 & 6 & 0 & 0 & 0 & 0 \\
\hline $350-500$ & 23 & 5 & 0 & 8 & 0 & 0 & 0 & 0 \\
\hline
\end{tabular}

The administration of KI is assumed to reduce the thyroid dose from inhalaxion of radioiodides with a $99 \%$ efficiency. 
Table 4-20. Residual Thyroid Effects for Fetal Exposure Under Normal Activity and Maternal Administration of $\mathrm{KI}^{*}$

\begin{tabular}{|c|c|c|c|c|c|c|c|c|}
\hline \multirow{2}{*}{$\begin{array}{l}\text { Distance } \\
\text { Interval } \\
\text { (miles) }\end{array}$} & \multicolumn{4}{|c|}{$\stackrel{\text { A }}{\text { Tocat Thyroid Cancers }}$} & \multicolumn{4}{|c|}{$\begin{array}{c}\text { B } \\
\text { Falat Thyroid Cancers }\end{array}$} \\
\hline & RSUR-1 & RSUR-2 & RSURR-3 & RSUR-4 & RSUR-1 & RSUR-2 & RSUR-3 & RSUR-4 \\
\hline$<5$ & 1 & 0 & 0 & 0 & 0 & 0 & 0 & 0 \\
\hline $5=10$ & 1 & 1 & 0 & 1 & 0 & 0 & 0 & 0 \\
\hline $10-25$ & 2 & 1 & 0 & 1 & 0 & 0 & 0 & 0 \\
\hline $25-50$ & 2 & 1 & 0 & 1 & 0 & 0 & 0 & 0 \\
\hline $50-100$ & 1 & 0 & 0 & 1 & 0 & 0 & 0 & 0 \\
\hline $100-150$ & 1 & 0 & 0 & 0 & 0 & 0 & 0 & 0 \\
\hline $150-200$ & 1 & 0 & 0 & 0 & 0 & 0 & 0 & 0 \\
\hline $200-350$ & 2 & \pm & 0 & 1 & 0 & 0 & 0 & 0 \\
\hline $350-500$ & 2 & I & 0 & ] & 0 & 0 & 0 & 0 \\
\hline \multirow{2}{*}{$\begin{array}{l}\text { Distance } \\
\text { Interval } \\
\text { (miles) }\end{array}$} & \multicolumn{4}{|c|}{$\stackrel{c}{\text { Thyroid Nodules }}$} & \multicolumn{4}{|c|}{$\frac{\text { D }}{\text { Hypothyroidiss }}$} \\
\hline & RSUR-I & RSUR-2 & RSUR-3 & RSUR-4 & RSUR-1 & RSUR-2 & RSUR-3 & RSUR -4 \\
\hline$<5$ & 3 & 2 & 0 & 1 & 0 & 0 & 0 & 0 \\
\hline $5 \cdot 10$ & 5 & 2 & 0 & 2 & 0 & 0 & 0 & 0 \\
\hline $10-25$ & 8 & 3 & 0 & 3 & 0 & 0 & 0 & 0 \\
\hline $25 \cdot 50$ & 7 & 3 & 0 & 3 & 0 & 0 & 0 & 0 \\
\hline $50-100$ & 5 & 2 & 0 & 2 & 0 & 0 & 0 & 0 \\
\hline $100-150$ & 4 & 1 & 0 & 2 & 0 & 0 & 0 & 0 \\
\hline $150-200$ & 3 & 1 & 0 & 1 & 0 & 0 & 0 & 0 \\
\hline $200-350$ & 6 & 2 & 0 & 2 & 0 & 0 & 0 & 0 \\
\hline $350-500$ & 9 & 3 & 0 & 4 & 0 & 0 & 0 & 0 \\
\hline
\end{tabular}

The administration of $\mathrm{Kl}$ is assumed to reduce the thyroid dose from inhalation or radiolodides witb $99 \%$ efficiency. 
Tahle 421. Avoidable Thyroid Effects for Fetuses with KI Prophylaxis

\begin{tabular}{|c|c|c|c|c|c|c|c|c|}
\hline \multirow{2}{*}{$\begin{array}{c}\text { Distance } \\
\text { Intervsd } \\
\text { (miles) }\end{array}$} & \multicolumn{4}{|c|}{ A } & \multicolumn{4}{|c|}{$\begin{array}{c}\text { B } \\
\text { Fatal Thyroid Cancers }\end{array}$} \\
\hline & RSUR-1 & RSUR-2 & RSUR-3 & RSUR-4 & RSUR-1 & RSUR-2 & RSUR-3 & RSUR-4 \\
\hline$<5$ & 2 & 1 & 0 & 1 & 0 & 0 & 0 & 0 \\
\hline $5-10$ & 4 & I & 0 & 2 & 0 & 0 & 0 & 0 \\
\hline $10-25$ & 7 & 1 & 0 & 2 & 1 & 0 & 0 & 0 \\
\hline $25-50$ & 5 & 1 & 0 & 2 & 1 & 0 & 0 & 0 \\
\hline $50-100$ & 3 & 0 & 0 & 1 & 0 & 0 & 0 & 0 \\
\hline $100-150$ & 3 & 0 & 0 & 1 & 0 & 0 & 0 & 0 \\
\hline $150-200$ & 2 & 0 & 0 & 1 & 0 & 0 & 0 & 0 \\
\hline $200-350$ & 4 & 0 & 0 & 1 & 0 & 0 & 0 & 0 \\
\hline $350-500$ & 6 & 1 & 0 & 2 & 1 & 0 & 0 & 0 \\
\hline \multirow{2}{*}{$\begin{array}{l}\text { Distance } \\
\text { Interval } \\
\text { (miles) }\end{array}$} & \multicolumn{4}{|c|}{ Thyroid Nodules } & \multicolumn{4}{|c|}{$\begin{array}{c}\text { D } \\
\text { Hypothyroidism } \\
\end{array}$} \\
\hline & RSUR-1 & RSUR-2 & RSUR-3 & RSUR-4 & RSUR-1 & RSUR-2 & RSUR-3 & RSUR-4 \\
\hline$<5$ & 6 & 2 & 0 & 2 & 1 & 0 & 0 & 0 \\
\hline $5-10$ & 13 & 2 & 0 & 5 & 1 & 0 & 0 & 0 \\
\hline $10 \cdot 25$ & 19 & 3 & 0 & 7 & 1 & 0 & 0 & 0 \\
\hline $25 \cdot 50$ & 15 & 2 & 0 & 6 & 0 & 0 & 0 & 0 \\
\hline $50-100$ & 10 & 1 & 0 & 4 & 0 & 0 & 0 & 0 \\
\hline $100-150$ & 7 & $\mathbf{l}$ & 0 & 3 & 0 & 0 & 0 & 0 \\
\hline $150-200$ & 6 & 1 & 0 & 2 & 0 & 0 & 0 & 0 \\
\hline $200-350$ & 10 & 1 & 0 & 3 & 0 & 0 & 0 & 0 \\
\hline $350-500$ & 54 & 2 & 0 & 5 & 0 & 0 & 0 & 0 \\
\hline
\end{tabular}




\section{CHAPTER 5}

\section{THE ECONOMIC COSTS AND BENEFITS OF KI PROPHYLAXIS}

As a rule, whenever radiation exposure can be reduced by a specific measure, its endorsement by policy-makers is linked to a cost-benefit ratio in which the benefit is perceived to be equal to or greater than the economic impact of the protective measure. A common problem encountered in defining a cost-benefit ratio is the quantification of the major elements that constitute either the cast or the benefit. When the elements are expressed in their normal units, a highy subjective approach is required at the final stage of decision-making. Conversely, an objective and defensible decision is supported by a cost-benefit analysis in which all parameters are expressed in dimensionally-equivatent terms.

The quantification of cost for making KI available can be obtained by the conventional method of assigning monetary values to materials, labor, and other needed resources. The assignment of monetary values to thyroid health effects is less standardized and of considerable complexity. Appendix D of this report provides a detailed description of the methodology used to establish monetary values for (1) the programmatic cost of providing $\mathrm{Kl}$ and (2) the reduction in thyroid health effects. In this section, only a limited summary is provided which identifies the principal cost elements and their assigned monetary values.

\subsection{The Economic Cost of KI Prophylaxis}

Critical to a discussion of cost is the method by which $\mathrm{KI}$ is made available to the general public. The two principal options include stockpiling and predistribution, and any policy decision must address not only the econonic aspects but also logistical factors imposed by either option. Logistical considerations are governed by (1) the potentially shor time interval between the initiating evepts of a serious reactor accident and atmospheric releases of radioiodines and (2) the need to administer KI prior to plume exposure for optimum thyroid protection. The timeliness of $\mathrm{KI}$ availability is most critical to persons living in close proximity to a nuclear facility where potential plume exposures are maximal and plume travel times are small.

In spite of the perceived advantage of timeliness for the predistribution option, there are limitations as well as disadvantages, which include the following:

- Accessibility - KI predistributed to households (and ascumedly stored at the residence) may not be readily available during times when residents are at work, school, etc.

- Availability - At any point in time, there are transients as well as new residents to whom KI may not have been provided. 
- Loss or misplacement - Based on a five-year shelf-life/replacement period, there is a significant probability that tablets will be lost or misplaced during this lengthy time interval.

- Improper storage - Improper storage may adverseiy affect its shelf-life and potency at time of administration.

- Misuse and accidental administration - Like any pharmacentical kept by a household, there is a potential for misuse and/or accidental administration with prolonged possession by the general public.

- Improper disposal - For expired tablets, there is a loss of control for proper disposal.

\subsubsection{Cost of Stockpiling}

Most of the disadvantages associated with predistribution are either eliminated or minimized for the stockpiling option. A program can be developed under the direction of a State's emergency management staff that provides for the necessary controls and oversight of stockpiles. Thus, the benefits include proper storage, controlled access to stockpiles, assurance of adequate replacement and proper disposal of expired capsules.

With a properly trained emergency staff and an informed public, potential problems associated with a timely distribution of $\mathrm{KI}$ can be minimized. Timely distribution requires an adequate number of strategically located stockpiles within the community. Suitable locations would include police stations, fire houses, schools, community centers, hospitals and major health care centers, from which an efficient localized dooz-to-door distribution could be conducted or where residents themselves cotld procure the needed $\mathrm{KI}$.

Beyond logistical and practical issues, costs must be considered a major factor in a policy decision which selects stockpiling, predistribution, or a combiration of these two options.

A unique aspect of the stockpile option is that it is essentially transparent to the public and the cost of distribution to residents only becomes a reality in the unlikely event of a major nuclear emergency. Thus, for the stockpile option, the principal cost is the initial purchase of KI and its periodic replacement from the two FDA approved sources: Carter Wallace and ANBEX.

- Carter-Wallace - At the current purchase price of $\$ 75.00 /$ carton containing 100 vials with 14 tablets of $130 \mathrm{mg} \mathrm{KI}$ per vial, the cost per tablet is about five cents. With a suggested five-year shelf-life (i.e., replacement period) and a ten-day supply (i.e., ten tablets/indjvidual), the annual cost of KI prophylaxis per individual is about ten cents for the stockpiling option. 
- $\quad$ ANBEX - The initial cost for 14 scored tablets of $130 \mathrm{mg} \mathrm{KI}$ in a moisture resistant blister pack is 60 cents per pack with a guaranteed four-year shelf-life. Thereafter, annual payments of 15 cents per package would be required if, and only if, the stockpiled product can pass required FDA tests for stability and effectiveness. The annual stockpiling cost of KI procuted from ANBEX would also be about ten cents per individual.

Additional costs might include the amendment of existing emergency plans to include protocols for distribution, public notification and training of the emergency staff. These one-time costs, however, are likely to be modest and may only marginally add to the baseline purchase/replacement cost of $\mathrm{KI}$ at ten cents per year per individual.

\subsubsection{Cost of Predistribution}

For predistribution, the cost of dispensing $\mathbf{K} \amalg$ tablets to residents is an integral part of the program cost. Additionally, for a predistribution program to be effective, there has to be a very comprehensive public relations program that not only informs the public of the objectives of iodide prophylaxis and provides supportive information regarding safe storage, proper usage, dosage, contraindications, etc., but also establishes public confidence. In summary, the cost for predistribution of $\mathrm{KI}$ includes the purchase/replacement of $\mathrm{KI}$, the predistribution of tablets, and a comprehensive public information program.

An assessment of cost for the predistribution option can be derived from the Tennessee pilot program in which State officials predistributed $\mathrm{KI}$ to residents within a 5-mile radius of the TVA's Sequoyah Nuclear Power Plant (see Appendix E of this report). It is estimated that the cost of predistribution of KI to 3704 households around the Sequoyah Nuclear Power Plant was accomplished at $\$ 125,000.00$. Conservatively assuming that within the five-year replacement time there is no loss of $\mathrm{KI}$ or relocation of households and that the average household represents four individuals, a lower bound cost per individual for the predistribution option is estimated at $\$ 1.70$ per year.

The cost estimates for providing KI to specific population segments of the Reference LWR are presented in Table 5-1 for stockpiling with and without predistribution to the less than five-mile resident population. 
Table 5-1. Annual Programmatic Costs of KI Prophylaxis

\begin{tabular}{|c|c|c|c|c|c|}
\hline \multirow[b]{3}{*}{$\begin{array}{l}\text { Distance } \\
\text { (miles) }\end{array}$} & \multirow[b]{3}{*}{$\begin{array}{l}\text { Number of } \\
\text { Individuats }\end{array}$} & \multicolumn{4}{|c|}{ Distribution Opxions } \\
\hline & & \multicolumn{2}{|c|}{ Stockpile } & \multicolumn{2}{|c|}{ Combination" } \\
\hline & & $\begin{array}{c}\text { segment cost } \\
\text { (x } \$ 1,000)\end{array}$ & $\begin{array}{l}\text { cumulative cost } \\
(x \$ 1, \infty 00)\end{array}$ & $\begin{array}{c}\text { segment cost } \\
(\mathrm{x} \$ 1,000)\end{array}$ & $\begin{array}{c}\text { cumulative cost } \\
(\mathrm{x} \$ 1,000)\end{array}$ \\
\hline$<5$ & 10,591 & 1.1 & 1.1 & 18.2 & 18.2 \\
\hline $5 \cdot 10$ & 55,142 & 5.5 & 6.6 & 5.5 & 23.7 \\
\hline $10 \cdot 25$ & 468,472 & 46.8 & $\$ 3.4$ & 46.8 & 70.5 \\
\hline $25-50$ & $1,820,396$ & 182 & 235.4 & 182 & 252 \\
\hline $50-100$ & $4,713,000$ & 471 & 706.4 & 471 & 723 \\
\hline $100-150$ & $7,855,000$ & 786 & 1,492 & 786 & 1,509 \\
\hline $150-200$ & $10,997,000$ & 1,100 & 2,592 & 1,100 & 2,609 \\
\hline $200-350$ & $51,843,000$ & 5,184 & 7,776 & 5,184 & 7.793 \\
\hline $350-500$ & $80,121,000$ & 8,012 & 15.788 & 8,012 & 15,805 \\
\hline
\end{tabular}

- includes predistribution for the less than five-míte resideat popalation.

\subsection{The Economic Benefits of $\mathbf{K I}$ Prophylaxis: The Cost-of-Illness Approach}

The "benefits" of protective measures commonly employed to safeguard public health, frequentiy involve the avoidance of disease, injury, or death. For such cost-benefit analyses, the monetary equivalence of human illness and disease must be assessed for the patient, family, and society. The burden of illness may include financial losses, pain and suffering, reduced quality of life, and premature mortality. At a minimum, the economic benefits must consider the cost of resources used for medical care and the loss of human resources due to morbidity, disability, and premature death. Additional consideration may be given to the impact of disease, injury. or death on the quality of life for the affected individual and family members.

The "cost-of-illness" approach was pioneered by Dorothy Rice, former Director of the National Center for Health Statistics (Rice 1985), and is frequently used to assess the economic burden of disease. In brief, this metholology is defined by three components which include: direct medical costs; morbidity/mortality costs; and psychological costs.

Direct costs include resources used for medical care from the time of diagnosis until total recovery or death. Morbidity and mortality costs, when combined, are referred to as indirect costs (Hodgson 1984). Indirect costs are the time and oetput lost or foregone by the individual and/or family members from employment (including inputed earnings for domestic work), 
volunteer activities, and leisure. Lastly, morbidity and mortality invariably cause patients and family members to incur psychological costs, such as pain and suffering, impaired function in personal relationships, and a general reduction in the quality of life.

\subsubsection{Derivation of Direct Costs}

Direct cost estimates of radiation-induced thyroid illness include medical costs associated with the initial diagnosis, treatment of the disease, and the long-term management, surveillance, and care of the patient. Estimates of costs for relevant diagnostic procedures, treatments, hospitalization, etc. in this report are based on 1991 Government and private insurers' rembursement schedules defined by Physicians' Current Procedural Terminology (CPT) Codes. CPT is a listing of descriptive terms and identifying codes for reporting medical services and procedures performed by physicians under Govermment and private health insurance programs. Additional information was obtained from the Health Care Financing Administration Division (HCFA) of the U.S. Department of Health and Human Services.

- Thyroid Nodules. Benign nodules may or may not require surgery. For either instance, costs inclute the initial diagnosis, treatrnent, and long-term follow-up. For long-term follow-up of potential patients resulting from an accidental exposure, an average residual jife-expectancy of 30 years is assumed following the initial diagnosis of a nodule. Estimates of costs for long-term patient management and surveillance include routine office visits, hormone replacement therapy, and diagnostic procedures. For a benign thyroid nodule that does not require surgery, a lifetime medical cost of $\$ 5,148$ to $\$ 7,375$ was identified. When surgery is required, direct medical costs for a benign nodule range between $\$ 11,820$ and $\$ 14,047$. For either situation, the upper value reflects the discretionary use of ultrasound for patient evaluation. For a detailed analysis of these and subsequent cost estimates, the reader is referred to Appendix D of this report.

- Thyroid Cancer. The major cost difference between a thyroid cancer and a thyroid nodule is the need for aggressive treatment of the former. Medical costs for a thyroid malignancy are estimated at $\$ 15,413$ to $\$ 19,348$. This range in cost estimates may, nevertheless, be low in instances where residual thyroid tissue is suspected of malignancy following an initial course of treatment. In cases of persistent suspected malignancy, additional I-131 therapies and associated procedures and services are repuired. It is estimated that each adlitional I-131 therapy would increase the total cost by about $\$ 4,000$. In rare instances, up to ten separate therapeutic treatments may be required for the total eradication of malignancy. 
For the ten percent of thyroid malignancies that are fatal, cost estimates are adjusted to reflect (1) the reduced follow-up period of medical care and (2) the terminal patient care costs. Based on mean survival times of papillary and follicular thyroid cancers, the mean follow-up period of 35 years assumed for non-fatal cancer is reduced to 9.4 years. It is estimated that the average terminal care of a cancer patient costs about $\$ 16,000$.

Given the options that are available for the treatment and management of thyroid malignancies and the multiple therapeutic treatments, the following direct costs will be assigned to thyroid cancer:

$$
\begin{aligned}
\text { Non-fatal Thyroid Malignancy } & =\$ 20,000 \\
\text { Fatal Thyroid Malignancy } & =\$ 32,000
\end{aligned}
$$

- Hypothyrojidism. Medical cost in casts of radjation incuced hypothyroidism are limited to initial diagnostic tests, which confirm the reduction or loss of thyroid function, homone replacement and management, and follow-up evaluation of thyroid status. Cost estimates are based on a 35-year life-expectancy following the diagnosis and loss of thyroid function. For hypothyroidism medical costs are estimated at $\$ 5,669$.

Table 5-2 summarizes direct medical cost estimates for the radiation thyroid effects under consideration.

Table 5-2. Summary of Direct Medical Costs

\begin{tabular}{lc}
\hline Thyroid Disorder & $\begin{array}{c}\text { Total Direct } \\
\text { Cost }(\$)\end{array}$ \\
\hline Thyroid Nodule* & 9,600 \\
Thyrotid Cancer & \\
- Non-fatal & 20,000 \\
- Fatal & 32,000 \\
Hypothyrotdista & 5,600 \\
\hline
\end{tabular}

- assumes that 50\% of nodules require surgery 


\subsubsection{Derivation of Indirect Costs}

Indirect costs principally reflect the time and output lost or forfeited by the patient due to illness, permanent disability, and premature mortality. Indirect costs may also be incurred by individuals other than the patient who may forego economic activities to acconumodate a family member's ilfness. Economic activities include occupational work that is lost to either the patient or his/her employer, as well as non-occupational (e.g., domestic) work that must be performed by someone else at the expense of the patient. For illness, the loss of time from economic opportunities corresponds to three discrete stages:

(1) Illness - The period during which the thyroid dysfunction becomes sufficiently symptomatic and prompts the indjvidual to seek medical evaltation and treatment. During this time, the patient may physically suffer from either hyper- or hyposecretion by the thyroid gland.

(2) Treatment - Thyroidectomy and therapeutic administration of I-131 reçuire hospitalization and convalescence; radioiodine therapy also requires that a patient be first rendered hypothyroid.

(3) Long-Term Management - Following treatment, the patient, in most instances, is subject to a lifetime dependency on daily doses of thyroxine and must be periodically monitored for proper dosage. The patient must also be monitored for the recurrence of nodule/cancer. Patient management and surveillance requite periodic office visits and clinical evaluation. It is estimated that office visits and outpatient clinical evaluation, on the average, represents a loss of one day per year for the residual portion of the patient's life.

Table 5-3 provides estimates of the average total number of days lost from economic activities for the various thyroid disorders.

The number of days appropriated to long-term management of the disorder is based on the average remaining years of life following diagnosis and latency periods previously identifjed. A special case involves a thyroid malignancy, which may result in premature death.

The indirect cost of ermanent impaiment. In addition to time lost from economic activity due to iJIness, a patient may also be permanently impaired and/or disabled. Permanent impairment or disability can reduce a patient's ability to be fully effective in occupational or economic activities and must, therefore, be included in assessing the total indirect cost. 
Table 5-3. Time Lost From Economic Activities Due to Radiation Induced Thyrold Illness

\begin{tabular}{|c|c|c|c|c|}
\hline \multirow[b]{2}{*}{ Thyroid Disorder } & \multicolumn{4}{|c|}{ Time Lost (Days) } \\
\hline & Illness & $\begin{array}{l}\text { Diagnosist } \\
\text { Treatment }\end{array}$ & $\begin{array}{c}\text { Long-Term } \\
\text { Managemem }\end{array}$ & Totel \\
\hline Thyroid Nodule & 14 & 14 & 30 & 58 \\
\hline $\begin{array}{l}\text { Thyroid Cancer } \\
\text { - Non-Fatal } \\
\text { - Fatal }\end{array}$ & $\begin{array}{l}14 \\
14\end{array}$ & $\begin{array}{l}14 \\
14\end{array}$ & $\begin{array}{c}35 \\
10.731^{\circ}\end{array}$ & $\begin{array}{c}63 \\
=10,750\end{array}$ \\
\hline Hypothyroidism & 14 & 7 & 35 & 56 \\
\hline
\end{tabular}

- For a fatal malignancy, this value representes lass of life-expectancy, which is escimared an 29.3 years.

The American Medical Association has published Guides to the Evaluation of Permanent Impaiment (AMA 1990). These Guides provide a reference framework within which physicians may evaluate and report medical impairments. Various terms used in the Guides, such as "impairment" and "disability" appear in laws, regulations, and policies of diverse origin and without consistent definition. The Gujdes define these terms as follows:

- Inpairment - an alteration of an individual's health status that is assessed by medical means.

- Disability - an alteration of an individual's capacity to meet personal, social, or occupational demands. Disability is assessed by non-medical means.

On the basis of these definitions, the econornic inpact of thyroid disorders on indirect costs is most objectively assessed in terms of their permanent medical impairments. The AMA provides guidelines for evaluating permanent medical impairment of the thyroid tue to hypothyroidism from radiation exposure or thyroidectomy as follows (AMA 1990):

Class 1 - A patient belongs in Class 1 when: (a) continuous thyroid therapy is required for correction of the thyroid insufficiency or for maintenance of normal thyroid activity, and (b) there is ro objective physical or laboratory evidence of inadequate repjacement therapy.

Class 1 Level of Impairment of the Whole Person: $0-10 \%$ 
Class 2 - A patient belongs in Class 2 when: (a) symptoms and signs of thyroid disease are present, or there is anatomic loss or alteration, and (b) continuous thyroid hormone replacement therapy is required for correction of the confirmed thyroid insufficiency; but (c) the presence of a disease process in another body system or systems permits only partial replacement of the thyroid hormone.

Class 2 Level of Impairment of the Whole Person: $15-20 \%$

In this report, the central value of five percent for Class 1 permanent impairment will be applied to the permanent hypothyroid conditions that are likely to result from (1) high radiation exposure doses recejved accidentally, (2) from the radiotherapy treatment for toxic nodules/cancer, or (3) the surgical removal of nodules/cancer. It will further be assumed that this five percent medical impaiment results in a five percent disability for occupational and non-occupational economic activities for the affected individual, family members, and/or society.

The conversion of time lost from economic activities to equivalent dollars is most fairly achieved by means of the Gross National Product (GNP). The GNP is considered the most comprehensive measure of the country's economic activity and includes the market value of all goods and services that have been bought for final use during a year. From the Gross National Product of $\$ 5,200$ billion in 1989 , the gross average annual per capita income of about $\$ 21,000$ is derived. This value of $\$ 21,000$ per year can be used to determine the equivalent dollar value for the number of days lost over the lifetime of an individual afflicted with a thyroid condition. This value can also be applied to determine the equivalent value of a five percent permanent disability (i.e., a five percent disability equates to about $\$ 1,000$ annually in reduced income). Table 5-4 provides estimates of the total average indirect costs associated with thyroid disorders.

Table 5-4. Average Lifetime Indirect Costs Assoctated with Thyroid Disorders

\begin{tabular}{lccc}
\hline & \multicolumn{3}{c}{ Lifetime lidirect Costs (\$) } \\
\cline { 2 - 4 } Thyroid Disorder & For Time Last & For Disability (\%,5) & Total \\
\hline Thyrotd Nodule & 3,337 & 30,000 & 33,337 \\
$\begin{array}{l}\text { Thyroid Cancer } \\
\text { Non-Fatal }\end{array}$ & 3,625 & 35,000 & 38,625 \\
$\quad$ Fatal & 619,586 & 9,400 & 628,986 \\
Hypothyroidism & 3,222 & 35,060 & 38,222 \\
\hline
\end{tabular}

\subsubsection{Derivation of Psychological Costs}

Disease may cause mumerous changes and impositions in the lives of the patient and family members that may in part be linked to, but are not reflected in. the direct and indirect economic 
costs identified above. The wide variety of deteriorations in the quality of life (QOL) brought on by jllness are frequently referred to as psychological costs. For thyroid neoplasms and dysfunction, a deterioration in the quality of life may be precipitated by the loss of badily function, a lifetime dependence on medication, hormonal instability, disfigurement from surgical scars, the uncertrinty of normal life expectancy, and reduced financial security. In characterizing psychological costs associated with disease, Thomas Hodgson (Hodgson 1985), chief Economist for the Department of Health and Human Services' Office of Analysis and Epidemiology states:

"Disease may bring about personal catastrophes ... to the victims of illness,... children, spouses, and siblings of victims, friends and co-workers of victims; and those who render care may all be affected. A victim may suffer a loss of a body part or speech, disfigurement, disability, impending death, pain, and grief. He and those atound him, may be forced into economic dependence and social isolation, unwanted job changes, loss of opportunities for promotion and education, relocation of living quarters, and other undesired changes in life plans. The envirotument created by illness often induces anxiety, reduced self-esteem and feeling of well-being, resentment, and emotional problems that often require psychotherapy. Problems of living may develop, leading to family conflict, antisocial behavior, and suicide. The victim and others may experience marked personality changes and reduced sexual function. Disrupted development and delinquency may occur among children. The quality of life may be reduced beyond restorative capability of current rehabilitation efforts. The combination of financial strain and psychological problems can be especially devastating."

Due to the fact that quality of life issues have only recently become the subject of formal investigations among health care professionals, QOL data is both sparse and lacks standardization. In July 1990, the National Institutes of Health (NIH) conducted a workshop on the quality of life assessment in cancer clinical trials (NCI 1990). Among the major objectives of the meeting were to define discrete guality of life elements and to identify currently available instruments (i.e., methods) for QOL assessment. The workshop group consisting of international experts concluded that (1) the quality of life of patients is affected by both the disease and by the treatment of the disease and (2) the quality of life is a multi-dimensional concept which must be evaluated by a set of instruments (i.e., methods) that measures both broad issues and disease/treatinent specific phenomena.

Although QOL measurements that specifically deal with thyroid cancer and/or thyroid dysfunction are not currently documented, the titeranure, nevertheless, identifies age, gender, marital status, educational level, religious beliefs, employment, and economic status, and the number of chiddren living at home as generic variables that affect changes in the quality of life imposed by a given disease.

Vahuation of Psychological Costs. In spite of the fact that psychological costs are consistently identified as a major cost component by health care researchers and economists, no formal 
attempt has been made to quantify these costs in monetary terms (Hodgson 1984; Rice 1985; Brown 1990). The reason for this omission is obvious. From the foregoing discussion, it is safe to conclude that the intangible dimensions which define the quality of life are (1) highly subjective, (2) vary greatly among individuals, and in time and space, and (3) are not readily expressed in monetary terms. Independent of these difficulties, past instances of excjuding psychological costs may have been justified for conditions in which the health effect is of unknown origin, self-inflicted or unavoidable.

The omission of psychological costs, however, is not readily justifited for situations in which the health effect is clearly avoidable, or is the conseguence of negligence or wrongful action of a second party. In litigation cases of wrongful injury or death, monetary compensation for psychological cost factors generally exceed those involving medical costs or loss of earnings. The thyroid health effects under consideration in this report must clearly be considered avoidable through the administration of $\mathrm{KI}$. Additionally, accidental public exposure to radioiodine is likely to be viewed as the direct or indirect consequence of buman negligence or wrongful actions. A complete cost-benefit analysis of $\mathrm{KI}$ prophylaxis must, therefore, include estimates of psychological costs expressed in the unit of dollars.

Based on the monetary awards for the radiation and non-radiation injury claims cited in Appendix $D$, and the opinion expressed by a subject matter expert, the psychological cost component for each radiation-induced thyroid health effect is estimated at $\$ 500,000$ and will be applied to the derivation of cost-benefit ratios for KI prophylaxis.

\subsection{Summation of Thyroid Health Effects Cost}

Table 5-5 summarizes previously derived values for the direct medical costs, the indirect cost of lost economic opportunities, and the psychological costs attributed to the reduced quality of life for each of the thyroid disorders considered in this report. For all three thyroid effects, the direct medical cost for diagnosis, treatment, and follow-up represents the smallest contribution to the total cost. The assigned common value of $\$ 500,000$ for psychological costs dominates the total cost of potential thyroid effects'.

1 Although the indirect cost of $\$ 629,000$ for a fatal thyroid cancer is considerably larger, the low frequency of fatal cancers among thyroid effects $(<3.5 \%)$ mitigates its impact on the average indirect cost of thyroid disorders. 
Table 5-5. Average Total Cost Per Radiation-Induced Thyroid Effect

\begin{tabular}{|c|c|c|c|c|}
\hline Thyrotd Effect & $\begin{array}{l}\text { Direct } \\
(\$)\end{array}$ & $\begin{array}{c}\text { Indireer } \\
(5)\end{array}$ & $\begin{array}{c}\text { Psychological } \\
(\$)\end{array}$ & $\begin{array}{c}\text { Total } \\
(\$)\end{array}$ \\
\hline Nodule & $9,600^{\circ}$ & 33,300 & 500,000 & 542,900 \\
\hline \multicolumn{5}{|l|}{ Cancer } \\
\hline Non-fatal & 20,000 & 38,600 & 500,000 & 558,600 \\
\hline Fatail & 32,000 & 629,000 & 500,000 & $1,161,000$ \\
\hline Нуротhyroistism & 5,600 & 38,200 & 500,000 & $\$ 43,800$ \\
\hline
\end{tabular}

- Value represents the midpoint of the range in direct medical cost estimates.

In Utero Cost Estimates. Fetal exposture in utero may also result in thyroid nodules, thyroid cancer, or congenital hypothyroidism. The resultant cost elements are similar to those involving the general population, but are somewhat higher in value, which reflects the reduced age at time of first diagnosis. Affected by this shift in time are costs associated with fong-term medical care and surveillance, and indirect costs of lost economic oppornmities. When in utero exposure results in thyroid disorders, the costs are based on the following ages of initial diagnosis:

- hypothyroidism: at time of birth

- thyroid nadule: at age ten

- thyroid cancer: at age five

- for fatal thyroid cancer, the time of death is assumed to occur at age 14.4

The cost of thyroid effects which are the result of in utero exposure is summarized in Table 5-6.

Table 5-6. Cost Estimates of Thyroid Effects for In Utero Exposure

\begin{tabular}{|c|c|c|c|c|}
\hline $\begin{array}{l}\text { In Utero Thyroid } \\
\text { Effect }\end{array}$ & $\begin{array}{l}\text { Direct } \\
(\$)\end{array}$ & $\begin{array}{l}\text { Indirect } \\
(\$)\end{array}$ & $\begin{array}{c}\text { Psychological } \\
\text { (\$) }\end{array}$ & $\begin{array}{c}\text { Towal } \\
(\$)\end{array}$ \\
\hline Nadule & 17,000 & 53,000 & 500,000 & 570,000 \\
\hline $\begin{array}{l}\text { Cancer } \\
\text { Non-fata] } \\
\text { Faral }\end{array}$ & $\begin{array}{l}24,000 \\
32,000\end{array}$ & $\begin{array}{c}56,000 \\
\mathrm{~N} / \mathrm{A}\end{array}$ & $\begin{array}{l}500,000 \\
500,000\end{array}$ & $\begin{array}{l}580,000 \\
532,000\end{array}$ \\
\hline Hypothyrojeism & 11,000 & 79,000 & 500,000 & 590,000 \\
\hline
\end{tabular}




\subsection{An Evaluation of the Derived Cost Estimates}

The appropriateness of monetary values for thyroid dystunction and neoplasms derived in this report may be assessed by comparing these vahues to those that have previously been published by the NRC and other Federal agencies. For example, as part of a study performed by Sandia National Laboratories to estimate the financial consequences of reactor accident health effects (NUREG/CR-2723), cost estimates were determined for on-site emergency workers for five severe accident categories. Health effect "costs" to emergency utility workers were converted to dollar-equivalents using the following conversion; (1) $\$ 1$ million per early fatality, and (2) $\$ 100,000$ per early injury or latent cancer. These 1983 cost estimates, when adjusted to the current medical costs and market value of the dollar, yield cost estimates that are very comparable to those defined in this report. It may furthet the argued that cost estimates derived in this report are subject to an adjustment factor, which accounts for the difference in the involuntary non-occupational exposure of a member of the general public and the "voluntary" exposure conditions of the utility emergency worker. As a rule, it is approptiate to assign a higher compensation value in instances of involuntary participation.

In a recent analysis of radiation risks to the public from residential radon exposure, the EPA evaluated the cost-effectiveness of radon testing and mitigation at various levels (EPA 1992). Results of this cost-effectiveness andlysis show that at the EPA's recommended action level of $4 \mathrm{pCi} /$, the cost per lung cancer death averted is about $\$ 700,000$. At this action level, the EPA concluded that ". . . the Radon Program would be as or more cost-effective than many other government programs for personal safety and environmental protection."

The cost-effectiveness of several other Federal programs was recentiy assessed in a report issued by the Office of Management and Budget (OMB 1991). The range of cost per life saved for three program areas are cited in Table 5-7.

Table 5-7. Ranges in Publicly Implied Valuations of Federal Programs*

\begin{tabular}{lc}
\hline Federal Program Area & Range of Cost Per L.jfe Saved (7991 \$\$s) \\
\hline Highway Safety & $63,000 \cdot 3,300,000$ \\
Air Transportation Safety & $100,000-1,600,000$ \\
Oecupational Safery & $100,000-74,000,000$ \\
\hline
\end{tabular}

- Reference: OMB 1991

In summary, values cited in Tables 5-5 and 5-6 foll within the range of existing NRC guidelines used in impact analyses as well as those recently published by the EPA. 


\section{CHAPTER 6}

\section{THE COST-BENEFIT RATIO OF KI PROPHYLAXIS}

A cost-benefit ratio for $\mathrm{KI}$ is represented by a dimensionless quotient derived by dividing the programmatic cost of KI stockpiling by the monetary equivalent value of avoided thyroid effects. In Chapter 5 of this report, the programmatic cost of KI prophylaxis for the stockpiling option was assumed to be principally determined by the purchase cost of $\mathrm{KI}$ and its periodic replacement.

KI tabiets, currently available from two FDA-licensed firms, continue to be evaluated by the FDA for residual potency. At this time, a minimum shelf life of five years can be assumed for KI under proper storage conditions. At the current retail price and a five-year replacement schedule, the programmatic cost of stockpiling KI was estimated at about $\$ 0.10$ per person per year. Multiplying the number of persons within each population cell by $\$ 0.10$ yields the annual programmatic cost estimates for discrete distance intervals shown in Table 6-1.

Table 6-1. Annual Programmatic Costs of KI Prophylaxis

\begin{tabular}{|c|c|c|c|}
\hline \multirow[b]{2}{*}{$\begin{array}{l}\text { Distance } \\
\text { (miles) }\end{array}$} & \multirow[b]{2}{*}{$\begin{array}{l}\text { Number of } \\
\text { individuals }\end{array}$} & \multicolumn{2}{|c|}{ Stockpile Option } \\
\hline & & $\begin{array}{l}\text { segment } \cos t \\
(x 51000)\end{array}$ & $\begin{array}{c}\text { cumulative coss } \\
(x \$ 1000)\end{array}$ \\
\hline$<5$ & 10,699 & 1.1 & 1.1 \\
\hline $5-10$ & 55,142 & 5.5 & 6.6 \\
\hline $10-25$ & 468,472 & 46.8 & 53.4 \\
\hline $25-50$ & $1,820,396$ & 182 & 235.4 \\
\hline $50-100$ & $4,713,000$ & 471 & 706.4 \\
\hline $100-150$ & $7,855,000$ & 786 & 1492 \\
\hline $150-200$ & $10,997,000$ & 1100 & 2592 \\
\hline $200-350$ & $51,843,000$ & 5184 & 7776 \\
\hline $350-500$ & $80,121,000$ & 8012 & 15,788 \\
\hline
\end{tabular}

Deriving a monetary equivalence for the thyroid health effects potentially avoided when $\mathbf{K I}$ blocks thyroidal uptake of radioiodides with a $99 \%$ efficiency was considerably more complex. Chapter 4 identified four specific accident scenarios with the potential to release large quantities of radioiodides into the atmosphere. By means of the MACCS computer code, atmospheric releases of radioiodides were modeled to yield integrated air concentrations at fixed distances and then converted to thyroid doses using age- and sex-specific ventilation rates and dose conversion factors. 
Also, in Chapter 4, thyroid doses to individuals in the plume pathway were converted to thyroid health effects by means of risk coefficients. Numbers of thyroid health effects were estimated for the general population and fetuses for discrete population cells defined by distance intervals.

In Chapter 5 (and Appendix D), the monetary equivalence for each thyroid health effect was derived. Estimates of cost equivalence included lifetime medical costs, loss of economic opportunity and psychological costs attributable to pain and suffering, reduction in quality of life, etc.

Multiplying the expected number of avoidable thyroid effects in each population cell (Chapter 4, Tables 4-18 and 4-21) with their economic worth (Chapter 5, Tables 5-5 and 5-6) yielded the economic benefits of avoidable thyroid health effects associated with each of the four reactor accident scenarios.

A cost-benefit ratio in which the programmatic costs are expressed in annual terms, however, reçuires that the economic benefits of avoided thyroid health effects also be expressed in annual terms. The monetary equivalence of avoided bealth effects resulting from each accident scenario can be expressed in annual terms by incorporating a factor that defines the probability that a given reactor accident scenario may occur in a year's time. Best estimates of accident frequencies for the four release categories analyzed were previously defined in Table $\mathbf{4 - 2}$ and are reproduced in Table 6-2.

Table 6-2. Reactor Accident Frequencies

\begin{tabular}{cc}
\hline Release Category & Prequency $\left(\right.$ year $\left.^{-1}\right)$ \\
\hline RSUR-1 & $2.9 \mathrm{E}-7$ \\
RSUR-2 & $2.4 \mathrm{E}-6$ \\
RSUR-3 & $3.3 \mathrm{E}-5$ \\
RSUR-4 & $1.6 \mathrm{E}-6$ \\
\hline
\end{tabular}

The multiplicative values of (1) the mumber of expected thyroid health effects, (2) their monetary equivalence, and (3) the accident frequency for each accident scenario provide an estimate of the yearly economic benefits of KI prophylaxis. Table 6-3 provides a breakdown of the average annual economic benefits. For the population cell defined by the zeto to five mile radius, for example, a yearly economic benefit of $\$ 487$ is estimated. To ensure that the reader understands the method employed to derive this value, a sample calculation is provided for the zero to five mile population cell. 
Table 6-3. Yearly Reduction in Population Thyroid Effects and Their Equivalent Monetary Valives

\begin{tabular}{|c|c|c|c|c|c|c|c|c|c|}
\hline \multirow{2}{*}{$\begin{array}{l}\text { Distance Interval } \\
\text { (miles) }\end{array}$} & \multicolumn{2}{|c|}{$\begin{array}{l}\text { Non-Fatal Thyroid } \\
\text { Cancers }\end{array}$} & \multicolumn{2}{|c|}{ Fatal Thyroid Cancers } & \multicolumn{2}{|c|}{ Thyroid Nodules } & \multicolumn{2}{|c|}{ Hypothyroidism } & \multirow{2}{*}{$\begin{array}{l}\text { Total } \\
\text { \$-Vatue }\end{array}$} \\
\hline & $\mathrm{No}_{+}$of Cases & Valne (\$) & No. of Cases & Value (5) & No. of Cases & Value (\$) & No. of Cases & Value (\$) & \\
\hline 0.5 & $1.84 \mathrm{E}-4$ & 103 & $2.05 \mathrm{E}-5$ & 24 & $5.18 E-4$ & 281 & $1.46 \mathrm{E}-4$ & 79 & 487 \\
\hline $5 \cdot 10$ & $2.83 \mathrm{E}-4$ & 148 & $3.14 E-5$ & 36 & $7.95 \mathrm{E}-4$ & 432 & $1.54 \mathrm{E}-4$ & 84 & 710 \\
\hline $10-25$ & $4.00 \mathrm{E}-4$ & 223 & 4.44E-5 & 52 & $1.12 E-3$ & 608 & $7.78 \mathrm{BE}-5$ & 42 & 925 \\
\hline $25 \cdot 50$ & $3.20 \mathrm{E}-4$ & 179 & $3.55 \mathrm{E}-5$ & 41 & $8.89 \mathrm{E}-4$ & 483 & $3.32 \mathrm{E}-6$ & 2 & 705 \\
\hline $50-100$ & $2.06 \mathrm{E}-4$ & 115 & $2.29 \mathrm{E}-5$ & 27 & $5.63 \mathrm{E}-4$ & 306 & $0.00 E+>$ & 0 & 448 \\
\hline $100-150$ & $1.54 \mathrm{E}-4$ & 86 & $1.71 \mathrm{E}-5$ & 20 & $4,13 E-4$ & 224 & $0.00 \mathrm{E}+0$ & 0 & 330 \\
\hline $150-200$ & $1.21 \mathrm{E}-4$ & 68 & $1.34 \mathrm{E}-5$ & 16 & $3.18 \mathrm{E}-4$ & 173 & $0.00 \mathrm{E}+0$ & 0 & 257 \\
\hline $200-350$ & $2.30 \mathrm{E}-4$ & $12 B$ & $2.55 E-5$ & 30 & $5.80 \mathrm{E}-4$ & 315 & $0.00 \mathrm{E}+0$ & 0 & 473 \\
\hline $350-500$ & 4.0SE-4 & 226 & $4.50 \mathrm{E}-5$ & 52 & $8.94 \mathrm{E}-4$ & 485 & $0.00 \mathrm{E}+0$ & 0 & 763 \\
\hline
\end{tabular}




\section{Table 6-3. Yearly Reduction in Population Thyroid Effects and Their Equivalent Monetary Values (Continued)}

SAMPLE CALCULATION: Derivation of the Yearly Reduction in Population Thyroid Effects and Their Equivalent Monetary Values for the O to 5-Mile Population Cell

1. From Table 4-18. the total number of ayoidable thyroid health effects per accident release caregory for the 0-5 mile popplation is as foilows:

\begin{tabular}{|c|c|c|c|c|}
\hline $\begin{array}{l}\text { Reicasse } \\
\text { Category }\end{array}$ & $\begin{array}{l}\text { Non-fatal } \\
\text { Cancer Cancer }\end{array}$ & $\begin{array}{l}\text { Fatal } \\
\text { Nodules }\end{array}$ & Hypothyroid & \\
\hline RSUR-1 & 107 & 12 & 303 & 99 \\
\hline RSUR-2 & 37 & 4 & 103 & 28 \\
\hline RSUR-3 & 0 & 0 & 0 & 0 \\
\hline RSUR-4 & 40 & 4 & 114 & 32 \\
\hline
\end{tabular}

2. Annual reduction in avoidable thyroid health effect $=$ (No. of expected effects) $\times$ (Accident frequency):

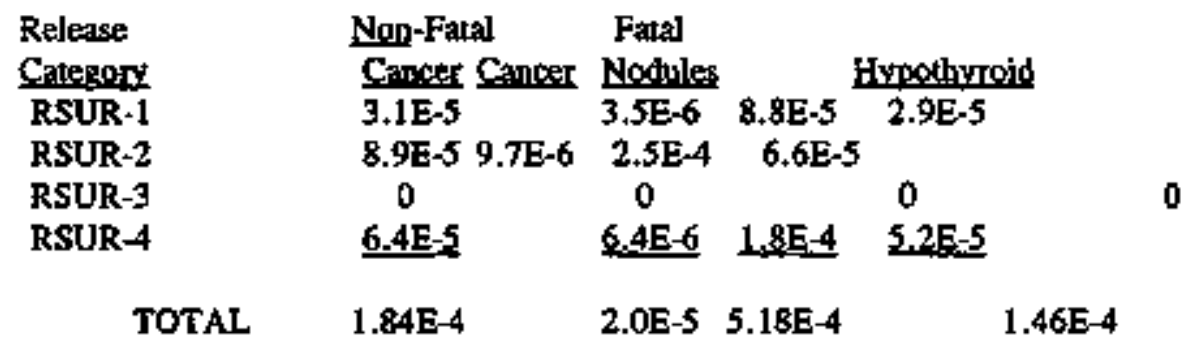

The total yalues of 1.84E-4 non-fatal cancers, 2.05E-5 fatal cancers, 5.18E-4 nodvles, and 1.46E-4 hypothyroid conditions are given in Table 6-3 for the 0-5 mile population cell.

3. Annual equivalent cost estimates $=$ (No. of thyroid effects) $\times$ (equivalent monetary cost)

- Non-fatal thyroid cager: (1.84E-4 cancers) $\times(\$ 558,600 /$ ancer $)=\$ 103$

- Fatal thyroid cancer: (2.05E-5 cancers) $\times(\$ 1,161,000 /$ cancer $) \quad=\$ 24$

- Thyroid Nodule: (5.18E-4 nodules) x (\$542,900/nodule) $\quad=\$ 281$

- Hypothyroidism: (1.46E-4 hypottyroids) x (\$543,800/bypotbyroid) $\equiv \$ 79$

TOTAL $=\$ 487$

Total yearly economic benefit for the 1-5 population cell $=\$ 242$ 
Using the identical approach, yearly economic benefits of avoided thyroid effects were determined for fetuses exposed in utero. These values are defined in Table 6-4. Fetal values, when added to those of the general population, yield the total economic benefit for each population cell.

Dividing the annual programmatic cost of stockpiling $\mathrm{KI}$ by the average anmual economic benefits from avoided thyroid effects (i.e., population and fetal) represents the cost-benefit ratio of KI prophylaxis. These two parameters and their quotient are presented in Table 6.5. For example, the anmual programmatic cost of stockpiling KI for about 11,000 people living within five miles of the reference $L W R$ is estimated at $\$ 0.10$ per person or $\$ 1,100$. The economic benefits of avoided thyroid effects for this population cell were estimated at $\$ 495$ per year, which gives a cost-benefit ratio of 2.22 .

The cost-benefit ratio in effect is a measure of the cost-effectiveness of the prophylactic measure. For the zero to five mile population cell, it can be estimated that $\$ 2.22$ would be spent in order to avoid the economic equivalent cast of $\$ 1.00$.

The cost-benefit ratios for population cells increase nearly exponentially with distance. This is to be expected inasmuch as the programmatic cost of ten cents per person per year is a constant while the integrated air concentration, which defines individual thyroid dose, can be expected to drop off exponentially with distance. Thus, the cost-benefit ratio for the $50-100$ mile population cell is reduced to 1,033 . Within this distance interval $\$ 1,033.00$ would be spent for stockpiling to avoid the economic equivalent of \$1.00.

Table 6-5 also provides cumulative cost-benefit ratios, which define the cumulative areas of the circle. If, for example, on the basis of thyroid intervention levels, cost-benefit consideration, logistical factors, etc., a decision was made to provide stockpiles for populations out to a distance of 100 miles, the cumulative cost-benefit ratio of 212 can be estimated. The limitations and the significance of these cost-benefit ratios with regard to a policy decision are discussed in the next chapter. 
Table 6-4. Yearly Reduction in Fetal Thyrofd Effects and Their Equivalent Monetary Values

\begin{tabular}{|c|c|c|c|c|c|c|c|c|c|}
\hline \multirow{2}{*}{$\begin{array}{l}\text { Distance } \\
\text { Interval } \\
\text { (míles) }\end{array}$} & \multicolumn{2}{|c|}{$\begin{array}{c}\text { Non-Fatal Thyroid } \\
\text { Cancers }\end{array}$} & \multicolumn{2}{|c|}{ Faal Thyroid Cancers } & \multicolumn{2}{|c|}{ Thyroid Nodules } & \multicolumn{2}{|c|}{ Hypothyroidism } & \multirow{2}{*}{$\begin{array}{c}\text { Total Value } \\
(\mathbf{\Phi )}\end{array}$} \\
\hline & $\begin{array}{l}\text { No. of } \\
\text { Cases }\end{array}$ & $\begin{array}{c}\text { Value } \\
(\$)\end{array}$ & $\begin{array}{c}\text { No. of } \\
\text { Cases }\end{array}$ & $\begin{array}{c}\text { Yalue } \\
(\$)\end{array}$ & $\begin{array}{l}\text { No. of } \\
\text { Cases }\end{array}$ & $\begin{array}{c}\text { Vajue } \\
(\$)\end{array}$ & $\begin{array}{l}\text { No. of } \\
\text { Cases }\end{array}$ & $\begin{array}{l}\text { Value } \\
\text { (\$) }\end{array}$ & \\
\hline 0.5 & $4.12 \mathrm{E}-6$ & 2.40 & $0.00 \mathrm{E}+0$ & 0 & $9.74 \mathrm{E}-6$ & 5.50 & $2.90 \mathrm{E}-7$ & 0.20 & 8.10 \\
\hline $5-10$ & $6.08 \mathrm{E}-6$ & 3.50 & $0.00 E+0$ & 0 & $1.66 \mathrm{E}-5$ & 9.50 & $2.90 \mathrm{E}-7$ & 0.20 & 13.20 \\
\hline $10-25$ & 6.87E-6 & 4.00 & $7.63 \mathrm{E}-7$ & 0.40 & $1.38 \mathrm{E}-3$ & 8.00 & $2.90 \mathrm{E}-7$ & 0.20 & 12.60 \\
\hline $25 \cdot 50$ & $6.35 \mathrm{E}-6$ & 3.70 & $7.05 \mathrm{E}-7$ & 0.40 & $1.87 \mathrm{E}-5$ & 10.70 & $0.00 E+0$ & 0 & 14.80 \\
\hline $50-100$ & $2.22 \mathrm{E}-6$ & 1.30 & $0.00 \mathrm{E}+0$ & 0 & $1.17 \mathrm{E}-5$ & 6.70 & $0.00 \mathrm{E}+0$ & 0 & 8.00 \\
\hline $100-150$ & $2.82 \mathrm{E}-6$ & 1.60 & $0.00 E+0$ & 0 & $9.23 \mathrm{E}-6$ & 5.30 & $0.00 \mathrm{E}+0$ & .0 & 6.90 \\
\hline $150-200$ & $1.96 \mathrm{E}-6$ & 1.10 & $0.00 E+0$ & 0 & $7.34 \mathrm{E}-6$ & 4.20 & $0.00 \mathrm{E}+0$ & 0 & 5.30 \\
\hline $200-350$ & $2.48 \mathrm{E}-6$ & $t .40$ & $0.00 \mathrm{E} \neq 0$ & 0 & 1.01E-5 & 5.30 & $0.00 E+0$ & 0 & 7.20 \\
\hline $350-500$ & $6.0 ! E-6$ & 3.50 & $7.34 \mathrm{E}-7$ & 0.40 & $1.69 \mathrm{E}-5$ & 9.60 & $0.00 \mathrm{E}+0$ & 0 & 13.50 \\
\hline
\end{tabular}


Table 6-5. The Cast-Benefit Ratio of KI Prophylaxis

\begin{tabular}{|c|c|c|c|c|c|c|}
\hline \multirow{2}{*}{$\begin{array}{l}\text { Distance } \\
\text { Iruerval } \\
\text { (Eurles) }\end{array}$} & \multicolumn{2}{|c|}{ KJ Cost: Stockpiling } & \multicolumn{2}{|c|}{$\begin{array}{l}\text { KI Benefits: Reduced } \\
\text { Thyroid Bffects }\end{array}$} & \multicolumn{2}{|c|}{ Cost/Benefn Ratio } \\
\hline & $\begin{array}{c}\text { Per Distarce } \\
\text { Interval } \\
\text { (\$/yr) }\end{array}$ & $\begin{array}{l}\text { Cumulative } \\
\text { (\$/yr) }\end{array}$ & $\begin{array}{c}\text { Per Distance } \\
\text { Itterva] } \\
\text { (S/yr) }\end{array}$ & $\begin{array}{c}\text { Cumulative } \\
\text { (S/yr) }\end{array}$ & $\begin{array}{c}\text { Per } \\
\text { Distance } \\
\text { liternal }\end{array}$ & Cumulative \\
\hline$<s$ & 1100 & 1100 & 495 & 495 & 2.22 & 2.22 \\
\hline $5 \cdot 10$ & 5500 & 6600 & 723 & 1218 & 7.61 & $\$ .42$ \\
\hline $10-25$ & 46,800 & 53,400 & 938 & 2156 & 49.9 & 24.8 \\
\hline $25-50$ & 182,000 & 235,400 & 720 & 2876 & 253 & 81.8 \\
\hline $50-100$ & 471,000 & 706,400 & 456 & 3332 & 1033 & 212 \\
\hline $100-150$ & 786,000 & $1,492,400$ & 337 & 3669 & 2332 & 407 \\
\hline $150-200$ & $1,100,000$ & $2,592,400$ & 262 & $393 \mathrm{t}$ & $4 j 99$ & 659 \\
\hline $200-350$ & $5,184,000$ & $7,776.400$ & 480 & 4411 & 10,800 & 1763 \\
\hline $350-500$ & $8,012,000$ & $15,788,400$ & 777 & 5188 & 10,311 & 3043 \\
\hline
\end{tabular}




\section{CHAPTER 7}

\section{THE APPLICABILITY OF KI COST-BENEFIT RATIOS TO A POLICY DECISION}

In Chapter 6, cost-benefit ratios were derived which conveniently expressed the ratio of programmatic costs and the avoidance of thyroid effects in the common unit of dollars. It would appear that an assessment of these cost-benefit ratios could lead directly to a defensible policy decision. In other words, a ratio value of one or less in which the programmatic cost of stockpiling $\mathrm{KI}$ was equal to or less than the equivalent cost of thyroid effects avoided, should logically provide the basis for a policy decision to use KI. Conversely, cost-benefit ratios of values that are significantly greater than one could justify a policy decision to reject the use of KI.

The unencumbered and direct application of the derived cost-benefit ratios for $\mathrm{KI}$ in a policy decision can in fact be justified only under the following two conditions:

Condition \#1: The derived cost-benefit atio values are absolute. Absolute values imply that all parameter values used to derive the cost-benefit ratio are $100 \%$ representative of the universe and, therefore, have an uncertainty value of zero.

Condition \#2: The prophylactic use of $\mathrm{KI}$ is applied independently of existing protective measures.

For reasons explained in the following sections, these two conditions do not exist. A valid policy decision must weigh the potential impact of model uncertainties and the prophylactic use of $\mathrm{KI}$ in the context of other protective measures.

\subsection{Condition \#1: Uncertainties and Their Impact on Cost-Benefit Ratios}

Primary assumptions and model parameters, which must be defined for reactor accident conseguence antajysis in this report, are numerous and potentially have a wide range of uncertainties. While the uncertainty value for some assumptions/parameters may have little impact on the final cost-benefit ratios, other parameter uncertainties could potentially shift the cost-benefit ratio by as much as one to two orders of magnitude.

A highly quantitative treatment of uncertainties and their collective impact on the derived costbenefit ratios is beyond the scope of this report. This chapter will identify the most important model parameters and assumptions used and will assess their relative effects on the derived costbenefit ratios. 


\subsubsection{Reactor Accident Frequencies}

By far, the single most significant parameter for accident consequence analysis is the probability of reactor accident occurrence. The probability values of the reactor accident frequencies used in this report were derived in NUREG-1150 (1987). Appendix A of NUREG-1150 discusses in detail the risk andysis steps and the interrelationships among steps. Using Monte Carlo techniques, frequency distributions of individual parameters were combined to yield frequency distributions of accident sequences, plant damage conditions, and total core damage. Although bounding values of the frequency distribution were "described, " they were not quantified in NUREG-1150 (see Exhibit 8-1; this figure is reproduced as it appears in NUREG-1150, Appendix A, page A-21).

In 1978, NRC chartered a risk assessment review group to evaluate the 1975 Reactor Safety Study (NUREG-75/014, also known as WASH 1400), which defined similar accident frequencies. This review committee consluded in NUREG/CR-0400:

". . We are unable to determine whether the absolute probabilities of accident sequences in WASH-1400 are high or low, but we believe that the error bounds on those estimates are, in general, greatly understated."

In a separate assessment, the authors of NUREG-1433 evaluated the probability of different types of reactor accidents. The following bounding estimates of core melt accidents were provided:

" . . the probability of core melt is less than $1.5 \times 10^{3}$ with 50 percent confidence, and less than $6.7 \times 10^{-3}$ with 95 percent confidence . . . These upper bound probabilities are approximateiy factors of 25 and 100 times the RSS values above $\left(4.6 \times 10^{-5}+1.4 \times 10^{-5}=6.0 \times 10^{-5}\right)$."

Applying a similar range of uncertainty to accident frequencies derived in NUREG-1150 would profoundly affect the cost-benefit ratio valtues defined in Chapter 6. Assuming that reactor accident frequencies are potentially 100 times higher than assumed in this report, the cost-benefit ratios defined in Chapter 6, Table 6-5, could be reduced by two orders of magnitude. A reduction of the cost-benefit ratios by 100 would yield a cost-benefit ratio of about 1.0 out to a radial distance of nearly 50 miles (i.e., the cumulative cost-benefit ratio out to 50 miles is 81.8 and, when divided by 100 , yields a $95 \%$ bounding ratio value of 0.818 ).

In summary, the values of reactor accident frequencies used in this report must be regarded as the single most significant uncertainty affecting the cost-benefit ratio cited in Table 6-5. 
Exhibit 7-1

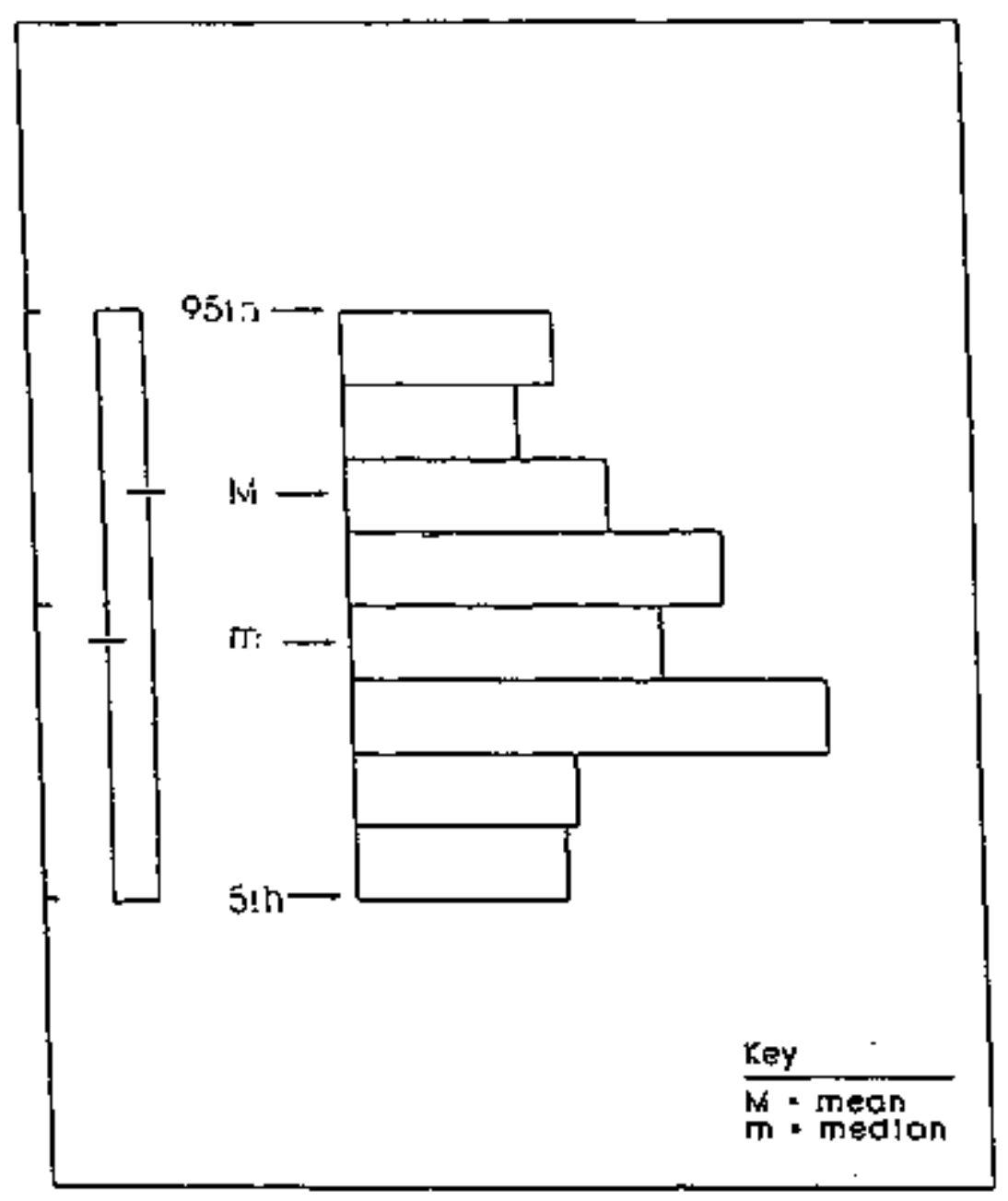

Figure A.6 Exmplt disploy of corc damage frequency discribuiton.

MUREG-1130 


\subsubsection{Core Inventory and Rélease Fraction}

Time-weighted variations in core inventory of radioiodines during power operations are relatively minor and, therefore, may be ignored. The physico-chemical nature of iodide/iodine is relatively well understood. Under severe accident conditions of core melt, techniques used to retain iodine in the primary coolant (which were used during the TMI accident) may not be possible. It can, therefore, be assumed that the release fraction applied to radiojodines in this report is appropriate and exhibits a low emor band.

\subsubsection{Atmospheric Dispersion and Meteorological Factors}

The MACCS computer code, like all other codes used for risk or consequence analysis, has associated uncertainties with regard to modeling plume dispersion in the environment. Limitations of the code that result in these uncertainties involve the absence of site-specific data such as topography. Other limitations involve assumptions such as the wind blows in a continuous straight line for extended periods of time, or assumptions about the meteorological conditions applied to the long-range transit of a released plume. For example, a single weather file is assumed to apply at all times and at all places of the plume pathway. Thus, if a site weather file assumes rain at the site, the code assumes that it rains everywhere at that time. Although such assumptions are commonly made to solve complicated differential equations for atmospheric dispersion models, they introduce uncertainties in the dispersion of radioactivity. Uncertainties in dispersion modeling have two major effects:

(1) For population risk analyses, the inpact of uncertainties regarding the atmospheric dispersion of radioactivity is relatively minor. Meteorological parameters have a profound effect on individual doses but only a limited impact on cumulative population doses. For example, a very stable condition producing a very narrow plume results in high air concentrations and high individual doses. In contrast, a very unstable condition disperses radiosctivity resulting in a larger number of exposed incividuals with lower individual doses. For extreme conditions of high and low stability, the cumulative population exposures and expected thyroid health effects may, nevertheless, be nearly identical. It is important to note that the cumulative population thyroid dose, which is relatively unaffected by dispersion, determines the denominator of the cost-benefit ratio.

(2) In contrast, uncertainties regarding atmospheric dispersion may have a profound effect on the numerator of the cost-benefit ratio. Table 6-5 clearly demonstrates that the costeffectiveness of $\mathrm{KI}$ prophylaxis deteriorates exponentially as a function of distance from the source term. Thus, a meteorological model, which maintains a straight-line plume over extended periods of time (i.e., the plume does not meander), projects unrealistically high centerline doses to populations at great distances.

The programmatic cost of stockpiling is principally determined by the size of the stockpile, which in uirn, is determined by the radial distance at which the plume centerline thyroid exposure dose exceeds a predetermined intervention level. From this 
relationship, it becomes readily apparent that a conservative computer dispersion model adversely affects the derived cost-benefit ratio and falsely implies a reduced costeffectiveness.

The MACCS code undoubtedly uses conservative assumptions that project unrealistically high plume centerline exposures.

\subsubsection{Age- and Sex-Specific Parameters and DCF Values}

Individuals vary considerably in their physiology, which affects the intemal exposure dose from the inhalation/ingestion of radionuclides. This report considers age- and sex- specific parameters, which have been well studied and reported in the literature, in converting timeintegrated air concentrations of radioiodide to thyroid doses. Nevertheless, the dose conversion values (DCFs) represent average values that vary symmetrically about their means. When applied to a large random population, however, dose variations among individuals for a given group defined by age and sex are likely to cancel out. It can, therefore, be assumed that uncertainties regarding individual variations in thyroid doses do not contribute significantly to an estimate of cumulative population thyroid doses and thyroid beath effects.

\subsubsection{Thyrofd Risk Coefficients}

The risk coefficients used in this report represent consensus values defined by the BEIR $V$ Committee and the NCRP. These scientific groups djd not provide estimates of uncertainty regarding their risk coefficients. Thyroid risk coefficients like all other risk coefficients are extrapolated from epidemiological data, which contain uncertainties and confounding variables. Based on historical trends in which risk coefficients for other radiation bealth effects have generally increased, it should not be assumed that the thyroid risk coefficients used in this report are conservatively high and overestimate the consequences of thyroid exposure to radioiodine.

\subsubsection{Uncertainties of Other Assumptions Used in Deriving Cost-Benefit Ratios}

The following is a partial list of major assumptions that affect the cost-benefit ratio either positively or negatively. A positive effect on the cost-benefit ratio by an assumption is defined as one that reduces the cost-benefit ratio. A reduction in cost-benefit ratio improves the costeffectiveness and supports the use of KI prophylaxis. A negative effect on the cost-benefit ratio by an assumption is defined as one that increases the cost-benefit ratio. An increase in costbenefit ratio reduces the cost-effectiveness and opposes the use of $\mathrm{KI}$ prophylaxis.

- Efficiency Factor. This report assumes that $\mathrm{KI}$ is administered to all irxividuats under optimal conditions. Thyroid exposures from internal radioiodides are assumed to be reduced with a $99 \%$ efficiency. This is a highly unrealistic assumption. The use of more realistic efficiency values (i.e., less than $99 \%$ ) would have a negative effect on the cost-benefit ratio that is inversely proportional to the reduction in efficiency. Thus, if an efficiency of about $50 \%$ had been 
used, the cost-benefit ratios would effectively increase by a factor of two, which also reduces the cost-effectiveness of KI prophylaxis by a factor of two.

Shelf-Life of KI. A conservative shelf-life of five years has been assumed, which in effect dictates the cost of stockpiling. An increase in shelf-life proportionately reduces the numerator of the cost-benefit quotient and has a positive effect. Thus, if the shelf-life could be increased to ten years, the cost-benefit ratio decreases by a factor of two and improves the cost-effectiveness by a factor of two.

- KI Stockpile Redundancy. No redundancy in stockpile quantities was assumed. This assumption is unrealistic. For efficient distribution, a stockpile is needed containing at least twice the quantity of $\mathrm{KJ}$ that would be distributed in the event of an accident. A more realistic redundancy of $100 \%$ has a negative effect by increasing the cost-benefit ratio by a factor of two.

- Sheltering. Population exposure is assumed to occur under conditions of nomal activity. If in fact KI were administered under conditions of sheltering, thyrojd dose reduction by KI would be lower (see Table 4-7). Under more realistic conditions of sheltering, the cost-benefit ratio is negatively affected.

- Population Distribution. The assumed population distribution for the Reference LWR has large standard deviations for each population cell. For actual nuclear facilities, the cost-effectiveness varies in proportion to differences in population distribution relative to the Reference LWR. For facilities having disproportionately larger percentages of their population closer to the source term, cumulative cost-benefit ratios are lower.

- Adverse Reaction to KI. Potential adverse reactions and an adverse reaction incidence rate were identified in this report (Chapter 2 and Appendix C). Due to their infrequensy and their uncertain monetary value, adverse reactions to $\mathrm{KI}$ were not factored into the cost-benefit ratio. The inclusion of adverse reactions to $\mathrm{KJ}$ in the cost-benefit ratio would have a minor but negative effect on the costbenefit ratio.

- Partial Predistribution. The derivation of cost-benefit ratios was confined to the stockpiling option only. The inclusion of $\mathrm{KI}$ predistribution to the proximal population would increase the programmatic cost of $\mathrm{KI}$ prophylaxis and have a negative effect.

- Multiple Plants per Site and Overlapping Populations. The cost-effectiveness of KI prophylaxis increases for facilities with more than one reactor per site or for facilities that are close to other facilities and share portions of the target populations. The assumption of a single reactor per site with no overlapping 
target population used to derive the cost-benefit ratio in this report has a negative effect. For nuclear facilities with as many as three reactors per site and emergency zones overlapping with other neighboring facilities, the coss-benefit ratios are improved by at least a factor of three.

\subsection{Condition \#2: The Relationship of KI Prophylaxis to Other Protective Measures}

In the event of a major accident involving a commercial nuclear power plant, a large-scale release of radioiodines would most likely occur along with a massive release of noble gases and varying quantities of other radionuclides. Thyroid and whole body exposures are, therefore, inextricably linked. Current protective action guidelines relating to population plume exposures are, therefore, defined by exposure limits to the whole body and the thyroid to doses of 1 to 5 rem and 5 to 25 rem, respectively.

Figure 7-1 depicts thyroid and whole body doses for the four accident categories considered in this report. Quantitative values of thyroid and whole body exposures for RSUR-1 are provided in Table $7-1$. The relative magnitude of thyroid to whole body exposures is defined as a catio in the right-hand colimn of the table.

To safeguard against primary plume exposure, current protective meastures are limited to sheltering or evacuation. Sheltering and evacuation are clearly not interchangeable, but represent a first and second priority for public protection. Sheltering woald most likely be recommended when expected doses span the lower limits of whole body and thyroid exposures. Projected doses in incremental excess of lower limits could be expected to change the recommendation from sheltering to evacuation. The relevance of $\mathrm{KI}$ prophylaxis to these two protective measures is simple: since KI cannot reduce extemal exposure and intemal exposure from nonradjoiodines, its usefuliness is restricted to the concurtent recommendation for sheltering. In combination, these two independent measures are complementary in reducing whole body exposure and thyroid exposure and are compatible in time and space. 

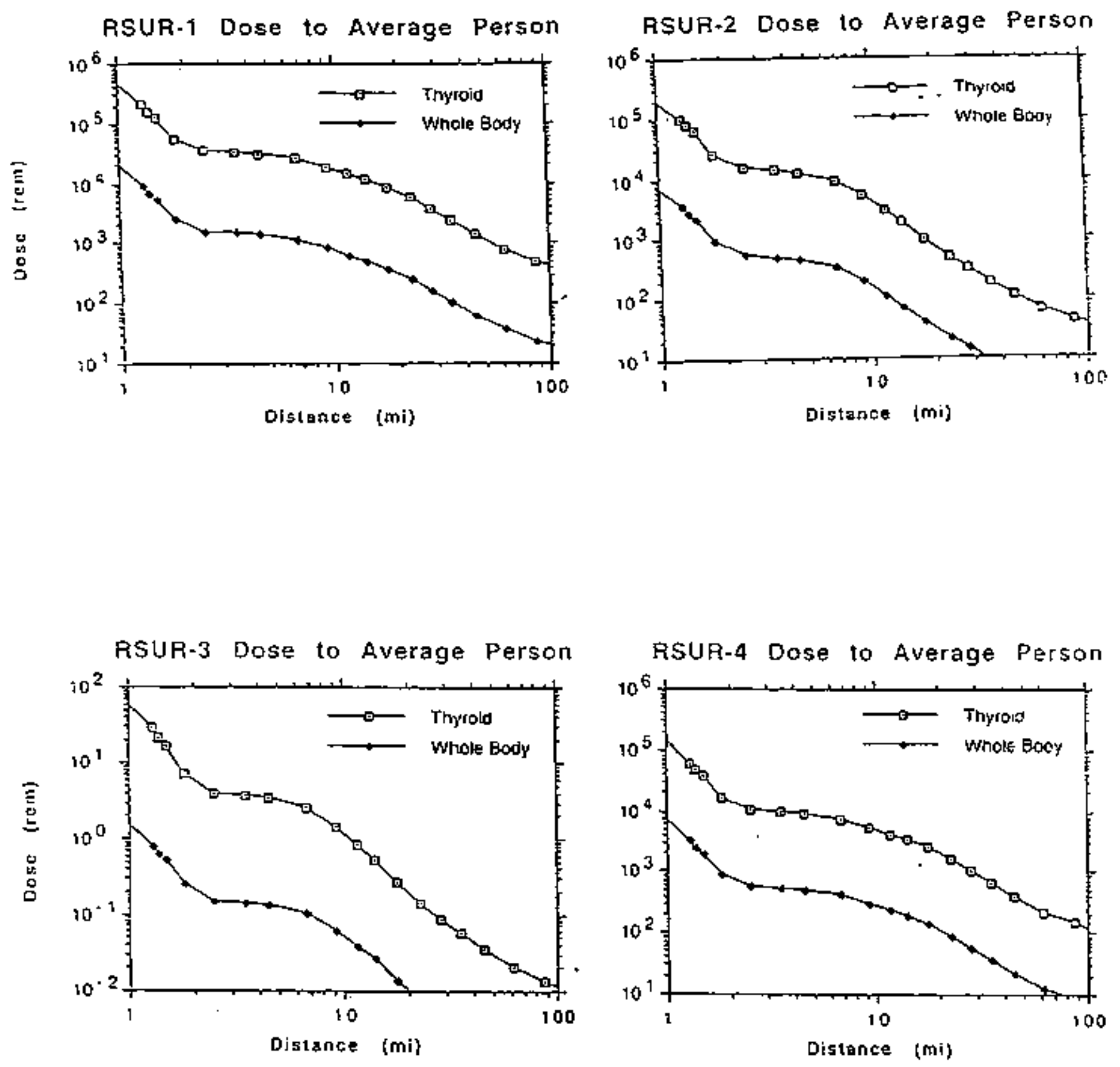

Figure 7-1. The Relationship of Thyroid to Whole Body Doses 
Table 7-1. The Relationship of Thyroid to Whole Body Exposure for RSUR-1

\begin{tabular}{|c|c|c|c|c|}
\hline \multirow[b]{2}{*}{$\begin{array}{l}\text { Distance } \\
\text { (niles) }\end{array}$} & \multicolumn{2}{|c|}{ Thyroid dose (rem) } & \multirow{2}{*}{$\begin{array}{c}\text { Whole Body } \\
\text { Dose } \\
\text { (rem) }\end{array}$} & \multirow{2}{*}{$\begin{array}{l}\text { Dose Ratio } \\
\text { (Thyroid/ } \\
\text { Whole Body) }\end{array}$} \\
\hline & Radioiodines & $\begin{array}{c}\text { Tatal } \\
\text { (All Pathways) }\end{array}$ & & \\
\hline $0-5$ & $1.9 E+04$ & $2,0 \mathrm{E}+04$ & $8.7 E+02$ & 23.0 \\
\hline $5-10$ & $6.9 \mathrm{E}+03$ & $7.3 \mathrm{E}+03$ & $3.2 \mathrm{E}+02$ & 22.8 \\
\hline $10-25$ & $1.7 \mathrm{E}+03$ & $1.9 \mathrm{E}+03$ & $7.9 \mathrm{E}+01$ & 24.0 \\
\hline $25-50$ & 2. $\mathrm{E}+02$ & $3.0 \mathrm{E}+02$ & $1.4 \mathrm{E}+01$ & 21.4 \\
\hline $50-100$ & $6.2 \mathrm{E}-01$ & $7.0 \mathrm{E}+01$ & $3.6 \mathrm{E}+00$ & 19.4 \\
\hline $100-150$ & $2.8 \mathrm{E}+01$ & $3.2 \mathrm{E}+01$ & $1,5 \mathrm{E}+\infty 0$ & 21.3 \\
\hline $150-200$ & $1.7 \mathrm{E}+01$ & $1.9 \mathrm{E} \div 0 \mathrm{I}$ & $9.6 \mathrm{E}-01$ & 19.8 \\
\hline $200-350$ & $7.8 \mathrm{E}+00$ & $8.5 \mathrm{E}+00$ & 4.3E-01 & 19.8 \\
\hline
\end{tabular}

In contrast, the prophylactic use of $\mathrm{KI}$ and the evacuation of residents must be regarded as mutually exclusive protective measures. The principal purpose of evacuation is to avoid primary plume exposure; KI prophylaxis is intended to mitigate its impact. More important is the potential conflict in time and space. Under conditions of evacuation, it would be counterproductive to request that residents either delay evacuation until $\mathrm{KI}$ is distributed door-todoor, or reroute and delay evacuation by first obtaining $\mathrm{KI}$ from a local distribution center.

The relationship of $\mathrm{KI}$ prophylaxis to existing protective measures and the need to assess the cost-benefit in context with these existing protective measures may best be illustrated by the following hypothetical example:

A major population center of 150,000 people resides in a downwind sector from the source term. Doses to this population center are projected to reach levels as high as 2.5 rem to the whole body and 50 rem to the thyroid. Sheltering is estimated to reduce these maximal doses to about $1 \mathrm{rem}$ and $20 \mathrm{rem}$, respectively. Based on the residual high thyroid dose, a recommendation is made for this group of residents to evacuate the area immediately.

In this scenario, it can be assumed that the prompt distribution of $\mathrm{KI}$ from local stockpiles could readily reduce thyroid exposures to less than the lower limit of five rem and in the process shift the recommended protective measure from evactation to sheltering.

The value of KI prophylaxis, therefore, has two discrete components: the first involves the reduction of thyroid health effects, as defined in the preceding chapter in terms of cost-benefit 
ratios; the second is the economic benefit of the potential shift from evacuation to sheltering for select target populations.

A thorough and quantitative treatment of this second economic benefit is complex and influenced by a host of modifiers. Critical modifiers that may influence a decision to shelter or evacuate include logistical problems affected by (1) the time interval before plume arrival, (2) the time of day, (3) the season of the year, (4) weather and road conditions, (5) plume direction(s) relative to evacuation routes, (6) the size of the exposed population, and (7) the ability to provide temporary shelter.

The literature contains limited information addressing logistical issues and comprehensive cost estimates associated with evacuation. A baseline cost estimate can be extracted from studies involving the Three Mile Island Accident. At the time of the TMI accident, it was estirnated that there were about 14,300 households within the $0-5$ mile radius, 40,000 between $5-10$ miles, and 72,000 in the 10-15 mile ring (Houts 1980). Although voluntary evacuation began almost immediately following the announcement of the emergency stans at TMI, the number of evacuees was initially minimal. Only 5 to $6 \%$ of the population within the $0-5$ mile radius evacuated within the first two days. On the third day, however, neariy $50 \%$ of the $0-5$ mile population had evacuated (Houts 1980). The increase was largely precipitated by the Governor of Pennsylvania's advisory on Friday, March 30, 1979, for voluntary evacuation of pregmant women and young children residing within five miles of the TMI facility. Over the two-week period, the percent of households that evacuated comesponded to $63 \%, 49 \%$, and $32 \%$, for the 0-5, 5-10, and 10-15 mile populations, respectively. In total, about 50,000 households, representing about 150,000 people, evacuated. Evacuation cosi estimates were divided into two categories: (1) direct cost outlays and (2) loss of eamed income. Direct cost outlays included the cost of travel, lodging, meals, and other incidental costs directly related to evacuation. Loss of earned income included either loss of wages or loss of business income for store owners. The median distance traveled by evacuees was 100 miles and the average household teft the area for about four to five days during the two-week period (Flynn 1979).

The NRC estimated that the cost of evacuation was $\$ 100$ per household for direct cost outlays and $\$ 100$ per evacuee whose income was affected. The total cost was estimated at around $\$ 20$ million (Flynn 1979). The reason that the costs were relatively low was that fully two-thirds of the evacuated households stayed with relatives, $15 \%$ stayed with friends, and only $8 \%$ elected to stay at a hotel/motel. The apparent low estimate for lost earnings was not explained.

A major factor not included in the baseline estimates of evacuation costs was the economic impact of psychological stress. Psychological stress was one of the most widely studied aspects of the Three Mile Island crisis (Houts 1980(a), Houts 1980(b), Hu 1980, Houts 1981(a), Houts 1981(b), Houts 1984). Between 20 and $30 \%$ of the TMI population reportedly suffered from heightened levels of distress. Psychological distress was most acute during the period of evacuation and, for a considerable number of individuals, persisted for up to a year. Stress symptoms consisted of somatic and behavioral changes. Common symptoms included headache, digestive and eating disorders, abdominal pain, sweating spells, memory loss, inpaired sleep. 
irritability, inability to work, etc. (Hu 1980, Houts 1984). Associated with these symptoms, investigators reported an increased consumption of cigarettes, alcohol, sleeping pills, and tranquilizers. Personal factors influencing psychological stress included proximity to TMI; age, sex, and education of the household decision-maker; and the presence of children.

Psychological distress protuces somatic and behavioral symptoms not too different from those of organic diseases. The economic value of psychological distress can be defined by the following three components:

- direct cost - medical casts incurred from the treatment of somatic and psychological symptoms

- indirect costs - loss of economic opportunity imposed by psychological distress

- psychological costs - a reduction in the quality of life precipitated by somatic or behavioral problems.

(This report's approach to assigning monetary values to these cost components is described in detail in Appendix D.)

No attempt was made to give monetary values to psychological distress and incorporate these values into the TMI economic impact analysis. Several studies, however, did assess the utilization of medical care following the Three Mile Island crisis (Hu 1980; Houts 1984). These studies assessed the utilization of medical care by means of: (1) Bhue Cross-Blue Shield records of claims by primary care physicians in the vicinity of TMI; (2) utilization rates in family practices located near the facility; (3) interviews with persons living within five miles of TMI; and (4) responses to a questionnaire by primary care physicians practicing within 25 miles of TMI. Although all four sudy methods showed increased trends in utilization rates during the year following the crisis, a reliable estimate of direct medical costs attributable to psychological stress could not be extracted from the data. 


\section{CHAPTER 8}

\section{CONCLUSION}

The principal purpose of this report was to provide a comprehensive analysis of the costs and benefits associated with the prophylactic use of KI by the general public in the event of a muclear accident. The most currently available data were used to define the prograrnmatic costs for stockpiling $\mathrm{KI}$ and the equivalent monetary values of thyrojo health effects that are potentially avoidable when KI is administered. Dividing the stockpiling costs of KI by the monetary values of thyroid health effects yielded cost-benefit ratios that provide a limited basis for a policy decision.

Although these cost-benefit ratios are as credible and objective as current data allow, caution must be exercised in using these values in a policy decision. Existing uncertainties in reactor accident frequencies and dispersion modeling could easily reduce the cost-benefit ratios derived in Chapter 6 by two orders of magnitude or more.

Additionally, the derived cost-benefit ratios do not represent a total assessment of the costeffectiveness of $\mathbf{K I}$ prophylaxis protective measures. The cost-effectiveness of KI prophylaxis must be assessed in the context of ofher protective measures. 


\section{APPENDIX A}

\section{SUMMARY FINDINGS OF THE CRCPD E-6 COMMITTEE'S SURVEY}

Stimulated by new information relating to the Chernobyl experience and by the urging of the American Thyroid Association (ATA), the Federal Radiological Preparedness Coordinating Committee (FRPCC) requested that the Conference of Radiation Control Program Directors (CRCPD) E-6 Committee conduct a survey to assess the emergency plans of individual States with regard to KI. States with commercial nuclear power plants or whose border(s) is within a ten-mile range of a nuclear facility were sent a survey questionnaire. A tacsimile of the questionnaire is provided in Addendum A-1. Specific information sought pertained to target populations and available quantities of $\mathrm{KI}$ for the ten-mile emergency protection zones (EPZ) for nuclear facilities.

A total of 32 States provided information regarding the use of $\mathrm{KI}$ for the ten-mile emergency planning plume exposure pathway zone(s). Data provided by States are summarized in Table A-1. Because the data were not consistent in format, some interpretation of the data was required for compilation. The following statements summarize the survey data:

- All States provide KI to off-site emergency workers.

- Of the 32 States, 21 have provisions to distribute KI to institutionalized persons within the ten-mile EPZ.

- Only three States have provisions to distribute KI to the general public residing in the ten-mile EPZ.

- Depending on anticipated size of the target population(s), which ranges from as few as 200 up to 50,000 persons, the size of KI stockpiles ranges from a few thousand tablets up to 700,000 tablets.

- Reflected in the size of target populations and stockpiles is the total number of EPZs in a State.

- The cumnlative stockpile for all 32 States is estimated to be between 2.5 and 3 million tablets.

Based on the information presented in this report, which indicates that a target population out to 100 miles or greater may be exposed to thyroid doses in excess of intervention level(s). the combined stockpiles of all States represent less than four percent of what might be reguired to protect the general public from thyroid exposure in the event of a nuclear emergency. 
Table A-1

Current KI Stockpiles Maintained by States

\begin{tabular}{|c|c|c|c|c|c|c|c|}
\hline \multirow[b]{2}{*}{ State } & \multicolumn{4}{|c|}{ Answer to Question $\sharp \Gamma^{2}$} & \multirow{2}{*}{$\begin{array}{l}\text { Total No. of } \\
\text { Tablets } \\
\text { Stockpiled }\end{array}$} & \multirow{2}{*}{$\begin{array}{l}\text { Estimated No. of } \\
\text { Persons Targeted } \\
\text { for Dissribution }\end{array}$} & \multirow{2}{*}{$\begin{array}{l}\text { Duration for KI } \\
\text { Prophylaxis } \\
\text { (Days) }\end{array}$} \\
\hline & $\bar{A}$ & $\mathbf{B}$ & $\mathrm{C}$ & $\mathrm{D}$ & & & \\
\hline $\mathrm{AL}$ & $\mathrm{X}$ & & $\mathbf{X}$ & & 35,000 & 9,000 & 4 \\
\hline $\mathrm{AR}$ & $\mathrm{x}$ & $\mathrm{x}$ & & & 28,000 & 4,000 & 7 \\
\hline $\mathbf{A Z}$ & $\mathrm{X}$ & & $\mathrm{X}$ & & 5,600 & 2,000 & 2 \\
\hline $\mathrm{CA}$ & $\bar{x}$ & $\bar{x}$ & & & $\mathrm{NI}^{\mathrm{P}}$ & $\mathrm{N}]^{\mathrm{b}}$ & 3 \\
\hline CT & $\mathbf{X}$ & & & & 14,000 & 1,000 & 14 \\
\hline $\mathrm{DE}$ & $\mathbf{x}$ & $\mathrm{x}$ & & & $\mathrm{NP}$ & $\mathrm{NI}^{\circ}$ & $\overline{N^{*}}$ \\
\hline FL & $\mathrm{x}$ & & & & 53,200 & 7,600 & 7 \\
\hline GA & $\mathbf{x}$ & & & & 8,400 & 600 & 14 \\
\hline lL & $\mathbf{x}$ & $\mathrm{x}$ & & & 196,000 & 14,000 & 14 \\
\hline JA & $x$ & $\dot{x}$ & & & 48,188 & 3,400 & 14 \\
\hline $\mathrm{KS}$ & $\bar{x}$ & $x$ & & & 5,600 & 800 & 7 \\
\hline LA & $\mathbf{X}$ & & & & $\mathrm{NI}^{b}$ & $N]^{b}$ & 10 \\
\hline ME & $\mathbf{x}$ & $\mathbf{x}$ & & & $\mathrm{N}]^{\mathrm{b}}$ & $\mathrm{N1} \mathbf{1}^{\mathrm{k}}$ & 14 \\
\hline $\mathrm{MD}$ & $X$ & $\mathrm{X}$ & & & 10,000 & 2,100 & $\mathrm{Nr}$ \\
\hline $\mathrm{MA}$ & $\mathbf{x}$ & $\mathrm{X}$ & & & 16,100 & 1,150 & 14 \\
\hline $\mathrm{MI}$ & $x$ & $x$ & & & 9,800 & 700 & 14 \\
\hline MS & $x$ & $\mathrm{x}$ & & & 14,000 & 1,000 & 14 \\
\hline $\mathrm{MO}$ & $x$ & $\mathrm{x}$ & & & 30,800 & 2,200 & 10 \\
\hline $\mathrm{NE}$ & $\dot{x}$ & & & & 1,400 & 200 & 7 \\
\hline $\mathrm{NH}$ & $\mathrm{x}$ & $\mathrm{x}$ & & & 99,120 & 9,912 & 10 \\
\hline $\mathrm{NY}$ & $x$ & $\mathrm{X}$ & & & 11,200 & 1,120 & 7.10 \\
\hline $\mathrm{NC}$ & $\mathrm{X}$ & $\mathrm{x}$ & & & 210,000 & 15,000 & 14 \\
\hline $\mathrm{OH}$ & $\bar{x}$ & $\bar{x}$ & & & 163,000 & 11,757 & $10-14$ \\
\hline $\mathrm{OR}$ & $\mathrm{x}$ & $\mathbf{X}$ & & & $N^{0}$ & 400 & 14 \\
\hline PA & $\mathrm{x}$ & $\bar{x}$ & & & 700,000 & 50,000 & 14 \\
\hline 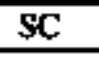 & $\mathrm{X}$ & $\mathrm{X}$ & & & 84,000 & 7,000 & 14 \\
\hline TN & $x$ & & $\mathrm{X}$ & & 425,000 & 26,800 & 14 \\
\hline$T X$ & $\mathrm{X}$ & $\mathbf{x}$ & & & 2,400 & 200 & $10-14$ \\
\hline VA & $\mathrm{X}$ & $\mathrm{X}$ & & & 39,200 & 2,800 & 14 \\
\hline WA & $\mathrm{X}$ & & & & 51,800 & 3,700 & 14 \\
\hline$w V$ & $x$ & & & & 6.000 & 600 & 10 \\
\hline WI & $\mathrm{X}$ & & & & 9,000 & 900 & 10 \\
\hline
\end{tabular}

- See Question \#I in attacthed Addendum

- NI = Not Identified. 


\section{ADDENDUM A-1}

\section{CRCPD E-6 COMMITTEE QUESTIONNAIRE ON STOCKPLLE AND DISTRIBUTION OF KI}

In view of European experience following the Chernobyl incident in which several million doses of $\mathrm{KI}$ were distributed, and in response to renewed interest within the medical community, the Federal Emergency Management Agency (FEMA) is re-evaluating the need for federal stockpile of Potassium Iodide (KI) for distribution in the event of an inadvertent release of radioiodine from a nuclear power generating facility.

FEMA has requested that the CRCPD E-6 Committee on Emergency Response Planning survey state programs on this issue.

Regardless of whether you do or do not at this time plan to distribute $\mathrm{KI}$ to emergency workers, institutionalized persons and/or the general public, please respond to the following questions, adiding any brief narrative which you feel is necessary to clarify your response. Unless your plans specify otherwise, for the purposes of this survey, the affected general public is assumed to be the resident and transient population within the Plume Exposure Pathway (approximately ten miles) emergency planning zone surrounding each commercial nuclear power generating facility. If parts of the ten-mile EPZ for a plant lie within two or more different states, answer only for that portion which is within your state.

In your answers, do not include utility employees or other persons for whom the utility would be responsible for provioing $\mathrm{KI}$.

1. What groups has your state targeted for possible distribution of KI?

Off-site Emergency Workers

Institutionalized Persons

General Public

No plans at this time to distribute $\mathrm{KI}$

2. Do you (or the responsible agency) maintain a stockpile of $\mathrm{KI}$ for these groups?

3. How many tablets (or liquid daily doses) would you issue to each person?

4. How many courses (7 to 10 day supply for one individual) do you have on hand? (If you maintain separate supplies for multiple EPZs, please report the respective quantity for each EPZ.) 


\section{CRCPD E-6 Committee KI Questionngire}

\section{Page 2 of 2 Pages}

5. Including inventories already on hand, how many courses (7 to 10 day supply of $\mathrm{KI}$ for 1 individual) would you need to complete distribution in accordance with your plan? If your state includes part or all of the ten-mile EPZ for more than one plant, please answer this question for each EPZ.

6. If you anticipate a need for additional supplies, possibly from a federal stockpile, to what agency at what location skould those suppleniental supplies be delivered? (If your state is responsible for responding to more than one power plant, please specify a location and responsible agency for each fixed nuclear facility to which you might respond.)

7. Please provide the name and telephone number of a cognizant individual within your state from whom clarification and/or additional information could be obtained.

8. Additional details/information/comment (Identify item number referred to):

Piease provide your answers to:

CRCPD E-6 Committee KI Survey

c/o Mr. Terry Devire

Conference of Radiation Control Program Directors, Inc.

205 Capitol Avenue

Frankfort, KY 40601 


\section{APPENDIX B \\ RECOMMENDATIONS BY THE WORLD HEALTH ORGANIZATION ON THE USE OF KI}

The World Health Organization (WHO) and the Commission of the European Communities (CEC) organized a joint workshop in July of 1988 to assess current knowledge and to make recommendations for National contingency plans involving nuclear emergencies.

The workshop committee submitted recommendations, which were subsequently adopted as WHO guidelines, for iodine prophylaxis in behalf of the following population groups:

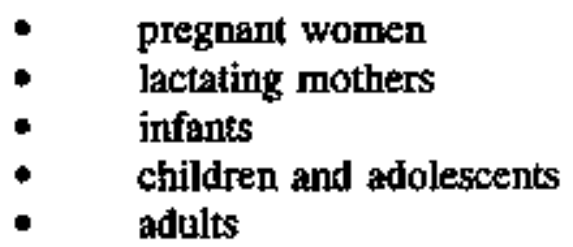

\section{Bregnant Women}

Radioiodine uptake by the matemal thyroid may be elevated during pregnancy due to enhanced stimulation of the maternal thyroid by human chorionic gonadotrophin which reaches maximal levels in the first trimester. For this reason, protection of the maternal thyroid gland from radiojodine exposure is desirable. However, the potential fetal adverse health effects from radioiodine as well as KI must be carefully considered. These fetal effects vary over the period of pregnancy.

First Trimester. Although the piacenta has been shown to freely transfer iodide (or radioiodide), the fetal thyroid is undeveloped and lacks the ability to concentrate iodine. The extent to which maternal thyroid hormone transfers across the placenta and serves as a surnogate source of thyroid hormone to the fetus is the subject of considerable debate. The significance of this uncertainty is that if there is fetal dependency on maternal thyroid hormones, care should be taken that maternal thyroid levels do not fatl. The administration of $\mathrm{KI}$ to the mother for several days could result in temporary reduction of sentm levels of the thyroid hormones $T_{4}$ and $T_{3}$.

WHO Reconmendations. Administration of stable iodine during the first trimester of pregnancy should be restricted to the minimum daily dosage and duration that still provides adeguate maternal thyroid protection. 
Second Trimester. During this time, the fetal thyroid is rapidly increasing in mass and has the ability to actively concentrate iodine. Due to its limited mass, the tetal thyroid dose is higher than that of its mother. Although fetal thyroid secretion of $\tau_{4}$ may begin at mid-gestation, fetal dependency on maternal $T_{4}$ for normal organogenesis inclusive of the brain may exist.

WHO Recommendations. If the predicted dose to the thyroid is likely to exceed the agreed intervention level, stable iodine should be given to pregnant women in the second trimester to protect both the fetal thyroid and the maternal thyroid. The duration of stable iodine prophylaxis in pregnant women should be limited to the minimum time frame that still provides adequate protection. Other countermeasures such as evacuation, and control of ingestion of contaminated foods/water are particularly important for this group.

Third Trimester. During this time of gestation, the fetal thyroid continues to concentrate iodine and secrete' increasing amounts of the thyroid hormone. Up to this time the feedback control mechanism involving the pituitary thyroid stimulating hormone has not been fully developed, and the fetus has an enhanced vulnerability to thyroid overload by stable iodine (Wolff-Chaikoff effect). This transient iodine overload can result in primary hypothyroidism in utero, which may adversely affect organ and brain development.

WHO Recommendations. If the predicted dose to the thyroid is likely to exceed the agreed intervention level for $\mathrm{KI}$, prophylaxis should be given to women in the third trimester to protect the fetal thyroid gland and to protect the maternal thyroid gland. The duration of stable iodine prophylaxis should be limited to the minimum that still provides adiequate protection. The fetus will need to produce $T_{4}$ and $T_{3}$ at birth and is likely to be susceptible to the Wolff-Chaikoff effect. Therefore, fetal TSH and T, levels should be assessed at birth for neonates whose mothers were administered iodine prophylaxis in the third trimesters. Replacement therapy must be administered as needed.

Neonates (birth to 1 monthl. At birth there is a dramatic rise in TSH levels that is followed by a rise in $T_{4}$ and $T_{3}$ levels. During this time, the fraction of iodine taken from blood and concentrated by the thyroid (i.e., $\mathrm{f}_{2}{ }^{\prime}$ fraction) reaches values in excess of $90 \%$. A neonatal exposure to radioiodine during this time leads to unusually high thyroid doses. However, the neozate is still vulnerable to the Wolff-Chaikoff effect from iodine overload. The long-term effects of transient thyroid depression are not established, and therefore monitoring of thytoid hormone levels in the neonate is advised.

WHO Recommendations. Stable iodine should be given to protect the neonatal thyroid. Thyroid hormone levels shoutd be assessed following iodine prophylaxis. The dosage and duration of prophytaxis should be kept to the minimum level that still offers adequate protection, with other countermeasures such as evacuation and sheltering given high priority. 


\section{Lactating Mothers}

Iodine is concentrated in breast milk and may become a source of both stable iodine and radioiodine for a nursing infant. If the mother is given stable iodine as well as the baby, the baby will receive stable iodine from two sources, which may increase the risk of jodine overload.

WHO Recommendations. Lactating mothers should be given stable iodine to protect the maternal thyroid but at minimal dosage and duration.

\section{Infants, Children, Adolescents}

Due to higher thyroid doses, increased thyroid sensitivity, and longer periods at risk than adults, the youngest members of the population are at highest risk and, therefore, are most likely to benefit from iodine prophylaxis. Adverse reactions to stable $\mathrm{KJ}$ involving intrathyroidal and extrathyroidal effects are less likely than for adult populations.

WHO Recommendations. Stable iodine should be given to infants, children, and adolescents to protect the thyroid. Hecause of the low probability of adverse effects to stable iodine, a less restrictive policy may be adopted to include individuals in the farfield where thyroid doses may not necessarily exceed intervention levels. Stable iodine should be withheld from those individuals with known allergies to iodine or who have previously been treated to thyroid disorders.

\section{Young Adults (18-45 years)}

Neither the radjation risks nor the adverse risks to stable iodine are extraordinary for this group.

WHO Recommendations. Iodine prophylaxis is recormmended for those individuals who may exceed intervention levels of thyroid exposure. Individuals with known thyroid disorders or allergies toward jodine should avoid the use of stable iodine.

\section{Older Adults}

With increasing age and diminishing years of life expectancy, the risk of thyroid cancer expression decreases. The incidence of thyroid diseases increases significantly with age. especially among women. Stable iodine can exacerbate or precipitate thyrotoxicosis among individuals treated for or with asymptomatic Graves' Disease or with autonomously functioning thyroid nodules. Among this susceptible group, iadine prophylaxis can be life-threatening, especially if recognition is delayed. 
WHO Rexommendations. Because the potential side effects of stable iodine are likely to be greatest in this age group, iodine prophylaxis is recommended only when intervention levels have a high probability of being exceeded. Emphasis must be placed on contraindications with instructions strongly discouraging $\mathrm{KI}$ use among individuals with known iodine allergies, known thyrojd pathologies (i.e., goiters; autoimmune thyroid disease), hypocomplementemic vasculitis, and dermatitis herpetiformis.

\section{The Applicability of WHO Guidelines for U.S. Population}

When evaluating WHO Guidelines for U.S. poputations, it is important to acknowledge the major difference in dietary intakes between the population of the United States and those of other countries. The average daily dietary intake of about $200 \mu \mathrm{g}$ of iodide in the United States is considered high compared to that in other countries.

When iodine deficiency is present, the thyroid has a higher avidity for iodine (and, therefore. radioiodine) than the thyroid of a person with a nonnal or high iodine intake. In areas with low iodine intake, the amount of radioiodine accumulated in the thyroid can be expected to be up to as much as two to three times higher from an identical environmental exposure than in a poputation with normal or high iodine intake (Delange 1989). Stated somewhat differently, the prophylactic benefit of $\mathrm{KI}$ is higher for individuals with low dietary intake.

Along with its higher thyroid protection among persons with lower dietary intake of iodine, the potential side effects of $\mathrm{KI}$ are also more likely. This is because nodular goiter is more prevalent with low dietary intakes of iodine. Since some goitrous modules are likely to be autonomous (i.e., function independently of thyroid-stimulating hormone (TSH)), this sudden increase in available iodine can facilitate the increased synthesis of thyroid hormone. Similarly, individuals with Graves' Disease whose condition is sub-clinical due to dietary restrictions of iodine, when given $\mathrm{KI}$, would be subject to the full expression of the disease. 


\section{APPENDIX C}

\section{ADVERSE REACTIONS TO IODIDE AND ESTIMATION OF ADVERSE INCIDENCE RATE}

The freguency of potential adverse reactions to iodide when taken orally in daily doses of $130 \mathrm{mg}$ can be assumed to be very small based on extrapolation from documented data. Potassium iodide is a major ingredient in cough syrups and expectorants whose principal purpose is to liquify tenacious bronchial secretions associated with respiratory infections, allergic bronchitis, asthma, pulmonary emphysema, etc.

The Food and Drug Administration's Division of Epidemiology and Surveilfance (DES) maintains a computerized data base of adverse drug reactions. Known as either the Adverse Reaction Reporting System (ARRS) or the Spontaneous Reporting System (SRS), the present data base contains over 400,000 reports that have been collected since 1969. The primary purpose of this data base is to serve as an early waming system for adverse reactions not detected during pre-market testing.

Approximately $90 \%$ of the reports in the SRS data base are submitted by drug manufacturers, who must, by law, report adverse events that become known to them. The remaining $10 \%$ of reports are received directly by DES from sources other than manufacturers (i.e., health professionals and consumers).

\section{Adverse Reactions to KI}

For the period of 1969 through July 1991, the SRS data base contained only 97 reports of suspected adverse reactions to $\mathrm{KI}$. Summary data supplied by the FDA concerning these 97 cases are furnished as Addendurn-1 in this appendix. Table C-1 characterizes these cases with respect to age and gender of the subjects and quantifies exposure. Individuals tended to be above the age of 40 , with about twice as many males as females. The duration of therapy was skewed and bimodal, having a mean of 19 days and a standard deviation of 60 days. While most individuals were medicated for less than two weeks, there were few individuals whose therapy lasted months and up to one year. Although the FDA provided daily dosage information, the data could not be converted into milligram quantities of KI. An estimate of daily doses administered was derived from the recommended doses prescribed by phamaceutical firms (see Table C-4). No adverse reactions were reported for children.

Table C-1. Adverse Reaction Profile to $\mathbf{K I}^{\mathbf{1}}$

\begin{tabular}{|c|c|c|c|c|c|}
\hline $\begin{array}{l}\text { Total A of } \\
\text { Individuals }\end{array}$ & $\begin{array}{l}\text { Route of } \\
\text { Adsnivist. }\end{array}$ & $\begin{array}{l}M^{2} \text { Gender } \\
\text { F }\end{array}$ & $\begin{array}{c}\text { Avg. Age } \\
\quad \pm / S D \\
\end{array}$ & $\begin{array}{c}\text { Duration of } \\
\text { Therapy (days) }\end{array}$ & $\begin{array}{l}\text { Daily } \\
\text { Dose' (mg) }\end{array}$ \\
\hline 97 & PO & 61 $28 \quad 8$ & 54 土 16 & $19 \pm 60$ & $100->1,000$ \\
\hline
\end{tabular}

1 Source: Addenduor-1 of this appendix.

2 See Table C-4. 
Table C-2 identifies specific adverse reactions among these subjects and the frequency of their occurrence. With rare exceptions, the adverse reactions cited were not life-threatening and were quickly reversed upon discontinuation of medication. The sum of adverse reactions exceeds the number of individuals because sorme individuals reponted more than one reaction. Of the 97 individuals, recovery was cited for 65 without medical intervention; for 31 indjviduals, the patient outcome was not addressed in the initial report received by the FDA and is, therefore, identified as "unknown;" in one instance, the adverse reaction was sufficiently severe to require hospitalization; and one death was reported. The adverse reactions cited in the case requiring hospitalization included fever, skin necrosis, eye pain, and petechia. For the fatality, the major adverse reaction identified in the report was limited to vesiculobullous rash.

Cause and effect interpretation from these data must be done with caution. The FDA issued the following caveats (personal conmunications):

1. "For any report, there is no certainty that the suspected drug caused the reaction. This is because physicians are encouraged to teport all suspected adverse drug events, not just those that are known to have been caused by the drug. The event may have been related to an underlying disease for which the drug was given, to other drugs being taken concurrently, or may have occurred by chance at the time the suspected drug was taken."

2. "Accumulated case reports cannot be useo to calculate incidence or estimates of drug risk. They must be carefilly interpreted as reporting rates and not occurrences or incidence rates. Comparison of drug safety cannot be made from these data," 
TabJe C-2. Suspected Adverse Reactions to KI Reported Since 1969

\begin{tabular}{|c|c|c|}
\hline Adverse Reaction & $\begin{array}{c}\text { No. of } \\
\text { Occiurrences }\end{array}$ & Definition/Description \\
\hline $\mathrm{ACNE}$ & 4 & Pustular skin enuption. \\
\hline ALLERGIC REACTION & 1 & $\begin{array}{l}\text { Unspecified response which could range from a fever type } \\
\text { symptom to severe asthra. }\end{array}$ \\
\hline $\begin{array}{l}\text { ANAPHYLACTOID } \\
\text { REACT }\end{array}$ & $\mathbf{3}$ & $\begin{array}{l}\text { Life-threatening allergic teaction usually manifested by severe } \\
\text { spasm of the bronchi in the lung with associated like } \\
\text { syndrome. }\end{array}$ \\
\hline ANGIOEDEMA & 3 & $\begin{array}{l}\text { Another form of allergic reaction manifested by swelling of } \\
\text { the moncus membranes of the eyes, nose, month, pharynd, } \\
\text { and occasionally the larynx. Also in its more diffuse form } \\
\text { will cause diffuse soft tissure swelling throughout the body and } \\
\text { is associated with glant bives. }\end{array}$ \\
\hline ANTHRALGLA & 1 & Bone pain. \\
\hline ASTHMA & 1 & Wheezing respiration due to bronchial restriction. \\
\hline CONJUNCTIVIFIS & 4 & Rediness of the eye membrane. \\
\hline COUGH INCREASED & 1 & Self-explanalory. \\
\hline $\begin{array}{l}\text { DERMATTTIS, } \\
\text { EXFOLIATIVE }\end{array}$ & 1 & $\begin{array}{l}\text { Anotier form of toxic reaction to medication where the } \\
\text { superficial layers of the skin become inflaned and } \\
\text { desquamate. }\end{array}$ \\
\hline DIARRHEA & 1 & Self-explanatory. \\
\hline EDEMA FACE & 2 & Self-explanatory. Again a form of allergic reaction. \\
\hline BOSINOPHILLA & 2 & A type of white blood cell which is increased in its numbers. \\
\hline $\begin{array}{l}\text { ERYTHEMA } \\
\text { MULTIFORME }\end{array}$ & 2 & Another form of loxic skin reaction. \\
\hline ERYTHEMA NODOSUM & 1 & $\begin{array}{l}\text { A nodular form of inflammatory disease of the skin. Again, } \\
\text { usually associated with toxic reaction to some medication. }\end{array}$ \\
\hline FEVER & 5 & Self-explanatory. \\
\hline GLOSSITIS & 1 & Sweiling and infiammation of the tongate. \\
\hline GOITER & 2 & An enlarged thyroid. \\
\hline HEADACHE & 1 & Self-explanatory. \\
\hline HEMATURIA & 1 & Blood in the urine. \\
\hline HYPOTHYROIDISM & 1 & Lack of thyroxine hormone. \\
\hline LYMPHADENOPATHY & 1 & Swelling of the Jymph nodes, usually multiple. \\
\hline NECROSIS OF SKIN & 1 & Again simitar exfoliated dermetitis. \\
\hline PAIN & I & Self-explanatory. \\
\hline PAIN EYE & $\mathbf{I}$ & Self-explanatory \\
\hline
\end{tabular}


Table C-2. Suspected Adverse Reactions to KI Reported Since 1969 (Continued)

\begin{tabular}{|c|c|c|}
\hline Adverse Reaction & $\begin{array}{l}\text { No. of } \\
\text { Oxcurrences }\end{array}$ & Defintion/Description \\
\hline $\begin{array}{l}\text { PAROTID } \\
\text { ENLARGEMENT }\end{array}$ & 3 & $\begin{array}{l}\text { Self-explanatory. Parotid is the salivary gland just th front of } \\
\text { the ear. }\end{array}$ \\
\hline PETECHIA & 1 & $\begin{array}{l}\text { Sanall hemorthasic skin spots usually associated with toxic } \\
\text { reaction to medication. }\end{array}$ \\
\hline PRURITUS & 3 & Sten itcb. \\
\hline RASH & 9 & Non-specific term. \\
\hline $\begin{array}{l}\text { MACULOPAPULAR } \\
\text { RASH }\end{array}$ & 24 & $\begin{array}{l}\text { Maltiple skin areas of punctate erythema with slight } \\
\text { elevation. }\end{array}$ \\
\hline PURPURIC RASH & 1 & Qute similar to petectra. \\
\hline PUSTULAR RASH & 2 & Very similar to acne. \\
\hline $\begin{array}{l}\text { VESICULAR BULLOUS } \\
\text { RASH }\end{array}$ & 3 & $\begin{array}{l}\text { Superficial layers of the skin develop considerable } \\
\text { inflammetion with flutid accurmulation causing bubble-like } \\
\text { lestons. }\end{array}$ \\
\hline $\begin{array}{l}\text { REACTION } \\
\text { UNEVALUATED }\end{array}$ & y & Self-explanatory. \\
\hline $\begin{array}{l}\text { SALIVARY GLAND } \\
\text { ENLARGEMENT }\end{array}$ & 11 & $\begin{array}{l}\text { Related to parotid enlargement which inciudes submandibular } \\
\text { salivary glands. }\end{array}$ \\
\hline SARCOIDOSIS & 1 & A granulomatous noninfectious disease of unknown etiology. \\
\hline SERUM SICKNESS & $\mathbf{l}$ & $\begin{array}{l}\text { A delayed type of allergic reaction to foreign protein. It can } \\
\text { be life-threatening. }\end{array}$ \\
\hline SIALADENITIS & 4 & Inflammation of the salivary glands. \\
\hline SPUTUM, INCREASED & ] & Self-explanatory. \\
\hline STOMATITIS & 1 & $\begin{array}{l}\text { Inflammation of the oral cavity; freagnently associated with } \\
\text { giossitis. }\end{array}$ \\
\hline URTICARIA & 7 & Hives. \\
\hline VASODILATATION & 1 & Dilatation of the snall blood vessels. \\
\hline VOMITING & 1 & Self-explanatory. \\
\hline $\begin{array}{l}\text { SALIVARY GLAND } \\
\text { ENLARGEMENT }\end{array}$ & 1 & Self-explamatory. \\
\hline IODISM & & $\begin{array}{l}\text { A morbid clinical condition cbaracterized by stlivary glaxd } \\
\text { enlargement, cutaneous eruption, etc. induced by iodine. }\end{array}$ \\
\hline LYMPHADENOPATHY & & Proviausly described. \\
\hline PHARYNGITIS & & Inflammation of the pharynx. \\
\hline PRURTITS & & Previously described. \\
\hline RASH & & Previously described. \\
\hline $\begin{array}{l}\text { RASH MACULA } \\
\text { PAPULAR }\end{array}$ & & Previously described. \\
\hline PHINITIS & & Inflammetion of the mucus nembranes of the nose. \\
\hline TASTE PER VERSION & & Self-explanatory. \\
\hline
\end{tabular}


Nevertheless, the NCRP in 1977 (NCRP 1977) attempted to use FDA's SRS data to establish incidence rate estimates. At the time of the NCRP study, six pharmaceutical firms were identified as manufacturers of products containing KI. However, only two companies provided production data, which was only for 1975 . By using the average andrial number of adverse reactions reported between 1969 and 1975, and 1975 manufacturing data from only two out of six companies, a conservative adverse reaction rate of about $5 \times 10^{-7}$ was estimated. To determine a baseline estimate of the potential adverse reaction incidence rate, it is necessary to correlate the number of adverse reactions for a fixed time frame to the total quantity of $\mathrm{KI}$ consumed.

In an attempt to update eariier data and refine the adverse reaction incidence value, five pharmaceutical firms were identified in the Physicians' Desk Reference as manufacturers of dnugs containing KI (a sixth company producing SSKI was not included). The companies were contacted and asked to provide information regarding production quantities for their $\mathrm{KI}$ containing products. Without exception, all companies stated that production information dating back to 1969 was not available. Data, however, were available for the most recent five years. Company representatives also wamed that recent production data could not be used to extrapolate production quantities back to 1969. There was emphatic consensus among firms that production quantities of $\mathrm{KJ}$-containing orugs have been drastically reduced over the past two decades. This trend is strongly supported by the frequency distribution of the number of adverse drug reactions reported to the FDA between 1969 and 1991 (Table C-3).

Table C-3. Number of Adverse Reactions to KI by Year

\begin{tabular}{|c|c|c|c|c|c|c|c|c|c|c|c|c|c|}
\hline 769 & 70 & 71 & 72 & 73 & 74 & 75 & $76-79$ & 80 & $781-83$ & 184 & 185 & $76-90$ & 91 \\
\hline 7 & 37 & 43 & 9 & 12 & 2 & 2 & none & 1 & none & 1 & 1 & none & 1 \\
\hline
\end{tabular}

The five companies provided the product information and production estimates given in Table C-4. 
Table C-4. Product Profile and Production Quantity for 1986-1990

\begin{tabular}{|c|c|c|c|c|c|}
\hline $\begin{array}{l}\text { Phatm. } \\
\text { Firm }\end{array}$ & $\begin{array}{l}\text { Praduct } \\
\text { Description }\end{array}$ & $\begin{array}{l}\text { KI Content or } \\
\text { Coucentration }\end{array}$ & $\begin{array}{l}\text { Recommeaded } \\
\text { Daily Dose } \\
\text { (daily KI) }\end{array}$ & $\begin{array}{c}\text { Qtaantity } \\
\text { Maqufactured }\end{array}$ & $\begin{array}{l}\text { Equivalent } \\
\text { Dases } \\
\text { (130 mig ea.) }\end{array}$ \\
\hline A & liquid & $324 \mathrm{mg} / 5 \mathrm{mt}$ & $\begin{array}{c}20-60 \mathrm{ml} \\
(1,300-1,900 \mathrm{mg})\end{array}$ & $830,0000 z^{\circ}$ & $12,410,000^{-}$ \\
\hline B & tablet & $320 \mathrm{mg} /$ tablet & $\begin{array}{c}\text { 3-4 tablets } \\
\text { (960-1,280 mg) }\end{array}$ & $\begin{array}{l}15.106,000 \\
\text { cablets }\end{array}$ & $37,648,800$ \\
\hline c & titquid & $75 \mathrm{mg} / 5 \mathrm{ml}$ & $\begin{array}{c}20-30 \mathrm{ml} \\
(300-450 \mathrm{mg})\end{array}$ & $4,662,54402$ & $16,139,575$ \\
\hline $\mathrm{D}$ & tablets & $195 \mathrm{mg} / \mathrm{tablet}$ & $\begin{array}{c}\text { 3-4 tablets } \\
\text { (585-780 Jug) }\end{array}$ & $\begin{array}{l}2,000,000 \\
\text { tablets }\end{array}$ & $3,000,000$ \\
\hline E & Etquid & $130 \mathrm{mg} / 15 \mathrm{ml}$ & $\begin{array}{c}30-45 \mathrm{ml} \\
(260-390 \mathrm{mg})\end{array}$ & $1,264,280 \mathrm{oz}$ & $2,528,560$ \\
\hline
\end{tabular}

- Values represent best estimates by pharmacentical firms.

For the most recent five-year period, pharmaceutical firms produced oral medication containing approximately 10,000 kilograms of $\mathrm{KJ}$. To convert quantities mamufacfured to quantities consumed, it is necessary to estimate what percentage of the manufactured quantities is actually sold to wholesalers/retailers, the quantity sold by retailers to consumers, and the percentage acturally consumed. In response to these questions, pharmaceutical firms stated that essentially $100 \%$ of their manufactured products are sold to wholesalers and retaiters, with no significant quantities discarded for reasons of shelf-life expiration, etc. When asked about the potential quantities consumed, representatives of pharmaceutical firms speculated that an estimate of $50 \%$ may be appropriate for the following reasons: the symptoms of coughs, colds, and allergies are frequently of shorter duration than the quantity prescribed or purchased, and the use of medication is frequently confined to that period of time when individuals feel the need for medication. This is especially true for $\mathrm{KJ}$-containing medication that also contains codeine and barbiturates. For the most recent five-year period, therefore, it will be estimated that about $5,000 \mathrm{~kg}$ of $\mathrm{KI}$ was consumed, which corresponds to 38 million equivalent doses of $130 \mathrm{mg}$ each. During this same five-year period, only a single adverse reaction to $\mathrm{Kl}$ was reported (see Addendum-1: Report Accession No. 91040801600011). This adverse reaction was classified as "unevahuable" and did not involve a biological reaction. In fact, the complaint was confined to the physical discoloration of the medication. In sumuary, for the most current data involving 38 million equivalent doses of $\mathrm{KI}$ consuned, there were no reports of adverse reactions.

While the absence of adverse reactions for the most recent five-year period does not imply a zero risk, the data do suggest that the previous risk coefficient of $5 \times 10^{-7}$ as estimated by the NCRP (NCRP 1977) is conservative. If the NCRP's risk coefficient were applied to the consumption of about 38 million equivalent doses, a total of 19 adverse reactions would be expected. 
The current data support an adverse reaction incidence rate value of $1 \times 10^{-7}$ or less per unit dose of $130 \mathrm{mg}$ of $\mathbf{K}$.

\section{Adverse Reactions to Iodinated Contrast Media}

A second source for deriving potential risk estimates involves iodinated $x$-ray contrast media and their occasionally toxic side effects that are presumed to be caused in part by their high iodide content. For a single diagnostic procedure, the dose of organically bound iodide may involve quantities of several grams. Adverse reactions to iodinated contrast media are usually of mild to moderate severity. About $95 \%$ of these reactions include aches and pain, stiffness, nausea, and vomiting. These reactions, usually occurring 1 to 10 hours after the injection, last for a few hours and usually disappear within 24 hours. Severe life-threatening anaphylactoid reactions, mostiy of cardiovascular origin, have been observed.

Cardiovascular complications include arrhythmias (including PVCs and PACs), angina, hypotension, and cardiac arrest.

Studies assessing adverse reaction incidence rates are fragmented. Frequently, the size, selection criteria of study subjects, and the type of reported adverse reaction are of limited scope. The following provides a brief summary.

- In one of the earliest studies involving iodinated contrast media, the unfavorable sequelae and deaths were assessed for a total of 662,000 urographic examinations (Pendergrass 1942). A total of 26 deat'ss was reported of which eight were attributed to the medical condition under investigation. If the remaining 18 deaths were exclusively the consequence of iodine reactions, the fatal incidence rate would be 27 per $10^{6}$ exposures (one fatality per approximately 37,000 examinations) involving doses of iodine between 2.5 and 16.8 grams per examination.

- This incidence rate appears consistent with the data of Tucker and diBaguo (Tucker 1956) who observed no severe reactions/fatalities among 2,000 patients who had received either Neo-iopax with 5.2 grams of iodine per examination or Urokon with 4.9 grams of iodine.

- In a sndy of 196 Japarese hospitals involving 77,040 injections of ionic and 42,581 injections of non-ionic iodinated contrast media, one fatality and 38 severe reactions were reported. Severe reactions were defined as those requiring hospitalization of the patient. The overall incidence of severe reactions is 34 per $10^{5}$ with a fatality incidence of $1.7 \times 10^{-5}$ (Katayama 1963).

Because iodine/iodide is considered a significant risk to the fetus, iodinated pharmaceuticals and diagnostic $x$-ray media are avoided during pregnancy. No reliable medical data, therefore, exist concerning fetal risks. 
- A study of 3,808 hospital patients investigated for various thyroid disorders showed that the frequency of hyperthyroidism increased from $3.7 \%$ to $5.4 \%$ when patients were segregated on the basis of exposure (within the previous 12 months) to iodinated $x$-tay contrast medium (Oberhausen 1988).

- In controlled clinical triats involving 1,270 patients administered the contrast medium OMNIPAQUE, one fatality occurred. A cause and effect relationship befween this death and iohexal, the phamacological ingredient of OMNIPAQUE, has not been established (PDR 1991).

To obtain more current and comprehensive data, information from the Food and Drug Administration's Adverse Reactions Reporting System was requested. Adverse reactions to iodide-containing diagnostic contrast media have been reported to the FDA since 1969. Between 1969 and August 1991, 5,131 cases of adverse reactions were reported in which iodinated contrast media were suspected as the causative agent. The majority of adverse reactions involved extrathyroidal effects that were transient, mild to moderate in severity, and required no medical intervention for patient recovery. In a few cases, adverse reactions were severe and included cardiac arrest, myocardial infarction, anaphylactoid reactions, shock, and death. Table C-5 identifies the most severe adverse reactions in the context of the total number of reactions reported.

Table C-5. Adverse Reactions to Iodinated Contrast Media Reported to the FDA Between 1969 and August 1991

\begin{tabular}{|cccccc|}
\hline $\begin{array}{c}\text { Iodinated Contrast } \\
\text { Media }\end{array}$ & $\begin{array}{c}\text { Anapitylactoid } \\
\text { Reations }\end{array}$ & $\begin{array}{c}\text { Cardfac Artest \& } \\
\text { Myoc. Infart. }\end{array}$ & Shock & Death & $\begin{array}{c}\text { Tolal Cabes of } \\
\text { Adverse } \\
\text { Reactions }\end{array}$ \\
\hline $\begin{array}{c}\text { Domestic } \\
\text { Foreign }\end{array}$ & 157 & 122 & 88 & 26 & 4,933 \\
\hline TOTAL & 6 & 8 & 9 & 4 & 198 \\
\hline
\end{tabular}

- Includes all manufacturers of contrast media approved by the FDA.

To convert the FDA's ARRS data to adverse reaction incidence rate data requires knowledge of the total quantity of diagnostic contrast media used for the corresponding time frame. The quantity of diagnostic contrast media that had been used was estimated based on (1) the total quantity manufactured, (2) the total number of diagnostic procedures performed, and (3) the total reimbursements made by Federal and private insurers for procedures involving iodinated contrast media. Statistical data were sought from pharmaceutical firms, the HFCA, FDA, other governmental agencies, and private organizations (e.g., American Medical Association; Commission on Professional and Hospital Activities, IMS America). In all instances, data were either incomplete, lacked the necessary specificity for reliable quantification, or were considered confidential. 
The inability to convert FDA's ARRS data to an adverse reaction incidence rate for iodinated contrast media, however, is not significant for this report. Any extrapolation of adverse reaction incidence data involving iodinated contrast media to potassium jodide would likely have been considered inappropriate for the following reasons:

- The one to five grams of iodine per diagnostic procedure involving iodinated contrast media represents quantities that are 10 to 50 times higher than the recommended $100 \mathrm{mg}$ of iodide contained in a $130 \mathrm{mg}$ tablet of $\mathrm{KI}$.

- Iodinated contrast media, in most instances, exist in organically bound form. The iodinated protein globulin is water soluble and remains non-dissociated (nonionic) in the bloodstream with little or no metabolism, deiodination, or biotransformation prior to rapid urinary excretion. Serum levels of free iodide for thyroid metabolism are, therefore, either unknown or assumed minimal.

- The role of the organic component in extrathyroidal hypersensitivity reactions is uncertain but must be suspected,

- Unlike KI that is administered orally, iodinated contrast media ate infused intravascularly or intrathecally.

- The underlying medical condition warranting the diagnostic procedure involving iodinated contrast media must be viewed as a confounding variable with respect to the etiology of the reported adverse reactions. 


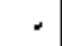




\section{ADDENDUM $\mathrm{C}^{*}$}

FDA SPONTANEOUS REPORTIHG SYSTEN

CAUSE-EFFECT RELATIONSHIP DETWEEN EACH ORUG AND REACTIOH

CANNOT DE ESTADLISHED NITH CERTAINTY IN ALL CASES

POTASSIUA IODIDE

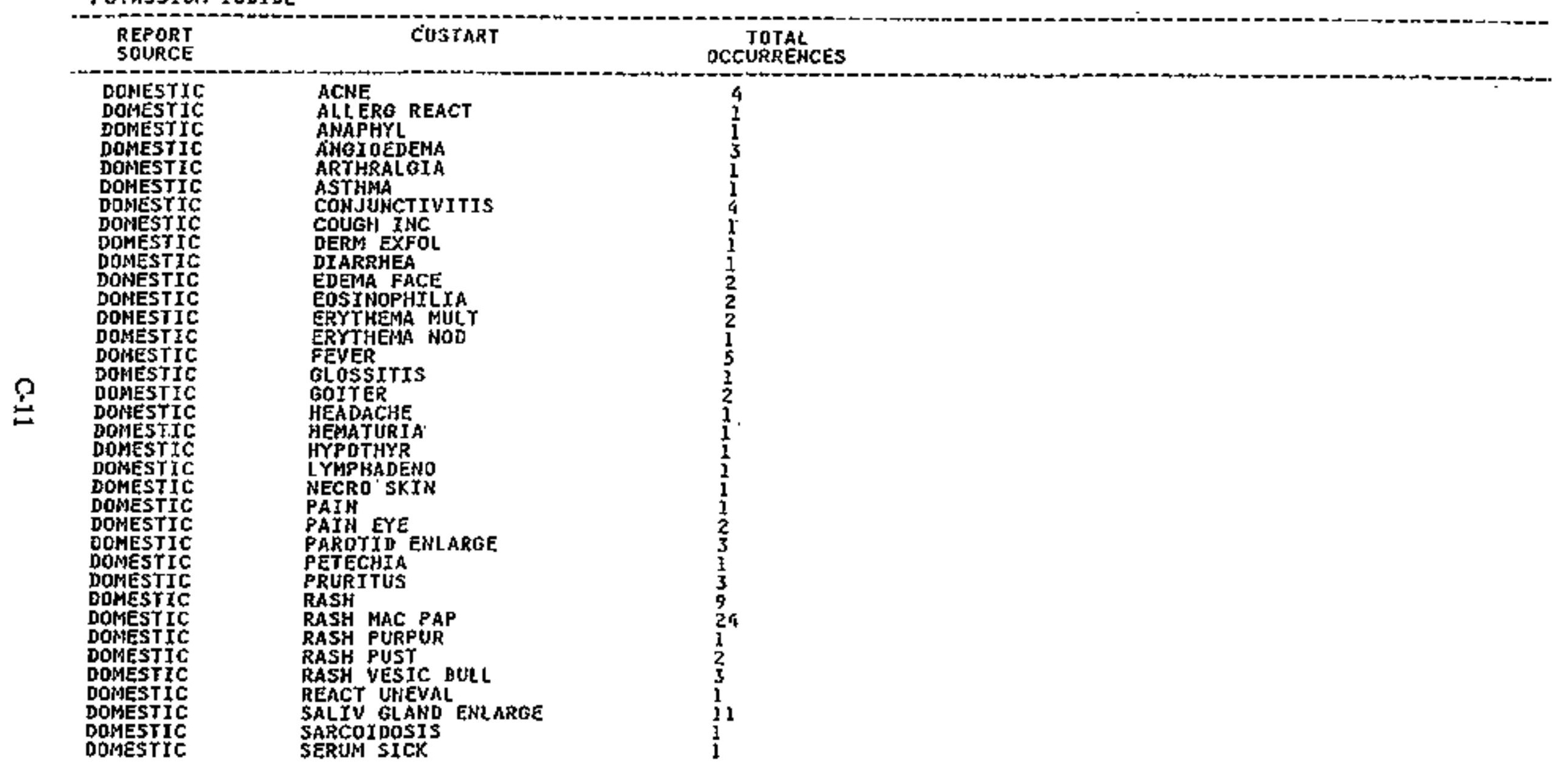

* These data sheets were provided by the FDA's Division of Drug Experience under the Freedom of Information Act. 
FDA SPONTANEOUS REPORTING SYSTEM

CAUSE-EFFECT RELATIONSHIP DETHEEN EACH DRUG AND REACTION

CANNOT QE ESTABLISHED WITH CERTAINTY IN ALL CASES

POTASSIUM IODIDE

\begin{tabular}{|c|c|c|}
\hline $\begin{array}{l}\text { REPORT } \\
\text { SOURCE }\end{array}$ & COSTART & $\begin{array}{c}\text { TOTAL } \\
\text { OCCURRENCES }\end{array}$ \\
\hline $\begin{array}{l}\text { DOMESTIC } \\
\text { DOMESTIC } \\
\text { DOMESTIC } \\
\text { DOMESTIC } \\
\text { DOWESTIC } \\
\text { DOMESTIC } \\
\text { FOREI GN }\end{array}$ & $\begin{array}{l}\text { SIALADENITIS } \\
\text { SPUTUM IHC } \\
\text { STOMATITS } \\
\text { URTICARIA } \\
\text { VASODIIAT } \\
\text { VOMIT } \\
\text { SAIIV GLAND EHLARGE }\end{array}$ & $\begin{array}{l}4 \\
1 \\
2 \\
7 \\
1 \\
1 \\
1\end{array}$ \\
\hline DOHESTIC & & 96 \\
\hline FOREIGH & & 1 \\
\hline THE GRAND & IS & 97 \\
\hline
\end{tabular}

吕 
FDA SPONTANEOUS REPORTING SYSTEM

CAUSE-EFFECT RELATIDNSHIP BETWEEH EACH DRUG AHD REACTION

CANNOT BE ESTABLZSHED WITH EERTAINTY IN ALL CASES

POTASSIUM IODIDE

\begin{tabular}{|c|c|c|c|c|c|c|c|c|c|}
\hline $\begin{array}{l}\text { ACCESSI ON } \\
\text { WUNBER }\end{array}$ & $\begin{array}{l}\text { DAILY } \\
\text { DOSE }\end{array}$ & UNITS & $\begin{array}{l}\text { SUSPECT } \\
\text { DRUG }\end{array}$ & $\begin{array}{l}\text { RDUTE } \\
\text { ADH. }\end{array}$ & $\begin{array}{l}\text { DURATION } \\
\text { THERP. }\end{array}$ & AGE : & SEX & $\begin{array}{r}\text { REPORT } \\
\text { SOURCE } \\
\end{array}$ & $\begin{array}{l}\text { PAT I EHT } \\
\text { DUTCONE }\end{array}$ \\
\hline \multicolumn{10}{|c|}{ ALL DRUGS } \\
\hline \multicolumn{10}{|c|}{ ALL REACTIDNS } \\
\hline \multicolumn{10}{|c|}{ PESSAGE } \\
\hline 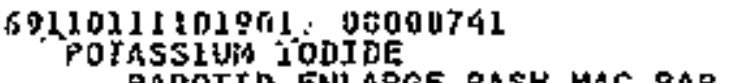 & 060.010 & H & $\mathbf{s}$ & $P 0$ & & 057 & $M$ & DOMESTIC & RECDVĘR \\
\hline 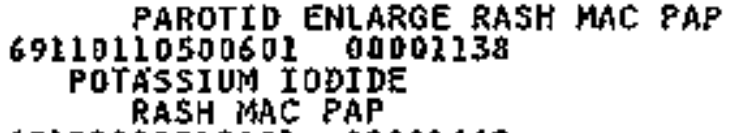 & 005.000 & $\mathrm{CC}$ & $\mathbf{S}$ & PO & 00002 & 048 & $\mathbf{M}$ & DOMESTIC & RECOVER \\
\hline $\begin{array}{l}69122008212001 \text { ODO01642 } \\
\text { POTASSIUM IODIDE PHENDBARBITAL } \\
\text { RASH MAC PAP }\end{array}$ & & & 5 & & & 063 & $F$ & DOMEST IC & RECOVER \\
\hline $\begin{array}{l}69100400600101 \text { 000018 } \\
\text { POTASSIUM IODIDE } \\
\text { RASH MAC PAP }\end{array}$ & 030.000 & M & $\mathbf{5}$ & PO & 00005 & 053 & N & DOMESTIC & RECOVER \\
\hline $\begin{array}{l}70010108800201 \text { 00001992 } \\
\text { POTASSIVH IODIDE } \\
\text { FEVER }\end{array}$ & 020.000 & M & $s$ & PO & 00005 & 041 & $\mathbf{F}$ & DOMESTIC & RÉCDVẸR \\
\hline $\begin{array}{l}70020105503901 \text { 00002770 } \\
\text { POTASSIUH IODTDE } \\
\text { ANGIOEDEAA }\end{array}$ & 004.000 & $C C$ & $\mathbf{s}$ & PD & 00001 & 072 & $M$ & DONESTIC & UNKNOHN. \\
\hline $\begin{array}{l}70010111102201 \text { ODO004397 } \\
\text { POTASSIUH IODIDE } \\
\text { ACNE }\end{array}$ & 060.000 & is & 5 & PO & 00180 & 075 & $M$ & DOMESTIC & UtKNOWN \\
\hline $\begin{array}{l}69010115700501 \text { D0004556 } \\
\text { POEASSIUM IODIDE PHEHDBARDITAC }\end{array}$ & 040.000 & $M$ & $\$$ & PO & 00002 & 0.53 & $M$ & DONESTIC & RECOVER' \\
\hline
\end{tabular}


FDA SPONTANEOUS REPORTING SYSTEM

CAUSE-EFFECT RELATIONSHIP BETWEEN EACH DRUG AHD REACTION CANWOT DE ESTADLISHED WITH CERTAINTY IN ALL CASES

POTASSIUM IDDIDE

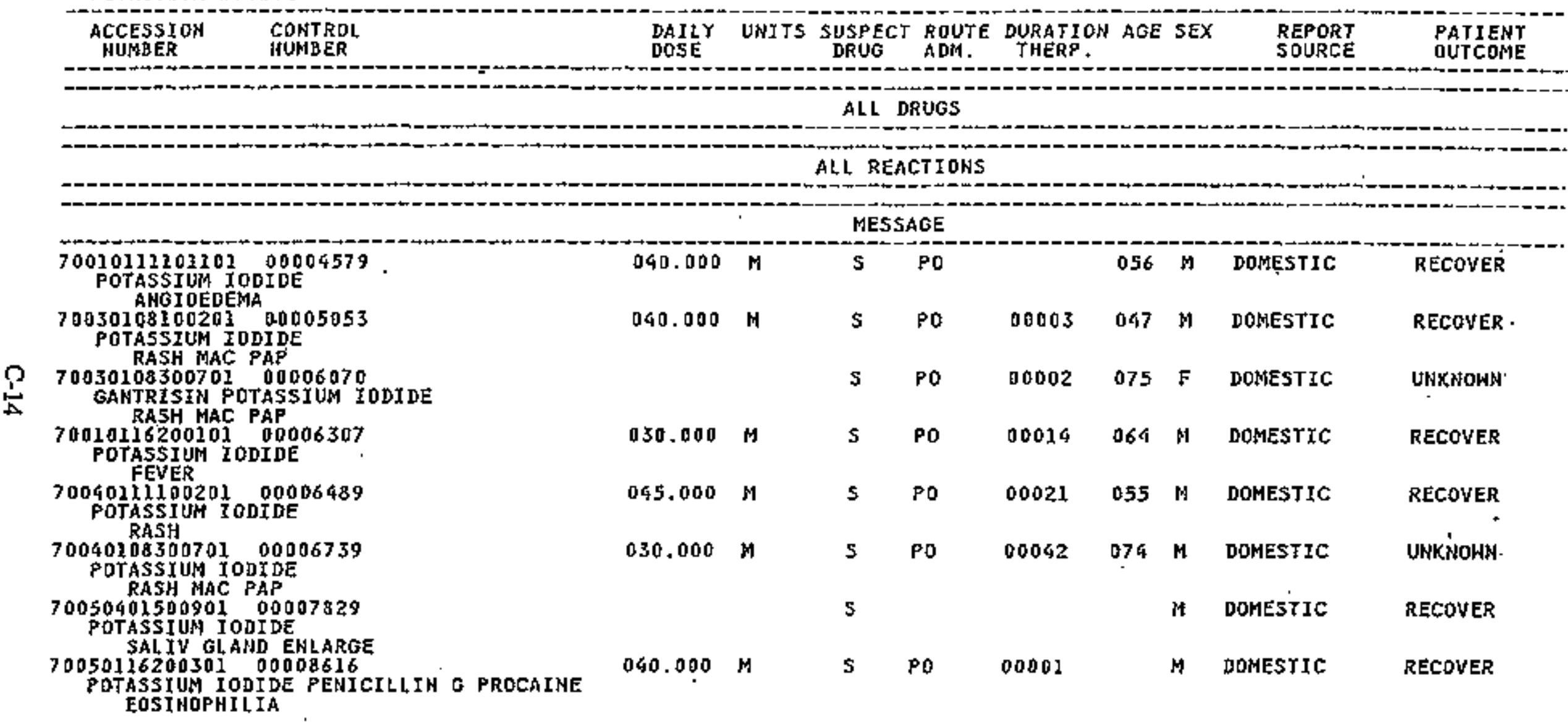


FDA SPONTANEOUS REPORTING SYSTEM

CAUSE-EFFECT RELATIONSHIP BETWEEN EACH DRUG AHD REACTION CANHOT DE ESTADLISHED WITH CERTAINTY IN ALL CASES

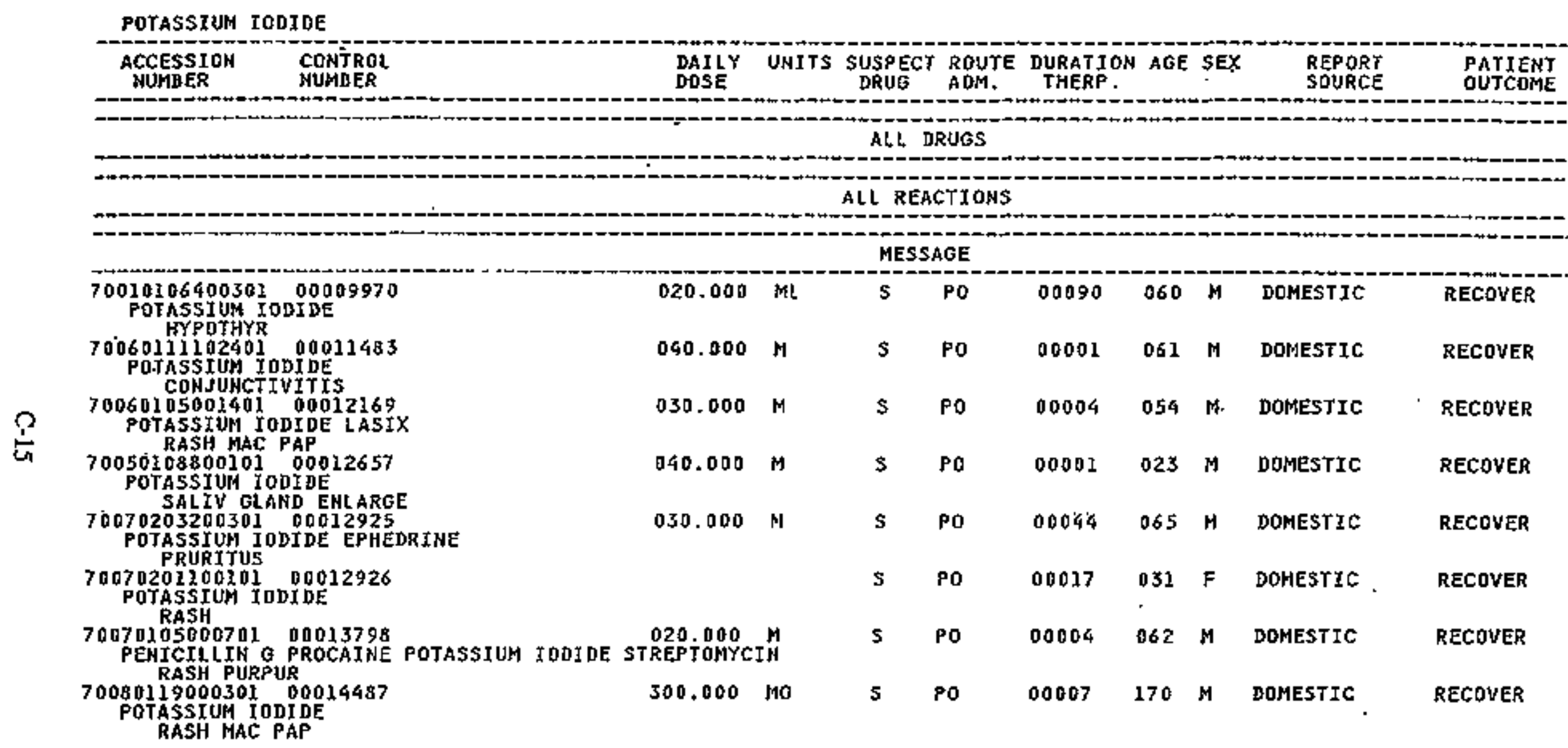


FDA SPONTANEOUS REPORTIHS SYSTEM

CAUSE-EFFECT RELATIONSHIP BETHEEN EACH DRUS AND REACTIOH CANNOT BE ESTABLISHED WITH CERTAINTY IN ALL CASES

POTASSIUM IODEDE

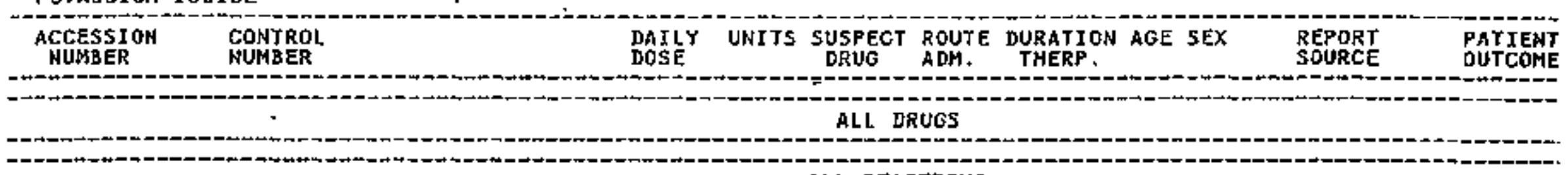

ALL REACTIONS

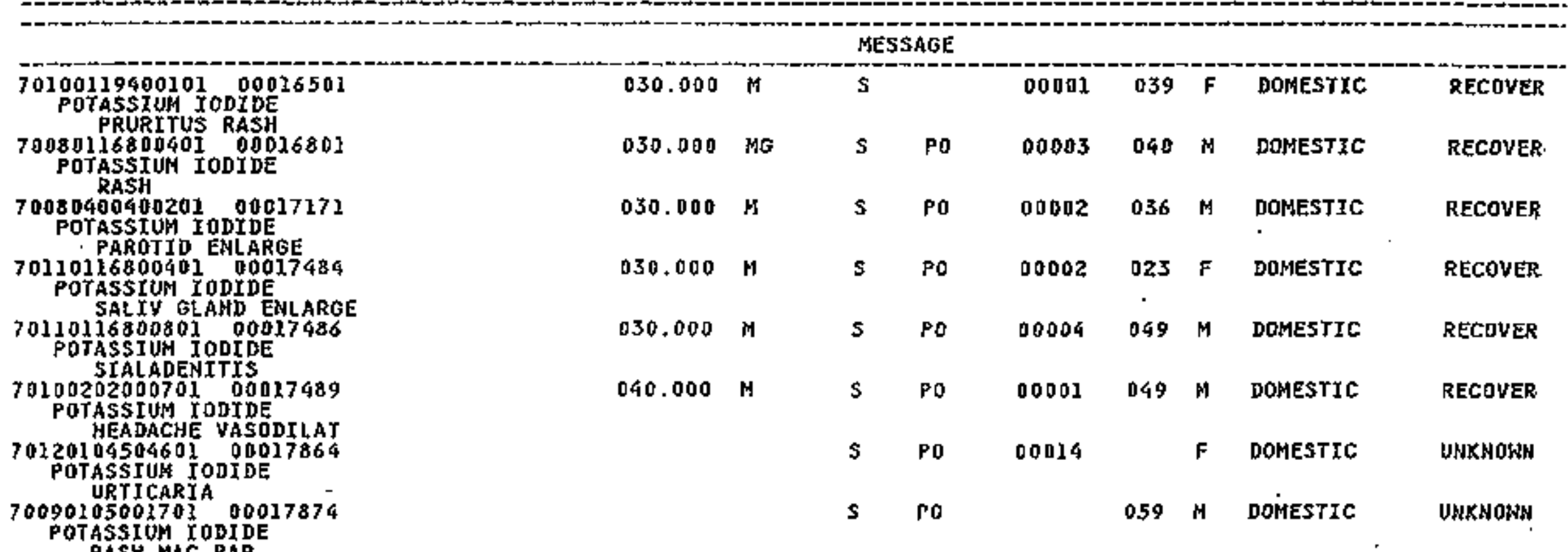


FDA SPONTANEOUS REPORTING SYSTEM

CAUSE-EFFECT RELATIDNSHIP GETHEEH EACH DRUOG AND REACTION CANNOT BE ESTADLISHED WITH CERTAYNTY IN ALL CASES

POTASSIUM IODIDE

$\begin{gathered}\text { ACCESSION } \\ \text { NUMABR }\end{gathered}$
MONTROL

\section{AL, L REACTIONS}

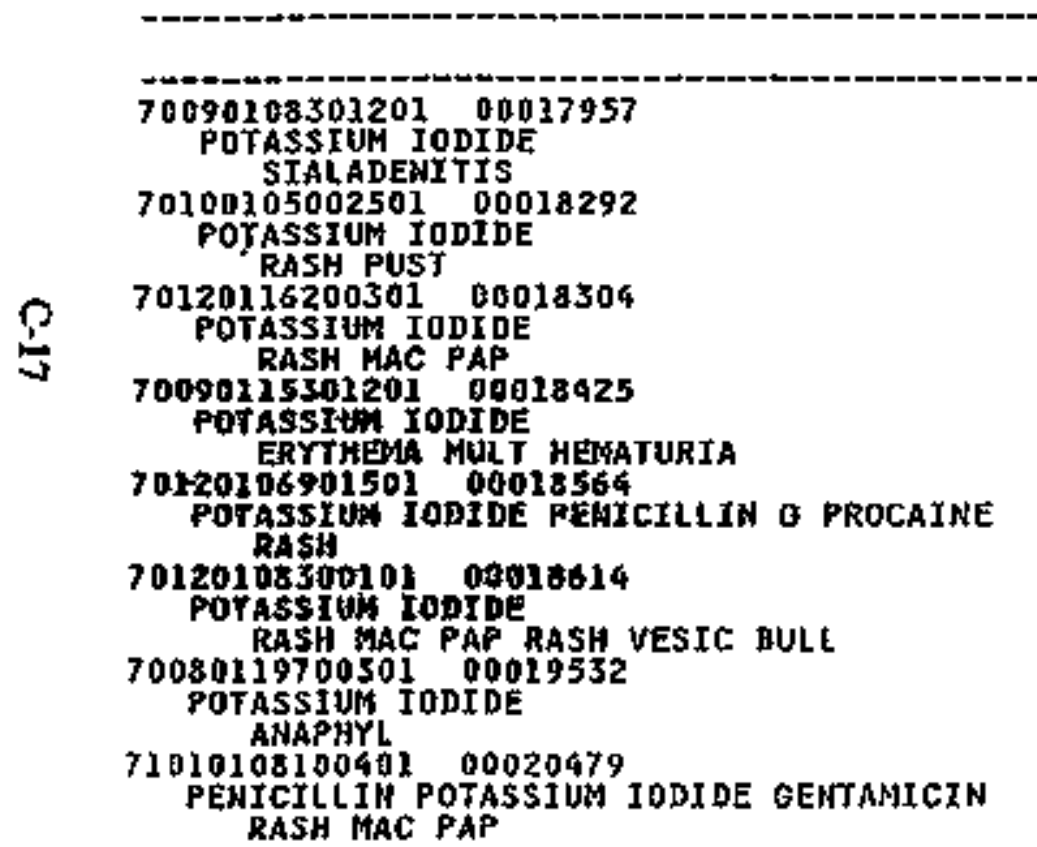

MESSAGE

\begin{tabular}{|c|c|c|c|c|c|c|c|c|}
\hline 025.000 & MO & $\mathbf{s}$ & PO & 00005 & 068 & $M$ & DONESTIC & UNKHYOWN \\
\hline 030.900 & $\mathbf{H}^{+}$ & $\mathbf{s}$ & RO & 0000:144 & 060 & $n$ & DOMESTIC & UNKWOKN \\
\hline 060.000 & MG & $s$ & $\mathrm{PO}$ & 00004 & 061 & $\mathbf{F}$ & DOHESTIC & RECOVER \\
\hline 004.000 & Ts & $s$ & PO & 00002 & 069 & $F$ & DONAESTIC & UNKNOWN \\
\hline 021.030 & h & $s$ & PO & 00004 & & 0 & DOMESTIC & UNKNOWN \\
\hline 040.000 & $M$ & $s$ & Po & 00012 & 045 & $M$ & DOMESTIC & UNKNDWH \\
\hline 020.000 & $M$ & $s$ & PO & 00002 & 036 & $\boldsymbol{F}$ & DOMESTIC & UWKNOWN \\
\hline 020.000 & CC & s & po & 00002 & 072 & $M$ & DOMESTIC & RECOVER \\
\hline
\end{tabular}


FDA SPONTANEOUS REPORTING SYSTEM

CAUSE-EFFECT RELAT JONSHIP BETWEEN EACH DRUG AND REACTIOH CANNOT BE ESTADLISHED WITH CERTAINTY IH ALL CASES

POTASSIUH IODIDE

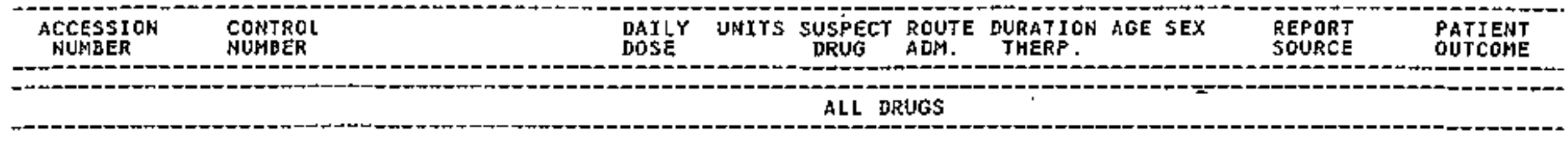

ALL REACTIONS

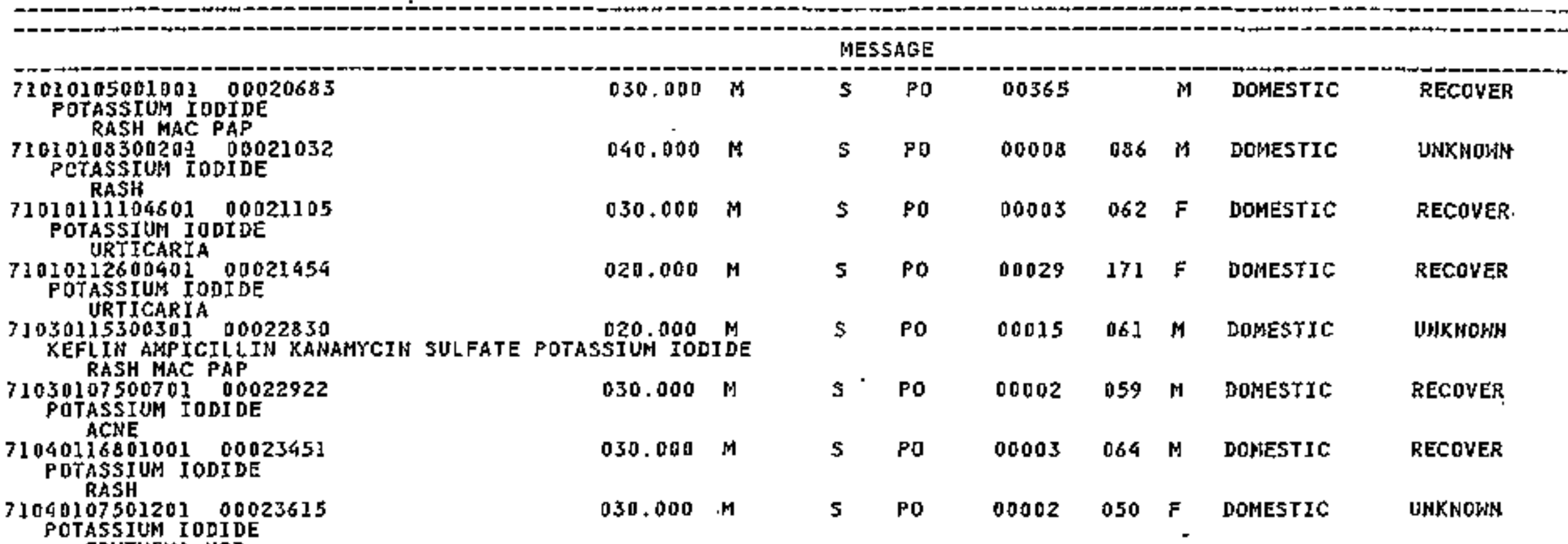


FDA SPONTANEOUS REPORTING SYSTEM

CAUSE-EFFECT RELAT IONSHIP BETHEEN EACH DRUG AND REACTION

CANHOT BE ESTABLISHED WITH CERTAIHTY IN ALL CASES

PDTASSIUM IODTDE

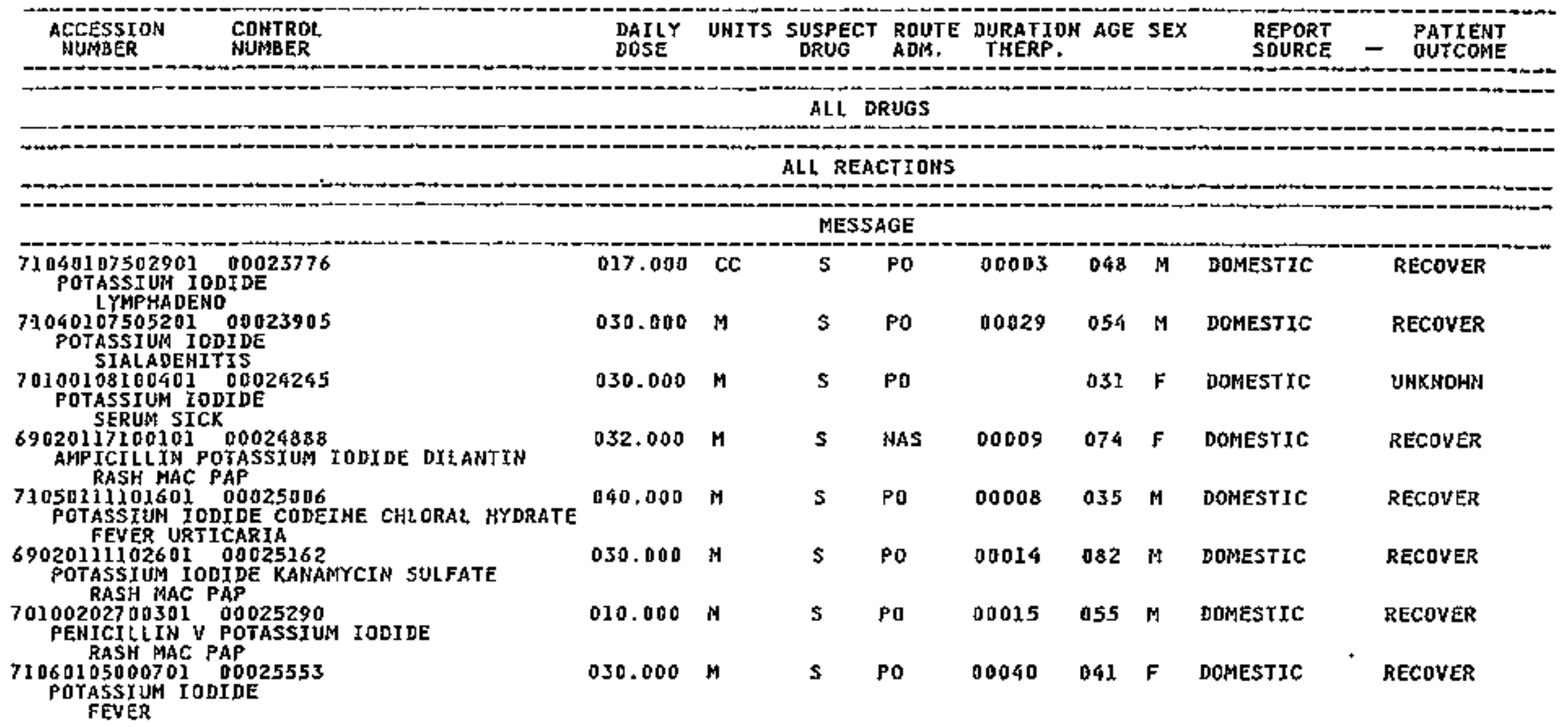


FDA SPONTANEOUS REPORT ING SYSTEM
CAUSE-EFFECT RELATIONSHIP BETWEEN EACH DRUG AND REACTION

CANNDT BE ESTABL ISHED HITH CERTAINTY IN ALL CASES

POTASSIUM IODIDE

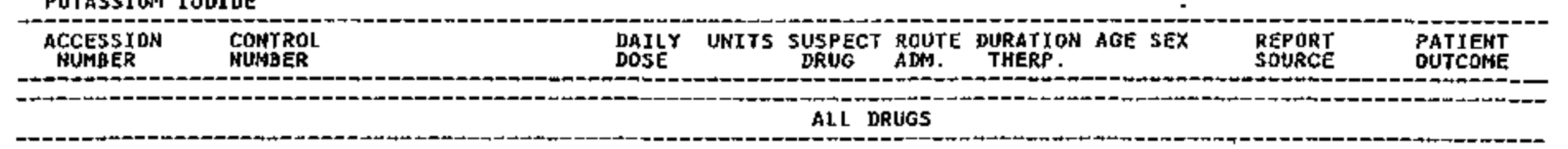

ALL REACTIONS

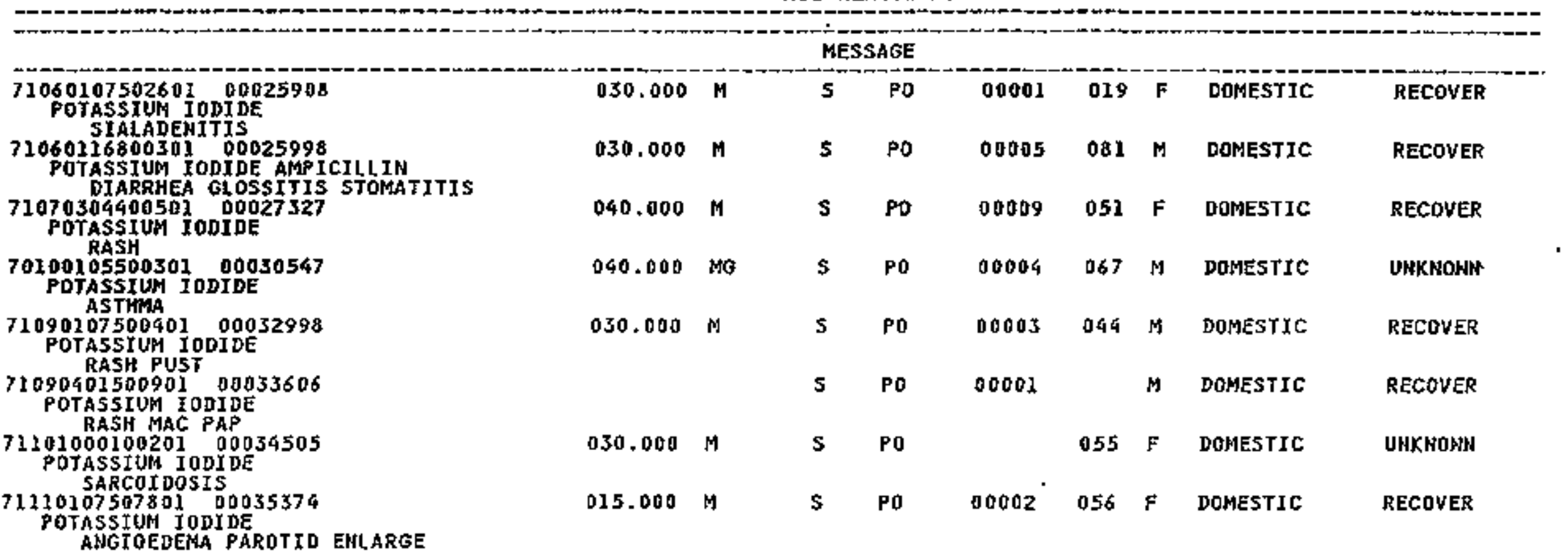


FDA SPONTANEOUS REPORT ING SYSTEM

CAUSE-EFFECT RELATIONSHIP BETWEEN EACH DRUG AHD REACTION CANHOT BE ESTABL SHED WITH CERTAINTY IN ALL CASES

POTASSIUM IODIDE

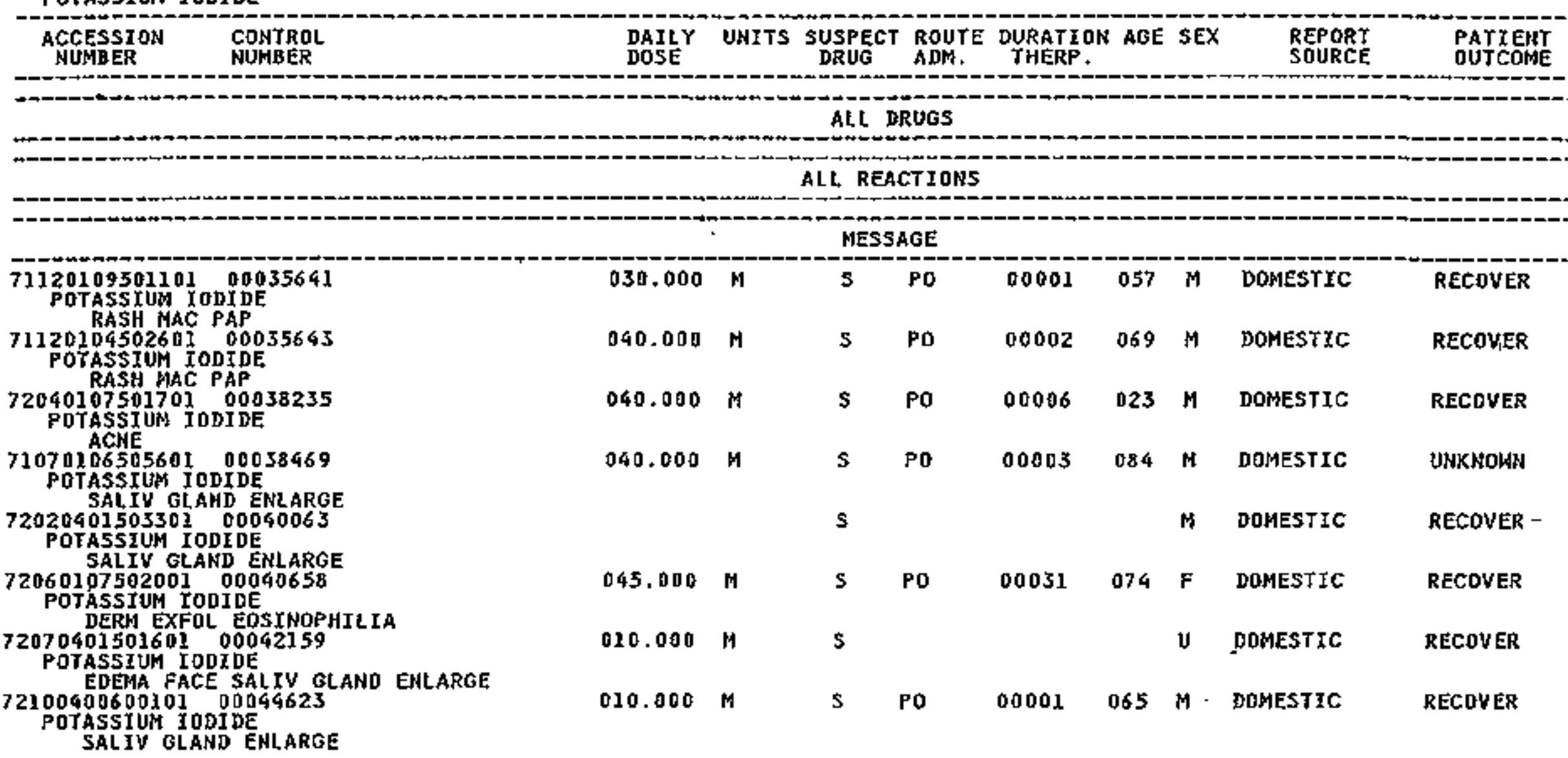


FDA SPONTANEOUS REPORTING SYSTEM

CAUSE-EFFECT RELATIOHSHTP BETNEEN EACH DRUG AND REACTION CANHOT BE ESTABLISHED WITH CERTAINTY IN ALL CASES

PQTASSIUM IODIDE

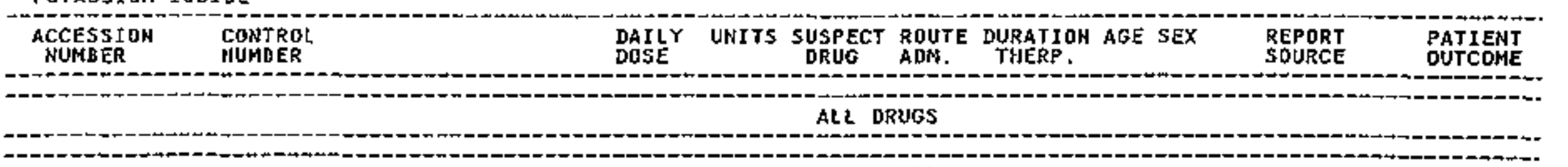

ALL REACTIONS

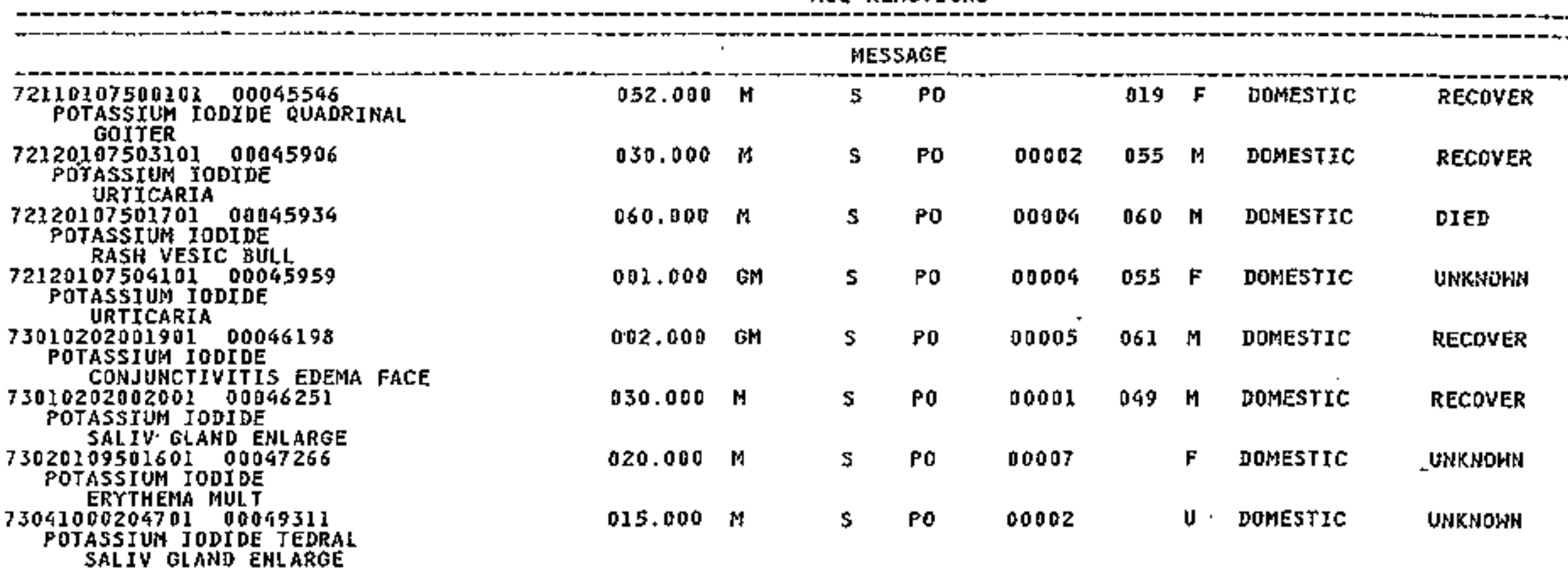


FDA SPOHTANEOUS REPORTIHO SYSTEM

CAUSE-EFFECT RELATIOHSHIP DETWEEH EACH DRUG AND REACTION

CANNOT BE ESTABLISHED UITH CERTAINTY IN ALL CASES

POTASSIUM IODIDE

ACCESSION
HUMBR CONTROE
NUMBER


FDA SPONTANEOUS REPORTING SYSTEM

CAUSE-EFFECT RELATTONSHIP DETUEEN EACH DRUG AND REACTION CANHOT-BE ESTADEISHED WITH CERTAINTY IN ALL CASES

POTASSIUM IODIDE

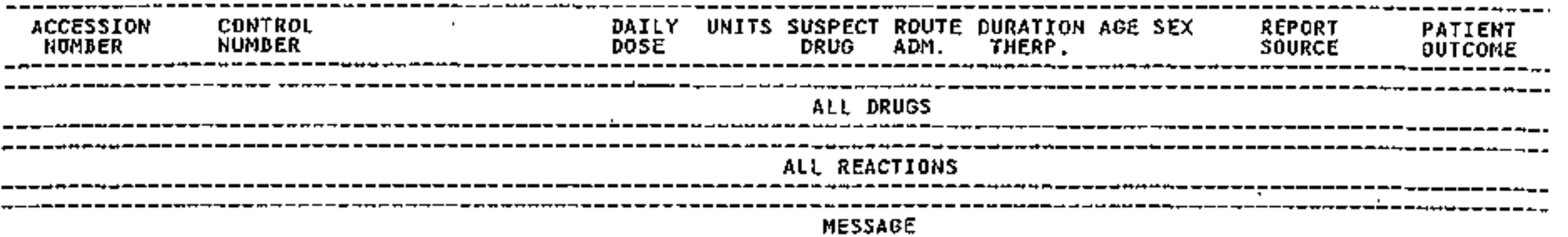

7404100020090100060089

AARANE MARAX POTASSTUM IODIDE

CDUGH INC SPUTUM INC

74120707100503 O0072041

POTASSIUM TODIDE AARANE

GOITER

0

$75040301700301 \quad 00072618$

POTASSIUH IODIDE

75060107506401 00075045

POTASSIUH IODIDE VOMIT

8003110010020100307326

POTASSIUM IODIDE ORAGRAFIN CALCIUM

COHJUNCTIVITIS

HERPES-LIKE ERUPTIONS AND DRAIHAGE FROM EYES.

8408080180001100189743

POTASSIUH IODIDE ASPIRIN

CONJUNCTIVITIS PAIN EYE URTICARIA

EXFEHPORAMENOUPSLY COMPUNDED PRESCRIPTION FOR USE IN RETAIDING THE GRDWTH OF CATARACTS.

a503110010016100332693

PDTASSIUN IODIDE PREMARIN

$\mathbf{s}$

0 DONESTIC UNKNONN

FEVER NECRQ SKIN PAIN EYE PETECHIA

YX DF ALLERGIES TO STREPTOMYCIN, CHLORDIAZEPOXIDE; OCCUPATION: WURS"S AID.

9104080160001100736896 POTASSIUH IODI DE

REACT UNEVAL

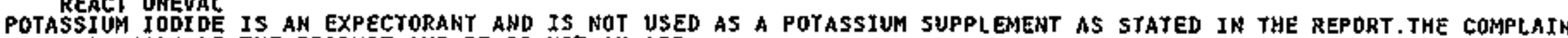
DISCDLDRATION OF THE PRODUCT AND IT IS NOT AH ADR. 
FDA SPOHTANEOUS REPORTIHG SYSTEM

CAUSE-EFFECT RELATIONSHIP DETHEEN EACH DRUG AND REACTIOH CANNDT DE ESTABLISHED WITH CERTAINTY IN ALL CASES

POTASSIUM IODIDE

$\begin{array}{lll}\text { ACCESSION } \\ \text { NUHBER } & \text { CONTROL } & \text { DAILY UNITS SUSPECT ROUTE DURATION AGE SEX } \\ \text { NUMUE } & \text { DOSE }\end{array}$

$$
A L \div D R U G S
$$

ALL REACT IONS

MESSAGE

79121000100000 70009047

POTASSIUM IODIDE

$$
\text { s }
$$

064

DOMESTIC

REPQRT

SOURCE

PATIENT OUTCOME RASH

ثิ 


\section{APPENDIX D}

\section{COST-BENEFIT ANALYSIS}

\section{Introduction}

The rapid proliferacion of commercial nuclear power in the 1970's gave rise to increasing concerns among policy makers to control radiation exposure to the worker and the general public. Policy decisions relating to radiation protection standards had to balance the benefits of exposure reduction to the economic impacts of protective measures. As a nule, whenever radiation exposure can be controlled by a protective measure, its endorsement by policy makers is linked to a favorable cost-benefit ratio. A major difficulty that is frequently encountered, however, is that the cost-benefit requires value judgements for which there are few points of reference, and on which administrative and political authorities must, nevertheless, take a stand. In 1972, Sagan (Sagan 1972) assessed the human cost of nuclear power by establishing a monetary link between radiation exposure and the pririary health consequence of cancer. Applying the 1972 BEIR Committee's risk coefficient of $10^{-4}$ fatal cancers per person-rern to an assigned value of life at $\$ 300,000$, he established the monetary equivalence of $\$ 30$ per personrem.

Over the years, cost-benefit analyses have adopted this or other simplistic models in which radiation exposure is directly converted to monetary terms. White this model approach may be appropriate for some applications, it is grossly jnadequate for others. For example, the previously cited 1972 figure of $\$ 300,000$ would yield a current value of about $\$ 1$ million for a human life. This value may be considered appropriate since it is well witkin the range of values curtently used by Federal agencies as discussed below.

The limitation of this model is demonstrated, however, when it is applied to complex sinuations such as the 1979 accident at the Three Mile Island Nuclear Station. Exposure to the general public was estimated at 3,300 person-rem (Behling 1986). At $\$ 30$ per person-rem, the total econonic impact to the general public at the time of the accident would have been estimated to be between $\$ 100,000$ and $\$ 200,000$. For the complex condition of a major accident, the need for more sophisticated models is obvious.

The first step in the conduct of an impact-value analysis is the identification of pertinent factors that constitute the cost and the benefit. Included are subjective factors that must assess logistical/practical problems, public perceptions, etc. The second and more difficult requirement is the coherent quantification of all factors, ingsmuch as these are not normally expressert in commensurate terms. When cost-benefit parameters are expressed in their usual units, a highly subjective approach is required at the final stage of decision making. A cost-benefit analysis, in which all parameters are expressed in monetary units, can support a more objective and defensible decision. 
The quantification of cost for the protective measure can be made by the conventional method of assigning monetary values to materials, labor, and other resources needed. In specjal circumstances, however, the cost of providing a protective measure must also incorporate a term that represents the potential ham associated with the protective measure itself. For potassium iodide prophylaxis, the cost of public protection must consider the potential adverse reactions to $\mathrm{KI}$ that some individuals may experience (see Appendix C).

The assignment of monetary values to avoidable radiation health eftects is less standardized and of considerable complexity. This appendix provides a comprehensive cost-benefit analysis that compares the programmatic cost of providing KI to the public to the avoidance of costs associated with radioiodine induced thyroid effects. In order to minimize the need for a subjective decision, all major elements that define the cost or the benefit of $\mathrm{KI}$ prophylaxis are expressed in terms of their dollar value.

\section{The Economic Cost of KI Prophylaxis}

Critical to a discussion of cost is the method by which $\mathrm{KI}$ is made available to the general public. The two principal options include stockpiling and predistribution and any policy decision must address the logistical and economic aspects for either option. Logistical considerations are governed by (1) the potentially short time interval between the initiating events of a serious reactor accident and atmospheric releases of radioiodines and (2) the need to administer KI prior to plume exposure for optimum thyroid protection. The timeliness of KI avaijability is most critical to persons living in close proximity to a nuclear facility where potential plume exposures are maximal and plume travel times are small.

In spite of the apparent advantage of timeliness for the predistribution option, there are limitations as well as disadvantages that include the following:

- Accessibility - KI predistributed to households (and stored at the residence) may not be readily available during times when residents are at work, school, etc.

- Availability - At any poimt in time, there are transients as well as new residents to whom KI was not provided.

- Loss or misplacement - Based on a five-year shelf-life/replacement period, there is a significant probability that tablets will be lost or misplaced.

- Improper storage - Improper storage may adversely affect its shelf-life and potency.

- Misuse and accidental administration - Like any pharmaceutical kept by a household, there is a porential for misuse and/or accidental administration.

- Improper disposal - For expired tablets, there is a loss of control for proper disposal. 
Most of the disadvantages associated with predistribution are either eliminated or minimized for the stockpiling option. A program can be developed under the direction of a State's emergency management staff that provides for the necessary controls and oversight of stockpiles. Thus, the advantages for the stockpiling option include proper stotage, controlled access to stockpiles, assurance of adequate replacement and proper disposal of expired capsules.

With a propery trained emergency staff and an informed public, potential problems associated with a timely distribution of KI can be minimized. Timely distribution requires an adequate number of strategically located stockpiles within the community. Suittable locations would include police stations, fire houses, schools, community centers, hospitals and major health care centers, from which an efficient localized doot-tondoor distribution could be conducted or where residents themselves coild procure the needed $K I$.

Beyond logistical and practical issues, a major factor that must be considered in a policy decision that selects stockpiling, predistribution, or a combination of these two options is cost.

A unique aspect of the stockpile option is that it is essentially transparent to the public, and the cost of distribution to residents only becomes a reality in the unlikely event of a major nuclear emergency. Thus, for the stockpile option, the principal cost is the initial purchase of $\mathrm{KJ}$ and its periodic replacement from the two FDA approved sources: Carter Wallace and ANAEX.

- Carter-Wallace - At the current purchase price of $\$ 75.00 /$ carton, containing 100 vials with 14 tablets of $130 \mathrm{mg} \mathrm{KI}$ per vial, the cost per tablet is about five cents. With a suggested five-year shels-life (i.e., replacement period) and a ten-day supply (i.e., ten tablets/individual), the annual cost of KI prophylaxis per individual is about ten cents for the stockpiling option.

- $\quad$ ANBEX - The initial cost for 14 scored tablets of $130 \mathrm{mg} \mathrm{KI}$ in a moisture resistant blister pack is 60 cents per pack with a guaranteed four-year shelf-life. Thereafter, annual payments of 15 cents per package would be required if, and only if, the stockpiled product can pass required FDA tests for stability and effectiveness. The annual stockpiling cost of KI procured from ANBEX would also be about ten cents per indivizual.

Additional costs might include the amendment of existing emergency plans to include protocols for distribution, public notification and training of the emergency staff. These one-time costs, however, are likely to be modest and may only marginally add to the baseline purchase/replacement cost of $\mathrm{KI}$ at ten cents per year per individuas.

For predistribution, the cost of dispensing $\mathrm{KI}$ tablets to residents is an integral part of the program cost. Additionally, for a predistribution program to be effective, there has to be a very comprehensive public relations program, which not only informs the public of the objectives of iodide prophylaxis and provides supportive information regarding safe storage, proper usage, dosage, contraindications, etc., but also establishes public confidence. In summary, the cost for 
predistribution of $\mathrm{KI}$ inciudes the purchase/replacement of $\mathrm{KI}$, the predistribution of tablets, and a comprehensive public information program.

An assessment of cost for the predistribution option can be derived from the Tennessee pilat program in which State officials predistributed KI to residents within a fjve-mile tadjus of the TVA's Sequoyah Nuclear Power Plant. (For a detailed cost analysis of this pilot project, see Appendix E of this report.) It is estimated that the cost of predistribution of $\mathrm{KI}$ to 3,704 households around the Sequoyah Nuclear Power Plant was accomplished at $\$ 125,000.00$. Conservatively assuming that within the five-year replacement time there is no loss of $\mathrm{KI}$ of relocation of bouseholds and that the average household represents four individuals, a lower bound cost per individual for the predistribution option is estimated at $\$ 1.70$ per year.

The cost estimates for providing $K I$ to specific population segments of the Reference LWR are presented in Table D-1 for stockpiling with and without predistribution to the less than five-mile resident population.

Table D-1. Annual Progranmatic Costs of KI Prophytaxis

\begin{tabular}{|c|r|c|c|c|c|}
\hline \multirow{2}{*}{$\begin{array}{c}\text { Distance } \\
\text { (miles) }\end{array}$} & \multirow{2}{*}{$\begin{array}{c}\text { Number of } \\
\text { lindividuals }\end{array}$} & \multicolumn{4}{|c|}{ Distribution Options } \\
\cline { 3 - 6 } & & $\begin{array}{c}\text { Segment cost } \\
(\mathrm{x} \$ 1000)\end{array}$ & $\begin{array}{c}\text { sumulative cost } \\
(\mathrm{x} \$ 1000)\end{array}$ & $\begin{array}{c}\text { segment cost } \\
(\mathrm{x} \$ 1000)\end{array}$ & $\begin{array}{c}\text { cumularive cost } \\
(\mathrm{x} \$ 1000)\end{array}$ \\
\hline$<5$ & 10,699 & 1.1 & 1.1 & 18.2 & 18.2 \\
$5-10$ & 55,142 & 5.5 & 6.6 & 5.5 & 23.7 \\
$10-25$ & 468,472 & 46.8 & 53.4 & 46.8 & 70.5 \\
$25-50$ & $1,820,396$ & 182 & 235.4 & 182 & 252 \\
$50-100$ & $4,713,000$ & 471 & 706.4 & 471 & 723 \\
$100-150$ & $7,855,000$ & 786 & 1,492 & 786 & 1,509 \\
$150-200$ & $10,997,000$ & 1,100 & 2,592 & 1,100 & 2,609 \\
$200-350$ & $51,843,000$ & 5,184 & 7,776 & 5,184 & 7,793 \\
$350-500$ & $80,121,000$ & 8,012 & 15,788 & 8,012 & 15,805 \\
\hline
\end{tabular}

- includes predistribution for the $<5$-mile resident population

\section{The Economic Benefit of KI Prophylaxis}

The "benefits" of protective measures commonly employed to safeguard public health, frequently involve the avoidance of disease, injury, or death. For such cost-benefit analyses, the monetary equivalence of human illness and disease must be assessed for the patient, family, and society. The burden of illness may include financial loss, pain and suffering, reduced quality of life, and premature mortality. This collective burden may extend to family members who must share the 
emotional trauma and economic losses associated with morbidity and mortatity. At a minimum, the econornic benefits must consider the cost of resources used for medical care and the loss of buman resources due to morbidity, disability, and premature death. Additional consideration should be given to the impact of disease, injury, or death on the quality of bife for the affected individual and family members.

To aid decision-makers in situations where allocations of resources can affect health and lifeexpectancy, economists have offered several valuation methods. Methods and models comrnonly used to assess disability, impaiment, and loss of life in monetary terms include, (1) publicly implied valuation, (2) court compensation, and (3) direct valuation by the "cost of illness" approach. These three approaches are briefly discussed below.

\section{Publicly Implied Valuation}

It is clear that society uses implicit values in order to make administrative decisions on resource allocations in areas where human health and lives are at risk. It is reasonable to conclude that administrative decision-makers in their role as public servants, make decisions from which a "social value" of life can be calculated. In the most recent anmual report issued by the Office of Management and Budget (OMB 1991), the cost effectiveness of several Federal programs was assessed. The range of cost per life saved for three Federal prograrn areas are cited in Table D-2. Specific example vahues for medical and traffic safety programs are provided in Table D-3 and D-4, respectively.

Table D-2. Ranges in Publicly Inplied Valuations of Federal Programis"

\begin{tabular}{lc}
\hline Fedemal Program Area & Range of Cosi Per Life Saved (1991 \$'s) \\
\hline Highway Safety & $63,000-3,300,000$ \\
Air Transportation Safery & $100,000-1,600,000$ \\
Occupational Safety & $100,000-74,000,000$ \\
\hline
\end{tabular}

- Reference: OMB 1991 
Table D-3. Publicly Implied Valuation of Life-Saving Medical Programs ${ }^{1}$

\begin{tabular}{lc}
\hline \multicolumn{1}{c}{ Program } & $\$ /$ Llfe-Saved $^{2}$ \\
\hline Cervical Cancer Streening & 63,000 \\
Breast Cancer Screening & 204,000 \\
Lung Cancer Screeaing & 178,000 \\
Colo-Rectal Screening & \\
Fecal Blood Test & 26,000 \\
Proctoscopic Exarns & 76,000 \\
Hypertension Coptrol & 191,000 \\
Kidney Dialysis & 510,000 \\
Mobile Intensive Care Units & \\
in Smal] Towns & 153,000 \\
\hline
\end{tabular}

Reference: Cohen, 1980

Costs as presented in original reference were for 1975. Because health care costs bave more than doubled since 1975, these costs have been adjusted to $1991 \mathrm{~s}$ 's by multiplying original costs by 2.55.

Table D-4. Publicly Implied Valuation of Traffic Safety Measures'

\begin{tabular}{lc}
\hline \multicolumn{1}{c}{ Traffic Safety Measure } & $\$ /$ Life $^{- \text {Saved }^{2}}$ \\
\hline Improved Traffic Signs & 31,000 \\
Improved Lighting & 80,000 \\
Upgtade Guard Ratls & 101,000 \\
Breakaway Sign Supports & 125,000 \\
Obstacle Renoval & 160,000 \\
Median Barrier & 163,000 \\
Impact Attentuator & 167,000 \\
Median Strip & 181,000 \\
Channels; Tum Lanes & 290,000 \\
New Flashing Lights at Railroad & 295,000 \\
Crossings & \\
\hline
\end{tabular}

Reference: DOT 1984

Costs are based on fatal accidents and assume that there are 1.1 fatalities per fatal accident. Cosis are expressed in 1984 dollars.

The relatively wide range in values is not surprising inasmuch as the only common denominator is a reduction in mortality rates. Not reflected in these sets of cited values are important variables, which include (1) average years of life-lost per mortality, (2) the ratio of monality to morbidity/injury and, (3) property damage. Additionally, there may be a host of value judgements that may inctude the potential contribution of the victim by his own conduct, the 
degree with which individual participation is voluntary/involuntary, and the moral, ethical, and/or legal obligation to provide protection.

The public's willingness to pay to save a "statistical life" (i.e., buy risk reduction) was reviewed by the EPA. In a 1983 study, the EPA concluded that the public appears to value risk reduction at a cost between $\$ 600,000$ and $\$ 9,900,000$ per life saved (EPA 1983).

In summary, publicly implied valuations may serve as a reference. However, there are too many ill-defined variables that obscure their direct application in assigning definitive monetary values to thyroid related morbidity and mortality.

\section{Compensation in Lexal Claims}

The second method commonly used to assess the monetary value of injury, morbidity, or death involves the legal system. In instances of medical malpractice, product failure, negligence, etc., the courts must frequently assess the monetary awards granted to the injured party or the survivors. The Court's purpose and function are decision-making on the basis of conflicting evidence. In court, the burden is on the plaintiff and defendant to present information that is believable and accepted by the judge and jury. It can be argued that the size of the awards of damages reflects society's values of compensation for the "collective detriment" of a given situation involving injury or death. In addition to awards of punitive damages, compensatory awards determined by litigation (or ont-of-court settlements) frequently represents the sum of medical costs, property damage, loss of earnings, and psychological factors involving pain and suffering, loss of quality of life, etc. An assessment of monetary judgements awarded plaintiffs in persomal injury cases involving radiation and other injurious agents are discussed below (pages D-28 through D-33).

\section{The "Cost-of-Illness" Approach}

The "cost-of-illness" approach is the third and last method discussed in this repor. Because it is the most common and defensible of the methods used among health-policy researchers and health care administrators, a more detailed analysis of this method will be provided. The "costof-iliness" approach was pioneered by Dorothy Rice, former Director of the National Center for Health Statistics (Rice 1985), and is frequently used to assess the economic burden of disease. In brief, this methoplology is defined by three components that inciude: direct medical costs; morbidity/mortality costs; and psychological costs.

Direct costs include resources used for medical care from the time of diagnosis until total recovery or death. Morbidity and mortality costs, when combined, are referred to as indirect costs (Hodgson 1984). Indirect costs are the time and output lost or foregone by the family members and others from employment (inciuding imputed earnings for domestic work), volunteer activities, and leisure. Lastly, morbidity and mortality invariably cause patients and family members to incur psychological costs, such as pain and suffering, impaired function in personal relationships, and a general reduction in the quality of life. 
National estimates of the direct and indirect economic burden of neoplasms were originally reported for the year 1980 (Rice 1985). Direct costs were derived from data collected by the Health Care Financing Administration, which has estimated national health expenditures according to type of service (e.g., hospital care and physician services) and source of funds (Gibson 1983). The direct costs of personal health care are summarized in Table D-5 below.

For 1980, the American Cancer Society estimated that there were over five million living Americans with a history of cancer, of which two million were diagnosed within the previous five years and with new cases occurring at the rate of 900,000 per year (ACS 1982). For that same year, neoplasms required 26 million days of hospital care and 27 million visits to physicians for diagnosis and treatment. The total costs for medical care of neoplasms for the five million cancer patients were $\$ 13.6$ billion in 1980 . This yiejds an average annual medical cost of about $\$ 2,700$ per cancer patient.

Table D-5. Summary of Direct Health Care Expenditures for Neoplasms in $1980^{1}$ (cost expressed in millions of dollars)

\begin{tabular}{lcccccc}
\hline Neoplasms & $\begin{array}{c}\text { Hospital } \\
\text { Care }\end{array}$ & $\begin{array}{c}\text { Physicians } \\
\text { Services }\end{array}$ & $\begin{array}{c}\text { Nursing Homle } \\
\text { Care }\end{array}$ & Drugs & $\begin{array}{c}\text { Other Profess. } \\
\text { Services }\end{array}$ & Total \\
\hline All Neoplasnts & 9,130 & 3,163 & 469 & 677 & 184 & 13,623 \\
Malignant & 7,462 & 2,264 & -- & 430 & 166 & $10,322^{2}$ \\
Benign & 1,667 & 900 & - & 247 & 18 & $2,832^{2}$ \\
\hline
\end{tabular}

' Reference: Rice 1985

? Does not include expenditures for Nursing Home Care.

The indirect casts for morbidity were derived from work-loss days due to illness data obtained from the National Health Interview Study. Morbibity costs of neoplasms were estimated for the currently employed, persons not institutionalized, who were unable to wotk, and women unable to keep house because of illness or disability (Table D-6).

Table D-6. Summary of Morbidity Costs of Neoplasms' (in millions of doltars)

\begin{tabular}{lcccc}
\hline Type & $\begin{array}{c}\text { Currently } \\
\text { Enployed }\end{array}$ & $\begin{array}{c}\text { Unable } \\
\text { To Work }\end{array}$ & $\begin{array}{c}\text { Keepiag } \\
\text { House }\end{array}$ & Tota] \\
\hline All Neoplastrs & 1,017 & 1,205 & 342 & 2,563 \\
Malignant & 582 & 1,096 & 205 & 1,882 \\
Benign & 435 & 109 & 137 & 681 \\
\hline
\end{tabular}

1 Reference: Hadgson 1984 
Morbidity and disability from neoplasms in 1980 resulted in nearly $\$ 2.6$ billion of the output and productivity foregone as measured wages and salaries of idled labor and housekeepers. Morbidity losses from malignant neoplasms were aearly three times those of benign neoplasms. For each of the five million living cancer patients in 1980, the average indirect cost due to loss of economic opportunity was $\$ 512$ per year.

Lastly, the indirect costs due to cancer mortality were based on estimates of the number of years lost to premature cancer-induced deaths using cancer-mortality data from the National Center for Health Statistics (Table D-7). The number of years lost for each age/sex category was multiplied by the expected eamings for each category, including imputed value of housekeeping services. For the 422,702 persons who died of neoplasms in 1980 , it is estimated that their premature death represented a total of 6.8 million person-years lost. The average number of years lost per individual was estimated at 14 for males and 18 for females. These values yield an average monetary value of about $\$ 64,000$ per premature cancer death or about $\$ 4,000$ for every year of life lost.

Table D-7. Summary of Mortality Costs for Neoplasms in 1980

(in millions of dollars)

\begin{tabular}{lccc}
\hline & Both Sexes & Males & Females \\
\cline { 2 - 4 } All Neoplasms & 26,994 & 15,713 & 11,280 \\
Maligtant & 26,506 & 15,438 & 11,068 \\
Benigga & 488 & 275 & 212 \\
\hline
\end{tabular}

The economic impact of neopjasms for 1980 was updated for the year 1985 (Rice 1989) and more recently for 1990 (Brown 1990). Table D-8 is a summary of the direct and indirect costs of neoplasms for 1990 . 
Table D-8. Estimated Direct and Inditirect Costs for Neoplasms for $\mathbf{1 9 9 0}$

\begin{tabular}{cc}
\hline Cost Category & $\begin{array}{c}\text { Cost for } 1990 \\
\text { (millions of \$) }\end{array}$ \\
\hline Direct Costs & 35,256 \\
Malignant & 29,328 \\
Benigd & 5,928 \\
Indirect Costs & \\
\hline Morbidity & 11,896 \\
Malignant & 9,895 \\
Benign & 2,001 \\
Mortality & 56,788 \\
Malignant & 55,127 \\
Tocal_(Direct and Indirect) & 103,940 \\
Malignant & 94,350 \\
Benign & 9,590 \\
\hline
\end{tabular}

While the above cited prevalence-basted data provides useful information regarding the economic burden incurred for a given year for various diagnostic groups of neoplasms, this type of information is not without criticism (Robirson 1986; Shiell 1987) and has a limited value in the application of a cost-benefit analysis (Weinstein 1986).

A frequent criticism of the prevalence-based approach is that it represents the aggregate economic burden of direct and indirect costs incurred only in the current year due to all prevalent disease in that same year.

It is generally assumed that a cost-benefit analysis is more accurately defined by an "incidencebased" cost, which represents the direct and indirect costs of a disease as they occur from the time of diagnosis until recovery/death. These dated costs can then be summed, using the economic principle of discounting. In principle this states that when costs to be incurred in the future are discounfed, they are reduced when compared with current costs in order to account for the fact that dollars invested in productive resources today will yield returns in the future. A discount rate of five percent is commonly used in cost-benefit studies of health care issues (Luce 1990).

Federal agencies are currently cootdinating efforts to construct incidence-based cost-of-illness estimates (Brown 1990). This involves the linkage of data between NCl's Surveiltance, Epidemiology, and End Results (SEER) Program, and the Medicare program files maintained by the Health Care Financing Administration (HCFA). The successful linkage of these databases will, in the future, provide cost estimates of illness on a patient by patient basis from the time of diagnosis to the time of death or total recovery. 
Preliminary direct cost-of-illness data have recently been obtained on this basis (Baker 1989). From the continuous Medicare History Sample File (CMHSF) maintained by the Health Care Financing Administration, 125,832 individuals were identified with an "initial" diagnosis of cancer among the 1.6 million CMHSF sample cohort. Data analyzed for these Medicare beneficiaries included costs for inpatient hospital stays, skilled nursing facility stays, home heatth agency use, physician services, and outpatient care. Costs were assigned to three time intervals; (1) initial treatment (i.e., first three months following diagnosis); (2) continuing care (i.e, interval between initial and terminal treatment); and (3) terminal treatment (i.e., final six months prior to death).

Table D-9 lists phase-specific treatment costs for each of the 13 cancer diagnostic groups.

Table D-9. Charges Made to Medicare for Treatment During the Initial, Continuing, and Terminal Phases of Cancer of 13 Sites (in 1984 dollars)

\begin{tabular}{|c|c|c|c|c|c|}
\hline \multirow{3}{*}{$\begin{array}{l}\text { Conber Site } \\
\text { Colorectal }\end{array}$} & \multicolumn{5}{|c|}{ Cancer Ptast } \\
\hline & \multicolumn{2}{|c|}{$\begin{array}{c}\text { Initital } \\
\text { (3 montis) }\end{array}$} & \multirow{2}{*}{$\begin{array}{c}\begin{array}{c}\text { Contrinting } \\
\text { (Monthly) }\end{array} \\
\$ 572\end{array}$} & \multicolumn{2}{|c|}{$\begin{array}{l}\text { Terminal } \\
\text { (6 months) }\end{array}$} \\
\hline & $\$ 14,190$ & $(96.5)$ & & $\$ 15,776$ & $(222.3)$ \\
\hline Lung & 12,916 & $(147,1)$ & 690 & 15,565 & $(273.1)$ \\
\hline Prostate & 8,112 & $(69.4)$ & 560 & $\{4,613$ & $(283,2)$ \\
\hline Breast & 7,606 & $(58.1)$ & 483 & 15,136 & (301.9) \\
\hline Bladder & 8,470 & $(122.2)$ & 766 & 18,577 & $(447.3)$ \\
\hline Leukemia & 9,068 & $(307.7)$ & 676 & 19,777 & $(692.9)$ \\
\hline Pancteas & 14,009 & $(468.5)$ & 677 & 14,790 & $(737,9)$ \\
\hline Stomach & 14,443 & $(314.7)$ & 660 & 16,132 & $(639.5)$ \\
\hline Uterine Corpus & 9,260 & $(134,8)$ & 424 & 17,623 & $(741.2)$ \\
\hline Kidney & 12,608 & (241.1) & 670 & 19,302 & (994.2) \\
\hline Ovary & 11,055 & $(272.5)$ & 647 & 18,650 & (867.9) \\
\hline Uterine Cervix & 8,979 & $(269.6)$ & 493 & 16,414 & $(924.6)$ \\
\hline Melanouta & 6,954 & $(201.8)$ & 488 & 16,194 & $(905.9)$ \\
\hline $\begin{array}{l}\text { All sites } \\
\text { coinbined }\end{array}$ & 10,039 & (35.1) & 578 & 16,280 & $(98.7)$ \\
\hline
\end{tabular}

- (Standard ertor of the mean)

Initial treatment of a cancer varied in average cost from about $\$ 7,000$ for melanoma to more than $\$ 14,000$ for digestive system cancers. Differences in initial costs are thought to reflect the extent of etrrgery involved as well as the foed for short-term post-surgical care representing the 13 cancer sites. Continuing care costs do not show as much variation by site as do initial treatment costs. Contimuing care costs were, however, defined per unit of time (i.e., month) and provide no cost estimate for the full duration. Terminal care costs show the least variability 
by site, when compared to the initial or contiming care phases of cancer treatment. The weighted average direct costs for all cancer sites yielded values of $\$ 10,039$ for the initial, $\$ 578$ per month for continuing, and $\$ 16,280$ for teminal care of cancers expressed in 1984 dollars.

\section{Conclusion}

For a cost-benefit analysis involving radiztion induced thyroid disorders, currently avaijable incidence-based cost-of-iliness data is neither sufficiently detailed nor complete. This is due to the following reasons: (1) thyroid neoplasms have not been identified as a distinct cancer category, (2) costs such as psychological costs bave not been quantified for any cancer site, and (3) even if incidencetbased thyroid cost values were extracted from the CMHSF database, these values would require extensive modification to account for a shift in age: CMHSF prevalencebased cost-of-illness vajues presented above comespond to spontaneous occurring/idiopathic carcers in the U.S. population. On the average, thyroid cancer induction by accidental exposure to radioiodine would undoubtedly occur at a younger age than spontaneously occurring thyroid cancers. This shift in age woujd have a significant inpact on indirect costs.

In summary, there currently exists insufficient incidence-based data for quantifying costs for thyroid disorders. In order to assess the cost-beneft of $\mathrm{KI}$ prophylaxis, the author of this report considered it necessary to derive cost estimates for each thyroid disorder, on the basis of (1) direct medical expendinures, (2) individual costs resulting from the loss of economic opportunities, and (3) psychological costs imposed by the intangible impacts of the thyroid disorder. The derivation of these monetary values is preseated below.

\section{Derivation of the Monetary Value of Avoidable Thyroid Health Effects}

\section{Derivation of Direat Costs}

Direct cost estimates of radiation-induced thyroid illness include medical costs associated with the initial diagnosis, treatrnent of the tisease, and the long-term management, surveillance, and care of the patient. Estimates of costs for relevant diagnostic procedures, treatments, hospitalization, etc. are based on 1991 government and private insurers' reimbursement schedules defined by Physicians' Current Procedural Tenminology (CPT) Codes. CPT is a listing of descriptive terms and identifying codes for reporting medical services and procedures performed by physicians under government and private health insurance programs. Additional information was obtained from the Health Care Financing Administration Division (HCFA) of the U.S. Department of Health and Human Services. The HCFA maintains a computer database that identifies current health care costs for specific Diagnosis Related Groups (DRGs). DRG 290 identifies surgical procedures involving the thyroid.

Thyroid Nodules. Table D-10 identifies specific cost elements for a benign nodule that may or may not require surgery. Costs are segregated on the basis of belonging to the initial diagnosis, trearment, or long-term follow-up. For long-term follow-up of patients, an average residual life- 
expectancy of 30 years is assumed following the initial diagnosis of a nodule. Estimates of costs for long-term patient management and surveiflance inchude routine office visits, hormone replacement therapy, and diagnostic procedures. For a benign thyroid nodule that does not require surgery, a lifetime medical cost of $\$ 5,148$ to $\$ 7.375$ was identified. When surgery is required, direct medical costs for a tenign nodule range between $\$ 11,820$ and $\$ 14,047$. For either situation, the upper value reflects the discretionary use of ultrasound for patient evaluation.

Tạble D-10. Medical Costs for Benigg Thyroid Nodule

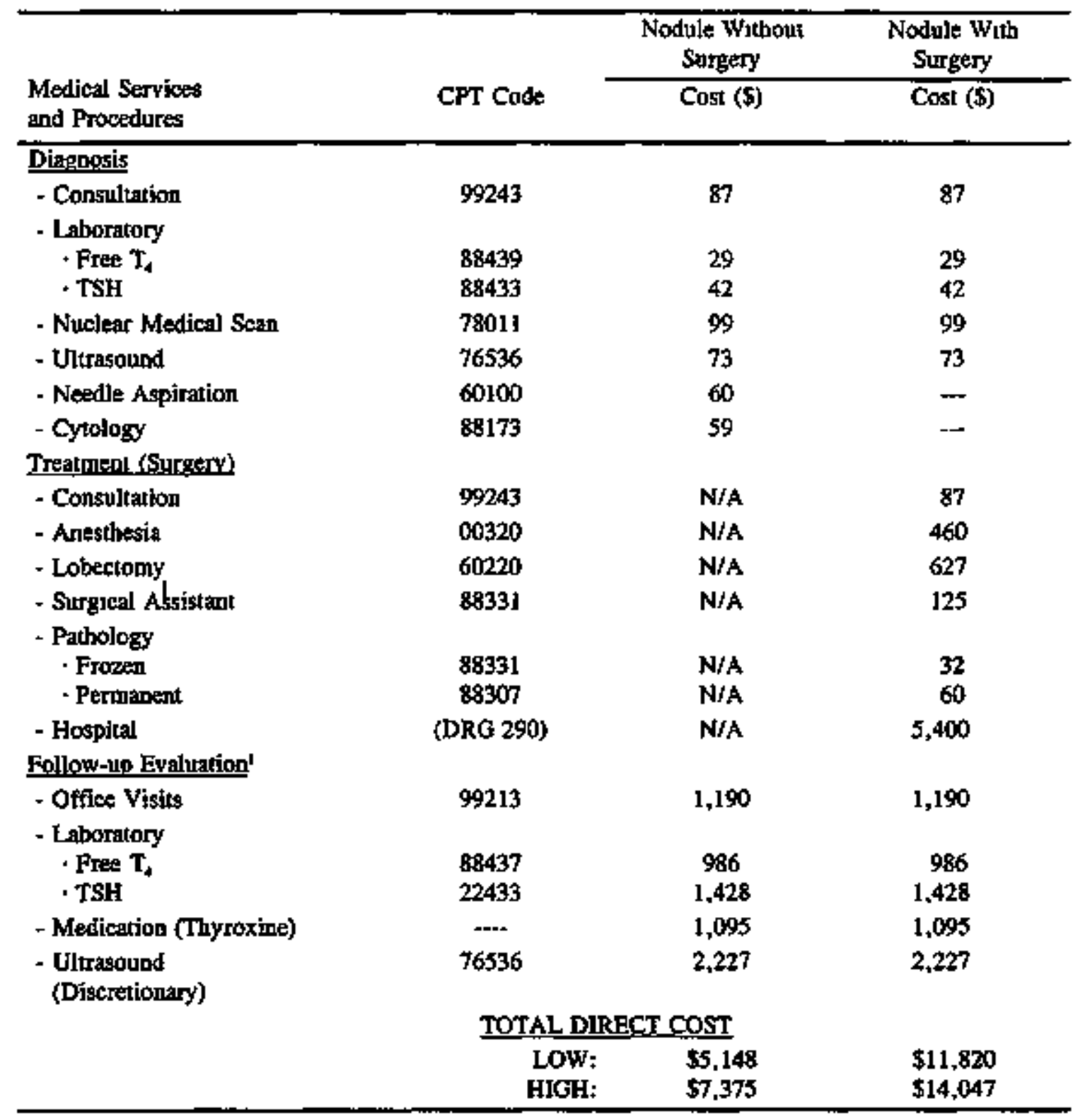

1 Follow-up evaluation assumes an average of 30 years of residual life-expectancy following injtial diagnosis of benign nodule. Patient follow-up evaluations are four times in first year, two times to second year, and once a year for the temaining 28 years. 
Thyroid Cancer. The major cost difference between a thyroid cancer and a thyroid nodule is the need for aggressive treatment of the former. Tabie D-11 cites medical costs for a thyroid malignancy that is estimated to range between $\$ 15,413$ and $\$ 19,348$. This range in cost estimates may, nevertheless, be low in instances where residual thyroid tissue is suspected of malignancy following an initiai course of treatment. In cases of persistent suspected malignancy, additional I-131 therapies and associated procedures and services are required. It is estimated that each additional I-131 therapy would inerease the total cost by about $\$ 4,000$. In rare instances, up to ten separate therapeutic treatments may be required for the total eradication of malignancy.

For the ten percent of thyroid malignancies that are fatal, cost estimates are adjusted to reflect (1) the reduced follow-up period of medical care and (2) the terminal patient care costs. Based on mean survival times of papiliary and follicular thyroid cancers, the mean follow-up period of 35 years assumed for non-fatal cancer is reduced to about nine years. From the previous Table D-9, it was conservatively estimated that the average terminal care of a cancer patient costs about $\$ 16,000$.

Given the variable options available for the treatment and management of thyroid malignancies and the range of virulence that may require multiple therapeutic treatments with I-131 or result in premature death, the following direct costs were assigned to thyroid cancer:

$$
\begin{aligned}
\text { Non-fatal Thyroid Malignancy } & =\$ 20,000 \\
\text { Fatal Thyroid Malignancy } & =\$ 32,000
\end{aligned}
$$


Table D-11. Medical Casts for Thyroid Cancer

\begin{tabular}{|c|c|c|}
\hline Medicat Services and Proctudures & CPT Code & $\cos (5)$ \\
\hline 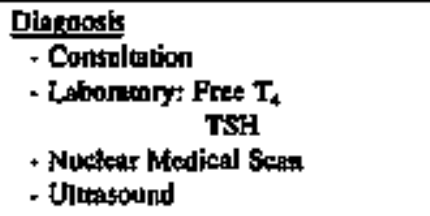 & $\begin{array}{l}99243 \\
\$ 8437 \\
99433 \\
78011 \\
76596\end{array}$ & $\begin{array}{l}87 \\
29 \\
42 \\
99 \\
73\end{array}$ \\
\hline 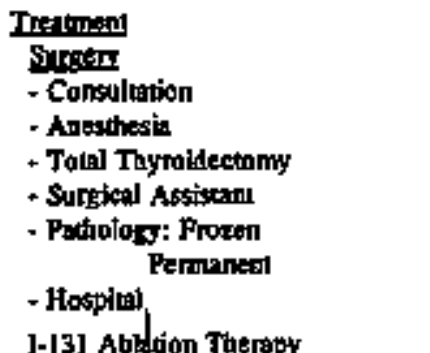 & $\begin{array}{c}99243 \\
00320 \\
60252 \\
201 \\
88331 \\
88307 \\
\text { (DRO 290) }\end{array}$ & $\begin{array}{r}87 \\
576 \\
975 \\
195 \\
32 \\
60 \\
5.460\end{array}$ \\
\hline 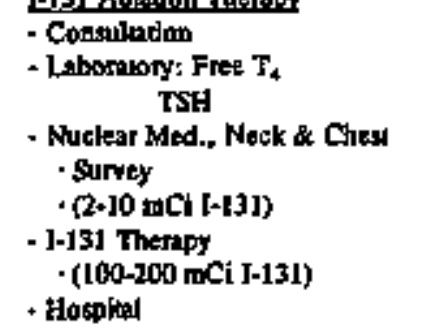 & $\begin{array}{l}99243 \\
88437 \\
88433 \\
78015 \\
79900 \\
79035 \\
79900 \\
(0 R 0299)\end{array}$ & $\begin{array}{c}87 \\
29 \\
42 \\
115 \\
90-1204 \\
129 \\
564-1,064 \\
1,350\end{array}$ \\
\hline 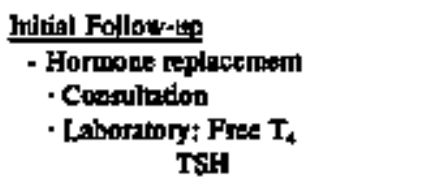 & $\begin{array}{l}99213 \\
88437 \\
88433\end{array}$ & $\begin{array}{l}35 \\
29 \\
42\end{array}$ \\
\hline 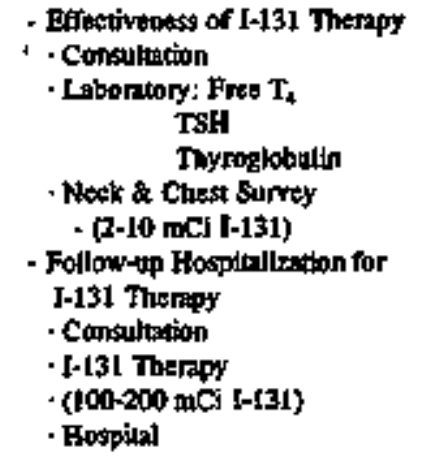 & $\begin{array}{c}9913 \\
88457 \\
88433 \\
86318 \\
78015 \\
79900 \\
\\
99221 \\
78015 \\
7900 \\
\text { (0RO 290) }\end{array}$ & $\begin{array}{c}35 \\
29 \\
42 \\
19 \\
115 \\
90-120 \\
\\
210 \\
115 \\
564-1,064 \\
1,350\end{array}$ \\
\hline 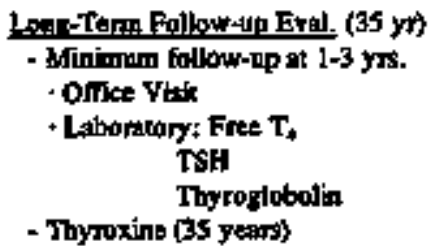 & $\begin{array}{c}99213 \\
88437 \\
88433 \\
88318 \\
25\end{array}$ & $\begin{array}{llr}3 \mathrm{Yr} & \text { or } & 1, \mathrm{Yr} \\
420 & 1,225 \\
348 & 1.015 \\
504 & 1.470 \\
228 & & 565\end{array}$ \\
\hline & $\begin{array}{l}\text { TOTAL DRECT COSTS: } \\
\text { LOWER RANCIE COSTS: } \\
\text { UPPER RANGE COSTS: }\end{array}$ & $\begin{array}{l}\$ 15,413 \cdot \$ 19,348 \\
>\$ \$ 0,000\end{array}$ \\
\hline
\end{tabular}

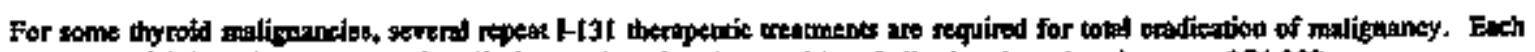

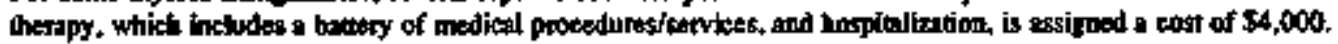


Hypothyroidism. Medical cost in cases of radiation induced hypothyroidism are limited to initial diagnostic tests that confirm the reduction or loss of thyroid function, hormone replacement and management, and follow-up evaluation of thyroid status. Specific cost elements are identified in Table D-12. Cost estimates are based on a 35-year life-expectancy following the diagnosis and loss of thyroid function. For hypothyroidism, medical costs are estimated at $\$ 5,669$.

Table D-12. Medical Costs for Hypothyroidism

\begin{tabular}{|c|c|c|}
\hline Medical Service of Procedure & CPT Code & Cost (\$) \\
\hline \multicolumn{3}{|l|}{ Diagnosis } \\
\hline - Consultation & 99243 & 87 \\
\hline $\begin{array}{c}\text { - L,aborasory: Free } \mathbf{T}_{4} \\
\text { TSH }\end{array}$ & $\begin{array}{l}88439 \\
88433\end{array}$ & $\begin{array}{l}29 \\
42\end{array}$ \\
\hline - Nuclear Medicine Scan & 78011 & 99 \\
\hline \multicolumn{3}{|l|}{ Follow-un Evaluations ${ }^{-1}(35 \mathrm{yt})$} \\
\hline - Office Visit & 99213 & 1,365 \\
\hline $\begin{array}{c}\text { - Laboralory: Free } T_{4} \\
\text { TSH }\end{array}$ & $\begin{array}{l}88439 \\
88433\end{array}$ & $\begin{array}{l}1,131 \\
1,638\end{array}$ \\
\hline \multirow[t]{2}{*}{$\begin{array}{l}\text { - Hormone Replacement } \\
\text { (medication) }\end{array}$} & $m$ & 1,278 \\
\hline & RECT COSTS: & $\$ 5,669$ \\
\hline
\end{tabular}

4ssumes four times in first year, two times in second year, and once for remaining years.

Table D-13 provides a summary of direct medical costs estimates for the four radiation thyroid effects under consideration.

Table D-13. Summary of Direct Medical Costs

\begin{tabular}{lc}
\hline Thyroid Disorder & $\begin{array}{c}\text { Total Direct } \\
\text { Cost }(\mathbf{5})\end{array}$ \\
\hline Thyroid Nodule" & 9,600 \\
Thyroid Cancer & \\
- Non-fatal & 20,000 \\
- Fatal & 32,000 \\
Hypothyroidism & 5,600 \\
\hline
\end{tabular}

D-16 


\section{Derivation of Indirect Costs}

Loss of Time. Indirect costs principally reflect the time and ouput lost or forfeited by the patient due to illmess, permanent disability, and premature mortaiity. Inoirect costs may also be incurred by ${ }_{j}$ individuals other than the patient who may forego economic activities to accommodate a family member's iliness. Economic activities include ockupational work that is lost to either the patient or his/her employer, as well as non-occupational (e.g., domestic) work that must be performed by someone else at the expense of the patient. For illness, the loss of time from economic opportunities corresponds to three discrete stages:

(1) Illness - The period of time during which the thyroid dysfunction becomes sufficiently symptornatic and prompts the individual to seek medical evaluation and treatment. During this time, the patient may physically suffer from either hyper* or hyposecretion by the thyroid gland.

Hypersecretion by the thyroid due to a toxic nodule/cancer may be manifested by nervousness, weight Ioss, heat intolerance, tachycardia, palpitation, diarrhea, tremor, and muscle weakness.

Hyposecretion due to ablation of the thyroid gland may be manifested by slowing of mental processes, lethargy, weakness, cold intolerance, dry skin, constipation and possible myocardial insufficiency.

Either of these conditions is likely to render an individual physically unfit for nomal work and leisure activities.

(2) Treatment - Thyroidectomy and therapeutic administration of I-131 require hospitalization and convalescence: radiojodine therapy also requires that a patient be first rendered hypothyroid.

(3) Long-Term Manggement - Following treatment, the patient in most instances, is stbject to a lifetime dependency on daily doses of thyroxine and must be periodically monitored for proper dosage. The patient must also be monitored for the recurrence of nodule/cancer. Patient maragement and surveillance require routine office visits and clinical evaluation. It is estimated that office visits and outpatient clinical evaluation on the average, represents a loss of one day per year for the life of the patient.

Table D-14 provides estimates of the average total number of days lost from economic activities for the various thyroid disorders. 


\section{Table D-14. Time Last From Economic Activities Due to Radiation Induced Thyroid Illness}

\begin{tabular}{lcccc}
\hline & \multicolumn{4}{c}{ Time Lost (Days) } \\
\cline { 2 - 5 } Thyroid Disorder & Iliness & $\begin{array}{c}\text { Diagnosist } \\
\text { Treatment }\end{array}$ & $\begin{array}{c}\text { Long-Term } \\
\text { Management }\end{array}$ & Total \\
\hline Thyroid Nocile & 14 & 14 & 30 & 58 \\
Thyroid Cancer & 14 & 14 & 35 & 63 \\
- Nont-Fatal & 14 & 14 & $10,731^{\prime}$ & $=10.750$ \\
- Fatal & 14 & 7 & 35 & 56 \\
Hypothyroidism & 14 & & & 35 \\
\hline
\end{tabular}

I For a fatal malignancy, this value represents loss of life-expectancy. See discussion below.

The number of days appropriated to long-term management of the disorder is based on the average remaining years of life following diagnosis and latency periods previously identified. A special case involves a thyroid malignancy that may result in premature death.

Years of Life-Lost to Mailggant Thyroid Cancer. Radiation-induced thyroid cancers are essentially confined to the papilary and follicular kind. The proportion of papillary and follicular thyroid carcinomas when induced by radiation are assumed to be $90 \%$ and $10 \%$, respectively (Beach 1962). The fatality rate for this ratio of thyroid carcinomas is assumed to be about $10 \%$ which, therefore, results in years of life-lost. The times at which deaths from papillary and follicular thyroid cancer occur following diagnosis have been documented by McConahey (1981) and Cady (1976) who collectively analyzed a population of 1,595 thyroid cancer patients treated between 1931 and 1971. The distribution for the time of death for each of the cancer types as well as their weighted mean values are provided in Table D-15.

Table D-15. Time Distribution of Deaths Due to Papillary and Folficular Carcinoma of the Thyroid

\begin{tabular}{cccc}
\hline $\begin{array}{c}\text { Time after } \\
\text { Diagnosis (Years) }\end{array}$ & $\begin{array}{c}\text { Papillary } \\
(\%)\end{array}$ & $\begin{array}{c}\text { Foljjeular } \\
(\%)\end{array}$ & $\begin{array}{c}\text { Weighted Average } \\
\text { Vatue (\%) }\end{array}$ \\
\hline $1-5$ & 44 & 51 & 44.7 \\
$6-10$ & 22 & 17 & 21.5 \\
$11-15$ & 10.5 & 8.5 & 10.3 \\
$16-20$ & 3.5 & 20.5 & 5.2 \\
21 or more & 20 & 3 & 18.3 \\
TOTAL & 100 & 100 & 100 \\
\hline
\end{tabular}


Using the midpoint of time-intervals and the corresponding percentege value as a weighting factor, an overall mean survival time of 9.3 years following cancer diagnosis can be estimated. From 1990 United States population data (see Chapter 3, Table 3.3) and a cancer induction of five years, it can be estimated that the average mumber of years lost per fatal thyroid cancer is 29.4 years or 10,731 days.

The Indirect Cost of Impaiment. In addition to time lost from economic activity due to illness, treatment, long-term management of the disease, and premature death, a patient may also be permanently impaired and/or disabled. Permanent impairment or disability can reduce a patient's ability to be fully effective in occupational or economic activities and must, therefore, be included in assessing the total indirect cost.

The American Medical Association has published Guides to the Evaluation of Permanent Impaiment (AMA 1990) that provides a reference framework within which physicians may evaluate and report medical impaimnents. Various terms used in the Gujdes, such as "impairment," "disability," and "handicap" appear in laws, regulations, and policies of diverse origin and without consistent definition. The Guides define these terms as follows:

- Impairment - an alteration of an infjuidual's health status that is assessed by medical means.

- Disability - an atteration of an individual's capacity to meet personal, socjal, or occupational demands. Disability is assessted by non-medical means.

The Guides amplify these definitions by stating that:

". . . 'impairment' is what is wrong with a body part or organ system and its function; 'disability' is the gap between what the individual can do and what the individual would have been able to do or needs to do. Thus, an individual who is 'impaired' is not necessarily 'disabled'. Impairment only gives rise to disability when the medical condition limits the individual's capacity to meet the demands of life's activities. For example, losing the distal phalanx of the little finger, right hand, will impair the function of the digit and hand of both a concert pianist and a bank president, but the bank president is less likely to be disabled than the pianist."

"The concept of 'handicap' is related to, yet independent of the terms 'impairmens' and 'disability', although some use it interchangeably with these terms. Under provision of Federal Law, an individual is identified as 'handicapped' if he or she has an impairment that substantially limits one or more of life's activities, has a record of such impairment, or is regarded as having such an impaitment." 
On the basis of these definitions, the economic impact of thyroid disorders on indirect costs is most objectively assessed in terms of their permanent medical impairments. The AMA provides guidelines for evaluating permanent medical impairment of the thyroid due to hypothyroidism from radiation exposure or thyroidectomy (AMA 1990). .

Class 1 - A patient belongs in Class 1 when; (a) continuous thyroid therapy is required for correction of the thyroid insufficiency or for maintenance of normal thyroid activity, and (b) there is no objective physical or laboratory evidence of inadequate replacement therapy.

Class 1 Level of Impaiment of the Whole Person: $0-10 \%$

Class 2 - A patient belongs in Class 2 when, (a) symptoms and signs of thyroid disease are present, or there is antomic loss or alteration. and (b) continuous thyroid hormone replacement therapy is required for correction of the confirmed thyroid insufficiency; but (c) the presence of a disease process in another body system or systems permits only partial replacement of the thyroid hormone.

Class 2 Level of Impairment of the Whole Person: $15-20 \%$

In this report, the central value of five percent for Class 1 permanent impairment will be applied to the permanent hypothyroid conditions that are likely to result from (1) high radiation exposure doses recejved accidentally, (2) from the radiotherapy treatment for toxic nodules/cancer, or (3) the surgical removal of nodules/cancer. It will further be assumed that this five percent medical impairment results in a five percent disability for occupational and non-occupational economic activities for the affected individual, family members, and/or society.

Up to this point of the discussion, indirect costs have been quantified in terms of time lost. The conversion of time lost from economic activities to equivatent dollars is most fairly achieved by means of the Gross National Broguct (GNP). The GNP is considered the most comprehensive measure of the country's economic activity and includes the market value of all goods and services that have been bought for final use during a year. From the Gross National Product of $\$ 5,200$ billion in 1989 , the gross average annual per capita income of about $\$ 21,000$ is derived. This value of $\$ 21,000$ per year can be used to determime the equivalent dollar value for the number of days jost over the lifetime of an individual afflicted with a thyroid condition. This value can also be applied to determine the equivalent value of a five percent permanent disability (i.e., a five percent disability equates to about $\$ 1,000$ annually in reduced income). Table D-16 provides estimates of the total average indirect costs associated with thyroid disorders. 
Table D-16. Average Llfetime Indirect Costs Associated with Thyrold Digorders

\begin{tabular}{|c|c|c|c|}
\hline \multirow[b]{2}{*}{ Thyroudd Dinorder } & \multicolumn{3}{|c|}{ Llfetims Indirect Cous! (s) } \\
\hline & For Time Lou & For Disability (\$5) & Total \\
\hline Thyrold Nadule & 3,337 & 30.000 & 33,337 \\
\hline $\begin{array}{l}\text { Thyroid Canser } \\
\text { Non-Fatal } \\
\text { Fatal }\end{array}$ & $\begin{array}{r}3,625 \\
619,586\end{array}$ & $\begin{array}{r}35,000 \\
9,400\end{array}$ & $\begin{array}{r}38.625 \\
628,986\end{array}$ \\
\hline Hypouhyroidtam & 3,222 & 95,000 & 38,222 \\
\hline
\end{tabular}

\section{Derivation of Psychological Costs}

Disease may bring about numerous changes and impositions in the lives of the patient and family menbers that may in part be linked to, but are not reflected in the direct and indirect economic costs identified above. The wide variety of deteriorations in the ifuility of life (QOL) brought on by illness are frequently referred to as psychological costs. For thyroid neoplasms and dysfunction, a deterloration in the quality of life may be precipitated by the loss of bodily function, a lifetime dependence on medication, hormonal instability. disfigurentent from surgical scars, the uncertainty of normal life expeciancy, and reduced fittancial security. In characterizing psychological costs associated with disease. Thomas Hodgson (Hodgson 1984), clitef Economist for the Department of Health und Human Services' Office of Analysis and Epldemiology states:

"Disease may bring about personal catastrophes . . to the vietims of illness.... children, spouses, and siblings of victims, friends and co-workers of victims; and those who render care may all be affected. A victim may suffer a loss of a body part or speech, disfigurement, dtsablitity, impending desth, pain. and grief. He and those around him, may be forced into economic dependence and soctal isotation, unwanted job changes, loss of opportunlties for promotion and education, relosation of living quarters, and other undesired changes in life plans. The environment created by ill ntess often induces anxiety, reduced self-esteem and feelings of well-being, resentment, and emotjonal problems that often require psychotherapy. Problems of living may develop, leading to family conflict, antisocial behavior, and suicide. The vietim and others may experience marked personality changes and reduced sexual function. Disnupted development and delinquency may oeenr among chlidren. The quality of life may be reduced beyond restorative cespebility of current rehabilitation efforts. The combination of financial atrain and psychological problems can be especially devastating."

Qualitative Eisments Affectine OOL. Due to the fact that quality of life issues have only recently solicited a formal interest among heaith care professionais, QOL data is both sparse and 
lacks standardization. In July of 1990 , the National Institutes of Health (NIH) conducted a workshop on the quality of life assessment in cancer clinical trials (NCI 1990). Among the major objectives of the meeting were to define discrete quality of life elements and to identify currently available instruments (i.e., methods) for QOL assessment. The workshop group consisting of international experts concluded that (1) the quality of life of patients is affected by both the disease and by the treatment of the disease and (2) the quality of life is a multidimensional concept that must be evaluated by a set of instruments (i.e., methods) which measure both broad issues and disease/treatment specific phenomena.

Data on a number of QOL dimensions have been collected from among cancer patients (Kaplan 1990; Patrick 1989; Patrick 1988). The most frequently cited dimensions that characterized the quality of life include (1) physical symptoms of pain and discomfort, (2) functional ability, (3) family well-being, (4) emotional well-being. (5) spirituality, (6) financial concerns, (7) future orientation (planning and hope), (8) sexuality/intimacy (including body image), (9) social functioning, and (10) occupational functioning. Research over the past 20 years has also identified a host of socio-economic variables that modulate these quality of life dimensions (Mor 1987; Teta 1986; Houts 1986). Given the literanure, there is justification to identify age, gender, marital status, educational jevel, religious beliefs, employment and economic status, and the number of children living at home as crucial variables that affect changes in the quality of life imposed by a given disease.

Ouantitative.Methods for OOL_Assessment. Various questionnaires and protocols inclusive of psychometric evaluation have recently been developed and have been used in clinical trials to provide QOL mensurements among cancer patients (Schag 1990; Ganz 1990; Schipper 1984) and patients with chronic debilitation medical conditions (Stewart 1988 and 1989; McCorkle 1983 and 1989).

QOL measurements that specifically deal with thyroid cancer and/or thyroid dystunction are not currentiy documented. Additionally, available quality of life measurement data frequently focused not on the disease itself but on specific treatment options in which the risks and benefits of the treatment were assessed relative to their impact on the patients' lives. Factors considered in these studies included treatment toxicity, physical disfigarement, and bodily/sexual dysfunction. Not surprisingly, therefore, among the limited mumber of clinical studies the most frequently evaluated cancers with regard to QOL issues are those that involve the lung, female breasts, ovaries, and prostate.

In summary, while various QOL measurement protocols have been developed and used to aid health care practitioners in clinical decisions, no standard format exists that would allow such measurements to be used for economic or other non-clinical purposes. Of limited application is the Social Security Administration's (SSA 1985) guidelines for assessing impairment due to mental and behavioral disorders. (The term "limited" refers to the fact that mental and behavioral disorderg are but two of several dimensions that may characterize QOL changes.) Severity is assessed in terms of functional limitations on activities of daily living; social functioning; concentration, persistence and pace; and adaptive functioning in response to stressful 
circumstances. Table D-17 provides the SSA's guide for rating impairment in each of the four areas of functional limitation on a five-point ordinal scale, ranging from none to extreme:

- None means there is no impairment noted in this area of function.

- Mild implies that any impaiment that is discerned is compatible with most useful function.

- Moderate means that impairments that are found are compatible with some but net all useful functions.

- Marked is a level of functional impairment that significantly impedes useful function.

- Extreme signifies that the impairment is not compatible with useful function.

Table D-17. Social Security Adninistration's Guidelines for Assessing Impairments

\begin{tabular}{|c|c|c|c|c|c|}
\hline $\begin{array}{l}\text { Arre of } \\
\text { Funetion }\end{array}$ & $\begin{array}{l}\text { Class } 1 \\
\text { No } \\
\text { imprairment }\end{array}$ & $\begin{array}{l}\text { Class } 2 \\
\text { Mild Inpairment }\end{array}$ & $\begin{array}{l}\text { Class } 3 \\
\text { Moderate } \\
\text { Lupairment }\end{array}$ & $\begin{array}{l}\text { Class } 4 \\
\text { Marked } \\
\text { Impairment }\end{array}$ & $\begin{array}{l}\text { Class 3 } \\
\text { Extrane } \\
\text { IJupairment }\end{array}$ \\
\hline $\begin{array}{l}\text { Activities of } \\
\text { Daily Living } \\
\text { Sociad } \\
\text { Funetioning } \\
\text { Concentration } \\
\text { Adaptation }\end{array}$ & $\begin{array}{l}\text { No } \\
\text { impatituents } \\
\text { noted }\end{array}$ & $\begin{array}{l}\text { Impairments } \\
\text { levels } \\
\text { compalibte with } \\
\text { most usefful } \\
\text { function }\end{array}$ & $\begin{array}{l}\text { Irmparment } \\
\text { levels } \\
\text { compatible with } \\
\text { some but not all } \\
\text { useful function }\end{array}$ & $\begin{array}{l}\text { Impaiment } \\
\text { levels } \\
\text { signtfificantly } \\
\text { impiede ustoful } \\
\text { function }\end{array}$ & $\begin{array}{l}\text { Impairnent } \\
\text { levels preclude } \\
\text { useful function }\end{array}$ \\
\hline
\end{tabular}

To illustrate these ratings, extreme limitation in activities of daily living implies complete dependency on another for persomal care. In the area of sacial functioning, extreme impairment implies that the individual engages in no meaningful social contact. An extreme limitation in concentration, persistence, or pace means that the individual cannot contribute to conversation or any productive/occupational tasks at all. In an otherwise ordinary individual, a single area of extreme impairment would be likely to preclude performance of any complex task, such as recreation or work. Two or more areas of marked limitation would also be likely to preclude performance of complex tasks without special support or assistance. An individual who was impaired to a moderate degree in all four areas of function would be expected to be limited in many, but not all, complex tasks. Mild and moderate limitations reduce overall performance but do not preclude performance. 
The AMA warns, however, that:

"Translating these guidelines for rating individual impairment on ordinal scales into a method for assigning percentage impairments, as if the ratings were made on precisety measured intenval scales, is not recommended. For example, we cannot be certain that the difference in impaiment between a rating of mild and moderate is the same as the difference between moderate and marked. Furthermore, a moderate impairment does not imply 50\% limitation in useful function. Similarly, a rating of moderate impaiment in all four areas of function does not imply a $50 \%$ impairment of the whole person. In reality, however, physicians often are required to make such judgments. It is important to remember that such judgments are based on clinical impression rather than on empirical evidence. In those circumstances in which it is essential to make a percentage rating, the ordinal scale might be of some belp: one could assume that the extreme rating approaching $100 \%$ mental impairment is similar to a coma, which is the extreme impaiment of central nervous system function and level of consciousness.

Eventually research may support the direct link between medical findings and percentage of mental impairment. Unti] that time the medical profession must refine its concepts of mental impairment, improve its ability to measure limitations and contimue to make clinical judgments."

In the absence of thyroid-specific clinical data, as well as a standardized generic protocol for assessing QOL dimensions, the author of this report consulted with medical professionals experienced in the diagnosis, treatment, and strveillance of patients with thyroid cancers.

Consensus opinion of several qualified physicians is that the QOL impact of thyroid cancers, in general, ranks low in comparison to most other cancers. This view is supported by the fact that thyroid cancers of papillary or follicle cell origin have a relatively low mortality rate and patients are reassured of a high survival probability. In addition to a good prognosis, treatment for a primary thyroid cancer (i.e., thyroidectomy and/or radioiodine) involves well-established protocols and procedures. Absent is the toxic side effects of chemotherapy and/or extensive whole body irradiation that is associated with many other cancers. Following successful treatment of the cancer. proper replacement levels with exogenous thyroid hormone in most patients is readily established with only "minor" discomfort to the patient. In fact some physicians regard the functional loss of the thyroid gland as a mere "medical nuisance."

While the physicians" opinions may be understandable, they are not without bias. Given the high mortality rate and toxic treatment for other cancer sites, it is understandable why physicians view thyroid cancer more casually and without the usual intensity reserved for more vinulent cancers. 
For the patient, however, who up to the time of diagnosis of a thyroid neoplasm may have been perfectly healthy, the anticipation of surgery, radioiodine therapy, hormonal instability, a lifetime dependence of homone replacement therapy, and the probability of one chance in ten of dying is not likely to be inconsequential with regard to the patient's quality of hife. This discrepancy between patients and physicians has been documented in severa! studies, which have shown that the attending physicians of patients were not a suitable source for patient QOL ratings (Slavin 1988; Martini 1976; Wartman 1983). When patient QOL ratings were compared to those of their attending physiciars, a correlation value of only 0.63 was found to exist. In one study, for example, physicians did not recognize $34 \%$ of both psychiatric problems and life crises reported by patients (Wartman 1983). The conchusion among the QOL researchers was that individual patients provide the most accurate information for evaluating the impact of a cancer or a chronic disease.

For this reason and at the recommendation of the NRC, the author of this report, in the presence of a health care professional, sought the personal testimony of an individual with a long and complex history of thyroid cancer. The patient who provided testimony is a white male in his late forties. He is a professional, currently employed, married, and the father of one child. In the time frame of $1948 / 1949$, this individual received external medical radiation for the treatment of enlarged tonsils/adenoids. It has been estimated that this exposure resulted in a thyroid dose of about 750 rads.

In 1973, the patient was first diagnosed to have a thyroid carcinoma of mixed papillary/follicular cell origin. Following the surgical removal of about $80 \%$ of thyroid tissue, the patient was treated for thyroid insufficiency with desiccated bovine thyroid extract. This treatment resulted in cyclic fluctuation of serum levels that were either too high or too low. The patient, during this time, suffered many symptoms commonly associated with hypo-and hyperthyroid conditions inclusive of emotional and behavioral changes, depression, fatigue, hyperactivity, etc. Substitution of desiccated bovine thyroid extract with synthetically produced thyroid homone (Synthroid), which became available in 1978, did not eliminate these problems.

Because of persistent hormone imbalance thought to be, in part, the result of residual thyroid activity, the patient received two separate radioiodine doses of $30 \mathrm{mCi} \mathrm{I-131} \mathrm{each} \mathrm{in} 1983$.

As part of the continuing patient's surveillance, coctors identified a "new" thyroid malignancy in 1988 for which the patient received another $100 \mathrm{mCi}$ dose of I-131. In 1989, the patient was subjected to yet a fourth therapeutic dose of radioiodine involving $150, \mathrm{mCi}$ of $\mathrm{I}-131$. As part of each I-131 therapy, the patient was intentionally rendered hypothyroid in order to maximize the uptake of radioiodine and to ensure maximum therapeutic tissue destruction. Subsequent thyroid scans showed residual evidence of viable thyroid tissure/ cancer. As of 1992, future treatment is likely to include surgery and more radioiodine therapy. To date, the prospect for successful treatment and hence the patient's prognosis remains uncertain.

The disease and its symptoms, its persistence, the prescribed intermittent treatments, and the uncertain prognosis have had a significant impact on the patient. There were extended periods 
of time during which the patient was unable to function in his professional capacity. He stated that he felt debilitated from fatigue, depression, and anxiety, which also affected his relationship and the well-being of his wife, chijd, and other members of his family. The emotional trauma was particularly acute prior to each radioiodine therapy when the patient's normal hormone repiacement therapy had to be altered and following radioiodine therapy when the patient, for radiological reasons, was isolated from family and the nomal hospital environment. Due to the uncertain prognosis, the patient and his wife have made a decision not to have any additional children. The patient also feets that his career has been significantly impacted by his disease. The patient stated that he sought counseling and psychiatric help at various times over the course of his illness for reasons that were ditectly linked to his thyroid illness.

Valuation of Psychological Costs. In spite of the fact that psychological costs are consistently identified as a major cost component by health care researchers and economists, no formal attempt has been made to quantify these costs in monetary terms (fodgson 1984; Rice 1985; Brown 1990). The reason for this omission is obvious. From the foregoing discussion, it is axiomatic to conclude that the intangible dimensions, which define the quality of life, are (1) highty subjective, (2) vary greatly among indjviduals, and in time and space, and (3) are not readily expressed in monetary terms. Independent of these difficulties, the exclusion of psychological monetary costs in some instances may be justified for conditions in which the health effect is of unknown origin, self-infticted or unavoidable. The omission of psychological costs, however, is not readily justified for situations in which the health effect is clearly avoidable, or is the consequence of negligence or wrongful action. A complete cost-benefit analysis of $\mathrm{KI}$ prophylaxis must, therefore, include estimates of psychological costs expressed in the unit of dollars.

There are several potential approaches that can be used to estimate the monetary value of psychological costs associated with disease or inzpaired health. Mooney (1977) and Schelling (1968) proposed the use of survey techniques. Survey methods associated with quality of life valuation can be based on the amount an individual is either prepared to pay to avoid a rectuction in the quality of life or would accept in compensation for an existing reduction in the quality of life. Such a survey technique, however, is not without flaws.

Survey-solicited responses may reflect a limited and unrealjstic interpretation of the proposed hypothetical condition and are, therefore, difficult to evaluate. Moreover, the valuation of death cannot be assessed by such a survey technique. (Nevertheless, the reader may ask this very question of himself in assigning a monetary value for a thyroid cancer and/or loss of thyroid function.)

Another approach is to analyze data on health and life insurance premiums, which cover disability and death. Again, there is difficulty in the interpretation of this type of data due to socio-economic variables that motivate individuals. For instance, it cannot be assumed that (1) a person 'who does not purchase health or life insurance does not value his health or life or (2) that there is a proportional relationship between premium and personal valuation of health and life. 
The most credible approach to monetize psychological costs is to assess the judgements awarded to plaintiffs in cases of wrongful injury or death. Traditional legal remedies of monetary awards in personal injury and wrongful death litigation are also generally applicable in cases involving radiation exposure.

To date, litigation data involving claims of radiation injury and death, are relatively sparse. In spite of numerous legal claims that have been filed in recent years, many radiation cases have been resolved on other legal issues with no damages being awarded. Only a few cases have gotten as far as a specific economic valuation. Three prominent cases in which plaintiffs were granted financial compensation are briefly summarized below:

\section{Alten versus United.Stgtes.}

In this landmark case, actions were brought against the United States by 24 plaintiffs in 1982, to recover for cancer or leukemia allegedly caused by the Atonic Energy Commission testing of atomic devices prior to 1963. The District Court held that the United States had been negligent in its conduct of the testing program by failing to properly monitor radioactive fallout and by failing to properly inform and warn the people in the vicinity of the test site. Of the ten plaintiffs awarded comperzsation, eight were wrongful death cases and two involved personal injuries.

Under Uth Law, the court stated that in an action alleging wrongful death, ". . the full value of the life of the deceased is determined and recovered." The jodge highlighted the following elements as important in assessing recoverable damages: "(1) financial support furnisted, (2) loss of affection, counsel and advice, (3) loss of deceased's care and solipinude for the weifare of the family, and (4) loss of the confort and pleasure the family of the deceased would have received" (Switzer versus Rempolds, 606 P. 2d, 244 Utah 1980, p.246).

Among the eight leukemia cases compensated for wrongful death, four involved children. When a wrongful dealh involves the loss of a child, there is minimal tangible monetary compensation. However, the intangible loss to family and society involving human relationships is considered the greatest loss.

In summary, for the eight plaintiffs in Allen et al. versus the United States, four elements were considered in determining compensation to survivors in wrongful denth actions: (1) loss of support; (2) loss of assistance and service to the family; (3) loss of society, companionship and happiness of association; and, (4) loss of the possibility of inheritance, if the decedent is an adult. Awards in the eight cases of wrongful death ranged from $\$ 235,000$ to $\$ 625,000$ with an average vatue of $\$ 320,000$.

The Utah/Arizona Law concerning damages to personal injury is also clear. The laws allow injured plaintiffs to recover general and special damages that maturally and necessarily result from the harm done, including damages for the loss of time and 
earnings, impairment of future earning capacity, all costs pertaining to medical treatment and care, pain and suffering, and other psychological impacts.

Of the two claims involving injury, one involved an adenocarcinoma of the thyroid of a twenty-one yeat old female suspected of having received a thyroid dose between 30 and 340 rads from the fallout of radioiodine during early childhood. For the benign thyroid cancer, the plaintiff was awarded $\$ 100,000$.

\section{Silkwood versus Kerr-McGee.}

In November 1974, plutonium contamination was found in the private apartment of a chemical technician (Karen Silkwood) an employee of the Kerr-McGee Corporation. Following her death in a fatal car accident, post mortem analysis of tissue samples were conducted. It was estimated that the total body-burden for plutonium was less than 10 $\mathrm{nCi}$, yielding 50-year committed organ doses of about $0.5,2$, and $0.8 \mathrm{rads}$, respectively to the lung, liver, and bone. Based on the 1972 BEIR Committee risk estimates, her lifetime risk of fatal cancer was calculated to be between zero and 0.0005 .

Two key issles presented in the subsequent jury trial involved (1) the liability of Kerr$\mathrm{McGe}$ for the contamination and (2) the injury question due to a plutonium exposure that was less than permissible limits for occupational exposure. (The death of Karen Silkwood in the automobile accident was not a point of contention in the trial).

The jury found Kerr-McGee negligent in its operation of the facility under the strict liability and also found that Silkwood had been injured by plutonium according to the Court's definition of injury. The court ruled that . . . "Cerainly physical injury can include a nomvisible or non-detectable injury and may include injury to bone, tissue, or celis. If a person has suffered physical injury ... on the basis of expert medical opinion, it is only necessary that a person believe he or she has been physically injured as a basis for mental pain and suffering to occur."

The jury awarded the Estate of Karen Silkwood $\$ 500,000$ for injury, $\$ 10,000,000$ for punitive damages, and $\$ 5,000$ for property damage. In the appeal decision, the Tenth Circuit Federal Court decided that the case should have been tried urider the Oklahoma Workman's Compensation Law rather than under common tort law. Thus, the $\mathbf{1 0 . 5}$ million judgement was reversed.

Kerksieck versus McDemott Inc.

The plaintiff (Kerksieck) was the owner of a Cable Television business located next to McDermott's pipe fabrication facility, which engaged in radiographic pipe testing of welds. The plaintiff alleged he had been exposed to gamma radiation between 1978 and 1984. Dosimetry experts 50 the plaintiff estimated his exposure between 75 and 300 rem. Experts for the defendant estimated his exposure at less than 2 rem. The plaintiff's injuries were basically benign, consisting of pancreatic carcinoids in 1985, a benign thyroid condition in 1987 and lymphocytosis in 1989, as well as parathyroid numors and 
the appearance of benign adrenal nodules. Alt of the plaintiff's conditions were benign and his thyroid had been surgically removed.

The jury awarded a total of $\$ 1,250,000$ to the plaintiff: $\$ 830,060$ in punitive damages; and $\$ 415,000$ in compensatory damages. Of the compensatory award, $\$ 180,000$ was for anticipated future medical expenses. The only testimony on further health costs, however, was presented by the plaintiff's treating physician, which identified the need for continual checkups and patient surveillance.

In radiation injury litigation there are problems not faced in routine cases. One such problem is the long latency period between exposure and the biological consequences of radiation. Long latency periods tend to obscure the causal relationship between radiation exposure and radiation injury. Other problems are sui generis to raclear litigation and may, in part, account for the relatively smatl number of cases that have come to trial.

The relatively ftw radiation injury cases that have been resolved in court may, in part, be due to (1) the unsettled state of the law relating to Federal preernption, at least until the Supreme Court decided Silkwood versus Kerr-McGee, 464 U.S. 238 (1984) and (2) to the problems associated with having to sae the United States under the Federal Torts Claims Act (e.g., the Nevada test site cases; Prescott versus United States 1992 WL 54002, F.2d, 9th Cir. 1992).

Due to the limited database involving radiation injuries, it is appropriate to review representative legal cases pertaining to other cancer-causing agents. It is worth noting that over the last 10 to 20 years the haw has evolved considerably in this area. Based on emotional distress arising from theit risk or their fear of developing cancer, persons exposed to carcinogenic substances may now recover damages more easily than in the past. Older cases required a plaintiff seeking damages for emotional distress to prove: (1) physical harm as a result of the conduct that caused the emotional distress, (2) that the physical harm either caused or was caused by the emotional discress, and (3) that the physical harm had objective symptomatology. Therefore, in the past, risk without any accompanying physical injury was insufficient to recover damages (Mink versus University of Chicago, 460 F. Supp. 713 (N.D. I1l. 1978); Sypert versus United States, 559 F. Supp. 546 (D.D.C. 1983)).

These strict requirements have been relaxed in many jurisdictions. Some courts have held that the physical harm requirement is satisfied by evidence that a demonstrable physical change in the plaintiff's body has occurred (Plummer versus United States, 580 F.2d 72 (3d Cir. 1978)). Other courts have held that the ingestion of a toxic substances is sufficient for a cause of action to accrue, even though a significant physical effect cannot be shown (Hagerty versus L\&L Marine Services, Inc. 788 F.2d 315 (Sth Cir. 1986)). Once a plaintiff satisfies either the demonstrable physical change or ingestion of a toxic substance test, many, if not most, jurisdictions will allow recovery of damages for the fear of a potential future disease (J. Allison, Evidence Supporting Recoverable Damages for Potential Disease, XXIV Tort and Ins. L.J. 39 (1988)). 
Other courts have also allowed damages for the impairment of quality of life. In those cases, a plaintiff has been allowed to recover damages for those activities, which need not be profit making, that he could enjoy prior to his injury but not afterwards.

One element of damages frequently considered and allowed in tort litigation, but which wilt not be taken into account in this analysis, is the element of punitive damages. The reason that this will not be considered is that such damages do not bear a direct relationship to the value of life or health. Rather, punitive damages are designed to punish the wrongdoer who has acted in reckless disregard for the health and safety of others. It is not extraordinary for punitive damages in some particularly egregious cases to be 10 or 20 times the amount of the compensatory datmages. For this reason, some jurisdictions, either by statute or decisional law, have limited the amount of punitive damages that may be awarded.

Accordingly, listed below are selected cases that reflect what value courts and juries in various jurisdictions have placed on some elements of damages discussed above. Significant among the missing cases is Silkwood versus Kerr-McGee, supra. This case is not listed because the issue decided by the Supreme Court involved principally punitive damages (which represented $\$ 10$ million of the $\$ 10.5$ million originally awarded), The personal injury award, the Court of Appeals decided, should have been decided under state workers' compensation law.

- Allen versus United States, 588 F. Supp. 247 (D. Utah 1984): wrongful death and personal injury chains from radioactive fallout from open air testing of nuclear weapons - eight wrongful death verdicts from $\$ 235,000$ to $\$ 625,000$ and a personal injury verdict of $\$ 100,000$.

- Kerksieck versus McDermott Inc., Louisjana district court, 16th judicial district, St. Mary's Parish, 1991: pre-cancerous thyrojd condition and pancreatic carcinoids from gamma radiation -- compensatory damages of $\$ 415,000$ ( $\$ 180,000$ of which was for future medical expenses).

- In Re: Fernald Litigation, U.S. District Court, S.D. Obio, No. C-1-85-0149, filed September 29, 1989: settlement fund of $\$ 73-78$ million created by United States for radioactive fallout from Fernild affecting a 14,000-person class. Covered by the fund are medical monitoring, emotional distress, and diminution in property values.

- Ochiuto versus Johns-Manville Corporation, 1992 WL 67140, A.2d (Pa. Super. April 7, 1992): $\$ 400,000$ to husband and wife for husband's exposure to astestos resulting in increased risk of cancer (pleural thickening) and resulting emotional distress. 
- Ward versus Terminix, 1991 WL 87336 (Tenn. Ct. App. May 29, 1991): In this case, a chemical (ostensibly a fungicide) was applised to portions of a house occupied by a mother and two daughters. The chemical had been inadvertently mixed with another that caused plaintiffs to suffer physical symptoms, e.g., dizziness, memory lapses. The mother was awarded compensatory damages of $\$ 1$ million and each of two daughters were awaried compensatory damages of $\$ 500,000$ each. The daughters' verdicts were subsequently reduced by the trial judge to $\$ 100,000$.

- Moran versus G. \& W.H. Corson, Inc., 402 Pa. Super. 101, 586 A.2d 416 (1991): wrongful death action based on decedent's exposure to asbestos and contracting mesothelioma. Three defendant's setrled for a total of $\$ 500,000$.

- Poter versus Firestone Tire and Rubber Co., 232 Cal. App. 30 1114, 274 Cal Rptr. 885 (Ct. App. 1990): Defendant put carcinogens in water supply, which plaintiffs drank. Although there were no physical manifestations or any other evidence showing that cancer was likely to occur, each property owner was entitled to $\$ 200,000$ for fear of getting cancer.

- Eagle-Picher Industries versus Balbos, 84 Md. App. 10, 578 A.2d 228 (Ct. Spec. App. 1990): Defendant survived husband by 17 months. Husband died from occupational exposure to asbestos. Decedent's estate was awatded $\$ 750,000$ essentially for decendent's emotional suffering, inasmuch as there was little proof of other damages.

- Novelli versus Johns-Manville, 395 Pa. Super. 144, 576 A.2d 1085 (1990): Decedent's estate received $\$ 700,000$ in compensatory damages for his death from mesothelioma and widow received an additional $\$ 150,000$ for loss of consortium.

- Nussbaum versus Gibstein, 531 N.Y.S. $2 d 276$ (N.Y.A.D. 1988): Jury awarded $\$ 500,00$ for pain and suffering and loss of enjoyment of life. This malpractice suit involved a 35 year-old women's two-year losing battle with breast cancer.

In summary, it appears that society, through the legal system, has shown an increasing willingness to share the burden of illness and injury that befall the individual. This attitude is particularly evident in matters of radiation cancer and injury. Mr. Don Jose, Esquire, legal expert on radiation injury claims, in a personal communication has stated: 
". . My personal belief is that every radiation case is a million-dollar case even though the person had no cancer or disease (Silkwood $=10.5$ million) or had a benign thyroid condition (Kerksieck $=1.245$ million). Thus, I would assess a value of around $\$ 750,000$ to $\$ 1,250,000$ for any thyroid problems resulting from an accident at a muclear power plant. This number is a market value and the market is the legal system. This number is likely to be what an innocent victim could recover if they sued the owners of the nuclear power plant."

Based on the monetary awards for the radiation and non-radiation injury claims cited, and the opinion expressed by a subject matter expent, the psychological cost component for any radiation-induced thyroid health effect is estimated at $\$ \$ 00,000$ and will be applied to the derivation of cost-benefit ratios for KJ prophylaxis.

\section{Summation of Thyroit Health Effects Cost}

Table D-18 summarizes previously derived values for the direct medical costs, the indirect cost of lost economic opportunities, and the psychological costs attributed to the reduced quality of life for each of the thyroid disorders considered in this report. For all thyrojd effects, the direct medical cost for diagnosis, treatment, and follow-up represents the smallest contribution to the total cost. The assigned common value of $\$ 500,000$ for psychological costs dominates the total costs of potential thyroid effects. ${ }^{1}$

Table D-18. Average Total Cost Per Radiation-Induced Thyroid Effect

\begin{tabular}{lcccc}
\hline Tbyroid Effect & $\begin{array}{c}\text { Direct } \\
(\$)\end{array}$ & $\begin{array}{c}\text { Indirect } \\
(\$)\end{array}$ & $\begin{array}{c}\text { Psychological } \\
(\$)\end{array}$ & $\begin{array}{c}\text { Total } \\
(\$)\end{array}$ \\
\hline Nodule & $\$, 600^{\circ}$ & 33,300 & $\$ 00,000$ & 542,900 \\
Cancer & & & & \\
Non-fatal & 20,000 & 38,600 & $\$ 00,000$ & $\$ 58,600$ \\
Fatal & 32,000 & 629,000 & $\$ 00,000$ & $1,161,000$ \\
Hypothyroidism & 5,600 & 38,200 & 500,000 & 543,800 \\
\hline
\end{tabular}

- Value Iepresents the mid-point of the range in direst nutical cost estimates.

1 Although the indirect cost of $\$ 629,000$ for a fatal thyroid cancer is considerably larger, the low frequency of fatal cancers among thyroid effects $(<3.5 \%)$ mitigates its impact on the average indirect cost of thyroid disorders. 
In Utero Cose Estimates. Fetal exposure in utero may also result in thyroid nodules, thyroid cancer, or congenital hypothyroidism. The resultant cost elements are similar to those involving the general population, but are somewhat higher in value to reflect the earlier age at time of first diagrosis. Affected by this shift in time are costs associated with long-term medical care and surveillance, as well as indirect costs. When in utero exposture results in thyroid disonders, the costs are based on the following ages of initial diagnosis:

- hypothyroidism: at time of birth

- thyroid nodule: at age ten

- thyroid cancer: at age five

- for fatal thyroid cancer, the time of death is assumed to oceur at age 14.4

The costs of thyroid effects that are the result of in utero exposure are surnmarized in Table D-19.

Table D-19. Cost Estimates of Thyroid Effects for In Utero Exposure

\begin{tabular}{lcccc}
\hline $\begin{array}{l}\text { In Utero } \\
\text { Thyroid Effect }\end{array}$ & $\begin{array}{c}\text { Direal } \\
(\$)\end{array}$ & $\begin{array}{c}\text { Infirect } \\
(\$)\end{array}$ & $\begin{array}{c}\text { Psychological } \\
(\$)\end{array}$ & $\begin{array}{c}\text { Total } \\
(\$)\end{array}$ \\
\hline Nodule & 17,000 & 53,000 & 500,000 & 570,000 \\
Carcer & & & & \\
$\quad$ Non-fatal & 24,000 & 56,000 & 500,000 & 580,000 \\
Falal & 32,000 & N/A & $\$ 00,000$ & 532,000 \\
Hypothyroidism & 11,000 & 79,000 & $\$ 00,000$ & 590,000 \\
\hline
\end{tabular}

\section{An Evaluation of Derived Cost Estimates}

The appropriateness of monetary values for thyroid dysfunction and neoplasms derived in this report may be assessed by comparing these values to those that have previously been endorsed by the NRC and other Federal agencies. For example, as part of a study performed by Sandia National Laboratories to estimate the financial consequences of reactor accident health effects (NUREG/CR-2723), cost estimates were determined for on-site emergency workers for five severe accident categories. Health effect "costs" to emergency utility workers were converted to dollar-equivalents asing the following conversion: (1) \$1 million per early fatality, and (2) $\$ 100,000$ per early injury or latent cancer. These 1983 cost estimates, when adjusted to the current medical costs and market value of the dollar, yield cost estimates that are very comparable to those defined in this report. It may further be argued that cost estimates derived in this report are subject to an adjustment factor, which accounts for the difference in the involuntary non-cccupational exposure of a member of the general public and the "voluntary" 
exposure conditions of the utilty emergency worker. As a nule, it is appropriate to assign a higher compensation value in instances of involuntary participation.

In a more recent value impact analysis involving public exposure to radon, the EPA evaluated the cost effectiveness of radon testing and radon mitigation for five different action levels of residential indoor radon (EPA 1992). Table D-20 provides a summary of the results of EPA's analysis of action levels. The results of this cost-effectiveness analysis show that the EPA's selection of $4 \mathrm{pCi} / 1$, as its recomrnended action level, would result in a cost of roughly $\$ 700,000$ per long cancer death averted. At this action level, the EPA concluded that ". . the Radon Progran would be as or more cost-effective than many other government programs for personal safety and environmental protection."

Table D-20. Cosł Per Lffe Saved for EPA's Radon Testing and Mitigation Programs

\begin{tabular}{cccc}
\hline & $\begin{array}{c}\text { Number of Lives } \\
\text { Saved Annuatly }\end{array}$ & $\begin{array}{c}\text { Aturuajized Cost } \\
(1,000 \$ \text { of } 1991 \$)\end{array}$ & $\begin{array}{c}\text { Average Cost per Life } \\
\text { Saved }\end{array}$ \\
\hline $2 \mathrm{pCi} / 1$ & 3,100 & $3,421,000$ & $\$ 1,110$ \\
$3 \mathrm{pCi} / 1$ & 2,600 & $2,181,000$ & 800 \\
$4 \mathrm{pCi} / 1$ & 2,200 & $1,504,000$ & 700 \\
$8 \mathrm{pCi} / 1$ & 1,100 & 501,000 & 400 \\
$20 \mathrm{pCi} / \mathrm{s}$ & 220 & 116,000 & 500 \\
\hline
\end{tabular}

In conclusion, values cited in Tables D-18 and D-19 are in agreement with values cited in other Federal impact analyses and publicly implied valuations of Federal progtam areas derined in Table D-3. 


\section{APPENDIX E}

\section{KI EXPERIENCE IN PAST NUCLEAR EMERGENCIES}

Although there had been previous reactor accidents, it was the Three Mile Island Accident on March 28, 1979 that initiated major review of existing policies by regulatory agencies and public officials responsible for protecting the public in the event of a nuclear emergensy. The TMI Accident demonstrated that (1) when KI prophylaxis is not an integral part of a nuclear emergency plan, and (2) if no readily available stockpile of KI exists, a decision by public officials to mitigate thyroid exposure following the declaration of a nuclear emergency cannot succeed.

The success of KI prophylaxis even if these two conditions are met may be less than optimal. In response to the TMI experience, Tennessee State health officials attempted to provide KI tablets for near-field residents under the simulated conditions of a muclear emergency drill. Distribution at the time of a nuclear emergency proved too slow to avoid the initial plume inhalation exposure to near-field residents. In recognition of this potential limitation, Tennessee State Health officials in 1981 condteted a pilot project in which KI was predistributed to residents within a five-mile radjus of the Sequoyah nuclear facility. Authorities considered predistribution as the preferred option of providing prompt access to the drug for those persons at highest risk and most likely to benefit by its early administration.

The accident at the Soviet Chemobyl muclear facility on Aptil 26, 1986, which involved massive releases of radioiodine, tested the efficacy of the Soviet emergency plan in providing $\mathrm{KI}$ to nearfield residents from existing stockpiles. KI was also administered to far-field residents of Potand where fallout of radioiodine resulted in significant air concentrations and contaminated food products.

This appendix briefly describes these three events and identifies salient findings that may be useful in reassessing Federal and State policies regarding KI prophylaxis.

The Three Mile Island Experience.

In the early morning hours of March 28, 1979, the Unit-2 reactor at the Three Mile Island Nuclear Station located in south central Pennsylvania experienced a loss of feedwater to the steam generators. Because of a combination of design deficiencies, mechanical failures, regulatory policies, training inadequacies and human errors, the initial loss of feedwater progressed to the point of severe fuel core damage and the atmospheric release of radioactivity.

Following the accident, extensive investigations were conducted (NUREG-0588; NUREG-0600; NUREG-0637). It was concluded that $30 \%$ of the core inventory of iodines was released from the damaged fuel into the primary coolant. However, the majority of iodine was chemically absorted by the coolant, which was enhanced by increasing the alkalinity through the deliberate injection of sodium hydroxide. The general reducing environment created by a hydrogen-rich 
mixture of steam, water, and hydrogen in which little or no free oxygen was present promoted the formation of metallic iodides. The majority of the iodine released in the partial core melt at TMI was found to have been converted to cesium iodide, a highly water soluble and relatively nonvolatile compound. Thus, the cesium jodide was largely retained in the water that leaked from the primary containment structure or was retained within the reactor's primary system. Although the containment building was not completely isolated, there was no structural faikure of the reactor containment building at TMI. The release of radioactivity occurred through penetrations in the secondary systems of the auxiliary building. Of a total inventory of $64,000,000 \mathrm{Ci}$ of $1-131$, only about $17 \mathrm{Ci}$ were released to the environment, yielding a release fraction of $2.7 \times 10^{-3}$.

The average thyroio dose from internal exposute to the released radioiodine to the near-field population bas been estimated at less that 0.001 rad with an upper limit individual exposure of about $0.02 \mathrm{rad}$.

While in retrospect these small quantities of released radioiodine and the resultant insignificant thyroid exposure did not warrant the prophylactic use of potassium iodide, the potential did exist for release of large quantities of radioiodine. The ability to implement KI prophylaxis was compromised because there were no commercially available preparations of potassium iodide in suitable form and quantity for timely public distribution.

Onfy months earlier, the FDA had solicited sponsors for new drug applications (NDAs) for KJ as a non-prescription drug in oral dosage form for use as a thyroid-blocking agent in a tadiation emergency (43 FR 58798, December 15, 1978). At the time of the TMI Accident, no NDAs had been received. The FDA's concern for high thyroid exposure on March 29th prompted its Bureau of Drugs to petition on an emergency basis drug manufacturers and pharmaceutical suppliers for the needed patassium jodide. It was estimated that the equivalent of $7,500 \mathrm{~kg}$ of KI was needed in a saturated solution (SSKI). FDA's request could not be met: companjes had neither the quantity of KI and containers, nor the facilities to manufacture SSKI within the needed time frame.

A chemical manufacturer, Mallinckrodt Company, had the necessary quantity of KI and mobilized a workforce on an emergency basis. Joined by Parke-Davis Company, SSKI was delivered to Harrisburg as quickly as it was being manufactured over a period of several days, with the first shipment of 11,000 bottles arriving at 11:00 p.m. on March 31st (Halperin 1989). Over the next four days, six more shipments totaling 225,033 bottles arrived in Harrisburg with the last shipment arriving at 9:00 a.m. On April 4, 1979.

Under these emergency conditions, the manufacturers experienced problems with labels and erroneously included droppers not calibrated to deliver the $65 \mathrm{mg}$ of $\mathrm{KI}$ per drop for a two-drop dose. By the time the various problems had been resolved and a decision was made to provioe SSKI to area residents of the TMI facility, the risk of radioiodine release had declined considerably and the State decided not to use the drug. 


\section{The Tennessee Experience}

Following the Three Mile Island Accident and the failure to provide $\mathrm{KI}$ to the public in a timely manner, an attempt was made to simulate distribution of $\mathrm{KI}$ to area residents as part of a nuclear emergency drill at the Sequoyah Plant operated by the Tennessec Valley Authority. On two separate occasions, the simulated distribution of KI to downwind residents was considered "too slow" with respect to plume arrival time in order to protect residents effectively (Fowinckle 1983).

As a result, Tennessee public heajth officiajs decided to predistribute KI to resicients within a 5-mile radius of the power station. A significant consideration was the anticipared degree of public acceptance and anxiety induced by the predistribution of $\mathrm{KI}$ tablets. While TVA officials expressed concern and recommended that predistribution not be undertaken, State health officials, nevertheless, proceeded on the premise that open communications and proper explanations can achieve public acceptance. The method for predistribution included the following:

(1) A letter from the Tennessee Commissioner of Public Health was mailed to respective households. The letter advised recipients that a member of the local health depariment would corne to their home to deliver a vial of $\mathrm{KI}$ tablets and to explain their proper use.

(2) The field staff selected to make house-to-house deliveries were professional personnel who were experienced in communicating with the public. A total of 38 individuals were given a one-day training session to ensure their abitity to provide technical information and respond to potential questions.

(3) News media reporters were also encouraged to attend the one-day training session, which schooled the home visitors for their tasks. News coverage of the project was extensive and involved local and national television and newspapers. Dr. Fowinckle, Director of Tennessee's State Health Department, stated that ". . . during the week preceding and the first week of distribution, there was intense public interest. Answering questions from the press and the public reguired almost all the time of two physicians. Thereafter, each Monday and Tuesday produced a large number of inquiries during the six-week period when KI was distributed" (Fowinckle 1983).

(4) Each household was provided a package containing a child-proof capped vial of 14 tablets each containing $130 \mathrm{mg} \mathrm{KI}$. This quantity was considered sufficient to give household members a starter dose for thyroid blocking and yet be insufficient to cause serious consequences if an overdose were taken accidentally or the package instructions were ignored.

(5) The labeling on the vial and a package insert from the mamufacturer provided carefully worded information and instructions that the drug was to be used only for thyroidblocking in a radiation emergency. 


\section{Program Effectiveness:}

The KI packages were distributed door to door from November 16 through December 11, 1981. The 38 health depariment staff members spent 166 person-days visiting 5,591 households. A total of 3,022 househoids accepted the tablets. If residents were not home, a letter was forwarded which informed residents of their option to pick up KI tablets at one of two tocal health care centers. An additional 682 household members responded, which brought the total to 3,704 households or $66 \%$ of the total households in the area.

Health officials suspected that a significant percent of the $34 \%$ of the households where door-todoor distribution was unstucessful represented summer residents of cottages who, during the time of KI predistrilbution (November/December), had vacated their residence (Dr. Sarah Sell, 1991 - personal communications).

Additionally, a supply of 450 vials was provided to two schools located within the five-mile radius in order to provide a first dose to the 6,100 students at those schools.

In the fall of 1984, three years after the initial door-10-door predistribution of KI, residents within the same five-mile radius were contacted by mail and advised that their supply of KI had expired its shelf-life and that a new supply of KI was available for picioup at the local health department. Those that received KJ previously could exchange their expired KI for a new supply; and those who had either lost or had never accepted any pteviously could also obtain a new supply.

Thirty-two percent of the eligible households responded by coming to the health department. This response can be compared to the $66 \%$ of households that initially accepted the $\mathrm{KJ}$ distributed door-to-door in 1981. To date, there have been no reports of accidental administration or adverse effects of misuse of predistributed KI (Dr. Sarah Sell 1991 - personal communication).

In surnmary, the Tennessee State health officials considered the predistribution pilat program a "success," but no official cost-benefit analysis was performed. While it is difficult to argue the benefits of prompt access to KI to near-field residents who would most likely experience the highest thyroid doses with the shontest time interval, predistribution is considerably less efficient than might be expected. The cost of predistribution is considerably higher than that of stockpiling-

For a KI prophylaxis program limited to local stockpiles, the program costs are primarily those of initial purchase and five-year replacement at the estimated price of $\$ 0.70$ per vial of 14 tablets. In contrast, predistribution includes the up-front costs associated with predistribution, which are independent of the unlikely occurrence of a major nuclear accident. Based on the Tennessee experience, the collective cost for the predistribution of 3,704 vials to a corresponding 
number of households was estimated at \$125,000 (Fowinckle 1983; and Fowinckle 1991 persoral communications). The unit cost of predistribution at about $\$ 30$ per vial can, therefore, be estimated to be $\mathbf{4 2}$ times the cost of stockpiling.

\section{The Chernobvl Experience}

Soviet Union. The accident at the Chernobyl nuclear power station occurred on April 26, 1986, at 1:23 a.m. This facility is located three km from the nearest town of Pripyat and $30 \mathrm{~km}$ from the nearest city of Kiev. The phenomena associated with the Chemobyl accident, including release fraction, duration, rate, and pathways for environmental release, were greatly influenced by design features and materials unique to the RBMK- 1000 reactor, which differ from those of U.S. commercial power reactors. Thus, the Chernobyl data on radionuclide release are not directly applicable to predicted releases from U.S. reactors.

Moreover, the release of radionuclides from Chernobyl did not occur as a single acute event. Only about $25 \%$ of the radio-particulate release to the environment took place in the first 24 hours (Table E-1); the remaining $75 \%$ of the activity was released as a protracted process (NUREG-1250), Nevertheless, owing to the high temperature of the molten fuel, the initial explosion and fuel fragmentation disproportionately released volatile radionuclides of radioiodine, -tellurium, and -cesium. It is estimated that of the 7.3 million curies of $1-131$ released in tota!, about 4.5 million cuties were released in the first 24 hours (NUREG-1250).

Table E-1. Dafly Releases of Radioactivity into the Atmosphere (Exclussive of Noble Gases)

\begin{tabular}{lcc}
\hline Date & $\begin{array}{c}\text { Days After } \\
\text { Accident }\end{array}$ & $\begin{array}{c}\text { Quantity of Activity } \\
\text { (Mega Cuties) }\end{array}$ \\
\hline $4 / 26$ & 0 & 12 \\
$4 / 27$ & 1 & 4.0 \\
$4 / 28$ & 2 & 3.4 \\
$4 / 29$ & 3 & 2.6 \\
$4 / 30$ & 4 & 2.0 \\
$5 / 1$ & 5 & 2.0 \\
$5 / 2$ & 6 & 4.0 \\
$5 / 3$ & 7 & 5.0 \\
$5 / 4$ & 8 & 7.0 \\
$5 / 5$ & 9 & 8.0 \\
$5 / 6$ & 10 & 0.1 \\
$5 / 9$ & 14 & 0.01 \\
\hline
\end{tabular}


The radiological conditions in the near-field and far-field were complex and profoundly affected by the release conditions and the changing meteorological conditions prevailing over the ten-day period. In the first hours after the accident, the radioactive release bypassed the town of Pripyat; but later when the effective release height declined substantially along with changes in the wind direction, contamination and gamma dose-tate levels incteased to alarming levels. By 7:00 a.m. on April 27,1986, the gamma dose rate in areas closest to the plant had reached 180 to 600 mrem per hour levels (Il'in 1987).

The Soviet radiation emergency preparedness plans included procedures for stockpiling and distribution of potassium iodide tablets. KI tablets were made available to on-site personnel at 3:00 a.m. on April 26, one-and-a-half hours after the accident. On the assumption that local residents were at home asieep with closed windows (i.e., effectively sheitered) during the first few hours, public notification of the accident was delayed until morning. Door-to-door distribution of $\mathrm{KJ}$ tablets to the 45,000 residents of the town of Pripyat commenced at 8:00 a.m., or six-and-one-half hours after the accident. It took much longer, from April 28th to the firse days in May to complete distribution of $\mathrm{KI}$ to an additional 90,000 persons residing in 71 villages within a $30-\mathrm{km}$ radius of the damaged plant.

In light of predictions that the external exposures received by near-field residents might exceed the protective action level used in the Soviet Union, it was also decided to evacuate the inhabitants of Pripyat and several other nearby population centers. The criteria in the Soviet Union for taking protective measures are provided in Table E-2. 


\section{Table E-2. Soviet Criteria* for Taking Protective Actions}

(Ref. I'in 1987)

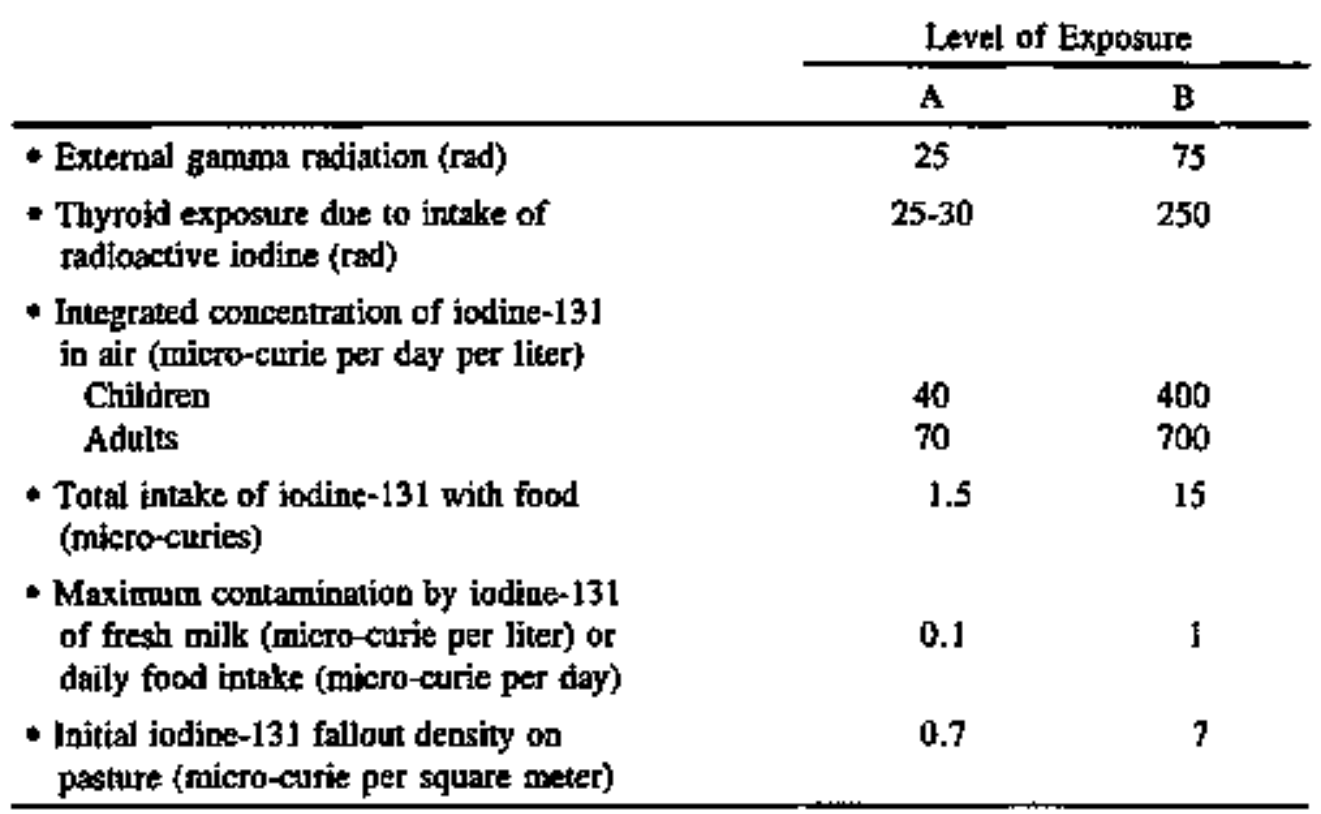

"Notes:

If exposure of contamination does not exceed level A, emergency measures that involve the temporary disuption of the normal living routine of the public are not needed. If exposure or contannination exceds level A but does not reach leves $B$, it is recornmenied bat decisions be taken based on the attual situation and local conditions.

If exposure or contamination reaches or exceds level B, it is reconyonded that energency measures be taken to ensure the radiation protection of the public; the public should immediately seek shelter indoors; time spent outdoors should be restricted; on the basis of the actual situation, rapid evacuation should be organized; prophylactic iodine thould be distributed; the use of cantaminated products in food should be banned or linited; dairy caltle should be switched to uncontaminated pasture of fodder.

The decision to evacuate the local population was based on a projected external exposure value in excess of the lower level (level A or $25 \mathrm{rem}$ ). For intemal exposure of the thyroid due to inhalation of radioiodine, the decision to evacuate was based on the upper leve] $\mathrm{B}$ or 250 rads to the thyroid. These selected dose levels of intervention fall within the range of the two levels of intervention cited by the ICRP, WHO, and the LAEA for decisions to evacuate populations at an early stage of an accident (i.e., 5 to 50 rads for whole body exposure and 50 to 500 rads for thyroid exposure).

Orders for the evacuation of the 45,000 residents of Pripyat were announced at 12:00 hours with buses artiving from Kiev at 14:00 hours on April 27 (36 hours after the accident). Evacuation was completed in three hours. Evacuation of the additional 90,000 residents within the $30-\mathrm{km}$ 
radius started several days latet and was not completed until one week after the accident. Among the 135,000 persons administered $K I$ and stbsequently evacuated were about 2,000 pregnant women.

\section{Estimates of Public Exposure}

The combined ptotective actions of sheltering, decontamination efforts, limiting ingestion of contaminated food products, potassium iodide prophylaxis, and evactation have been credited for reducing exposures among residents tiving within the $30-\mathrm{km}$ radius of the plant. With the exception of evacuation, which was slowed by the absence of privately owned vehicles, the Soviets were otherwise prepared to enact emergency measures including KI distribution. School children received $\mathrm{KI}$ in most instances within six hours of the initial releases. The use of KI by the approximately 135,000 incividuals in the immediate area of Chemobyl did not result in any adverse side-effects requiring hospitalization. Among residents of Pripyat and those within a $30-\mathrm{km}$ radius, average exposure to the whole body has been estimated, at $3.3 \mathrm{rem}$ and $16 \mathrm{rem}$, respectively (NUREG-1250). Although a precise measure of the prophylactic value of $\mathrm{KI}$ is difficult to ascertain, thousands of thyroid activity measurements of indjviduals in the exposed poputation suggest that the observed levels were markedly lower than those that would have been expected had the prophylactic measure not been taken (Table E-3).

\section{Table E-3. Thyroid Burdens to Near-Field Residents of the Chernobyl Nuclear Facility (Ref.: Linnemann 1987)}

\begin{tabular}{cc}
\hline $\begin{array}{c}\text { Thyroid Burden } \\
(\mu \mathrm{Cj})\end{array}$ & $\begin{array}{c}\text { Persons Affecsed } \\
(\%)\end{array}$ \\
\hline$<20$ & 87 \\
$<50$ & 94 \\
$100-150$ & 1.5 \\
$>200$ & 0.5 \\
\hline
\end{tabular}

In August of $1991(08 / 03$ to $08 / 17)$, the World Federation of Ukrainian Medical Association (WFUMA) held its third congressional session which specifically addressed medical consequences including thyroid disorders, to residents of the most highly contaminated regions of the Ukraine. Included were regions well beyond the 30-kilometer radius where KI had not been distributed. On the basis of radioiodine intakes by inhalation and consumption of dairy products as well as measurements performed on populations, thyroid doses were estimated. Using a "realistic" rather than a conservative model, the following thyroid doses among children were estimated (Shandala 1990): 
- 56,000 children received thyroid doses of up to 30 rads.

- 29,000 children received thyroid doses between 30 and 200 rads.

- For 7000 children, the thyroid dose is thought to have exceeded 200 rads.

- Based on risk models used by the WFUMA, it was estimated that the collective thyro-oncogenic dose of 7,400,000 rads among these children could cause about 300 future thyroid malignancies'.

- For a significant number of children, the individual thyroid exposures exceeded the threshold dose for hypothyroidism. For the coliective $4,200,000$ thyroid rads in excess of threshold levels, 418 cases of hypothyroidism were estimated.

The impact of radiation exposure on thyroid endocrinological and auto-immunological status was also evaluated. Measurements among 1,074 exposed pregnant women and 9.560 neonates showed an elevated level of thyrotropin hormone and $T_{4}$ (Yakolev 1991; Oliinyk 1991). Children evaluated for their immunological competence showed a generalized weakening of $T$ cell mediated immunity (Chaban 1991). This evidence may imply an increased risk of autoimmune disease of the thyroid gland in the future.

\section{The Chernobyl Experience: Poland}

The effective release height generated by the intense heat of the Chernobyl accident was such that radioactive fallout outside the Soviet Union was sufficiently high to prompt various protective measures including $\mathrm{KI}$ prophylaxis. Plume arrival in northeastern Poland was thought to occur some time during the night of Aptil 27 (Linnemann 1987). Analysis of air samples by the Polish Central Laboratory for Radiological Protection verified the presence of radioiodines and other nuclides around noon on April 28. High air concentrations of I-13I in most parts of Poland Iasted from April 29 to April 30, reaching a maximum value of $5.4 \mathrm{gCi} / \mathrm{m}^{3}$. In the eariy hours of April 29, a Polish governmental task group evaluated the radiological situation and established the following protective actions with respect to thyroid exposure (Nauman 1988):

(1) The committed thyroid dose in persons less than 16 years of age should not exceed 5 rem.

(2) The committed thyroid dose for persons over the age of 16 years should not exceed 50 rem.

1 Using the lifetime risk coefficients for I-131 employed in this report, approximately 381 thyroid malignancies would be expected among this highty exposed population of children (i.e., $(31.5+71.5) / 2$ thyroid cancers per $10^{6}$ thyroid rads $=381$ thyroid malignancies). 
On the basis of radiological factors and the low dietary content of iodine among Poles, the government at 3:00 p.m. on April 29 approved the prophylactic use of potassium iodide to block further exposure from inhalation and ingestion as well as to minimize the recirculation and reutilization of radioiodine that had already been taken in. 'The decision initially limited iodide prophylaxis to children and teenagers and recommended the following daily doses of $\mathrm{KI}$ :

$\begin{array}{lll}\text { - less than two years: } & 30 \mathrm{mg} \\ \text { two to five years: } & 50 \mathrm{mg} \\ \text { - } \quad \text { ive years and older. } & 70 \mathrm{mg}\end{array}$

Initially, the protective administration of potassium iodide was not recommended for adults. It was agreed that the thyroid cancer risk in this group was low and the possibility of adverse side effects was higher in this group than in younger individuals. The government also assumed a neutral position on iodide prophylaxis for pregnant females. The mass media was used to announce and outline the protective guidelines to the public. Potassium iodide was distributed in all kindergartens, schools, public health centers, and pharmacies. Volunteers were used to distribute KI to these centers. On April 30, radiological conditions worsened and government recommendations for iodide prophylaxis became considerably less restrictive.

Follow-up studies were undertaken to assess the effectiveness of KI prophylaxis. The Central Laboratory for Radiological Protection estimated committed thyroid dose equivalents in children and adults in two different parts of Poland where contamination was considered "moderate" and "severe." The results of this study were included in the Government Commission Report (Dziuk 1987) and the WHO Working Group Study (WHO 1986). A summary of their findings is presented in Table E-4 below.

Table E-4. Thyroid Doses for Protected and Unprotected Populations In Poland Following the Chernobyl Accident ${ }^{*}$

\begin{tabular}{|c|c|c|c|c|}
\hline & \multicolumn{4}{|c|}{ Dose (rads) } \\
\hline & \multicolumn{2}{|c|}{ Without Protestion } & \multicolumn{2}{|c|}{ With Protection } \\
\hline & Adults & Children & Adults & Children \\
\hline \multicolumn{5}{|c|}{ Moderatecontamination } \\
\hline Inthatation & 0.12 & 0.84 & 0.12 & 0.75 \\
\hline Ingestion & 0.45 & 6.00 & 0.15 & 0.40 \\
\hline Total & 0.57 & 6.84 & 0.27 & 1.15 \\
\hline \multicolumn{5}{|l|}{ Semere Contanination } \\
\hline Iribalation & 0.36 & 2.5 . & 0.36 & 230 \\
\hline Ingestion & 1.35 & 18.0 & 0.45 & 1.20 \\
\hline Total & 1.71 & 20.5 & 0.81 & 3.50 \\
\hline
\end{tabular}


The obvious conclusion cited by the study was that the prophylactic administration of KI was highy effective in reducing radioiodine uptake through ingestion, which contributed the bulk of the thyroid dose among unprotected individuals. Because $\mathrm{KI}$ prophylaxis had been delayed and did not commence for several days after the initial plume arrival, it did not significantly reduce thyroid exposure from inhalation.

\section{Adverse Reactions to KI}

The most likely population groups to manifest intrathyroidal adverse reactions leading to hypothyroidism and hyperthyroidism are neonates whose mothers were administered KI during pregnancy and older adults with underlying thyroid pathologies. Although the exact number of pregnant women who received $\mathbf{K I}$ is unknown, a best estimate assumes that approximately 10,000 pregnant females took 70 or $100 \mathrm{mg}$ of jodide in single or repeated daily doses (Nauman 1988 ). Clinical data for 140,000 newbons delivered in the "severely" contaminated portions of Poland and tested for neonatal hypothyroidism indicate that neither radioiodine nor KJ prophylaxis significantly affected the incidence rate of neonatal hypothyroidism (Nauman 1988). Among the approximately eight million adults who were administered $\mathrm{KI}$, no single case of thyroiditis was reported. However, among an unspecified number of individuals with a history of Graves' Disease whom under medical supervision had becone euthyroid, relapse was expected to have occurred in some, but this remains undocumented.

For extrathyroidal effects, Nauman (1988) reported the following: (1) Among the 10.5 mitlion teenagers and children given $\mathrm{KI}$, only a few minor to moderate allergic responses were noted and (2) for the eight million adults, severe but non-fatal anaphylactoid reactions were reported for only three individuals. There were, however, reports of nearly 5,000 cases involving mild to moderate reactions.

The adverse reaction incidence rates experienced by Poles are not directly applicable to U.S. populations due to significant differences in dietary levels of iodine.

\section{Conclusions}

The ability of stable iodide to block thyroidal uptake of radioiodine with an efficiency approaching $100 \%$ is a matter of scientific observation. For programmatic iodide prophylaxis, which is primarily directed to the plume inhalation pathway, the single most limiting factor. effecting efticacy is time. For effective prophylaxis, stable iodide must be administered shortly before and no later than exposure to radioiodine. The potentially brief time interval between the initiating events of a serious nuclear accident and the subsequent release of radioactivity into the environment dictates the need for quick decisions and rapid implementation of emergency actions.

During the TMI Accident, the absence of available KI clearly limited its potential use. For any emergency plan with provisions to provide stable iodide to the general public, a readily accessible stockpile and a prompt method for distribution are essential reguirements. Even when 
these two requirements are met, distribution to residents in the immediate vicinity of a muclear plant may not be achievable before plume arrival. Under conditions of delayed distribution, the residual prophylactic value would be limited to the balance of plume expasure following the administration of stable iodide. An alternative to the stockpiling option, is a limited predistribution of $\mathrm{KI}$ to nearby residents. The pilot project undertaken by the Tennessee State health officials, however, demonstrated the limitations and costs for this option.

To date, the only experience with $\mathbf{K I}$ prophylaxis involves the Chernobyl accident. In spite of claims that the Soviets were well prepared for such an emergency, KI distribution to nearby residents was delayed by hours to days following the initial burst of released radioactivity. Similar delays by government officials in Poland to make KI available, reduced or eliminated the efficacy of KI to prevent inhalation thyroid exposures. The bulk of iodide prophylaxis was restricted to the avoidance of thyroid burdens from ingestion of contaminated food products.

The ability to extrapolate the value of iodide prophylaxis based on the Chernobyl experience to a potential future accident in the United States is complicated by a host of differences that may either enhance or diminisk its potential benefits or need. The following is a partial list of variables:

- Engineering design features of the Soviet RBMK-1000 reactor versus the typical United States LWR affect the accident scenario including release fraction, release rate, duration of release, etc.

- Housing and population density differences for the near-field populations. Population densities affected by multi-family residents in the Soviet Union have a profound affect on distribution procedures, methods, and distribution efficiency.

- Availability of privately owned vehicles may play a key role in the distribution of KI as well as the prompt and alternative protective measure of evacuation.

- Food distribution system and the degree of dependency on locally obtained food products. For the Soviet Union and eastern bloc countries, total or partial dependency on locally contaminated food products implies prophylactic benefits from the ingestion pathway. For U.S. populations, there is a lack of dependency on lacalized food products in the event of a nuclear emergency which, therefore. limits the value of iodide prophylaxis to phume inhalation of radioiodine.

- Dietary intake of iodine. A low dietary intake of iodine (i.e., 50-70 $\mu \mathrm{g}$ per day is common among European countries versus $125-700 \mu \mathrm{g}$ per day in the U.S.) increases the thyroid uptake and thyroid dose for a given exposure condition. The prophylactic benefit of stable iodide is, therefore, enhanced by low dietary intakes. Offsetting this benefit is the adverse intra- and extrathyroidal effects associated with stable jodide that are disproportionately seen among persons with low dietary intakes of iodine. 


\section{REFERENCES}

ACS-1982, "1982 Cancer Facts and Figures," American Cancer Society.

AMA 1990, Guides to the Evahuation of Permanent Impaiment, American Medical Association, Third Edition (Revised).

APS-1985, "Report to the American Physical Society of the Study Group on Radionuclide Release from Severe Accidents at Nuclear Power Plants," Rev. Mod. Phys., 57: No. 3, Part II.

Aldrich, D.C., D.M. Ericson, and J.D. Johnson, 1978, 'Public Protection Strategies for Potential Nuclear Reactor Accidents; Sheltering Concepts with Existing Public and Private Structures," SAND 77-1725, Sandia Laboratories, Albuquerque, New Mexico.

Alexander, W.D., R.M. Harden, D.A. Koutras, and E. Wayne, 1965, "Influence of Iodine Intake After Treatment With Antithyroid Drugs," Lancet, ï: 866.

Baker, M.S., L.G. Kessler, and R.C. Smucker, 1989, "Site-Specific Treatment Costs for Cancer: An Analysis of the Medicare Continuous History Sample File," in Cancer Care and Costs: DRG's and Beyond. R.M. Scheffler and N.C. Andrews eds., Ann Artor: Health Administration Press.

Beach, S.A. and G.W. Dolphin, 1962, "A Study of the Relationships Between X-Ray Dose Delivered to the Thyroids of Children and the Subsequent Development of Malignant Tumors," Phys. Med. Biol., 6: 583.

.Becker, D.V., 1987, "Reactor Accidents: Public Health Strategies and their Medical Implications," JAMA, 258 (5): 649.

Becker, D.V., L.E. Braverman, J.T. Dunn, E. Gaitan, C. Gorman, H. Maxon, A.B. Schnejder, L. VanMiddlesworth, and 3. Wolff, 1984, "The Use of Iodine as a Thyroid Blocking Agent in the Event of a Reactor Accident," JAMA, 252 (5): 659.

Becker, D.V., G.W. MoConahey, B.M. Dobyns, E.A. Tompkims, G.E. Sheline, and J.B. Wotkman, 1971, "The Results of Radioiodine Treatment of Hyperthyrojdism" in Further Advances in Thvoid Research, K. Fellinger and R. Hofer, Eds. (G. Gistel and Cie, Vienna, Austria).

Behling, U.H. and J.E. Hildebrand, 1986, "Radiation and Health Effects: A Report of the TMI2 Accident and Related Health Studies," GPU Nuclear Corporation, Parsippany, NJ. 
Boukis, M.A., D.A. Koutras, A. Souvatzoglou, A. Evangelopoulou, M. Vrontaski, and S.D. Moulopoulos, 1983, "Thyroid Hormone and Immunological Studies in Endernic Goiter," J. Clin. Enoocrin. Metabol., 57: 859.

Braverman, L.E., S.H. Ingbar, A.G. Vagenakis, L. Adams, and F. Maloof, 1971, "Enhanced Susceptibility to Iodide Myxedema in Patients with Hashirnoto's Disease," J. Clin. Endocrin. Metabol., 32: 515.

Brown, M.S., 1990, "The National Economic Burden of Cancer: An Update," J. of the Natl. Cancer Inst. 82 (23): 1811 .

Blum, M. and M. Eisenbud, 1967, "Reduction of Thyroid Irradiation from I-131 by Potassium Iodide," JAMA, 200; 1036.

Bryant, P.M., 1969, "Data for Assessments Concerning Controlled and Accidental Releases of I-131 and Cs-137 to Atmosphere," Health Physics, 17 (1): 51.

Burrow, G.N., 1975, "The Thyroid in Pregnancy," Med. Clinics of N. America, 59: 1089.

Carswell, F., 1970, "Congenital Goiter and Hypothyrojdism Produced by Maternal Ingestion of Iodides," Lancet, i: 1241.

Chaban, A, A. Chamak, and D. Afanasev, 1991, "Clinical-Immunological Characteristics of the Thyroid Gland in Children Exposed to Ionizing Radiation During the Chernobyi NPS Disaster" (an abstract), Health Physics, 61: 153.

Chanin, D. I., J. L. Sprung, L. T. Ritchie, and H. N. Jow, 1990, "MELCOR Accident Consequence Code System (MACCS), Vohume 1: User's Guide," NUREG/CR-4691, Sandia National Laboratories, Albuquerque, NM.

Chanoine, J.P., P. Bourdoux, A. Pardou, and F. Delange, 1986, "Iodinated Skin Disinfectants in Mothers at Delivery and Impairment of Thyroio Function in their Breast-Fed Infants," in Erontiers of Thyroidology, G.A. Meiceiros-Neto and E. Gaitan, eds., Plenum Press, N.Y.: p. 1055.

Church, B.W., D.L. Wheeler, C.M. Campbell, R.V. Nutley, and L.R. Ausphaugh, 1990, "Overview of the Department of Energy's Off-Site Radiation Exposure Review Project" (ORERP), Health Physics, 59 No. 5: 503.

Cody, B., C.E. Sedgwick, W.A. Meissner, J.R. Bookwalter, V. Romagosa, and J. Werber, 1976, "Changing Clinical Pathologic, Therapeutic, and Survival Patterns in Differentiated Thyroid Carcinoma. Records Over a 40 Year Period from the Lahey Clinic," Annals of Surgery, 184: 541. 
Cohen, B.L., 1980, "Society's Valuation of Life Saving in Radiation Protection and Other Contexts," Health Physics, 3요: 33.

Conard, R.A., 1984, "Late Radiation Effects in Marshall Islanders Exposed to Fallout 28 Years Ago," in Radiation Carcinogenessis: Epiderniology and Biological Significance, J.D. Boice, Jr. and J.F. Fratmeni, Jr., eds., N.Y., Raven Press: p. 57.

Conard, R.A., K.D. Knudsen, and B.M. Dobyns, 1975, "A Twenty Year Review of Medical Findings in a Marshallese Population Accidentally Exposed to Radioactive Fallout, " U.S. Dept. of Energy Publication (BNL), Upton, N.Y., Brookhaven Natt. Lab., 50: 424.

Connoily, R.J., G.I. Vidor, and J.C. Stewart, 1970, "Iodine Induced Thyrotoxicosis in Endemic Goiter Area after Iodination of Bread," Lancet, i: $\mathbf{5 0 0}$

Costa, A., V. DeFilippis, M. Panizzo, G. Giraudi, E. Bertino, R. Arisio, M. Mostert, G. Trapani, and C. Fabris, 1986, "Development of Thyroid Function Between Vl-IX Month of Fetal Life in Humans," J. Endocrin. Invest., 2: 273.

Cronquist, A., E.E. Pochin, B.D. Thompson, 1971, "The Speed of Suppression by Iodate of Thyroid Iodine Uptake," Health Physics, 21: 393.

Crile, G, 1975, "Carcinoma of the Thyroid after Radiation to the Neck" Surg. Gynecol. Obstet., 141: 602 .

Curd, J.G., H. Milgrom, D.D. Stevenson, D.A. Mathison, and J.H. Vaughn, 1979, "Potassium Iodide Sensitivity in Four Patients with Hypocomplementernic Vascultits," Ann. Int. Med., 21: 853 .

DeGroot, L.S., M. Reilly, K. Pinnameneni, and S. Refetoff, 1983, "Retrospective and Prospective Sndy of Radiation-Induced Thyroid Disease," American Journal of Medicine, 74: 852 .

DeGroot, L.J., L.A. Frohman, F.L. Kaplan, and S. Refetoff, 1977, "Radiation-Associated Thyroid Carcinoma," Grune and Stratton Publ., N.Y.

Delange, F., and H. Burgi, 1989, "Iodine-Deficiency Disorder in Europe," Bulletin of the World Health Organization.

Delange, F., J.P. Chanoine, C. Abrassart, and P. Bourdoux, 1988, "Topical Iodine, Breast Feeding and Neonatal Hypothyroidism," Arch. Disease in Childhood, 63: 106.

Delange, F., D.A. Fisher, and P. Malvaux, 1985, "Transient Disorders of Thyroid Function and Regulation in Pretem Infants," in Pediatric Thvroicology, Delange, F., ed., Basel, Karger: p. 369. 
Delange, F., 1984, "Increased Risk of Primary Hypothyroidism in Preterm Infants," Journal of Pediatrics, 105: 462 .

DeLawter, D.S. and T. Winship, 1963, "Follow-up Study of Adults Treated with Roentgen Rays for Thyroid Disease," Cancer, $\underline{16}$ : 1028.

Department of Transportation, 1984, "The 1984 Annual Report on Highway Safety Improvement Programs."

Dobyns, B.M., G.E. Sheline, J.E. Workman, E.A. Tompkims, W.M. McConahey, D.V. Becket, 1974, "Malignant and Benign Neoplasms of the Thyroid in Patients Treated for Hyperthyroidisn: A Report of the Cooperative Thyrotoxicosis Study," J. Clin. Endocrinol. Metab., 38: 976.

Dunning, D.E. and G. Schwarz, 1981, "Variability of Human Thyroid Characteristics and Estimates of Dose from Ingested I-131," Health Physics, 40: 661.

Dumont, J.E., B. Corvilain, J. Coclet, E. Raspe and S. Reuse, 1988, "Recent Progress in Fundarnental Thyroidology with Relevance to the Prevention of Medical Consequences of a Nuclear Accident," in Iodine Prophylaxis Following Nuclear Accidents, E. Rubery and E. Srales, eds., Pergamon Press, N.Y.

Dyer, N.C. and A.B. Brill, 1972, "Matemal-Fetal Transport of Iron and lodine in Human Subjects," Adv. Exp. Med. and Biol., 27: 351.

Dzituk, E., 1987, "Medical Aspects of the Accident in the Chernobyl Power Station," Problems of Nuclear Medicine, 2: 73 .

Einhorn, J. and G. Wikholm, 1967, "Hypothyroidism After External Itradiation to the Thyroid Region," Radiology, 요: 326.

EPA, 1992, Technical Support Document for the 1992 Citizen Guide to Badon, U.S. Environmental Protection Agency.

EPA, 1983, Requlatory Impact Analysis Guidelines, U.S. Environmental Protection Agency.

EPA, 1975, 1980, Mamual of Protective Action Guides and Protective Actions for Nuclear Incidents, EPA-520/1-75-001, U.S. Environmenta] Protection Agency, Sept. 1975/Revised June 1980.

EPA, 1974, "Evacuation Risks - An Evaluation", EPA-520/6-74-002, U.S. Environmental Protection Agency. 
Evans, T.C., R.M. Kretzchmar, R.E. Hodges, and C.W. Song, 1967, "Radioiodine Uptake Studies of the Human Fetal Thyroid," J. of Nucl. Med., \& 157.

FDA, 1982, U.S. Food and Drug Administration, "Potassium lodide as a Thyroid-Blocking Agent in a Radiation Emergency - Final Recommendations on U'se," Federal Register, 47 (125); 28158 .

Federal Emergency Management Agency, July 24, 1985, "Federal Policy on Distribution of Potassium Iodide Around Nuclear Power Sites for Use as a Thyroidal Blocking Agent," 50 FR 30258.

Fisher, D.A., 1985, "Ontogenesis of Hypothalamic-Pituitary-Thyroid Function in the Human Fetus," in Pediaric Thyroidology, Delange, et al., eds., Basel, Karger. p. 19.

Fisher, D.A. and A.H. Klein, 1981, "Thyroid Development and Disorders of Thyroid Function in the Newborn, ${ }^{n}$ New England J. of Medicine 304; 702.

Fisher, D.A, 1975, "Thyroid Function in the Fetus and Newtom," Medical Clinics of North America, 52; 1099 .

Fisher, W.D. M. Lo Voothees, and L.T. Gardner, 1963, "Congenital Hypothyroidism in Infants Following Matemal I-131 Therapy," J. of Pediatrics, 62: 132.

Flynn, C.B., 1979, "Three Mile Island Telephone Survey, Preliminary Report on Procedures and Findings, Social Impact Research, Inc., Seattle, Washington. (NUREG/CR-1093)

Food and Drug Administration, 1982 (June 29), "Potassium Iodide as a Thyroid-Blocking Agent in a Radiation Emergency: Final Recommendation on Use," Federal Register, 47 (125): 28158 .

Food and Drug Administration, Dec. 15, 1978, 'Potassium Iodide As A Thyroid-Blocking Agent in a Radiation Emergency," Federal Registers, 43 (242); 58798.

Fowinckle, E.W., S.H. Sell, and R.E. Wolle, 1983. "Predistribution of Potassium Iodide The Tennessee Experience," Public Health Report, 90(2): 123.

Fradkin, J.E. and J. Wolff, 1983, "Iodine Induced Thyrotoxicosis," Medicine, 62; 1.

Frohmnan, L.A., A.B. Schneider, M.J. Favus, M.E. Stachura, J. Amold, and M. Amold, 1977, "Thyroid Carcinoma After Head and Neck Irradiation. Evaluation of 1,476 Patients" in Radiation-Associated Thyroid Carcinoma, Degroot et. al Eds, Grane \& Statton, N.Y. 
Ganz, P.A., C.A. Schag, and H. Cheng, 1990, "Assessing the Quality of Life - A Study in New-Diagnosed Breast Cancer Patients," J. of Clin. Epidemiology, 43: 75.

Gibson, R.M., D.R. Waldo, and K.R. Levit, 1983, National Health Expenditures," Health Care Financing Review, 5 (1); 1 .

Gillespie, F.C., J.S. Ort, and W.R. Greig, 1970, "Microscopic Dose Distribution from I-125 in the Toxic Thyroid Gland and its Relationship to Therapy," Br. J. Radiology, 43: 40 .

Goldschmidt, H., 1977, "Dermatologic Radiotherapy and Thyroid Cancer," Arch. Demnatology, 113: 362 .

Green, H.G., F.J. Garcis, T.H. Shepard, and V.C. Kelley, 1971, "Cretinism Associated with Maternal Sodium Iodide-131 Therapy During Pregnancy," Am. J. Dis. of Children, 122. 247.

Greenman, G.W., 1962, "Thyrọid Function in Pregnancy. Fetal Loss and Follow-Up Evaluation of Surviving Infants, "New England J. Of Medicine, 267; 426.

Hall, R., M. Turner-Warwick, and D. Doniach, 1966, "Autoantibodies in lodide Goiter and Asthma," Clin. and Exptl. Immunol., 1: 285.

Halperin, J.A., 1989, "Potassium Iodide as a Thyroid-Blockex - Three Mile Island To Today," DICPP, The Annals of Pharmacotherapy, 23; 421.

Hamilton, T.E., G. vanBelle, and J.P. LoGerfo, 1987, "Thyroid Neoplasia in Marshall Islanders Exposed to Nuclear Fallout," JAMA, 2558; 629.

Hamill, G.C., J.J. Jarman, and M.D. Wynne, 1961, "Fetal Effects of Radioactive Iodine Therapy in a Pregnant Woman with Thyroid Cancer," Am. J. of Obstet. \& Gynecol., 81: 1018.

Heinrichs, K., A. Kaul, and H.D. Roedler, 1982, 'Estimation of Age Dependent Internal Dose from Radiopharmaceuticals," Phys. Med. Biol., 27; 775.

Henneman, $0 ., 1986$, "Place of Radioactive Iodine in Treatment of Thyrotoxicosis," Lancet, ii: 1369.

Hempelmainn, L.H., W.J. Hall, M. Phillips, R.A. Cooper, and W.R. Ames, 1975, "Neoplasins in Persons Treated with X-Rays in Infancy: Fourth Survey in 20 Years," J. Natl. Cancer Inst., 55: 519. 
Hodgson, T.A., 1984, "The Economic Burden of Cancer," in The Fourth National Conference on Human Values and Cancer Procedings, American Cancer Society, Inc., New York, March 15-17, 1984: 147.

Holm, L.E., K.E. Wicklund, G.E. Lundell, J.D. Boice, N.A. Bergman, G. Bjelkengren, E.S. Cederquist, U.B. Exicsson, L.G. Larsson, M.E. Lidberg, R.S. Lindberg and K.V. Wicklund, 1988, "Thyroid Cancer After Diagnostic Doses of Iodine-131: A Retrospective Study," J. Natl. Cancer Inst., 80: 1132.

Holm, L.E., 1984, "Malignant Disease Following Iodine-131 Therapy in Sweden," in Radjation Carcinogenesis: Epidemiology and Biologic Significance, Boile, J.D. Jr.,and J.F. Fraumen, Jr., eds., Raven Press, N.Y.

Holm, L.E., G. Lundell, and G. Walinder, 1980(a), 'Incidence of Malignant Thyroid Tumors in Humans after Exposure to Diagnostic Doses of Iodine-131: I Retrospective Cohort Study," J. Natl. Cancer Inst., 64: 1055.

Holm, L.E., G. Eklund, and G. Lundell, 1980(b), "Incidence of Maiignant Thyroid Tumors in Humans after Exposure to Diagnostic Doses of Iodine-131: II. Estimation of Actual Thyroid Gland Size, Thyroidal Radiation Dose and Predjcted Versus Observed Number of Malignant Thyroid Tumors," J. Natl. Cancer Institute, $\underline{65}$ : 1221.

Houts, P.S., J.M. Yasks, and B. Kahn, 1986, "Unmet Psychological, Social and Economic Needs of Persons with Cancer in Pennsylvania," Cancer, s8: 2355.

Houts, P.S., T. Hu, R.A. Henderson, P.D. Cleary, and G.K. Tokuhata, 1984, "Utilization of Medical Care Following the Three Mile Istand Crisis, " Amer. J. Public Health, 74: 140.

Houts, P.S. and M.K. Goldhaber, 1981(a), "Psychological and Social Effects on the Population Surrounding Three Mile Island After the Nuclear Accident on March 28, 1979," in Energy Environment and the Econnmy, S. Majunndar, ed., Penn. Academy of Sciences.

Houts, P.S., R.M. Disatella, and M.K. Goldhaber, 1981(b), "Health-Related Behavioral lmpact of The Three Mile Island Nuclear Incident: Part III." Report submitted to the TMI Advisory Panel on Health Research Studies of the Pennsylvania Department of Health.

Houts, P.S., R.W. Miller, G.K. Tokuhata, and K.S. Ham, 1980(a), "Health-Related Behavioral Impact of the Three Mile Island Nuclear Accident: Parts I \& II." Report submitted to the TMI Advisory Panel on Health Research Studies of the Pennsylvania Deparment of Health.

Houts, P., 'R. Miller, K. Ham, and G.K. Tokuhata, 1980(b), "Extent and Duration of Psychological Distress of Persons in the Vicinity of Three Mile Island, " Proceedings of the Pennsylvania Academy of Sciences, 54: 22. 
Hu, T., K.S. Sleysmant, K.S. Hany, and M. Yoder, 1980, "Health Related Economic Costs of the Three Mile Island Accident," a report issued by the Pennsylvania State University, Center for Research and Humant Resources, Institute for Policy Research and Evaluation, University Park, PA.

IAEA, 1985, "Pripciples for Establishing Intervention Levels for the Protection of the Public in the Event of a Nuclear Accident or Radiojogical Emergency," International Atomic Energy Agency, Safety Series, $\underline{72}$, Vienna.

ICRP, 1988, "Radiation Dose to Patients from Radiopharmaceuticals. " International Commission

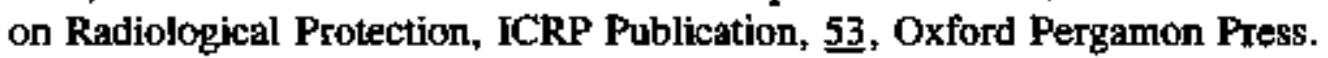

ICRP, 1977, "Recommendations of the International Commission on Radiological Protection," International Commission on Radiological Protection, Publication 26, Oxford Pergamon Press.

ICRP, 1975, "Report on the Task Group on Reference Man," Intemational Commission on Radiological Protection, ICRP Publication 23, Oxford Pergamon Press.

ICRP, 1959, "Report of Committee II on Permissible Dose for Internal Radiation," Interrational Commission on Radiological Protection, ICRP Pubjication 2, Oxford Pergamon Press.

ICRP, 1966, "Depositions and Retention Models for Intemal Dosimetry of the Human Respiratory Tract," International Commission on Radiological Protestion, Health Physics, 12(2): 173.

Il'in, L.A., G.V. Arkhangel'skaya, Y.O. Konstantinov, and I.A. Likhtarev, published in Moscow 1972, issued in 1974, "Radioactive Iodine in the Problem of Radiation Safety, Translation Series," USAEC 7536.

Il'in, L.A. and O.A. Pavlovski, 1987, "Radiological Consequences of the Chemobyl Accident in the Soviet Union and Measures Taken to Mitigate Their Impact, " IAEA Bulletin 4.

INSAG, 1986, "Summary Report on the Post-Accident Review Meeting on the Chernobyl Accident," International Nuclear Safety Advisory Group, August 30-September 5, 1986, GC(SPL.1)/3, LAEAC, Vienna.

Jensen, P.H., 1985, "Shielding Factors for Gamma Radiation From Activity Deposited on Structures and Ground Surfaces," Nuclear Technician, 68: 29.

Johnson, J.R., 1982(a), "Fetal Thyroid Dose from Intakes of Radiomuclides," Health Physics, 43 (4): 573 . 
Johnson, J.R., 1982(b), "Fetal Thyroid Dose from Intakes of Radioiodine by the Mother," Health Physics, 4I (4); 573.

Johnson, J.R., 1981, "Radioiodine Dosimetry," J. Radioanal. Chem., 65: 223.

Jow, H-N, J. L. Sprung, J. A. Rollstin, L. T. Ritchie, and D. I. Chanin (1990), "MELCOR Accident Consequence Code System (MACCS) Volume 2: Model Description," NUREG/CR-4691, \$andia National Laboratories, Albuquerque NM.

Kaplan, R.M. and J.P. Anderson, 1990, "The General Health Policy Model: An Integrated Approach" in: Quality of Life Assessments in Clinical Trials, B. Spiker, ed., Raven Press Ltd: p. 131.

Kaplan, M.M., M.B. Gamick, R.L. Gelber, J.R. Cassady, S.F. Sallan, W.F. Fine, and M.J. Sack, 1983, "Risk Factors for Thyroid Abnormalities After Neck Irradiation for Childhood Cancer," Am. J. of Medicine, 74: 272.

Katayama, H., 1963, "Clinical Survey on Adverse Reactions of Iodimated Contrast Media," Nippon Acta Radiologica, 48; 214.

Katz, S.I. and W. Strober, 1978, "The Pathogenesis of Dermatitis Herpetiformis," J. of Investigatory Dermatology, 70; 63.

Kocher, D.C., 1978, "Effects of Man's Residence Inside Building Structures on Radiation Doses from Routine Releases of Radionuclides to the Atmosphere," ORNL/TM6526, Oak Ridge Natl. Lab., Oak Ridge, Tenn.

Koutras, D.A., 1980, "Europe and the Middle East," in The Ecology of Iodine in Endemic Goiter and Endemic Cretinism. J.B. Stanbury and B.S. Hetzel, eds., John Wiley, N.Y: 185.

Lightner, E.S., F.A. Fismer, H. Giles, and J. Woolfenden, 1977, "Intra-ammiotic Injection of Thyroxine to a Human Fetus: Evidence for Conversion of $T_{4}$ and $T_{3}$, Am. J. of Obst. \& Gyn. 127: 487.

Linnemann, R.E., 1987, "Soviet Medical Response to the Chemobyl Nuclear Accident," JAMA, 258; 637.

Lombard, J. and F. Fagnani, 1981, Eqquity Aspects of Risk Management: Trade-offs Between Public and Occupational Hazards in the Nuclear Industry," Nuclear Safety, $22(5)$. 
Lowdell, C.P., H.J. Dobbs, G.S. Spathis, V.R. McCready, D.O. Cosgrove, and C.L. Harmer, 1985, "Lose Dose I-I31 in Treatment of Graves' Disease," J. of the Royal Society of Medicine, 78: 197.

Luce, B.R, and A. Elixhauser, 1990, "Estimating Costs in the Economic Evaluation of Medical Technologies," Int. J. Technol. Assess. Health Care, 6: 57.

Man, E.B. and S.A. Serumian, 1976, "Thyroid Function in Human Pregnancy. IX. Development or Retardation of 7 Year Old Progeny of Hypothyroxinemic Women, " Am. J. of Obstet. and Gynecol., 125: 949.

Martini, C.J. and I. McDowell, 1976, "Health Status: Patient and Physician Judgements." Health Services Res., 11: 508.

Maxon, H.R., 1982, "When Should Potassium Iodide Be Used as a Thyroid-Blocking Agent for Protection of the General Population from Potentially Harmful Effects of Radioiodine?," from Proceedings of the Electric Power Research Institute (EPRI) Workshop on Emergency Planning, Washington, D.C.

Maxon, H.R., E.L. Saenger, S.R. Thomas, C.R. Buncher, J.G. Kereiakes, M.L. Shafer, and C.A. McLaughlin, 1980. "Clinically Important Radiation-Assocjated Thyroid Disease," J. Am. Med. Assoc., 244: 1802.

Maxon, H.R., S.R. Thomas, R.L. Sgenger, C.R. Buncher, and J.G. Kerejakes, 1977, "Ionizing Irradiation and the Induction of Clinically Significant Disease in the Human Thyroid," Am. J. Med., 63: 697 .

Mays, C.W., 1966, "Thyroid Irridiation in Utah Infants Exposed to Jodine-131," Scientist Citizen, $8:$ : 3.

McConahey, W.M., W.F. Taylor, C.A. Gorman, and L.B. Woolner, 1981, "Retrospective Study of 820 Patients Treated for Papillary Carcinoma of the Thyroid at the Mayo Clinic between 1946 and 1971," in Advances in Thyroid Neoplasia: pp. 245.

McCorkle, R., J.Q, Benoliel, and G. Donaldson, 1989, "A Randomized Clinical Trial of Home Nursing Care for Lung Cancer Patients," Cancer 64: 1375.

McCorkle, R. and J. Q. Benoliel, 1983, "Symptom Distress, Current Concerns, and Mood Disturbances after Diagnosis of Life-Threatening Disease," Soc. Sa. Med., 17: 431.

MeGregor, A.M., A.P. Weetman, S. Ratanachaiyavong, G.M. Owen, H.K. Ibbertson, and R. Hall, 1985, "Iodine: An Influence on the Development of Autoimmune Thyroid Disease," in Thyroid Disorders Associated with Iodine Deficiency and Excess, R. Hall and J. Kobberling, eds., Raven Press: p. 209. 
Mehta, P.S., S.J. Mehta, and H. Vorherr, 1983, "Congenital Iodide Goiter and Hypothyroidism: A Review," Obstet. and Gynecol. Survey, 38: 237.

Modan, B., D. Baidatz, H. Mart, R. Steimitz, and S.G. Levin, 1974, "Radiation Induced Head and Neck Tumors," Lancet, 1: 277.

Mooney, G.H., 1977, "The Valuation of Human Life," Macmillan Press, London, England.

Mor, V., 1987, "Cancer Patients' Quality of Life Over the Disease Course: Lessons From the Real World," J. Chronic Dis. 40: 535.

Myant, N.B., E.E. Pochin, and E.A. Goldie, 1949, "The Plasma Iodide Clearance Rate of the Human Thyroid," Clin. Science, 8: 109.

Nagatiki, S., 1974, "Effect of Excess Quantities of Iodide," in Handbook of Physiology. Vol.II (Thyroid), M.A. Greer and D.S. Solomon, eds., Am. Physiology Society, Washington, D.C.

NAS, 1990, "Health Effects of Exposure to Low Levels of Ionizing Radiation," National Academy of Sciences, National Research Council Committee on the Biological Effects of Ionizing Radiation (BEIR V Report).

NAS, 1980, "The Effects on Populations of Exposure to Low Levels of Ionizing Radiation," National Academy of Sciences, National Research Council, Comnittee on the Biological Effects of Jonizing Radiation (BEIR III Report).

Nauman, J., 1988, "Potassium Iodide Prophylaxis in Poland: Review of Far Field Experience." in Iodine Prophylaxis Following Nuclear Accidents," E. Rubery and E. Smales, eds., Pergamon Press, New York.

NCI, 1990, "Quality of Life Assessment in Cancer Clinical Trials," Division of Cancer Prevention and Control, Bethesda, MD, July 16-17, Prepd. by S.G. Nayfield and B.J. Hailey.

NCI, 1989, "Proceedings of a Workshop on the Cost of Cancer, National Cancer Institute, NIH, Rockville, Maryland.

NCRP, 1985, 1987, "Induction of Thyroid Cancer by Ionizing Radiation," National Council on Radiation Protection and Measurements (NCRP Report No. 80) March 1985/Revised January 1987.

NCRP, 1984, "Predicting the Transport, Bioaccumulation and Uptake by Man of Radionuclides Released to the Environment," National Council on Radiation Protection and Measurements (NCRP Report No. 76). 
NCRP, 1980, "Influence of Dose and Its Distribution in Time on Dose-Response Relationship for Low-LET Radiation," National Council on Radiation Protection and Measurements (NCRP Report No. 64),

NCRP, 1977. "Protection of the Thyroid Gland in the Event of Releases of Radioiodine," National Council on Rodiation Protection and Measurements (NCRP Report No. 55).

NRC. 1990, "Potassium Iodide," Federal Register, 55 (189): 39668, September 28, 1990, U.S. Nuclear Regulatory Commission.

NUREG-75/014, 1975, "Reactor Safety Study Appendix VI: Calculation of Reactor Accident Consequences, WASH-1400," U. S. Nuclear Regulatory Commission.

NUREG/CR-0400, 1978, "Risk Assessment Review Group Report to the U.S. Nuclear Regulatory Commission," U.S. Nuclear Regulatory Commission.

NUREG-0172, 1977, "Age-Specific Radiation Dose Commitment Factors for a One Year Chronic Intake," Hoenes G.R. and J.K. Soldat, eds., U.S. Nuclear Regulatory Commission.

NUREG-0588, 1979, "Population Exposure and Health Impact of the Accident at the Three Mile Island Nuclear Station," U.S. Nuclear Regulatory Commission.

NUREG-0600, 1979, "Investigation into the March 28. 1979, Three Mile Island Accident," U.S. Nuclear Regulatory Commission.

NUREG-0637, 1980, "Report to the Nuclear Regulatory Commission from the Staff Panel on the Commission's Determination of an Extraordinary Nuclear Occurrence (ENO)," U.S. Nuclear Regulatory Commission.

NUREG-0880, 1983, "Safety Goals for Nuclear Power Plant Operation," Rev, l, U.S. Nuclear Regulatory Commission.

NUREG-1150, 1987, "Reactor Risk Reference Document," App. J-O, Vol. 3, Draft for Commert, U.S. Nuclear Regulatory Commission.

NUREG-1250, 1987, "Report on the Accident at the Chemobyl Nuciear Power Station," U.S. Nuclear Regulatory Commission.

NUREG-1251, 1987, "Implications of the Accident at Chernobyl for Safety Regulation of Commercial Nuclear Power Plants in the United States, "U.S. Nuclear Regulatory Conmission. 
NUREG/CR-1250, 1980, "Three Mile Island - A Report to the Commissioners and to the Public," U.S. Nuclear Regulatory Commission.

NUREG/CR-1433, 1980, "Examination of the Use of Potassium Iodide (KD) as an Emergency Protective Measure for Nuclear Reactor Accidents," David C. Aldrich and Roger M. Blond.

NUREG/CR-2723, 1983, "Estimates of the Financial Consequences of Nuclear Power Reactor Accidents," \$andia National Lab.

NUREG/CR-4214, 1985, "Health Effects Model for Nuclear Power Plant Accident Consequence Analysis," U.S. Nuciear Regulatory Commission.

NUREG/CR-3955, 1986, "Age- and Sex-Specific Estimation of Dose to a Nomnal Thyroid from Clinical Administration of Iodine-131," Oak Ridge National Lab., Killough, G.E., and K.F. Eckerman, eds.

Oberhausen, E., 1988, "Side Effects of Iodine-Containing Chemicals," in Iodine. Prophylaxis Following Nuclear_Accidents, E. Rubery and E. Smales, eds., Pergamon Press, New York.

Oddie, T.H., D.A. Fisher, W.M. McConahey, and C.S. Thompson, 1970, "Iodine Intake in the United States: A Reassessment," Joumal Clin. Endocrin. and Metsbol., 30: 659.

Oliinyk, V., O. Epshtein, and V. Markov, 1991, "Functional Activity of the Pituitary-Thyroid System in Children Exposed to Radiation Following the Chernobyl NPS Disaster" (an abstract), Health Physics, 61: 152.

OMB, 1991, Budget of the United States Government: Fiscal Year 1992, Office of Management and Budget.

Patrick, D.L. and R.A. Deys, 1989, "Generic and Disease Specific Measures in Assessing Health Status and Quality of Life," Med. Care, 27 (Sappl): 5217.

Patrick, D.L., and P. Erickson, 1988, "What Constitutes Quality of Life? Concepts and Dimensions," Clin. Nutr. 7: 53.

PDR, 1991, Physicians' Desk Reference, 45th Edition, E.R. Bambart Publ.

Pendergrass, E.P., G.W. Chamberlin, E.W. Godfrey, and E.D. Burdick, 1942, "A Survey of Deaths and Unfavorable Sequelae Following the Administration of Contrast Media," Am.

J. Roentgenology, 48: 741. 
Pochin, E.E., and C.F. Barnaby, 1962, "The Effect of Pharmacological Doses of NonRadioactive Iodide on the Course of Radioactive Uptake by the Thyroid," Health Physics, 2: 125.

Ratcliffe, G.E., I. Fogelman, and M.N. Maisey, 1986. "The Evaluation of Radiation Therapy for Thyroid Patients Using a Fixed-Dose Regime," British' J. of Radiology, 59: 1105.

Rallison, M.L., T.M. Lotz, M. Bishop, W. Divine, K. Haywood, J.L. Lyon, and W. Stevens, 1990, "Cohort Strky of Thyroid Disease Near the Nevada Test Site: A Preliminary Report," Health Physics, 59(5): 739.

Rallison, M.L., B.M. Dobyns, F.R. Keating, J.E. Rall, and F.H. Tyler, 1974, "Thyroid Disease in Children. A Strvey of Subjects Potentiatly Exposed to Fallout Radiation," Am. J. Med. 56, 457.

Raventos, S.A. and T. Winship, 1964, "The Latent Interval for Thyroid Cancer Following Iradiation," Radiology, 푸: 501.

Rice, D.P., T.A. Hodgson, and F. Capell, 1989, 'The Economic Burden of Cancer, 1985, United States and California," in Cancer Care and Costs 1989, Sheffler, R.M., and N.C. Andrews, eds., Ann Arbor, Michigan, Health Administration Press, p. 39.

Rice, D.P., T.A. Hodgson, and A.N. Kopstein, 1985, "The Economic Costs of lllness: A Replication and Update," Health Care Financing, Rev, 7: 61.

Robinson, J.C., 1986, "Philosophical Origins of the Economic Valuations of Life," Milbank Men. Fund Q Health Soc., 64: 133.

Rodesh, F., 1976, "Adverse Effect of Amniofetography on Fetal Thyroid Function," Am. J. Obstet. and Gyn., 126: 723.

Rollstin, J. A., D. I. Chanin, and H.N. Jow, 1990, "MELCOR Accident Consequence Code System (MACCS), Volume 3: Programmer's Reference Manual," NUREG/CR-4691, Sandia National Laboratories, Albuquerque, NM.

Ron, E., and B. Modan. 1984, "Thyroid and Other Neoplasms Following Childhood Scalp Irradiation," in Radiation Carcinogenesis: Epidemiology and Biological Significance," J.D. Boice and J.F. Fraumeni, eds., Raven Publ., N.Y; p. 139.

Rosenberg, G., 1958, "Biological Half-Life of I-131 in the Thyroid of Healthy Males," Journat Clin. Endocrin. and Metabol., 18: 516. 
Roti, E., A. Gnudi, and L.E. Braverman, 1983, "The Placental Transport, Synthesis and Metabolism of Hormones and Dugs Which Affect Thytoid Function," Endocrine Reviews, 4: 131.

RSS, 1975, Reactor Safety Sudy Apoendix II: Calculation of Reactor Accident Consequences, WASH-1400, (NUREG-75/014), U.S. Nuclear Regulatory Conmission.

Rubery, E.D., 1988, "Practical Aspects of Prophylactic Stable Iodine Usage," in Iodine Prophylaxis Following Nuclear Accidents, E. Rubery and E. Smales, eds., Pergamon Press, N.Y.: p. 141.

Russell, K.P., H. Rose, and P. Starr, 1957, "The Effects of Radioactive Iodine on Maternal and Fetal Thyrpid Function During Pregnancy," Surg. Gynecol. and Obstet, 104: 560.

Safa, A.M., O.P. Schumacker, and A. Rodrigues-Antunez, 1975, "Long-Term Follow-Up Results in Children and Adolescents Treated with Radioactive Iodine (I-131) for Hyperthyroidism," New Eng. J. of Med., 222: 167.

Sagan, L.A., 1972, "Human Costs of Nuclear Power," Science, 177: 487.

Schag, C.A. and R.L. Heinrich, 1990, "Development of a Comprehensive Quality of Life Measurement Tool: CARES," Oncology, 4: I35.

Schelling, T.C., 1968, The Life You Save May Be Your Own: Problems in Public Expendinure Analysis, Washington Bookings Institute.

Schipper, H., J. Clinch, A. McMurray, and M. Levit, 1984, "Measuring the Quality of Life of Cancer Patients: The Functional Living Index-Cancer: Development and Validation," J. of Clin. Oneol., 2: 472.

Segal, R.L., S. Silver, S.B. Yohalem, and R.A. Newbutger, 1958, "Use of Radioactive Iodine in the Treatment of Angina Pectoris," Am. J. of Cardiology, 1: 671.

Selenkow, H.A., 1975, "Thyroid Function and Dysünction During Pregnancy." Clin. Obstet. and Gynecol., 16; 66.

Selenkow, H.A., M.D. Bimbaum, and C.S. Hollander, 1973, "Thyroid Function and Dysfunction During Pregnancy," Clin. Obstet. and Gynecol., 16: 66.

Shafer, R.B. and F.Q. Nuttal, 1971, "Thyroid Crisis Induced by Radioactive Iodine," J. of Nuclear Med., 12: 262. 
Shandala, N., H. Hulko, and I. Kayo, 1991, "Thyroid Gland Radjation Doses to the Inhabitants of the Ukrainian SSR Following the Chernobyl NPS Disaster" (an abstract), Health Physics. 61: 153.

Sheppard, M.C., 1988, "Radioiodine Therapy for Hyperthyroidism and Risk of Malignancy" in Iodine Prophylaxis Following Nuclear Accidents, E. Rubery and E. Smales, eds., Pergamon Press.

Sherwin, J.R., 1982, "Development of the Regulatory Mechanisms in the Thyroid: Failure of Iođine to Suppress Iodide Transport Activity." Proc. Soc. Exp. Biol. and Med., 169: 458.

Shiell, A., K. Gerard, and C. Donaldson, 1987, "Cost-of-Illness Studies: An Aid to DecisionMaking?," Health Policy, : 317 .

Shore, R.E., E. Woodward, N. Hildreth, P. Dvoretzky, L. Hempelmann, and B. Pasternack. 1985, "Thyroid Tumars Following Thymus Irradiation," J. Natl. Cancer Inst., 74: 1177.

Shore, R.E., 1980, "Radiation and Host Factors in Human Thyroid Tumors Following Thymus Irradiation," Health Physics, 38: 451.

Shore, R.E., R.E. Albert, and B.S. Pasternack, 1976, "Follow-up Study of Patients Treated by $X$-Ray Epitation for Tenia Capitis: Resurvey of Post-Treatment Illness and Mortaliry Experience," Arch. Environ. Health, 31: 17.

Sinadovic, J., 1986, "Some Characteristics of Soluble Thyroid Proteins in Human Fetuses During Morphogenesis of Follicular Structure," Exp. Clin. Endocrin., 88: 346.

Slavin, M.L., H. Plant, and D. Lynch, 1988, "Who Should Measure Quality of Life, the Doctor or the Patient?,' J. Cancer, 57: 109.

Stanbury, J.B. and B.Z. Hetzel, 1980, "Endemic Goiter and Cretinism: Iodine Nutrition in Health and Diseass, John Wiley, New York.

Stanbury, J.B., 1954, Endemic Goiter. The Adaptation of Man to Iodine Deficiency, Harvard Univ, Press, Cambridge, MA.

Sternthal, E., L. Lipworth, B. \$tanley, C. Abreat, S. Fang, and L.E. Braverman, 1986, "Suppression of Thyroid Radioiodine Uptake by Various Doses of Stable Iodide," New Engl. J. of Med., 303: 1083.

Stewart, A.L., S. Greenfield, R.D. Hays, 1989, "Functional Status and Well-Being of Patients with Chronic Conditions - Results from a Medical Outcomes Study," JAMA, 212: 907. 
Stewart, A.L., R.D. Hays, and J.E. Ware, 1988, "The MOS Short-Form General Health Survey. Reliability and Validity in a Patient Population, "Med. Care, 26: 724.

Sridama, V., M. McCormick, E.L. Kaplan, R. Fauchet, and L.J. DeGroot, 1984, "Long Term Follow-up Study of Compensated Low-Dose I-131 Therapy for Graves' Disease," New Eng. J. of Med., 311: 426.

S.S.A., 1985, "Federal Old-Age, Survivors and Disability Insurance: Listing of Impaiments, Mental Disorders; Final Rub.," Social Security Adtninistration, Fed. Reg. 20CFR, Part 404 (Reg. No. 4, 50(167), 35038.

Stoffer, S.S. and J.I. Hamburger, 1976, "Iradvertent I-131 Therapy for Hyperthyrojdism in the First Trimester of Pregnancy," J. Nuc. Med., 17: 146.

Teta, M.J., M.C. DelPo, and S.V. Kasl, 1986, "Psychosocial Consequences of Childhood ano Adolescent Cancer Survival," J. Chronic Dis., $\underline{39}$ : 751.

Thilly, C.H., 1978, "Fetal Hypothyroidism and Maternal Thyroid Status in Severe Endemic Goiter," J. Clin. Endocrin. and Metabol., 47: 354.

Tucker, A.S. and G. diBaguo, 1956, "Intravenous Urography; a Comparative Study of NeoIopax and Urokon," Am. J. of Roentgenology, 75: 855.

Tunbridge, W.M., D.C. Evered, R. Hall, D. Appleton, M. Brewis, F. Clark, J.G. Evans, E. Young, T. Bird, and P.A. Smith, 1977, "The Spectrum of Thyroid Disease in a Community: The Whickham Survey," Clin. Endocrin. 1: 481.

Vagenakis, A.G. and L.E. Braverman, 1975, "Adverse Effects of Iodides on Thyroid Function," Med. Clinics of N. America, 59: 1075.

Vagenakis, A.G., C. Wang, A. Burger, F. Maloof, L.E. Braverman, and \$.H. Ingbar, 1972, "Iodide-Induced Thyrotoxicosis in Boston," New England J. of Med., 287: 523.

Vanterle, A.J., R.T. Young, D.A. Fisher, R.P. Uller, and C.R. Brinkman III, 1975, "IntraUterine Treatment of Hypothyroid Fetus, " J. Endocrin. and Metab., 40: 474.

Walfish, P.G., 1983, "Drug and Environmentally Induced Neonatal Hypothyroidism," in Congenital Hypothyroidism, J.H. Dussault and P. Walker, eds., M. Dekker Publish., New York.

Wartman, S.A., L.L. Morlock, and F.E. Malit2, 1983, "Impact of Divetgent Evaluations by Physicians and Patients of Patient's Complaints," Public Heatth Rep., 28: 141. 
Wasserman, R.H., F.W. Lengemann, J.C. Thompson, and C.I. Connor, 1965, "The Transier of Fallout Radionuclides from Diet to Man," Chapter 9 in "Radioactive Fallout. Soils. Plants, Foods, Man," Edited by E.B. Fowjer, Elsivier Publisher.

Webber, B.M., 1977, "Radiation Therapy for Pernussis; A Possible Exiologic Factor in Thyroid Carcinoma," Ann. of Int. Med., 86: 449.

Weinstein, M.C., 1986, "Challenges for Cost-Effectiveness Research," Med. Decision Making, 6: 194.

WHO, 1989, Guidelines for Iodine Prophylaxis, World Health Organization, Environmental Health Series, No. 35.

WHO, 1986, Report of the WHO Working Group on Assessment of Radiation Dose Commiment in Europe Due to the Chemobyl Accident, Worid Health Organization, Bitthoven, June 25-27, 1986.

Wolff, J., 1985, "Risks for Stable and Radioactive lodine in Radiation Protection of the Thyroid," in Thyroid Disorders Associated With. Iodine Deficiency and Excess, R. Halland and J. Kobberling, eds., Raven Press, New York, 22: 111.

Wolff, J., 1980, "Physiological Aspects of Iodide Excess in Relation to Radiation Protection," J. of Molecular Med., 4 151 .

Wolff, J., 1969, "Iodide Goiter and the Pharmacologic Effects of Excess Iodide," Am. J. of Med., 47: 101 .

Wolff, J., 1964, "Transport of Iodide and other Anions in the Thyroid Gland, " Physiol. Rev., 44: 45 .

Yakolev, O., A. Kolomiytseva, and T. Zadorozhnia, 1991, "The Status of the Endocronological and Immunological Systems of Pregnant Women and Newborn Infants Who Were Exposed to Radiation Following the Chernobyl NPS Dișaster," (an abstract), Health Physics, 61: 153.

Yalow, R.S., 1983, "Risks in Mass Distribution of Potassium Iodide," Bull. N.Y. Acad. Med., 59: 1020 .

Yamanaki, E., 1959, "The Development of Hormonal Biosynthesis in Human Fetal Thyroids," J. Clin. Endoctin. and Metabol., 19: 1437. 


\begin{tabular}{|c|c|}
\hline $\begin{array}{l}\text { U.S. NUCLEAA AEGHLATORY COHAAISSION } \\
\text { BIBLIOGRAPHIC DATA SHEET } \\
\text { iseo initantians on the rowersel }\end{array}$ & 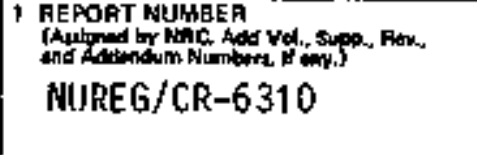 \\
\hline \multicolumn{2}{|l|}{ 2. TITLE ANSD SUBTITLE } \\
\hline \multirow{3}{*}{$\begin{array}{l}\text { An Analysis of Potassium Iodide (KI) Prophylaxis for the } \\
\text { General Public in the Event of a Nuclear Accident }\end{array}$} & DATE REPOH T PUB LISHED \\
\hline & \begin{tabular}{|c|c|} 
HAONTH & YEAA \\
February & 1995 \\
\end{tabular} \\
\hline & $\begin{array}{l}\text { 4. FIN OR GRANT NUMEER } \\
\text { L1844 }\end{array}$ \\
\hline H. Behling, K. Behling, S. Cohen \& Associates & Technical \\
\hline \multicolumn{2}{|c|}{ 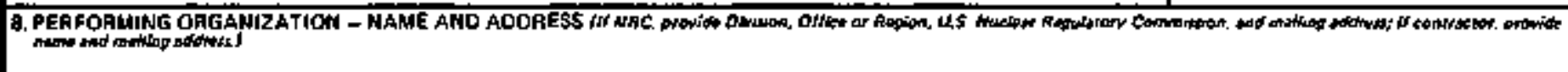 } \\
\hline \multicolumn{2}{|l|}{$\begin{array}{ll}\text { S. Cohen Associates, Inc. } & \text { Scientech, Inc. } \\
1355 \text { Beverly Road, Suite } 250 & 11821 \text { Parklawn Drive } \\
\text { McLean, VA } 22101 & \text { Rockville, MD } 20852\end{array}$} \\
\hline \multicolumn{2}{|c|}{ 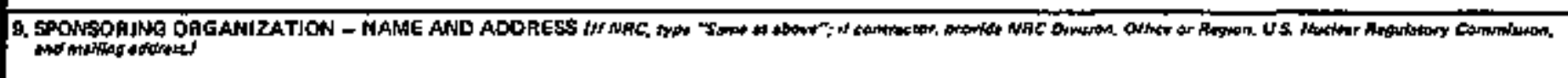 } \\
\hline \multicolumn{2}{|l|}{$\begin{array}{l}\text { Division of Systems Technology } \\
\text { Office of Huclear Regulatory Research } \\
\text { U.S. Nuclear Regulatory Research } \\
\text { Washington. BC } 20555-0001\end{array}$} \\
\hline \multicolumn{2}{|l|}{ 10. SUPPLEMENTAAY NOTES } \\
\hline \multicolumn{2}{|c|}{$\begin{array}{l}\text { A generic difficulty countered in cost-benefit analyses is the quantification of major } \\
\text { elements that define the cests and the benefits in commensurate units. In this study, the } \\
\text { costs of making KI available for public use, and the avoidance of thyroidal health effects } \\
\text { predicted to be realized from the availability of that KI (i.e., the bepefits), are defined } \\
\text { in the commensurate units of dollars. }\end{array}$} \\
\hline \multicolumn{2}{|l|}{ 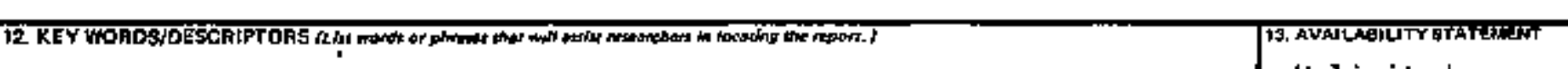 } \\
\hline \multirow{4}{*}{$\begin{array}{l}\text { Potassium Iodide } \\
\text { KI } \\
\text { Emergency Planning }\end{array}$} & Inl Inlimited \\
\hline & Unclassified \\
\hline & $\frac{\text { Unclassifjed }}{\text { 15. NumBEA OF PAGE }}$ \\
\hline & TE. PALCE \\
\hline
\end{tabular}

